\title{
Drittes Kapitel
}

\section{Beharrung und Wandel der regionalen Mentalitäten}

Die nationalprotestantischen bzw. republikanisch-laizistischen Milieumentalitäten in Westmittelfranken und der Corrèze prägten nicht nur die regionale Auseinandersetzung mit der bolschewistischen Revolution und ihren Folgen, sie blieben darüber hinaus auch nach den Jahren des Umbruchs 1918 bis 1920 in der Reaktion auf nationale Entwicklungen der politischen Kultur weiter wirksam. Vor allem beeinflußten sie die konkrete Ausprägung von völkischem und republikanischem Nationalismus, Militarismus und Pazifismus, "Agrarismus" und Regionalismus - Denkströmungen, die für die Stabilität der Demokratien von entscheidender Bedeutung waren. Wie stark nationalprotestantische und republikanisch-laizistische Milieumentalität dabei durchschlagen konnten, hing wesentlich von dem Zustand ihrer lutherisch-konfessionalistischen bzw. antiklerikalen Kernschichten ab. Diese waren auf den im weitesten Sinne kirchenpolitischen Feldern am deutlichsten zu erkennen.

\section{Anhaltender „Kulturkampf von unten“ ${ }^{{ }_{1}}$}

Das Ende des Ersten Weltkrieges markierte für die Kirchen in Deutschland und Frankreich einen Punkt, an dem sich ihre Entwicklungslinien gleichsam überkreuzten. Während in Deutschland die protestantische „Mehrheitskirche“ in ihrer Beziehung zum Staat durch den Sturz der Monarchien auf eine abschüssige Bahn geriet, sah der französische Katholizismus seine gesellschaftliche Stellung im Ergebnis der Union sacrée gestärkt. So unterschiedlich diese nationalen Verhältnisse auch lagen, so viel Bewegung brachten sie doch in beiden Regionen, in Westmittelfranken wie in der Corrèze, in den politisch-religiösen Komplex.

1 Es versteht sich von selbst, daß der Begriff ${ }_{n}$ Kulturkampf “ hier in einem speziell auf die Mentalitäten bezogenen Sinn Verwendung findet, ohne zu verkennen, daß dem Prozeß nicht mehr die Dramatik innewohnte, die den Kampf zwischen Staat und Kirche im 19. Jahrhundert charakterisiert hatte. Freilich hatte es, wie zu zeigen sein wird, auch gute sachliche Gründe, daß der Begriff in der Provinz nach wie vor zum festen Bestand der politischen Rhetorik gehörte. So wies beispielsweise ein Bauernvereinssekretär bei einer BVP-Veranstaltung in Kitzingen 1924 mit „ernsten Worten“ explizit auf die drohende „Entfachung des Kulturkampfes von links durch ... die Sozialdemokratie, von rechts ... seitens mancher deutsch-völkischer Kreise“ hin. Kitzinger Zeitung, 18. 3. 1924 . 


\section{Antiklerikalismus statt Union sacrée}

Zum Symbol der Annäherung zwischen Staat und Kirche in Frankreich wurde 1920 der Beschluß des Parlaments, einen neuen Nationalfeiertag zu Ehren der katholischen Märtyrerin Jeanne d'Arc einzuführen. Johanna war von der Kurie als Geste gegenüber dem französischen Patriotismus gerade heilig gesprochen geworden. Im Zuge des sogenannten second ralliement ${ }^{2}$ nahm die französische Republik auch die in der Zeit der Trennungsgesetze abgebrochenen diplomatischen Beziehungen zum Vatikan wieder auf $(1921)^{3}$. Das Bild einer beim engstirnigen Klerus verhaßten und vom undankbaren König verratenen Johanna diente zwar auch dem linken Antiklerikalismus während des gesamten 19. Jahrhunderts als Stütze, doch war Jeanne d'Arc gleichzeitig als Königsmacherin und Garantin des katholischen Glaubens ein Kultobjekt für die royalistisch-antirepublikanische Rechte gewesen; und spätestens seit der Dreyfus-Affäre galt sie der extremen Rechten als Schutzschild des „wahren Frankreich“ gegen die Angriffe von „Freimaurern und Juden", womit also ungefähr alle linken Republikaner gemeint waren. $\mathrm{Da}$ deren Johanna-Verehrung durch die zunehmend katholisch-nationalistische Interpretation zurückgedrängt worden war $^{4}$ - kein anderer als Maurice Barrès hatte 1914 die Gesetzesinitiative für einen Jeanne-Nationalfeiertag zur Symbolisierung der Union sacrée eingebracht ${ }^{5}$-, war der Schritt, den die Nationalversammlung im Jahr 1920 nun unternahm, in den Augen der Katholiken ein erfreulicher Beweis, daß sich in Frankreich wirklich etwas verändert hatte ${ }^{6}$. Fortan sollte es jährlich an jedem zweiten Maisonntag "einen Tag der großen ,union sacrée 6 , der einmütigen Freude geben "7, ein „zugleich religiöses und nationales Fest" ${ }^{\text {"8. }}$.

Allerdings war der Widerstand, den Radikalsozialisten und Sozialisten dem neuen Feiertag entgegenbrachten', bereits ein Indiz für die anhaltende Virulenz des Antiklerikalismus. Selbst während des Krieges hatten im Limousin immer wieder antiklerikale Gerüchte die Union sacrée bedroht: Ein örtlicher Priester war angeblich beobachtet worden, wie er sich an den Eisenbahnschienen zu schaffen machte, ein anderer geistlicher Kriegstreiber hätte 10000 Franc nach Deutschland überwiesen und der Pfarrer von La Geneytouse den Preußen zwei Fässer voller Geld geschickt ${ }^{10}$. Das infamste Gerücht aber richtete sich gegen jene unter den gedienten Klerikern, die - obwohl Junggesellen und in der Blüte ihrer Jahre - in der Etappe tätig seien, statt an der Front zu kämpfen. Abseits der Gefahren, so das Ondit, warteten diese klerikalen Drückeberger das Ende eines Krieges ab, den sie selbst gemeinsam mit dem Finanzkapital entfesselt hätten. Und wie viele Jesuiten würden nicht obendrein in den Lazaretten im Hinterland das Gewissen verwundeter Soldaten belasten ${ }^{11}$.

2 J.-M. Mayeur, La laïcité, 1989, S. 91.

3 G. Cholvy/Y.-M. Hilaire, Histoire religieuse, Bd. 2, 1986, S. $271 \mathrm{ff}$.

${ }^{4}$ G. Krumeich, Jeanne d'Arc in der Geschichte, 1989, S. 214.

5 Ph. Contamine, Jeanne d'Arc dans la mémoire des droites, 1992, S. 427.

6 G. Krumeich, Eine oder mehrere Jeannes, 1981, S. 29 f., 34.

7 La Semaine Religieuse du Diocèse de Tulle, 1920, S. 188.

8 Ebd., 1921, S. 136.

9 Ph. Contamine, Jeanne d'Arc dans la mémoire des droites, 1989, S. 221.

10 L. Pérouas, Refus d'une religion, 1985, S. 193.

11 Ebd., sowie R. Rémond, L’anticléricalisme, 1976, S. $229 \mathrm{ff}$. 
Tatsächlich blieben von den knapp 33000 eingezogenen Klerikern fast 5000 auf dem Felde; die "rumeur infâme" aber tauchte in der Zwischenkriegszeit immer wieder auf, sobald sich der „Kulturkampf“ zuspitzte. Aufgrund dessen sahen sich die „Ehemaligen“ unter den Priestern auch in der Corrèze veranlaßt, 1924 einen Verband von Prêtres anciens combattants zum Schutz ihrer Rechte ins Leben zu rufen ${ }^{12}$. Die Antiklerikalen indes rechneten weiterhin vor, daß nur $14,1 \%$ der eingezogenen Pfarrer und Klosterbrüder, hingegen 22,6\% der Volksschullehrer gefallen seien ${ }^{13}$. Noch Mitte der 1930 er Jahre mußten sich katholische Versammlungen in Brive mit dem Thema „Die Jesuiten und der Krieg“ befassen, wobei der Referent die von allen Seiten politisch instrumentalisierte Verlustziffer mit $19 \%$ angab. Die Kommunisten, und mit ihnen der ganze Antiklerikalismus in der Corrèze, blieben aber bei ihrer Geschichtsversion und warfen den Pfarrern auch bei dieser öffentlichen Versammlung in Brive (1935) vor, „den Krieg nicht in den Schützengräben mitgemacht, sondern sich in die Lazarette verdrückt zu haben"14.

Schon im ersten Wahlkampf nach dem Sieg über Deutschland 1919 hatten die corrézischen Radicaux zu jenem Teil der Partei gehört, der sich nicht entschließen konnte, mit der antiklerikalen Tradition zu brechen, und der statt dessen dem auf religionspolitischen Kompromiß zielenden Bloc national fernblieb. Bei den Sozialisten schien das antikirchliche Sentiment den Geist der Union sacrée vollständig verdrängt zu haben; so verspotteten sie den „Kreuzweg“ des gemäßigten Flügels der Radicaux und der Rechten in einem „Heldengedicht" als die politische Verführung Chammards und Lasteyries durch einen „salbungsvollen Geistlichen" oder polemisierten gegen die „Söldner des Königs und des Klerikalismus“ und die „fanatische Klientel der Priester und Nonnen“. Zwar würden diese Antirepublikaner heute höchstens in einigen verkommenen Dörfern der analphabetischen Bretagne oder der immer noch dem Klerus unterworfenen Vendée offen Farbe bekennen, doch man solle sich nicht täuschen: auch die im Bloc national getarnt agierenden Politiker seien Gegner einer roten Arbeiter- und Bauernrepublik $^{15}$.

Die Aktivitäten der antiklerikalen Traditionalisten demonstrierten, wie relativ die Bedeutung der Union sacrée für die politische Kultur der Corrèze einzuschätzen ist. Und was die nationale Ebene anbetraf, so hatten zwar bei der Gründung des Bloc national 1919 die daran beteiligten Katholiken - mit dem Segen des Pariser Kardinals Amette - die "Tatsache der Laizität des Staates“ akzeptiert, sofern dieser die Rechte und vor allem die Glaubensfreiheit seiner Bürger achten würde ${ }^{16}$. Aber die von katholischer Seite mit so großen Hoffnungen begleitete konservative Chambre bleu horizon mochte in den Jahren nach 1919 den kirchlichen Schulen keine staatlichen Subventionen bewilligen. So gehörte das Erziehungswesen in der Folgezeit weiterhin zu den ständigen Gravamina der französi-

12 Die Gründung erfolgte im November 1924; vgl. La Semaine Religieuse du Diocèse de Tulle, 1924, S. 458.

13 R. Rémond, L'anticléricalisme, 1976, S. 235.

14 Unterpräfekt an Präfekten, Brive, 20. 5. 1935, in: ADC 1 M 76.

15 La Corrèze Républicaine et socialiste, 11. 10. 1919, 18. 10. 1919.

16 J.-M. Mayeur, La laïcité, 1989, S. 87. 
schen Kirche ${ }^{17}$. Auch in der Corrèze wurden die christlichen Familien ermahnt, ihre Kinder, wenn irgend möglich, an eine freie Schule zu schicken; wenn es vor Ort selbst keine gebe, müßten Unbequemlichkeiten in Kauf genommen werden, da es vordringlich sei, den Schülern die notwendigste aller Wissenschaften, die Wissenschaft von Gott, nahezubringen. Die staatlichen Schulen, mit ihrem unmöglichen Neutralitätsanspruch, galten als „Schulen ohne Gott“, die bestenfalls zur religiösen Gleichgültigkeit erzögen. Angesichts solch gravierender Defekte des Unterrichtssystems, zudem konfrontiert mit einem scharfen regionalen Antiklerikalismus, hielt der corrézische Klerus die neue These von der Unantastbarkeit der laizistischen Gesetze bereits in der unmittelbaren Nachkriegszeit für verfehlt und undemokratisch ${ }^{18}$.

Nachdem sich jahrelang auf dem Felde der Kirchenpolitik nicht viel bewegt hatte - lediglich die 1901 aufgelösten Mönchsorden konnten nun vielfach ihre Arbeit stillschweigend wieder aufnehmen -, erklärten die französischen Bischöfe im Januar 1924 dem Laizismus offen den Krieg und kündigten an, mit allen legitimen Mitteln bis zur Abschaffung der ungerechten Gesetze kämpfen zu wollen. Die Kampagne trug überwiegend den Charakter einer Verteidigungsschlacht, denn schon seit 1923 hatten die Angriffe gegen die Kirche in der antiklerikalen Presse erneut zugenommen, und die Freimaurerloge Grand Orient war mit einem Manifest in einer Auflage von 500000 Exemplaren an die Franzosen herangetreten, um die Notwendigkeit eines Linksbündnisses gegen die angeblich dräuende Reaktion zu begründen ${ }^{19}$.

Tatsächlich lag der ideelle Kern des Konflikts darin begründet, daß die im Gefolge der Union sacrée eingetretene Klimaverbesserung im Verhältnis von Staat und Kirche vielen französischen Katholiken nicht weit genug, dem laizistischen Lager jedoch bereits entschieden zu weit ging. Je näher der Termin der Parlamentswahlen im Mai 1924 rückte, desto schärfer wurden die kirchenkämpferischen Töne von seiten eines neu begründeten Cartel des gauches, zumal der Antiklerikalismus von jeher das einigende Band zwischen Sozialisten und Radicaux gewesen war. Nun bildete er, wie zumindest die politische Rechte meinte, einmal mehr das Programm, „das ganze Programm“ des Linkskartells ${ }^{20}$. Jedenfalls standen die Einführung der laizistischen Gesetze in den zurückeroberten Provinzen Elsaß-Lothringens, der Abbruch der diplomatischen Beziehungen zum Vatikan sowie Repressionen gegen die zurückgekehrten Mönchsorden und die Einführung der staatlichen école unique im Zentrum der Forderungen ${ }^{21}$. Den Anhängern der école unique ging es darum, das bestehende Nebeneinander eines kostenlosen enseignement primaire, für Kinder aller Schichten, und eines weiterführenden enseignement secondaire, das kostenpflichtig und mithin faktisch Kindern aus

17 M. Launay spricht in seiner Darstellung des französischen „Schulkriegs (1919-1958) “ für die 1920 er und 1930er Jahre von einem "fragilen status quo". M. Launay, L'église et l'école, 1988, S. 93.

18 La Semaine Religieuse du Diocèse de Tulle, 1919, S. 313, 1920, S. 31, 1921, S. 43, 45 f.

19 Zur Rezeption des Beschlusses der Freimaurer in der Corrèze vgl. L'Action républicaine, 23.6. 1923; zum Hintergrund C. Bloch, Die dritte Französische Republik, 1972, S. 282 f.; G. Cholvy/ Y.-M. Hilaire, Histoire religieuse, Bd. 2, 1986, S. 282.

20 G. Cholvy/Y.-M. Hilaire, Histoire religieuse, Bd. 2, 1986, S. 283.

21 R. Rémond, L'anticléricalisme, 1976, S. 249. Zum Problem der „école unique“ vgl. J. Girault, Instituteurs, 1996, S. 77 ff., sowie die Studie von J.-F. Garcia, L'école unique, 1994. 
gutsituierten Familien vorbehalten blieb, aufzuheben und die Selektion nach dem Verdienst der Eltern durch eine reine Leistungsauswahl zu ersetzen.

In der Corrèze wurde das Linksbündnis mit seinen schul- und kirchenpolitischen Forderungen zwar besonders mächtig ${ }^{22}$, doch ganz Frankreich erlebte jetzt eine Renaissance des Antiklerikalismus. Und noch einmal bildete die kirchliche Opposition gegen die Politik der Regierung einen wesentlichen Konfliktstoff im öffentlichen Leben. Gerade in der Provinz bewirkte die 1924/25 gegründete Fédération nationale catholique (FNC) unter dem bekannten Weltkriegsgeneral Édouard de Curières de Castelnau mit bald 2 Millionen Mitgliedern einen katholischen Mobilisierungsschub, ließ indes nach dem System kommunizierender Röhren auch den Antiklerikalismus weiter anschwellen ${ }^{23}$.

In der Corrèze setzte sich der Bischof an die Spitze der katholischen Bewegung. Er gründete noch 1924 eine regionale Union des Catholiques de la Corrèze (UCC) und rief seine Pfarrer dazu auf, unverzüglich mit dem Aufbau eines organisatorischen Netzes in den einzelnen Pfarrgemeinden zu beginnen. Da man zumindest in den kirchlich orientierten Kantonen mit den Vereinigungen der Familienoberhäupter über „wohlpräparierte Kader“ verfügte, konnten die ersten Fäden rasch gezogen werden. Der Tuller Bischof ließ in einem Brief an die aktiven UCC-Mitglieder erst gar keinen Zweifel an der Berechtigung der katholischen Politik aufkommen: "Wir allein besitzen dank der kirchlichen Unfehlbarkeit die totale Wahrheit ..."24. Die geheimen illegalen Orden der allmächtigen Freimaurer hätten mit ihrem Einfluß in den Zeitungen einen hinterhältigen Anschlag gegen die Union sacrée geplant. Dieses $\mathrm{Mal}$ aber würden die ansonsten allzu fügsamen $\mathrm{Ka}$ tholiken die Notwendigkeit erkennen, sich zusammenzuschließen und ihre Rechte mit mehr Nachdruck zu verteidigen. Der am Heiligen Abend 1924 gewählte UCC-Vorstand, in dem Anwälte, Notare, Kaufleute und Militärs überwogen, entfachte in den folgenden Monaten eine Versammlungswelle mit über 100 Veranstaltungen, die auf Kantonsebene meist mehrere hundert Zuhörer erreichten. Nach vier Monaten waren 5000 Mitglieder in mehr als 150 Pfarrgemeinden organisiert - allerdings nur in der Hälfte der Dekanate, weil die Implantation in den stärker entkirchlichten Kantonen der Corrèze nicht vorankam. Thematisch befaßten sich die Konferenzen bevorzugt mit der Rolle der „Freimaurerei gegen die Religion“, der gesellschaftlichen Bedeutung der Familie oder dem, „was von der Unterrichtsfreiheit bleibt" ${ }^{\text {25 }}$.

Auch nachdem das Kabinett Herriot im April 1925 an seiner Finanzpolitik gescheitert war und die nachfolgende Regierung Painlevé die radikal-laizistischen Projekte des Linkskartells aufgegeben hatte, blieb der zum Bewußtsein seiner massendemokratischen Stärke gelangte politische Katholizismus bemerkenswert aktiv und versuchte nun, den Schwung seiner Erfolge auszunutzen, um auf dem schulpolitischen Terrain wieder an Boden gegenüber dem Staat zu gewinnen.

22 D. Faugeras, Recherches, 1986, S. 343 f.

23 C. Bloch, Republik, 1972, S. 302; G. Cholvy/Y.-M. Hilaire, Histoire religieuse, Bd. 2, 1986, S. $285 \mathrm{ff}$.

24 L'Union catholique de la Corrèze, Oktober 1925.

25 La Semaine Religieuse du Diocèse de Tulle, 1924, S. 483 ff., 1925, S. 302; die Zahlen nach einem Jahr Verbandstätigkeit wurden mit 4000 Mitgliedern in 180 Pfarrgemeinden und 15 Kantonen angegeben. La Semaine Religieuse du Diocèse de Tulle, 1925, S. 563. 
Denn von den 172 kirchlichen Schulen vor den Ferry-Gesetzen waren in der Corrèze bis 1890 nur 89 verblieben; diese Zahl hatte sich nach einer leichten Erholung dann in den Jahren 1901-1904 nochmals auf 52 reduziert und blieb seitdem trotz Union sacrée bis in die 1930er Jahre hinein fast konstant auf diesem niedrigen Niveau, wobei obendrein vier Fünftel reine Mädchenschulen waren, also auf die Ausbildung der politischen Aktivbürger keinen Einfluß nahmen ${ }^{26}$. Da die corrézischen Katholiken nach wie vor die große Mehrheit ihrer Kinder daran gehindert sahen, kirchliche Schulen zu besuchen, blieben sie unzufrieden mit einer Bildungspolitik, die in ihren Augen auf einem gegen die Eltern gerichteten Erziehungsmonopol des Staates basierte. Die darüber hinaus von den Radicaux favorisierte „école unique“ hielten viele sogar für den Ruin der väterlichen Autorität und damit der Familie schlechthin ${ }^{27}$.

Zwar konnte die UCC in der Corrèze keine Massenveranstaltungen mit über 100000 Teilnehmern organisieren, wie sie in den Hochburgen des kirchlichen Frankreichs zwischen 1925 und 1930 stattfanden $^{28}$, doch angesichts der antiklerikalen Traditionen des Departements war die Teilnahme von bis zu 10000 Menschen an den großen Kongressen in Tulle und Brive ebenfalls ziemlich beachtlich. Das bekannte Feindbild der Frankreich dechristianisierenden Freimaurerei wurde dabei häufig durch die These erweitert und aktualisiert, daß deren „schädliches Treiben ... uns in Richtung Kommunismus stürzt ..."29.

Allerdings erwuchs der Kirche seit 1926 überraschenderweise ein weiterer Gegner auf der äußersten Rechten: die wegen ihrer gegen die katholische Doktrin und Moral gerichteten Politik vom Papst verdammte Action Française (AF), die lange eine der Stützen des Episkopates im Kampf gegen die laizistischen Gesetze gewesen $\operatorname{war}^{30}$. Jetzt aber verschärfte die AF ihren Konfrontationskurs gegen Pius XI. als den „deutschesten Papst der Geschichte" und unterstellte ihm, Frankreich im Sinne einer deutschen Revanchepolitik abrüsten zu wollen ${ }^{31}$. Auch das limousinische AF-Organ Le Salut National gab dem Antiklerikalismus von rechts wiederholt zu Angriffen Raum. Dem Katholikenblatt Croix de la Corrèze verübelte man, den Maßnahmen gegen die Action Française polemisch zugestimmt zu haben, und verdächtigte es überhaupt „liberaler Neigungen“. Das Ideal der „demokratischen Kanoniker" in der Redaktion der Croix, die sich bei jeder passenden und unpassenden Gelegenheit als "leidenschaftlich republikanisch“ bekennen würden, sei eine zweifelhafte christliche Demokratie: „christlich ein wenig, demokratisch sehr "32. Als besonders scheinheilig empfand es Le Salut National, daß sich die katholischen Redakteure von einem scharfen Artikel gegen die laizistische

26 Vgl. den aus dem Departementsarchiv gearbeiteten Aufsatz in L'Union catholique de la Corrèze, Januar 1932.

27 AN F 7/13222, Umschlag Corrèze, Präfekt an Innenminister, Tulle, 10. 10. 1927; AN F/7 13224, Umschlag Corrèze, Präfekt an Innenminister, Tulle, 15. 10. 1929; La Semaine Religieuse du Diocèse de Tulle, 1926, S. $590 \mathrm{f}$.

28 Vgl. G. Cholvy/Y.-M. Hilaire, Histoire religieuse, Bd. 2, 1986, S. 288.

29 AN F 7/13222, Umschlag Corrèze, Präfekt an Innenminister, Tulle, 10. 10. 1927 (Zitat); Le Courrier du Centre, 11. 10. 1927.

30 G. Cholvy/Y.-M. Hilaire, Histoire religieuse, Bd. 2, 1986, S. 296. Vgl. auch K.-E. Lönne, Politischer Katholizismus, 1986, S. $248 \mathrm{ff}$.

31 R. Rémond, L'anticléricalisme, 1976, S. 264.

32 Le Salut National, 20. 2. 1927, 4. 3. 1928. 
Schule und die "atheistischen Volksschullehrer" wieder distanzierten, nachdem die corrézischen Sozialisten protestiert hatten. Mit derartiger Weichheit, so das Sprachrohr der Action Française, könne sich der Katholizismus keinen Respekt verschaffen ${ }^{33}$.

$\mathrm{Ob}$ dieser Antiklerikalismus der extremen Rechten allerdings wirklich den maßlosesten Erscheinungsformen seines linken Pendants gleichkam ${ }^{34}$, scheint fraglich; allzu deutlich wird jedenfalls am limousinischen Beispiel, wie sehr die AF ihre Kritik auf die „liberale“ römische Linie der Kirchenoffiziellen konzentrierte und auf eine später mögliche Wiederannäherung hoffte. Diese Hoffnung aber vertrug sich nicht mit überzogener Polemik, vielmehr beanspruchte die Action Française weiterhin, „einer der glühendsten Verteidiger" der katholischen Kirche im Limousin zu sein. Als der Tuller Bischof sich in einem Hirtenbrief 1927 grundsätzlich zur Bedeutung der Familie äußerte, stimmte ihm der Salut National in allen Punkten zu und betonte, ebenfalls schon immer als ,erste Wahrheit" verfochten zu haben, daß das Individuum der Familie nachgeordnet sei. Wenn zudem der Protest der Union Catholique gegen die familienfeindliche "école unique" mit der Bemerkung kommentiert wurde: „Nichts wahrer als das. Aber was gedenken die Katholiken zu tun, um die Verwirklichung dieses satanischen Planes zu verhindern " ${ }^{35}$, dann erhellt daraus, daß die Kritik der Action Française an der Kirche zumindest nicht destruktiv gemeint war.

Dennoch konnte man im Blick auf die nationale Entwicklung kaum übersehen, welch tiefe Zäsur die päpstliche Bulle gegen die Action Française für den gesellschaftlichen Ort der Kirche in Frankreich markierte. Die Angriffe von rechtsaußen sowie die plötzlichen Sympathien von Antiklerikalen, Protestanten und Freidenkern für die bislang verfemte $\mathrm{AF}^{36}$ bewirkten eine neue Unübersichtlichkeit im Kampf zwischen Laizisten und Klerikalen und rückten den französischen Katholizismus, der sich schon im Zuge der Union sacrée der Republik weit genähert hatte, noch stärker in die politische Mitte. Gewiß setzten die Katholiken auch in der Corrèze ihren Kampf gegen die „antichristlichen“ Schulgesetze nach 1926 unbeirrt fort, doch da dies „fast der einzige Konfliktpunkt" war, plädierte die Croix insgesamt für eine kompromißbereite Politik und wollte jedenfalls nicht mehr pauschal alle laizistischen Maßnahmen in Frage stellen ${ }^{37}$.

$\mathrm{Zu}$ dieser taktischen Haltung trug das Bewußtsein bei, in der Corrèze von einem sehr niedrigen Anteil „liberaler Wähler" - gemeint waren damit konservative Katholiken - ausgehen zu müssen und sich infolgedessen am besten mit den gemäßigten Radicaux zu arrangieren ${ }^{38}$. Diese gingen vor den Wahlen 1928 in den meisten Departements unter dem Einfluß Poincarés Mitte-Rechts-Bündnisse ein. Die corrézische Union Catholique hielt sich in den Wochen und Monaten vor dem Urnengang ziemlich zurück, verwies darauf, keine politische Partei zu sein,

33 Ebd., 19. 2. 1928, 13. 2. 1927.

34 Diese Position vertritt R. Rémond, L'anticlericalisme, 1976, S. 265.

35 Le Salut National, 20. 3. 1927, 17. 4. 1927.

36 G. Cholvy/Y.-M. Hilaire, Histoire religieuse, Bd. 2, 1986, S. 307.

37 La Croix de la Corrèze, 4. 3. 1928.

38 La Semaine Religieuse du diocèse de Tulle, 1928, S. 107 f., La Croix de la Corrèze, 4. 3. 1928, 11. 3. 1928; vgl. auch W. Loth, Geschichte Frankreichs, 1992, S. 46. 
und verzichtete auf eine direkte Wahlempfehlung ${ }^{39}$. Im Tuller Norden kam es sogar zu einer kuriosen sozialistisch-katholischen Allianz, indem einige Führer der Union Catholique für Spinasse und gegen den gemäßigten Kandidaten Lafarge Wahlkampf machten ${ }^{40}$. Obwohl aber führende Katholiken in der Corrèze mit der Friedenspalme wedelten, hielten die regionalen Radicaux an dem linken Kartell der vorherigen Parlamentswahlen fest, unterstützten also jene innerparteiliche Strömung um Édouard Daladier, die den Poincaré-treuen Kurs Herriots unterlief. Nach der Absprache mit den Sozialisten veröffentlichten die Radicaux erst im letzten Moment ihr Wahlprogramm und gingen erneut zum Angriff auf La Croix de la Corrèze über, der ihrer Meinung nach „kein Wort zu glauben“ war ${ }^{41}$.

Dabei fällt freilich auf, daß die Radicaux um so laizistischer agierten, je stärker die Position der Kirche vor Ort zu sein schien. Die unfreundlichen Worte des radikalen Briver Bürgermeisters (bei der Nominierungsversammlung der Radicaux) über die Redakteure der Croix, die hinter den Vorhängen der benachbarten Fenster "lauerten“, waren hierfür ebenso charakteristisch wie die Wahlprogramme der beiden Briver Kandidaten, J.-B. Laumond und Alexis Jaubert. Diese bekannten sich ausdrücklich zur aktuellen laizistischen Lieblingsidee der „école unique“, während Jacques de Chammard und Gustave Vidalin in den Tuller Stimmkreisen sich mit einem generellen Bekenntnis zum laizistischen System begnügten ${ }^{42}$. Von dem gelegentlichen Kirchgänger de Chammard war ohnehin bekannt, daß er sich guter Beziehungen zum Tuller Bischof erfreute ${ }^{43}$, und Queuille, der führende Politiker des corrézischen Radikalismus, hatte bei der Beerdigung eines Verwandten sogar die Christusfigur geküßt, die der Priester nach örtlichem Brauch mitführte. Linke Republikaner sprachen von Queuilles "Judaskuß" und fragten, warum der radikale Politiker nicht, wie andere antiklerikale Beerdigungsteilnehmer auch, während der kirchlichen Feier ins Café gegangen sei ${ }^{44}$.

Aufgrund der widersprüchlichen kirchenpolitischen Haltung des Parti radical kam auch der politische Katholizismus in der Corrèze $1928 \mathrm{zu}$ keiner einheitlichen Bewertung des Konflikts. Nur teilweise wurde aus der abermals erwiesenen Befangenheit corrézischer Radicaux in ihren alten "kartellistischen Irrtümern" der Schluß gezogen: Wer das Kartell wählt, wählt Moskau ${ }^{45}$. Das offizielle UCCOrgan dagegen bemühte sich nach dem erneuten Durchmarsch des Linksbündnisses bei den Wahlen in der Region darin gerade keinen antikatholischen Triumph zu sehen. Schließlich hatten die antiklerikalen Linksparteien wenigstens nach den absoluten Stimmenzahlen gegenüber 1924 verloren, die Gemäßigten

39 Vgl. die Ausgaben von L'Union Catholique de la Corrèze von Januar bis Mai 1928.

40 Allerdings scheinen hierbei die verwandtschaftlichen Beziehungen zwischen dem Sozialisten Spinasse und dem Diözesanvorsitzenden der UCC eine wichtige Rolle gespielt zu haben. Der Gegenkandidat Lafarge hatte sich außerdem geweigert, das Programm der UCC zu unterschreiben. Vgl. Le Salut National, 13. 5. und 27. 5. 1928.

41 La Croix de la Corrèze, 8. 4., 15. 4., 22. 4. 1928.

42 Siehe die Professions de foi der beiden Briver und Tuller Kandidaten zu den Elections Législatives vom 22. April 1928, in: ADC 3 M 197 und 3 M 198, sowie La Croix de la Corrèze, 22. 1. 1928.

$43 \mathrm{Zu}$ den deswegen wiederkehrenden Angriffen gegen Chammard vgl. etwa: La Corrèze Républicaine et socialiste, 11. 10. 1919; La Voix Corrézienne, 1. 4. 1936.

$44 \mathrm{La}$ Croix de la Corrèze, 13. 4. 1924.

45 Ebd., 22. 4. 1928. 
einige tausend Stimmen zugelegt, und überhaupt sei die Corrèze bezüglich ihrer politischen Mentalität „zum Glück ... nicht ganz Frankreich“46.

In den folgenden Jahren waren die corrézischen Sozialisten, zwischen einem präpotenten Radikalismus und einem besonders aktionistischen Ruralkommunismus eingeklemmt, am stärksten um ein antiklerikales Profil bemüht, und zwar paradoxerweise trotz der Sonderbeziehungen ihres Vorsitzenden Spinasse zur katholischen Kirche ${ }^{47}$. Mit der Voix Corrézienne bildete sich die SFIO im Mai 1929 eine Stimme, die explizit als "laizistische Tribüne" gegen die katholische Croix konzipiert war und schon im ersten Leitartikel die "bedrohte Laizität" thematisierte. Das sozialistische Blatt umwarb potentielle Abonnenten mit dem Hinweis, als einzige Zeitung den Skandal der Ordensschule von Chamboulive angeprangert zu haben, die entgegen der laizistischen Gesetze geöffnet bleibe. Darüber hinaus diente die Politik des 1929 erstmals zum Ministerpräsidenten gewählten „Reformators von rechts" ${ }^{48}$, André Tardieu, als Negativfolie, auf der sich die antiklerikalen Konturen des corrézischen Sozialismus um so deutlicher abzeichnen ließen. Einen Höhepunkt erlebte die Propaganda gegen die angeblich neokatholizistischen Tendenzen der Regierung Tardieu, als im März 1930 in der Tuller Kathedrale eine Messe für Katastrophenopfer im Midi stattfand und die Zivil- und Militärbehörden die Einladung hierzu nicht nur beantworteten, sondern einige Stadträte und die Stadtverwaltung an dieser „Kapuzinade“ auch noch teilnahmen. Ein Stammwähler der Radicaux, dessen Meinung die Voix Corrézienne-Redaktion nun als Leserbrief plazierte, wollte plötzlich begriffen haben, warum seine Partei landesweit so abnehme: weil ihr nur noch wenige (kirchenkritische, M. K.) Daladiers angehörten, aber immer mehr andere, die keine Radicaux mehr seien, sondern "radis blancs" (weiße, d.h. klerikale Radieschen) und "culs bénis“ (unübersetzbar; etwa: gesegnete A ... ${ }^{49}$. Mit Nachdruck versuchten vor allem die dem linken Flügel der Partei zuzurechnenden Sozialisten den Wählern nahezubringen, daß es in der Corrèze "solche und solche" Radicaux gebe, wobei die schlechten ein Mangel an laizistischen Grundüberzeugungen kennzeichne ${ }^{50}$. Daß Sozialisten nur für einen Kandidaten stimmen könnten, der als Garant der Laizität bekannt sei, sollte bis in die Tage der Volksfront hinein zu den wichtigen Topoi der SFIO-Propaganda gehören ${ }^{51}$.

Von allen linken Parteien am wenigsten antiklerikal agierten aufs Ganze gesehen die corrézischen Kommunisten ${ }^{52}$. Gewiß war auch bei ihnen eine gewisse Disposition zu Kundgebungen gegen die katholische Kirche vorauszusetzen ${ }^{53}$; und in einer KP-Hochburg wie Lagraulière führten sie einen jahrzehntelangen Zermürbungskrieg gegen die Geistlichen, wobei die Kosten für die anstehende Reparatur des Pfarrhauses bzw. ein angeblich zum Verkehrshindernis gewordenes

46 L'Union Catholique, Mai 1928.

47 Näheres hierzu bei I. Mallet, Charles Spinasse et la Corrèze, 1995, S. $4 \mathrm{ff}$.

48 Ch. Bloch, Die dritte Französische Republik, 1972, S. 362.

${ }^{49} \mathrm{La}$ Voix Corrézienne, Mai 1929, 1.2. 1930, 16. 2. 1930, 13. 4. 1930 (Zitate).

50 La Voix Corrézienne, 1. 5. 1932.

51 Ebd., 15. 9. 1929, 1. 5. 1932, 23.9. 1934.

52 Vgl. in diesem Sinne auch L. S. Boswell, Rural Communisme, 1988, S. 259 f.

53 Vgl. die Spekulation um die Teilnahme der Briver Kommunisten an einer antiklerikalen Demonstration im Nachbardepartement Lot in: AN F 7/13219, Präfekt an Innenminister, Tulle, 1. 6. 1926. 
Kreuz auf dem Marktplatz als Vehikel dienten ${ }^{54}$. Doch der führende Kopf der corrézischen KP, Marius Vazeilles, hatte schon 1921 den Blick auf den Kapitalismus als eigentlichen Hauptfeind gerichtet. Um diesen besiegen zu können, müßten lokale und religiöse Rivalitäten aufhören. In dem von Vazeilles verantworteten Kampfblatt spielte der Antiklerikalismus keine größere Rolle; höchstens war einmal die Empfehlung zu lesen, die Pfarrer heiraten zu lassen, als ein Priester, kurz nachdem er die Erstkommunion zelebriert hatte, wegen des Verdachts auf ein Sittlichkeitsverbrechen verhaftet worden war ${ }^{55}$. Grundsätzlich aber zielte die corrézische KP-Führung darauf ab, die Bauern loszureißen „von Diskussionen für oder gegen den Pfarrer" 55 .

Für den ausgeprägteren Antiklerikalismus von Radicaux und Sozialisten war das anhaltende Nahverhältnis zum republikanischen Mythos charakteristisch. Die in Brive 1924 zur Unterstützung des Cartel des gauches gegründete „Republikanische und laizistische Jugend" betonte, die „unsterblichen Prinzipien“ der GroBen Revolution, also Freiheit und soziale Gerechtigkeit, verteidigen zu wollen: all das, „was unsere Väter gegen das Regime des Absolutismus und der Theokratie

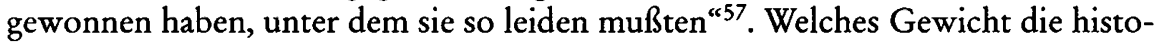
rische Argumentation in der antiklerikalen Debatte einnahm, zeigte sich auch, als 1930 in Rosiers-de-Juillac ein Denkmal für den früheren Generalrat Latrade eingeweiht wurde. Latrade, einst in den Kampfjahren der Republik Abgeordneter in Paris, wurde von der corrézischen Linken in ihre antiklerikale Ahnenreihe gestellt, hatte er doch schon 1849 im Parlament ausgerufen: „Die Jesuiten sind keine Franzosen", und 1877 hatte er gemahnt, die Freunde des Syllabus, die Priesterpartei, am meisten zu fürchten. Zu den größten Gegnern Latrades, so interpretierten die corrézischen Antiklerikalen ein halbes Jahrhundert später die Geschehnisse der 1870er Jahre, hätten „erschöpfter alter Adel“, Kleriker und Bonapartisten gehört, die „in Erwartung des Faschismus und des Staatsstreichs" nur darauf lauerten, die republikanische „Hure“ zu ermorden ${ }^{58}$. Konservative Kreise verwiesen demgegenüber auf die Konflikte Latrades mit Politikern der Radicaux und - mit seiner offensichtlich kirchlicher orientierten Ehefrau, die in Opposition zu den Ideen ihres Mannes gestanden habe.

Die meisten regionalen Vertreter der nationalen Staatsmacht, Präfekten und Unterpräfekten, scheinen das antikirchliche Ressentiment geteilt oder gar verstärkt zu haben. Denn nicht nur auf die Besetzung des Pariser Unterrichtsministeriums hatten die Radicaux stets ein wachsames Auge, sondern auch auf die Benennung der Präfekten in der französischen Provinz, wo die wichtigsten Bastionen des Parti radical lagen ${ }^{59}$. In der Corrèze jedenfalls waren die meisten während der Zwischenkriegszeit amtierenden (Unter-)Präfekten in der Wolle gefärbte Radi-

54 J. P. Duquesnoy, Lagraulière, 1996, S. 52-60.

55 Le Travailleur de la terre, Juni 1922.

56 Ebd., Dezember 1921, Juni 1924.

57 L'Effort Républicain, 30. 3. 1924, 6. 4. 1924.

58 Vgl. die Zeitungsartikel zum Fall Latrade vom September und Oktober 1930, in: ADC 1 M 111. Der Begriff „Hure“ (gueuse) gehörte zu den Schmähworten, mit denen man vor allem in der Action Française die Republik zu belegen pflegte.

59 Nach A. von Campenhausen waren von den 42 zwischen 1919 und 1939 amtierenden Unterrichtsministern 21 Mitglied der Radicaux. Vgl. A. Frh. v. Campenhausen, Staat und Kirche, 1962, S. 106. 
caux $x^{60}$. Auf einem Treffen ehemaliger Schüler der staatlichen Schulen in Brive (1928) gab der Unterpräfekt ganz offen seiner Erleichterung Ausdruck, hier in einem "essentiell laizistischen Milieu“ sprechen zu können; PRS-Bürgermeister Chapelle hatte am Horizont gar die erste Morgenröte einer neuen Religion ausgemacht, die den alten Glauben ersetzen werde ${ }^{61}$. Besonders kennzeichnend für die antiklerikale Position der staatlichen Behörden war es, wie genau jede noch so kleine Aktivität des ohnehin schwach entwickelten politischen Katholizismus in der Corrèze polizeilich überwacht wurde; größere Aufmerksamkeit fanden allenfalls die Action Française und die Kommunistische Partei. So berichtete der Tuller Polizeikommissar seinem Präfekten 1932 über das heimliche Plakatieren „klerikaler Propaganda“ gegen die staatliche „école unique“ und zugunsten der katholischen Schule ${ }^{62}$. Vor dem Diözesankongreß der Union Catholique in der linksrepublikanischen Hochburg Ussel (1930) hielt der Präfekt gar eine Mahnung an den dortigen Bürgermeister für angebracht, Ruhe und Ordnung zu gewährleisten und keine Gegendemonstrationen zu organisieren ${ }^{63}$.

Ein besonderes Kapitel aber waren die Feste zu Ehren der Jeanne d'Arc, bei denen nach Anweisung des Innenministeriums die staatlichen Repräsentanten in der Provinz präsent sein sollten. Im Gefolge des groß gefeierten 500 . Jahrestages der Befreiung von Orléans 1929 waren indes vor allem in der Presse der Volksschullehrer Vorbehalte gegen die heilige Johanna laut geworden. Das ganze Jahr 1930 über wurde sie kampagnenhaft als „Kriegsmaschine“ der katholischen Kirche attackiert, die den laizistischen Geist aus Frankreich vertreiben solle ${ }^{64}$. Nach dem vorliegenden Quellenmaterial ließ sich der corrézische Präfekt seit dieser Zeit bei dem morgendlichen Festakt in der Tuller Kathedrale vertreten, war außerhalb des Departements unterwegs oder kam „wahrscheinlich erst am Sonntag abend“ zurück $^{65}$. Auch bei anderen Veranstaltungen, etwa einem Totengedenken am Kriegerdenkmal, wollte der Präfekt „rechtzeitig vorher" wissen, ob der Bischof und die Tuller Priesterseminaristen eingeladen wurden ${ }^{66}$.

Die Vorsicht des Präfekten schien in diesen Fällen besonders nahezuliegen, weil bereits die Einweihung des Tuller Kriegerdenkmals 1924 zu politischen Verwicklungen geführt hatte. Damals war von einer Kommission unter dem Vorsitz des Tuller Bürgermeisters beschlossen worden, der Anregung eines Weltkriegssoldaten zu folgen und die Gedenkstätte von einem katholischen Geistlichen einweihen

60 Diesen Eindruck hatte nicht nur Le Salut National gewonnen (6. 5. 1928), er ergibt sich auch bei Durchsicht der präfektoralen Berichte über die politische Stimmung im Departement. Vgl. beispielsweise: Unterpräfekt an Präfekten, Ussel, 3. 9. 1919, in: ADC 3 M 195, oder Unterpräfekt an Präfekten, Brive, 5. 4. 1928, in: ADC 3 M 200.

${ }^{61} \mathrm{La}$ Croix de la Corrèze, 20. 5. 1928.

62 Polizeibericht an den Präfekten, Tulle, 29. 3. 1932, in: ADC 1 M 67; vgl. auch den Polizeibericht über das Katholikentreffen in Tulle vom 4. 10.1931, in: ADC 1 M 67, oder den Bericht des Präfekten an den Innenminister vom 12. 2. 1936 betreffs die sozialpolitischen Aktivitäten der Jungen Katholiken, in: ADC $1 \mathrm{M} 77$.

63 Präfekt an den Bürgermeister von Ussel, Tulle, 27. 9. 1930, in: ADC 1 M 67.

64 R. Rémond, L'anticléricalisme, 1976, S. 240.

65 Dies geht aus dem überlieferten Briefwechsel zwischen Bischof und Präfekt in den Jahren 1929 bis 1936 hervor; vgl. ADC 1 M 108, die zitierte Passage stammt aus einem Schreiben des präfektoralen Kabinettschefs an den Bischof (Tulle, 8. 5. 1936).

66 Cabinet du Préfet, Tulle, 7. 12. 1928, an „Mon chèr Robert“( $d$.h. den Referenten des Tuller Bürgermeisters), in: ADC 1 M 108. 
zu lassen. Die Tuller Sozialisten protestierten aber um so heftiger gegen diese "geplante klerikale Demonstration“, als auch zahlreiche corrézische Demokraten, Freidenker und Sozialisten Opfer des Krieges geworden seien. Außerdem verfehlte die Sektion der SFIO nicht, auf die überwältigende laizistische Mehrheit bei den vergangenen Parlamentswahlen in der Corrèze hinzuweisen, und drohte Gegenmaßnahmen an, falls ihrem Petitum nicht Rechnung getragen würde ${ }^{67}$. Nachdem der Präfekt und Minister Queuille in der Sache interveniert und die Anciens combattants sich von der Einzelinitiative eines ihrer Mitglieder distanziert hatten, verzichtete die Kirche in realistischer Einschätzung der örtlichen Machtverhältnisse darauf, das ohnehin religiöser Symbolik entbehrende Kriegerdenkmal zu weihen. Statt dessen beraumte der Tuller Bischof eine begleitende Zeremonie in der Kathedrale an, für die sich der Präfekt - ohne Angabe von Gründen - entschuldigte ${ }^{68}$.

Die nicht gerade wohlwollende Neutralität der staatlichen Behörden in Fragen der Religion ließ manche antiklerikalen Skandale überhaupt erst möglich werden. Als überzeugte Katholiken in Ayen ein Kreuz vor dem Kriegerdenkmal anbrachten, wies der Briver Unterpräfekt den Bürgermeister darauf hin, daß er es auf der Grundlage eines Gesetzes von 1905 entfernen könne. Der Gemeinderat forderte daraufhin den christlichen Familienvater, der mit dem Kreuz seine im Krieg gebliebenen Kinder hatte ehren wollen, dazu auf, das religiöse Symbol wieder zu entfernen. Da der Katholik sich aber weigerte, mußte es „eines Tages im Morgengrauen " der gemeindliche Feldwächter beseitigen. Jetzt erst wurde der Rat informiert, daß sich die Rechtslage durch einen Erlaß aus dem Jahr 1924 geändert hatte. Dem daraufhin wieder angebrachten Kreuz stellten die Lokalpolitiker nun aber zumindest eine rote Fahne zur Seite. Und nicht genug damit, wurde das Kreuz in der Folgezeit immer wieder beschädigt und schließlich sogar von einem nicht zu ermittelnden Dieb gestohlen. Ob ihn Unterpräfekt, Präfekt und Regierung wirklich gedeckt haben ${ }^{69}$, sei dahingestellt; ein für die politische Kultur der Corrèze charakteristischer, „sehr republikanischer Skandal“, wie La Croix de la Corrèze kommentierte, war die Episode in jedem Fall, da mit dem christlichen Kreuz hier nicht nur einmal Schindluder getrieben wurde ${ }^{70}$.

$\mathrm{Daß}$ der Antiklerikalismus in der politischen Kultur der Zwischenkriegszeit „kaum noch eine Rolle“ spielte ${ }^{71}$, weil die Katholiken - auch unter dem Einfluß der oft zur Regierungsmehrheit zählenden "gemäßigten“ Abgeordneten - überwiegend ihren Frieden mit der Republik gemacht und sich mit der Trennung von Staat und Kirche abgefunden hätten, ist eine These, die allenfalls mit Blick auf die nationale Ebene, und hier nur sehr bedingt, am ehesten für die Phase ab Mitte der 1930 er Jahre, bejaht werden kann $^{72}$. Erst nach dem Staatsbesuch Pierre Lavals bei

67 Landwirtschaftsminister an Präfekten, Paris, 29. 10. 1924, in: ADC 1 M 111.

68 Brief des Präfekten an Queuille, Tulle, 5. 11. 1924; Brief des Bischofs an den Präfekten, Tulle, 3. 12. 1924; Brief des Präfekten an den Bischof, Tulle, 5. 12. 1924. Sämtliche Dokumente in: ADC 1 M 111.

69 Diese Vermutung äußerte Le Salut National, der den Fall (am 13. 2. 1927) groß aufgriff.

70 Bei einer Wahlkampfveranstaltung 1928 wurde etwa einem dezidiert katholischen Kandidaten von der Tribüne aus ein Kreuz vor die Füße geworfen. L’Union catholique, April 1928.

71 Ch. Bloch, Die dritte Französische Republik, 1972, S. 257.

72 Auch J.-M. Mayeur (La laïcité, 1989, S. 83) oder Ph. Boutry/A. R. Michel (La religion, 1992, 
Pius XI. 1935 und dem feierlichen Empfang Kardinal Pacellis durch die Volksfrontregierung 1937 berief sich mit dem Pariser Erzbischof Jean Verdier ein hoher französischer Kleriker ausdrücklich auf die Erklärung der Menschenrechte von 1789, nahm also positiven Bezug auf die Große Revolution ${ }^{73}$. Sicher bildete der antikirchliche Affekt mit dem Aufkommen der faschistischen Gefahr ab 1934 nicht mehr generell den stärksten Zement für die Einheit der Linksparteien ${ }^{74}$; bis dahin aber zählte er in manchen Regionen zu den wichtigen Bindemitteln, zumal Schulstreitigkeiten periodisch aufflackerten und die philosophische Tiefe des Konflikts zwischen Katholiken und Laizisten immer wieder hell beleuchteten ${ }^{75}$. Nur so auch sind die antiklerikalen Topoi zu verstehen, die in der politischen Rhetorik der großen Politik präsent blieben. Noch 1931 betonte etwa der vom Parlament wegen seiner Agrarpolitik bedrängte linkskartellistische Ministerpräsident Steeg, sein Kabinett repräsentiere die von der Reaktion bedrohte laizistische Idee, die Weizenpolitik sei demgegenüber zweitrangig ${ }^{76}$.

Zwar mochte es schwerfallen, solche antiklerikalen Aussagen mit dem Prädikat der Rationalität zu versehen, doch sie zielten emotional auf eine in weiten Teilen des Landes verbreitete, in der Corrèze nur besonders verwurzelte politische Mentalität: "War die Ernte schlecht, so waren die Pfarrer schuld; ... die Pest auf Madagaskar, der Schiffbruch der Titanic, alles kam von den Pfarrern. Man brüllte: Nieder mit den Pfaffen! Und die Öffentlichkeit war damit zufrieden ... “77. Jedenfalls waren die kirchenfeindlichen Vorkommnisse auf dem limousinischen Land mehr als „Einzelfälle" ${ }^{\text {"78; }}$; selbst wenn nicht die Mehrheit der Bevölkerung zur antiklerikalen Tat schritt, waren es wie so oft in der Geschichte die Aktivitäten engagierter Gruppen, die das Klima der Gesamtgesellschaft prägten - und es doch nur prägen konnten, wenn die mentalen Voraussetzungen dafür in der Breite gegeben waren.

In der mehrheitlich linksrepublikanisch geprägten politischen Kultur der Corrèze gehörte eine, fast könnte man sagen "gesunde Portion“ Antiklerikalismus auch in der Zwischenkriegszeit noch immer zum guten Ton. Am Karfreitag fanden demonstrativ vor der Kirche üppige Fleischbankette statt, mit der wohlkalkulierten Folge, daß dieser Appetit der Freidenker ,auf Würste und alle anderen Schweinereien" die religiösen Empfindungen der Katholiken tief verletzte ${ }^{79}$. Mancher freute sich auch unverhohlen, als ein "zweifelsohne von Gott geschickter" Blitzschlag - „denn nichts geschieht ohne seine Fügung“ -, den Kirchturm von Beynat in Brand steckte ${ }^{80}$, fühlte sich bestätigt, wenn ein Bräutigam wenige Tage nach der

S. $667 \mathrm{f}$.) halten das Cartel des gauches nur für ein kurzes Zwischenspiel; davon abgesehen sei die religiöse Frage kein Trumpf mehr bei den Wahlen 1932 und 1936 gewesen.

73 A. Lindt, Zeitalter des Totalitarismus, 1981, S. $75 \mathrm{f}$.

74 A. Coutrot/F. G. Dreyfus, Les forces religieuses, 1965, S. 53.

75 Ebd., S. 54 ff.; die Autoren verweisen vor allem auf die katholische Opposition gegen die Reformprojekte der Regierung Herriot, die von 1927 an zunehmend vorangetrieben wurden, auf den Kampf um die Subventionierung der konfessionellen Schulen sowie auf die Emotionen, die sich besonders gegen den "unglücklichen Begriff“ der "école unique " richteten.

$76 \mathrm{La}$ Croix de la Corrèze (21. 2. 1932) kommentierte Steegs Äußerung lakonisch: Mögen die Bauern also krepieren, wenn nur die laizistischen Prinzipien gerettet werden.

77 Le Réveil du Bas-Limousin, 17. 1. 1935.

78 L. Pérouas, Refus d'une religion, 1985, S. 187.

79 Vgl. Le Courrier du Centre (Beilage Corrèze), 22./23. 4. 1935.

80 La Voix Corrézienne, 27. 3. 1932. 
kirchlichen Trauung verunglückte ${ }^{81}$, bedachte als Lausbube die Tuller Seminaristen bei ihrem Spaziergang in Soutane mit nicht zitierfähigen Schmähworten ${ }^{82}$, oder fand nichts dabei, wenn im Briver Krankenhaus eine staatliche Krankenschwester ebensoviel verdiente wie dreizehn Ordensschwestern zusammen. Der dortige Stadtrat, „antiklerikal und kartellistisch“ (1925), mochte nicht einmal den Wunsch des Ordens erfüllen, ihm die Friedhofsgebühren zu erlassen ${ }^{83}$.

Aufgrund der regionalen mentalen Tiefenstrukturen folgte dem „Altweibersommer" ${ }^{\text {"84 }}$ des Antiklerikalismus im Limousin seit Mitte der 1920er Jahre noch ein langer und goldener Oktober. Der Charakter dieses Antiklerikalismus war nach wie vor weniger antichristlich als antikatholisch. Nicht zufällig hatte gerade in der Haute-Corrèze am Ende des 19. Jahrhunderts auch der Protestantismus an Boden gewonnen ${ }^{85}$, und auch archaisch anmutende Formen tiefer Volksfrömmigkeit blieben dort noch lange verankert ${ }^{86}$. Dennoch wäre es irreführend zu sagen, daß der Antiklerikalismus nur „bis zur Haustür" reichte ${ }^{87}$. Jedenfalls nahm der Kirchgang vor allem unter den Arbeitern und Bauern weiter ab, lediglich das städtische Besitzbürgertum hielt an dieser Tradition tendenziell stärker fest. In den zwei ländlichen Kantonen um Tulle, wo 1911 noch 24,8\% der Männer und 68,4\% der Frauen ihre Osterpflicht erfüllt hatten, taten dies 1955 nur noch 6,2\% der Männer und 24,2\% der Frauen ${ }^{88}$. Das Bergland mußte nach dem Krieg sogar zum „Pays de mission“" erklärt werden, wo nun in Orten wie Treignac oder Bugeat Stationen der „Mission rurale" eingerichtet wurden ${ }^{89}$. Verwundern konnte die Entwicklung freilich kaum, da die linken Republikaner den Antiklerikalismus auch nach 1918 - wie schon während des 19. Jahrhunderts - als eine Art Ersatzreligion begriffen, die Freidenker ihre Bewegung als „Kultus“ inszeniert und vor allem die Volksschullehrer „laizistischen Glauben“" gepredigt hatten"0; so erfaßten die allgemeinen Säkularisierungstrends der Moderne die Corrèze mit besonderer Wucht.

\section{Konfessionalismus nach dem Burgfrieden}

Auch in der deutschen protestantischen Agrarprovinz war festgefügte Kirchlichkeit in der Zwischenkriegszeit längst nicht mehr überall essentieller Bestandteil der Dorfsitte ${ }^{91}$. Dort aber, wo sie es blieb, wo - von der Schwäbischen Alb bis

81 L. Pérouas, Refus d'une religion, 1985, S. 188.

82 J. Espinasse, Prêtre en Corrèze, 1979, S. 32.

83 L'Union Catholique de la Corrèze, Dezember 1925.

84 R. Rémond, L'anticléricalisme, 1976, S. 252.

85 L. Pérouas, Refus d'une religion, 1985, S. 167. In einem Ort, in dem Anfang der 1880er Jahre so gut wie die gesamte Bevölkerung zum Protestantismus konvertierte, meinte ein Gemeinderat, alle hier seien Freidenker, würden aber gleichzeitig am Glauben festhalten. L. Pérouas, Une religion des Limousins?, 1993, S. $85 \mathrm{f}$.

86 Vgl. E. Weber, La fin, 1983, S. 500, sowie P. Louty, Sur les sentiers, 1987, S. 11, $131 \mathrm{ff}$.

${ }^{87}$ So E. Plenel (L'État et l'école en France, 1985, S. 354) unter Verweis darauf, daß sogar die Freimaurer zumindest daran festhielten, ihre Kinder taufen zu lassen.

88 Vergleichszahlen ausschließlich für die Zwischenkriegszeit liegen nicht vor. Vgl. L. Pérouas, Refus d'une religion, $S$. 64 ff., 81.

89 F. Boulard, Problèmes missionaires de la France rurale, 1945, v. a. S. 132; L. Pérouas, Une religion des Limousins?, 1993, S. 116; E. Moratille, Contribution, 1991, S. 60.

90 L.Pérouas, Refus d'une religion, 1985, S. 164, 171.

91 W. Pyta, Dorfgemeinschaft, 1996, S. 56. 
nach Masuren - „die Zeit stehengeblieben zu sein schien “92, zeitigte dies eminent politische Folgen, weil das Land damit unter einen alltäglichen nationalkonservativen pastoralen Einfluß geriet. Gerade in Franken mit seiner "geradezu sprichwörtliche(n) Volksfrömmigkeit ${ }^{\text {“93 }}$, mit tiefreligiösen Gemeinschaftsbewegungen, die trotz organisatorischen Eigenlebens ihre geistliche Heimat innerhalb der Landeskirche suchten, gehörte es weiterhin zur Sitte, am Sonntag in die Kirche zu gehen; schon aus Rücksicht auf die Dorfmeinung konnte sich dem kaum jemand entziehen. Dorfsittlich vermittelt, wuchs der Kirche ähnliche Autorität zu wie den Eltern, was Unfolgsamkeit oder gar Auflehnung stark erschwerte ${ }^{94}$. Die „kleine Tradition" der kirchlichen Dorfsitte, wie sie vom bäuerlichen Volk gelebt wurde, verschmolz in Westmittelfranken mit der von wenigen Bildungsträgern in Pfarrhaus und Schulstube vermittelten "großen Tradition" des Nationalprotestantismus ${ }^{95}$.

Dagegen durften antiklerikale Agitatoren, noch dazu aus dem Umfeld der marxistischen Parteien, in der fränkischen Provinz weder mit der klammheimlichen Zustimmung der Bevölkerung noch gar mit der stillschweigenden Duldung seitens der Behörden rechnen. Beim Arbeiterturnfest in der kleinen Stadt Windsbach etwa war am Pfingstsonntag 1924 das Trommler- und Pfeiferkorps aus Nürnberg an der evangelischen Kirche vorbeimarschiert, obwohl es darauf aufmerksam gemacht worden war, daß noch Gottesdienst sei. Der Leiter des Musikzuges wurde daraufhin zu acht Tagen Haft verurteilt ${ }^{96}$. Auch gegen den kommunistischen Arbeiter im Bezirksamt Dinkelsbühl, der zwei Pfarrer als „Lügner und Strauchdiebe" beschimpfte, oder gegen die jungen Kommunisten, die auf der Bahnhofstraße in Gunzenhausen im Chor sangen: „Ein Vaterunser gibt es nicht, an einen Gott da glaub ich nicht", erstatteten die Behörden Strafanzeige. Mit Sorge beobachteten viele Bezirksamtsvorstände, wie die „Religionshetze ... sich auch schon in Landorten" auswirkte" ${ }^{97}$. In den Gemeinden war sie tatsächlich um so spürbarer, je stärker diese dem städtischen Einfluß ausgesetzt waren. In der Nürnberger Peripherie konnten es die Kommunisten wagen, in der Nacht vor den Reichspräsidentenwahlen 1932 die rote Fahne auf dem (Vacher) Kirchturm zu hissen ${ }^{98}$, und bei den (Zirndorfer) SPD-Mitgliedern verzeichnete die „lebhafte Werbung für den Kirchenaustritt" großen Erfolg99. Aber auch schon in kleinen Landstädtchen wie Rothenburg ob der Tauber oder Gunzenhausen fand die Forderung nach Kirchenaustritt und Schließung aller Kirchen bei den Anhängern von SPD und KPD manchmal „reichen Beifall“100.

${ }^{92}$ Ebd., S. 110.

${ }^{93}$ Ebd., S. 111.

${ }^{94} \mathrm{Vgl}$. auch M. Frommer, Isingen, 1976, S. $10 \mathrm{f}$.

${ }^{95} \mathrm{Da}$ in der Corrèze die „kleine Tradition der weitgehend unreflektierten Masse“ bereits mehr Distanz zur Kirche beinhaltete, konnte die „große Tradition“ des Laizismus besonders Platz greifen und auch die Mentalität der Dorfgemeinschaft in linksrepublikanischem Sinne formen. Zum Konzept der „little and great tradition“ vgl. R. Redfield, Peasant society, 1956, S. 70 f.

${ }^{96}$ StAN Rep. 218, Nr. 362, BA Ansbach an Pol. Nü-Fü, 3. 11. 1924.

${ }^{7}$ StAN KdI, II, Nr. 694, Pol. München an Staatsministerium des Innern betreffs Redeverbote, 27. 4. 1932; HStAM HMB, 7. 4. 1931.

${ }^{98}$ HStAM HMB, 18. 3. 1932.

${ }^{99}$ Ebd., 19. 7. 1932.

${ }^{100}$ Ebd. 
Je ländlicher aber die gesellschaftlichen Strukturen vor Ort waren und je geschlossener die Kirchengemeinden, desto schwerer fiel der Entschluß, sich dem parochialen Leben zu entziehen. Unter dem Druck der Verhältnisse kam es sogar vor, daß aus der Kirche ausgetretene Sozialdemokraten wieder zurückkehrten ${ }^{101}$ oder ein Arbeiterverein seine Fahnenweihe mit einem Gottesdienst in der Dorfkirche einleitete ${ }^{102}$. Auch während der Revolutionszeit 1918/19 hielten es die Sozialdemokraten in Ansbach für angebracht, sich in einer überfüllten Frauenversammlung zumindest gegen den Vorwurf zu wenden, sie wollten Kirche und Religion abschaffen ${ }^{103}$. Und wenn ein "Arbeiterrat" damals dem Pfarrer empfahl, die Predigten kürzer zu halten ${ }^{104}$, so mußte dies wohl eher als konstruktive Kritik interpretiert werden.

In dem nahe Dinkelsbühl gelegenen Arbeiterdorf Schopfloch (1800 Einwohner), wo 1905 der erste sozialdemokratische Bürgermeister Bayerns gewählt worden war und 1932 fast jeder dritte Mann der SPD angehörte, hielten die Bürger ebenfalls über alle parteipolitischen Lager hinweg am evangelischen Glauben fest, dessentwegen ihre Vorfahren vor Jahrhunderten aus dem österreichischen Raum hatten emigrieren müssen ${ }^{105}$. Noch 1932 war der örtliche Kirchenvorstand „zum weitaus überwiegenden Teil aus organisierten Socialdemokraten zusammengesetzt" und arbeitete „einträchtig mit dem Pfarrer zusammen“106. Der von Hartmut Mehringer im Blick auf das überwiegend katholische Unterfranken erstellte Befund, daß „der religiöse Agnostizismus unter den Sozialdemokraten eine offenbar nur geringe Rolle spielte ${ }^{\text {"107, }}$, trifft für die evangelische Provinz in Mittelfranken also ebenfalls zu.

Hier war überhaupt die anderswo zunehmende Bekenntnisunsicherheit noch kein kirchenpolitisches Problem geworden. Gerade in den zur Zeit des Eigenkirchenrechts im frühen Mittelalter entstandenen und daher meist kleinen Pfarrgemeinden Westmittelfrankens blieb das lutherische Erbe im Geiste Löhes auch nach dem Ersten Weltkrieg lebendig: „Es war Löhe-Land“, mit dem besten Verhältnis zwischen Pfarrstellen und Gemeindegliedern und den wenigsten Kirchenaustritten. Nirgendwo sonst in der evangelischen Landeskirche gab es so viele Dekanate mit einer Abendmahlskirchlichkeit von über $87 \%{ }^{108}$. Und auch von den Hausandachten war man in den Bauerndörfern wenigstens "noch nicht ganz abgekommen“, $j a$ in etlichen Gemeinden waren sie noch ,in den meisten Familien üblich" 109 . Hier lag „die Bauernreligion in eigentümlicher Mischung mit dem Luthertum vor“, wie es durch die Landesherren „in väterlicher, nachhaltiger

101 DA Eichstätt, Osterbericht Abenberg, 9. 6. 1919.

${ }^{102}$ So in Lehrberg. Siehe: Fränkische Zeitung, 1.7. 1930.

${ }^{103}$ Fränkische Zeitung, 4. 1. 1919Vm.

${ }^{104}$ S. Kadner, Kirchliches Jahrbuch, 1919/20, S. 144.

$10595,6 \%$ der Schopflocher bekannten sich 1933 zum protestantischen Glauben. Siehe A. Großmann, Milieubedingungen, 1983, S. 480 f., 485.

${ }^{106}$ Vgl. die „Beurteilung der Geistlichen der im Jahre 1932 visitierten Gemeinden“, in: LkAN Dek. Dinkelsbühl, Nr. 123.

${ }^{107}$ H. Mehringer, Bayern in der NS-Zeit, 1983, S. 336.

${ }^{108}$ H. Maser, Die Evangelisch-Lutherische Kirche, 1990, S. 82; P. Kremmel, Pfarrer, 1987, S. 12.

${ }^{109}$ LkAN Dek. Wassertrüdingen, Nr. 114, Kirchenvisitationsberichte 1931 der Gemeinden Altentrüdingen, Dambach und Ehingen, sowie Dekanat Leutershausen, Nr. 200, Kirchenvisitationsberichte 1930 (Binzwangen und Stettberg). 
Zucht dem Volk eingeprägt worden ist“"110. „Lutherische Sitte und zäh konservatives Bauerntum" hatten so im evangelischen Franken eine Form von Kirchlichkeit geschaffen, wie man sie z.B. in den gut kirchlichen Gemeinden Oberhessens ebenfalls fand. Denn das „Festhalten, das der Bauer im allgemeinen hat, an Scholle und Haus und Hof ", kam auf dem religiösen Gebiet voll zum Tragen ${ }^{111}$. Bauernreligion bedeutete zwar vor allem Einhalten der Sitte, doch lebte in dem an die Natur ausgelieferten Landvolk auch etwas „von dem Gefühl für die Übermacht der göttlichen Welt". So waren gerade „bäuerliche Erweckungen“ im 19. Jahrhundert besonders in die Tiefe gegangen, nicht persönliche Erlebnisse geblieben; vielmehr ergriffen sie manchmal das ganze Haus und die ganze Gemeinde ${ }^{112}$.

Die weitreichenden mentalen Prägungen werden in dem Leben eines Altmühlbauern wie Johann Adam Schuster aus Trommetsheim, viele Wegstunden von Neuendettelsau entfernt, exemplarisch deutlich: Mit seiner Mutter, einer „innig frommen Frau", war er schon als Knabe nach Neuendettelsau hinübergepilgert, „um den großen Gottesmann Löhe predigen zu hören“. Da der örtliche Pfarrer selbst zu den Freunden Löhes zählte, wuchs Schuster in einer ernsten christlichen Atmosphäre auf. Als Mitglied der Neuendettelsauer Gesellschaft für innere und äußere Mission sah ihn die "Zeit des politischen Aufwachens“ im Jahr 1894 „in den ersten Reihen" des neugegründeten Bunds der Landwirte, wobei er weder Kosten noch Mühen scheute, „der konservativen Sache zu nützen"113. Ähnliches galt für viele Bauernbürgermeister, die 1920 ein Fünftel der weltlichen Abgeordneten in der lutherischen Generalsynode zu Ansbach stellten und dort, angeführt vom Neuendettelsauer Rektor Hans Lauerer, zur konservativen Mehrheit zählten ${ }^{114}$. Welche Bindung diese politisch meinungsführenden „Landmänner" noch mitten in den 1920er Jahren an ihre Kirche hatten, artikulierte der Landwirt und Bürgermeister Hauf aus Eyb bei Ansbach: „Wir Bauern sehnen uns doch oft nach vertrauensvoller Aussprache ..., wenn wir im Herbst einsam hinter unserem Pflug gehen und ... auf einmal steht unser Pfarrer am Rain und weil gerade Vesperzeit ist, setzt er sich zu mir auf den Pflug ..., das ist uns ein Gottesdienst!“115

Auch in der lutherisch-orthodox gefärbten Kirchenlandschaft Westmittelfrankens waren Praktiken des Aberglaubens, wie sie schon für die Corrèze beschrieben wurden, nicht unbekannt. Bei Beerdigungen aus den eingepfarrten Orten Weihenzells etwa durfte der Sarg zur Aufbahrung nicht eher vom Wagen abgeladen werden, „als bis der Fuhrmann in drei Absätzen eine Maß Bier geleert hatte, weil sonst jemand aus seinem Haus stirbt ${ }^{\alpha 116}$. Nicht nur ein solcher Aberglauben war zu tadeln, zudem klagten manche Pfarrer über eine „steinern“ gewordene

\footnotetext{
${ }^{110}$ So Friedrich Fürstenberg im Blick auf die Frömmigkeit des Bauernvolkes in Hohenlohe-Franken.

Vgl. F. Fürstenberg, Protestantische Volksfrömmigkeit, 1986, S. 56.

111 I. Brunner-Schubert, Lebensformen, 1974, S. 166.

112 W. Trillhaas, Bauern - Bürger - Proletarier, 1949, S. 12 f.; selbst wenn religiöse Inhalte dem ländlichen Menschen „schon lange Zeit fremd geworden sein“ mochten, klammerte er sich doch „an die Form ..., solange deren Aussage noch irgendwie entfernte Bedeutung für ihn hatte". Vgl. H. Hörger, Kirche, Dorfreligion und bäuerliche Gesellschaft, 1983.

${ }^{113}$ Der Freimund, 1920, S. 2f., $6 \mathrm{f}$.

${ }^{114}$ H. Maser, Die evangelisch-lutherische Kirche, 1990, S. 17.

115 Der Freimund, 1927, S. 286 f.

${ }^{116}$ Vgl. das Kapitel „Religiosität und Sittlichkeit des Weihenzeller Gemeindelebens zu Beginn des 20. Jahrhunderts" in: G. Roesner, Weihenzell, o. J., S. 94 f.
} 
Kirchlichkeit ohne innere Anteilnahme seitens der Gläubigen, über ein bei der Masse zu materiell ausgerichtetes, nicht mehr bewußt gelebtes Christentum ${ }^{117}$. Doch hatte nicht schon der strenge Wilhelm Löhe bemerkt, daß die fränkischen Bauern zwar nicht evangelisch leben, „wohl aber gut im evangelischen Glauben sterben könnten" 118 ? Vor allem aber versuchten sie weiterhin auch, gut lutherisch zu wählen. Wenn die religiöse Kraft des Protestantismus also selbst auf dem fränkischen Lande hier und dort nachließ, so war seine politische Macht noch ungebrochen ${ }^{119}$.

Der christliche Glaube war jedenfalls noch so lebendig, daß man den in den Städten zunehmenden Verlust kirchlicher Öffentlichkeitsgeltung voller Betroffenheit registrierte. Kaum jemand bedachte dabei, daß die Kirchenaustrittsbewegung nach 1918 nicht die Folge einer kämpferischen Kampagne der politischen Linken war, sondern in der ersten deutschen Republik nur der „Schleier weggezogen“" wurde, der während des Kaiserreichs „die reale Situation des Christentums in der Gesellschaft durch das Staatskirchentum verdeckt" hatte ${ }^{120}$. In „bestimmten proletarischen Großstadtzentren“, so glaubte man dagegen in Westmittelfranken zu wissen, wurden "religiöse Genossen“, nicht nur Mitglieder der KPD, sondern auch Sozialdemokraten, vom "Terror der Gottlosen“ vergewaltigt ${ }^{121}$. Der 1930 von der kommunistischen Freidenker-Internationale gefaßte Beschluß, den Sitz nach Berlin zu verlegen ${ }^{122}$, stellte schließlich „die deutsche Christenheit vor eine neue Situation " 123 und löste bis in die kleinsten fränkischen Dörfer hineinreichende Strömungen aus, die sich mit der „bolschewistischen Kulturpropaganda und Kirchenbekämpfung " befaßten. In Dambach am Hesselberg lud der Pfarrer nun zu einem volksmissionarischen Gemeindeabend mit „Vorführung kommunistischer Gesänge und gottloser Lieder von der Schallplatte“, um den „Kampfwillen" der Gemeinde für die "Stunde der kommenden Entscheidung" zu stärken ${ }^{124}$.

Die partielle Anpassung der ländlichen Sozialdemokratie an die kirchlichen Traditionen des Raumes wurde vom Antiklerikalismus ihrer großstädtischen Genossen konterkariert, der im Zeitalter der Massenkommunikation bis tief in die Provinz ausstrahlte. Waren nicht auch schon im Vorwärts die angebliche religionspolitische Neutralität der SPD durchbrochen und evangelische Geistliche „mit borniert dummen Gesichtszügen und weit aufgerissenem Mund“ karikiert wor$\operatorname{den}^{125}$ ? Frank J. Gordon hat deshalb wohl zu Recht auf das Paradoxon verwiesen, wie sehr das „marxistisch antireligiöse Gepäck“ ausgerechnet der stärksten repu-

${ }^{117}$ Der Freimund, 1930, S. 20, sowie G. Roesner, Weihenzell, o. J., S. 94.

${ }^{118}$ H. Baier, Die Anfälligkeit, 1979, S. 26.

${ }^{119}$ Kritisch mit dem Topos vom besonders religiösen Bauern setzt sich, bezugnehmend u. a. auf Thesen Max Webers, C. Köhle-Hezinger auseinander. Dies., Evangelisch-katholisch, 1976, S. $49 \mathrm{ff}$.

${ }^{120}$ K. Nowak, Geschichte des Christentums, 1995, S. 230.

121 Der Freimund, 1931, S. 386.

${ }^{122}$ Aus dem von Sozialdemokraten und Kommunisten gemeinsam getragenen „Deutschen Freidenker-Verband" waren 1930 auf Befehl aus Moskau die kommunistischen Freidenker ausgeschieden; bis 1932 hatten sie ihre Weltzentrale in Berlin. Am stärksten war die Bewegung in der UdSSR, wo bis 1933 über sieben Millionen Erwachsene und zwei Millionen Jugendliche im „Bund kämpfender Gottloser" organisiert wurden. Vgl. J. Kahl/E. Wernig, Freidenker, 1981.

${ }^{123}$ K.-W. Dahm, Pfarrer und Politik, S. 137.

${ }^{124}$ F. Baumeister/G. Moninger, Friedrich Ernst, 1991, S. 356.

${ }^{125}$ K.-W. Dahm, Pfarrer und Politik, 1965, S. 139. 
blikanischen Partei den Weimarer Staat destabilisierte, indem es die protestantischen Kirchen, als größte nicht-gouvernementale Institution in Deutschland, dauerhaft abschreckte ${ }^{126}$. Daß in fränkischen Kleinstädten „die landwirtschaftliche Umgebung auf die Haltung der Arbeiterschaft" einwirkte und auch die lokalen Parteiführer „um der großen Zahl gutkirchlicher Christen willen, die sie in ihrer Gefolgschaft haben“, kirchenfeindliche Tendenzen möglichst zurückstellen mußten, war für die evangelische Geistlichkeit ein schwacher Trost; sie lebte im Bewußtsein „vom großen Sturmangriff des Satans auf das deutsche Volk“. Da überwiegend in den Städten zwischen 1919 und 1928 „bereits rund 2 Millionen deutscher Volksgenossen" aus der Kirche ausgetreten waren, fürchtete man bald, daß der Bolschewismus auch „auf dem Land unter den Bauern eindringen möchte“127. $\mathrm{Zu}$ diesem deprimierenden Bild gehörte es für die bewußten Lutheraner ferner, daß in der proletarischen Gottlosenbewegung bereits 900000 Mann gegen die christliche Kirche kämpften, was angesichts von „200 religionslosen Abgeordneten" im Reichstag nicht verwundere ${ }^{128}$.

Völlig aus dem Blick geriet hinter dieser Drohkulisse, daß aufs Ganze gesehen auch die evangelisch-lutherische Kirche Bayerns in den Weimarer Jahren eigentlich mehr gewonnen hatte als verloren. Zwar war die Kirche nunmehr ,frei vom Staat", aber der Staat - nach einem Wort des Sozialdemokraten Johann Meerfeld „nicht frei von der Kirche ${ }^{\text {"129. }}$. Jedenfalls wurde, wie oben schon dargelegt, die materielle und rechtliche Basis des kirchlichen Einflusses in der Weimarer und Bayerischen Verfassung gestärkt. Ein Reichsschulgesetz, wie es die Kirchen zur Absicherung des konfessionellen Unterrichtswesens wünschten, blieb zwar bis ans Ende der Weimarer Republik umstritten; doch bestätigte 1924 ein bayerisches Kirchenkonkordat den grundsätzlich konfessionellen Charakter des Volksschulunterrichts ebenso ausdrücklich wie die Beaufsichtigung des Religionsunterrichts durch die Geistlichkeit ${ }^{130}$. Diese Faktoren trugen auf ihre Weise dazu bei, daß gerade in der Agrarprovinz Westmittelfrankens die Entkirchlichung nach dem Ersten Weltkrieg weiterhin nur langsam fortschritt und Religion noch weit mehr bedeutete als eine reine Privatangelegenheit ${ }^{131}$.

Die Furcht vor der sozialistisch-bolschewistischen Gottlosenbewegung konnte in Westmittelfranken freilich nur deshalb besondere politische Virulenz entfalten, weil sie sich mit wachsenden Sorgen um eine katholische Gegenreformation verband. Nach der von Kaiser Wilhelm 1914 ausgegebenen Parole kannte man in Deutschland angeblich weder Parteien mehr noch Konfessionen. Tatsächlich ver-

${ }^{126}$ F. J. Gordon, Protestantism and Socialism, 1988, S. 442.

127 Der Freimund, 1931, S. 272, 280 f.

${ }^{128}$ So auch der Neuendettelsauer Missionsinspektor Kern auf einem Kirchenvertretertag im Dekanatsbezirk Feuchtwangen. Fränkische Zeitung, 12.7. 1932. Zu Kern, der auch Mitglied der "Christlich-Deutschen Bewegung" war, die als Vorläuferorganisation der "Deutschen Christen“ gilt, siehe den Hinweis bei C. Weiling, Die „Christlich-Deutsche Bewegung“, 1998, S. 229.

${ }^{129}$ Meerfeld saß für die SPD in der Weimarer Nationalversammlung. K. Nowak, Geschichte des Christentums, 1995, S. 211.

${ }^{130}$ Der Freistaat sicherte ferner die Erhaltung der Erlanger theologischen Fakultät zu sowie freiwillige Zuschüsse zur Besoldung und Ruhestandsversorgung der Pfarrer. Vgl. W. Brandmüller, Handbuch, 1991, S. $454 \mathrm{ff}$.

${ }^{131}$ Vgl. W. K. Blessing, Kirchenglocken für Eisner?, 1992, S. $418 \mathrm{ff}$. 
mochte das überkonfessionelle „Volkserlebnis“ des Ersten Weltkriegs ${ }^{132}$ die Geltung der antikatholischen Ressentiments im fränkischen Protestantismus nur kurz zu unterbrechen. Bald wurde „Katholizismus“ wieder mit politischem Katholizismus und dieser wiederum mit dem konfessionalistischen Kulturkatholizismus gleichgesetzt ${ }^{133}$. Mißtrauen gegen die alten „Reichsfeinde“ der Zentrumspartei und die dunklen Kräfte des römischen Ultramontanismus schien den meisten Protestanten nach der schmerzhaften Niederlage „ihres“ Bismarck-Deutschland 1918 berechtigter denn je. 1918 war für die Lutheraner mehr als ein politischer, es war ein Religionskrieg verloren worden ${ }^{134}$. Hatte nicht Benedikt XV. zu einem deutschen Journalisten gesagt, der Weltkrieg habe mit dem Sieg über Luther geendet? ${ }^{135}$ Auch kämpferische Weimarer Kulturkatholiken machten kein Hehl aus ihrer Genugtuung über das Ende einer jahrhundertelangen Vorherrschaft protestantischer Geisteskultur in Deutschland ${ }^{136}$. Für die protestantischen Pfarrer in den fränkischen Kernlanden der Reformation war das daraus resultierende „stolze Kraftbewußtsein “ der katholischen Kirche schier unerträglich ${ }^{137}$, auch wenn sich damit, anders freilich als es ihnen lieb sein konnte, nur eine Einsicht Thomas Manns bei Kriegsausbruch selbst erfüllt zu haben schien, daß nämlich die geistigen Wurzeln dieses Krieges „in dem eingeborenen und historischen ,Protestantentum ' Deutschlands liegen", in dem uralten deutschen Kampf gegen die römische Welt und den Geist des Westens ${ }^{138}$. Diese siegreiche Welt erhob sich jetzt auch "dunkel und nebelhaft“ über dem evangelischen Franken, und sie nahm, mit den Worten des monarchisch gesinnten Oberkonsistoriums zu reden, „vieles mit sich ..., was uns lieb und teuer war..." ${ }^{\text {139. }}$.

Zudem hielten die konfessionellen Konflikte, die der politisch-religiösen Mentalität im evangelischen Franken als lebensweltliche Erfahrung zugrunde lagen, auf der lokalen Ebene auch in den 1920er Jahren unvermindert an ${ }^{140}$. Die im Zeitalter von Reformation und Gegenreformation entstandenen, im Kulturkampf im 19. Jahrhundert vielfach wieder aufgerissenen Wunden auf katholischer wie auf protestantischer Seite waren im „Volkserlebnis“ des Ersten Weltkrieg keineswegs ganz verheilt. Nach wie vor sahen sich die Protestanten Westmittelfrankens in ihrer konfessionellen Identität einem besonderen Wechselbad der Gefühle ausgesetzt: Innerhalb Weimar-Deutschlands zählten sie zur großen evangelischen Mehrheit, im Freistaat Bayern dagegen waren sie eine relativ kleine Minderheit, in ihrer engeren Heimat wiederum gaben sie eindeutig den Ton an, immer aber auch dort unmittelbar mit einer beachtlichen Zahl von Diaspora-Katholiken konfron-

${ }^{132}$ W. Tilgner, Volk, Nation und Vaterland, S. 146.

${ }^{133}$ Vgl. A. Langner, Weimarer Kulturkatholizismus, 1984, S. 113.

${ }^{134}$ Nicht umsonst hatten deutsche Truppen beim Einmarsch in Frankreich das alte lutherische Kampflied „Ein' feste Burg ist unser Gott“ gesungen. Vgl. F. Hartweg, Kirchen und Konfessionen, 1997, S. 25 ff.; dazu auch: G. Ph. Wolf, Lutherbild, 1974.

135 Vgl. S. Kadner, Kirchliches Jahrbuch, 1921/22, S. 122.

${ }^{136}$ A. Langner, Weimarer Kulturkatholizismus, 1984, S. 72. So deutete etwa der jesuitische Theologe Hartmann Grisar die Niederlage Deutschlands „in einen konfessionellen Sieg des Katholizismus“ um. K. Nowak, Geschichte des Christentums, 1995, S. 208.

${ }^{137} \mathrm{Vgl}$. S. Kadner, Kirchliches Jahrbuch, 1921/22, S. 122.

138 Th. Mann, Betrachtungen eines Unpolitischen, 1956, S. $39 \mathrm{f}$.

${ }^{139}$ S. Kadner, Kirchliches Jahrbuch, 1919/20, S. 143.

${ }^{140}$ Vgl. K.-S. Kramer, Protestantisches in der Volkskultur, 1969. 
tiert, was das Trennende beider Konfessionen täglich ins Bewußtsein rücken konnte. Manchmal nahm dieser Konflikt Züge eines fortgesetzten „Kulturkampfs von unten" an.

Stein des Anstoßes war immer wieder das mit dem Codex juris Canonici 1917/ 18 verschärfte katholische Mischehenrecht in Deutschland, das alle von nichtkatholischen Pfarrern geschlossene Mischehen für ungültig erklärte und daraus hervorgehende Kinder mithin für unehelich ${ }^{141}$. Entschiedene Lutheraner erklärten sich diese Maßnahmen damit, daß die „Papstkirche ... im Hinblick auf die erwartete (und leider eingetretene) deutsche Niederlage" die Zeit für geeignet erachtete, „ihre Machtansprüche zu steigern“ und ihrer „Mißachtung des Protestantismus" ${ }^{142}$ Ausdruck zu geben. Zwar war seit dem Konzil von Trient 1563 die Gültigkeit der Ehe eines Katholiken an die Eheschließung in katholischer Form und durch einen katholischen Pfarrer gebunden, doch hatte für den Bereich des Deutschen Reichs Pius X., eine lange sonderrechtliche Entwicklung abschließend, 1906 die tridentinische Norm für die „Ehe zwischen Katholiken und Häretikern (Ketzern und Protestanten)“"143 außer Kraft gesetzt.

Nach Ansicht evangelischer Pfarrer auch in Westmittelfranken waren die Mischehen damit "auf eine Stufe mit Konkubinat und wilder Ehe“ gestellt ${ }^{144}$. Daß dies mehr als nur ein theologisches Problem war, erwies sich etwa 1923 in Ansbach, als ein katholischer Geistlicher ein bereits evangelisch getrautes, in Mischehe lebendes Paar katholisch wiedertraute, damit die im Sterben liegende Frau die katholischen Sakramente empfangen konnte. Die örtlichen Protestanten empfanden den Vorgang als eine „bis dahin in unserer Stadt unerhörte Kränkung der evangelischen Kirche" und sahen den für die Gegenwart doppelt notwendigen konfessionellen Frieden „auf das ernsteste gefährdet“. In einer überfüllten Protestversammlung in der Gumbertuskirche, die mit dem trutzigen „Ein feste Burg ist unser Gott“ eingeleitet wurde, führte der Dekan bewegte Klage, daß dies alles ausgerechnet in Ansbach, der Stadt Georgs des Frommen, geschehen konnte. Das katholische Stadtpfarramt wies die Vorwürfe als „Beeinträchtigung der freien Ausübung der Seelsorge“ zurück und berief sich auf eine differenzierte Stellungnahme des evangelisch-lutherischen Synodalpräsidenten von Pechmann zum Mischehenrecht. Pechmann aber verwahrte sich scharf gegen diese Inanspruchnahme und wollte wissen, „woran wir sind: Will die katholische Kirche Frieden in Deutschland oder Krieg?“". Eine Verallgemeinerung der Ansbacher Praxis jedenfalls käme einer Kriegserklärung gleich ${ }^{145}$.

Bei einem ähnlichen Fall in Schillingsfürst mußte der katholische Dekan Vorwürfe zurückweisen, die Wiedertrauung auf dem Sterbebett sei „erschlichen“ worden. Vielmehr habe die protestantische Frau des Sterbenden nach entsprechender Erläuterung eingesehen, daß die vor der evangelischen Kirche geschlos-

\footnotetext{
${ }^{141}$ E. Eichmann, Das katholische Mischehenrecht, 1995; K. Galling, Religion, 1960, S. $964 \mathrm{ff}$.

${ }^{142}$ Hauptverein des Evangelischen Bundes in Bayern, Jahresbericht 1926, in: LkAN Bestand Personen XXV (Steinlein) Nr. 33.

${ }^{143}$ Vgl. das Flugblatt „Evangelisch-katholische Mischehen - Achtung“, in: LkAN Bestand Personen XXV (Steinlein) Nr. 33.

144 S. Kadner, Kirchliches Jahrbuch, 1919/20, S. 175.

145 Vgl. Fränkische Zeitung, 9. 7., 13. 7., 14. 7., 24. 7. 1923.
} 
sene Ehe ungültig sei ${ }^{146}$. Die Gegenreaktion etwa des protestantischen Kirchenvorstandes von Leutershausen bestand darin, einem Katholiken, der sich "mit seiner Kirche ausgesöhnt hatte“, die Bestattung auf dem örtlichen evangelischen Friedhof zu verweigern. Daß der Friedhof schließlich mit Hilfe des Ansbacher Bezirksamtsmannes geöffnet werden mußte, war nun wiederum in den Augen der Katholiken eine "traurige Wahrheit"147.

Angesichts solch „schwerer konfessioneller Kämpfe“ rieten entschiedene Lutheraner dringend, „vor Eingehung einer Mischehe, noch besser vor Anknüpfung eines Verhältnisses zu einem Katholiken oder zu einer Katholikin“, zu bedenken, daß der katholische Teil gemäß dem Codex jederzeit das Recht habe, sich von Bett, Tisch und Wohnung zu trennen, wenn die Kinder nicht katholisch erzogen würden. Zwar könne auch eine Mischehe eine „Arbeits-, Freuden- und Leidensgemeinschaft werden, aber nicht Glaubengemeinschaft“; und damit fehle ihr „der innerste Einklang gleicher Lebens- und Weltanschauung", wenngleich ein junges Paar ,in seinem ersten Glück “ dies nur zu leicht verkenne ${ }^{148}$. Das vielgelesene Rothenburger Sonntagsblatt brachte in einem Aufsatz gegen die Mischehe ein weiteres, schulpolitisches Argument zur Sprache, war einem Mischehenkind doch in der katholischen Schule vom Geistlichen im Religionsunterricht gesagt worden, nur in der katholischen Kirche könne man selig werden. In einem an bayerischen katholischen Volksschulen weitverbreiteten Kirchengeschichtsbuch wurde obendrein nach wie vor behauptet, "unerhörte Sittenlosigkeit“ sei die "schlimme Frucht" der Reformation gewesen ${ }^{149}$.

Die „römische Seite“ schürte während der 1920er Jahre - nach Überzeugung entschiedener Lutheraner - nicht nur den Mischehenstreit „durch immer neue Vorstöße“, sie strebte auch unablässig "nach immer weiterer Ausdehnung der Fronleichnamszüge in den überwiegend protestantischen Gegenden" sowie nach einer allgemeinen Arbeitsruhe am Fronleichnamstag, während sie sich der Arbeitsruhe am Karfreitag widersetzte. Die Lutheraner wollten den „Kreuzigungstag unseres Herrn“ allerdings „unmöglich einem rein konfessionellen romkatholischen Fest" gleichgestellt sehen, dem Papst Urban IV. „ausdrücklich den Zweck einer gegen die Ketzer gerichteten Kundgebung" gegeben habe, sondern höchstens dem Reformationstag am 31. Oktober ${ }^{150}$. Daß dies alles mehr war als ein akademisch-theologischer Disput, der nur die Pfarrer und wenige Funktionäre im Evangelischen Bund interessierte, konnte in gemischt konfessionellen Gegenden an Fronleichnam und Karfreitag immer wieder beobachtet werden, wenn die Bauern des jeweils arbeitenden Bekenntnisses besonders viel Mist fuhren oder besonders laut mit den Peitschen knallten.

\footnotetext{
146 Mittelfränkische Volkszeitung, 22. 7. 1930.

147 Ebd.

${ }^{148} \mathrm{Vgl}$. Hauptverein des Evangelischen Bundes in Bayern, Jahresbericht 1926, sowie das Flugblatt „Evangelisch-katholische Mischehen - Achtung“, in: LkAN Bestand Personen XXV (Steinlein) Nr. 33.

149 Vgl. den Artikel „Wieder einmal die Münchner katholische Kirchenzeitung“ aus dem Rothenburger Sonntagsblatt von 1927, in: LkAN Bestand Personen XXV (Steinlein) Nr. 33.

150 Hauptverein des Evangelischen Bundes in Bayern, Jahresbericht 1926, in: LkAN Bestand Personen XXV (Steinlein) Nr. 33.
} 
Da die konfessionelle Problematik tief in existentielle lebensweltliche Bereiche wie Familie, Schule und Tod eingriff - in Bellershausen verweigerte der katholische Kurat sogar dem evangelischen Schwiegervater des Bürgermeisters bei der Beerdigung das herkömmliche Grabgeläut ${ }^{151}$-, blieb sie auch in die Mentalität der bäuerlichen und kleinstädtischen Bevölkerung Westmittelfrankens selbst fest eingegraben. Vielerorts brachen selbst rein menschliche Kontakte zwischen den Bewohnern verschiedener Dörfer an der Konfessionsgrenze ab, war an Mischehen vor allem auf dem Land ohnehin nicht zu denken, weil die Vermählten sofort enterbt oder wenigstens gesellschaftlich geächtet worden wären, und oft nicht einmal bei der Arbeit auf den Feldern, die an die Flurstücke des anderen Konfessionsgebietes grenzten, schlossen evangelische und katholische Bauern Bekanntschaft. Nach der Erinnerung eines protestantischen Landwirts haben die katholischen Bauern in der Gegend von Binzenweiler jedes Gespräch mit den „Ketzern“ rundweg abgelehnt. Die Lutheraner in Feuchtwangen wiederum bedachten die wenigen Katholiken in der Kleinstadt mit dem Ausdruck „Brockenfresser“, was auf die Form ihres Abendmahls anspielte. Und wenn am Tisch eines größeren evangelischen Bauern gebetet wurde, blieben die katholischen Dienstboten selbstverständlich draußen vor der Tür ${ }^{152}$. „Ins Luther" zu gehen, wie die Katholiken es nannten, bedeutete also ebenso wie umgekehrt eine Grenzüberschreitung für die noch stark konfessionell geprägten fränkischen Landbewohner. Infolge der konfessionellen Zerrissenheit unterschieden sich katholische Sprengel im Dialekt, und lange auch in der Tracht, merklich von unmittelbar benachbarten protestantischen Dörfern ${ }^{153}$.

Die konfessionelle Teilung wurde mancherorts aufgrund lokalhistorischer Spezifika durch die soziale Schichtung weiter vertieft. Wo sich etwa Katholiken im Zuge der reichsritterschaftlichen Peuplierung in kleinen bäuerlichen Anwesen angesiedelt hatten, stand ihnen eine alteingesessene Schicht "großer" evangelischer Bauern gegenüber ${ }^{154}$, rekrutierten sich auch die Dienstboten („ganz arme Teufel aus Weinberg drunten“) zu 90\% aus der katholischen Bevölkerung ${ }^{155}$. Den als Minderheit in überwiegend protestantischen Orten lebenden Katholiken blieb oft nichts anderes übrig, als zumindest nach außen hin klein beizugeben, und nach Möglichkeit keine BVP-Versammlung anzuberaumen, wenn die „konfessionellen Konflikte im Stadtrat" gerade besonders akut waren ${ }^{156}$. In dem von "mehreren fanatischen Protestanten“ durchsetzten Kitzingen sah sich der 2. Vorsitzende der BVP zum Rücktritt gezwungen, nachdem die Übernahme des Amtes dem Inhaber eines Feinkosthauses "geschäftlich soviel Schaden bereitet" hatte ${ }^{157}$. In Schillings-

${ }^{151}$ HStAM HMB, 19. 1. 1927.

152 Gespräch mit F. Trump sowie mit den Herren Wünschmeyer, Unger und Weiß im Feuchtwanger Stadtarchiv. Vgl. auch I. Brunner-Schubert, Lebensformen, 1974, S. $146 \mathrm{ff}$.

${ }^{153}$ Vgl. J. Brunner-Schubert, Lebensformen, 1974, S. 179 (Zitat), sowie F. Merkenschlager, Keuperbucht, 1928, S. 49.

${ }^{154}$ I. Brunner-Schubert, Lebensformen, 1974, S. 179.

${ }^{155}$ Gespräch mit F. Trump.

${ }^{156} \mathrm{StA}$ Kitzingen, Akten des BVP-Ortsverbandes, Allgemeiner Briefwechsel: Schreiben vom 16.1. 1931 an Landtagsabgeordneten Schwarz wg. Schwierigkeiten der Ortsgruppe Rödelsee.

${ }^{157}$ StA Kitzingen, Akten des BVP-Ortsverbandes, Allgemeiner Schriftwechsel, ,angefangen am 20. 4. 1920“: Undatierte Liste von Otto Schneider an Herrn Abt wg. Ergänzung der Wahllisten sowie Schreiben Adolf Peschkes an Herrn Abt. 
fürst hielten es die Katholiken sogar für angebracht, Infanteriegewehre in der Orgel ihrer Kirche zu verstecken, da sie, wie der Pfarrer als Entschuldigungsgrund angab, „zum Schutze bei Fronleichnamsprozessionen benötigt" seien ${ }^{158}$. In Feuchtwangen dagegen scheinen sich die ganz wenigen katholischen Geschäftsleute schon aus existentiellen Gründen mit der protestantischen Mehrheit gut gestellt zu haben ${ }^{159}$.

Ein besonderer Tiefpunkt des „Kulturkampfs von unten“ wurde 1924 an der südlichen Grenze Westmittelfrankens in Kipfenberg erreicht. Dort verband der katholische Pfarrer die Aufforderung zur Osterbeichte - von der Kanzel aus - mit dem Erfahrungsbericht eines ihm bekannten Irrenanstaltsleiters. Danach stellten die meisten Irren prozentual die Protestanten, weil sie anders als die Katholiken nicht in der Lage seien, durch die Beichte ihr Gewissen zu entlasten ${ }^{160}$. Vor diesem Hintergrund verwundern auch die Sorgen nicht mehr, die ein katholischer Priester 1926 seinem Osterbericht anvertraute: daß er nämlich, um den Rockflügel beim Fahrradfahren nicht in das Hinterrad zu drehen, die Röcke aufschürzen müsse, „was gewiß nicht schön und des klerikalen Kleides gewiß nicht decent ist, zumal man genötigt ist, des öfteren durch protestantische Ortschaften zu fahren ..."161. Besonders belasten konnte die bikonfessionelle Situation schließlich das Verhältnis der protestantischen und katholischen Pfarrer untereinander, als etwa der evangelische Geistliche von Königshofen in seine Bibelstunden auch junge katholische Leute einlud, ja „anlockte“, wie sein katholischer Kollege bitter vermerkte $^{162}$.

Wenn es während der Weimarer Jahre in Westmittelfranken eine Bewegung auf dem politisch-religiösen Feld gegeben hat, dann eher in Richtung eines verschärften Konfessionalismus. Ein Spiegelbild dessen bot die Entwicklung des von einem „manchmal kaum erträglichen Antikatholizismus"163 geprägten Evangelischen Bundes, der nirgendwo in Deutschland einen annähernd großen Zweigverein aufbauen konnte wie im Mittelfränkischen. Sein 1925 mit dem vielsagenden Namen Fränkische Wacht gegründetes inoffizielles Organ wurde immer wieder auch im Korrespondenzblatt empfohlen, dem wichtigsten Forum für die evangelischlutherischen Geistlichen in Bayern. Und die Kirchenvorstände kleiner Dörfer besprachen sein Wirken gleichfalls mit Interesse ${ }^{164}$.

1929 verstärkte der Evangelische Bund seine Aktivitäten in Westmittelfranken, wo schon bisher wichtige Tagungen stattgefunden hatten ${ }^{165}$, noch weiter und gründete auf einer „aus allen Kreisen der hiesigen protestantischen Bevölkerung sehr zahlreich besuchte(n) Versammlung“ anstelle der bestehenden Ortsgruppe

${ }^{158}$ Gendarmerie-Hauptstation Erlangen, 23. 4. 1932, an BA Erlangen, (wg. Stegmann-Veranstaltung) in: StAN Reg. von Mfr. KdI, Abg. 1968, II, Nr. 699.

159 Gespräch mit den Herren Wünschmeyer, Unger und Weiß im Feuchtwanger Stadtarchiv.

160 Die örtlichen Protestanten versammelten sich daraufhin nichtöffentlich und ersuchten den katholischen Pfarrer, künftig von Angriffen gegen Andersgläubige abzusehen. HStAM HMB, 20.5. 1924.

${ }^{161}$ DA Eichstätt, Osterberichte und Relationes status decanalis, Arberg, 3.7. 1926.

162 DA Eichstätt, Osterberichte und Relationes status decanalis, Arberg, 20.7. 1930.

${ }^{163} \mathrm{~K}$. Th. Bach, Das Verhältnis der evangelisch-lutherischen Kirche, 1982, S. $7 f$.

${ }^{164} \mathrm{Vgl}$. Bericht über die Zwischenvisitation in Veitsweiler, 1. 11. 1932, in: LkAN Dek. Dinkelsbühl, Nr. 123.

${ }^{165}$ Z. B. das „Landesfest“ am 4./5. September 1926 in Rothenburg. 
einen eigenen „Zweigverein für Ansbach und Umgebung“. Bezeichnenderweise grub dessen Vorsitzender Pfarrer Steinlein für sein Referat eine Festschrift des katholischen Bonifatiusvereins von 1899 wieder aus, die ,aus geistigen und materiellen Quadersteinen“ eine Brücke zwischen „nördlichen und südlichen Katholiken Bayerns" hatte bauen wollen; deren Mittelpunkt, so hieß es in der Broschüre, solle Nürnberg sein, wohin die katholische Kirche „in ihrer Macht und Majestät zurückkehren" müsse, und auch an Städte in Westmittelfranken wie Ansbach und Rothenburg hatte der Bonifatiusverein als „Stationen der erwähnten Brücke“ gedacht ${ }^{166}$. Um so bedrohlicher schien dies der lutherischen Pfarrerschaft Westmittelfrankens, weil sie mit Sorge sah, daß aufgrund der demographischen Entwicklung "manche einst evangelische Stadt ... allmählich eine katholische Mehrheit" bekomme: „Gebe Gott, daß unser Volk noch aufwacht, ehe es zu spät ist!“167

Steinleins Befürchtungen hingen auch mit jüngeren Vorfällen im Kampf der Konfessionen zusammen, der im Vorjahr wieder einmal eskaliert war. Die 1928 von evangelischen Kirchengemeinden in Westmittelfranken veranstalteten Vorführungen des Lutherfilms von Hans Kaysers wurden so zahlreich besucht, daß die katholischen Vereine in Ansbach durch Ministranten ein Flugblatt verteilen ließen, um gegen diese Störung des konfessionellen Friedens zu protestieren ${ }^{168}$. Ihres Erachtens übertrieb der Film „in tendenziöser Weise“ Mißstände in der katholischen Kirche zur Zeit Luthers; „besonders verletzend“ wirkte „die unwürdige Darstellung der Person Tetzels" auf $\operatorname{sie}^{169}$. Auch andernorts waren die Proteste lebhaft, weshalb in Bayern - als einzigem deutschen Land - ein Vorführungsverbot erlassen wurde. In den Augen der konfessionalistischen Lutheraner war dies nur ein weiteres Glied in einer Beweiskette, die davon ausging, daß jetzt - im Deutschland der 1920er Jahre - eine "neuzeitliche Gegenreformation“ stattfinde ${ }^{170}$. Deren Abwehr sahen sie obendrein - wie schon im Kulturkampf des 19. Jahrhunderts - durch die mangelnde Geschlossenheit des Protestantismus erschwert, weil z.B. auch „ein Nürnberger evangelischer Geistlicher“ an dem Lutherfilm „kaum einen guten Faden“ gelassen hatte ${ }^{171}$.

Tatsächlich aber war der Gegensatz zwischen den konservativen Lutheranern in der Provinz und städtischen liberalen Kulturprotestanten in den Jahren nach dem Krieg schwächer geworden, nicht zuletzt deshalb, weil das Gewicht des Liberalismus innerhalb der Pfarrerschaft noch weiter abnahm und, wie schon seit 1919/20 zu beobachten war, das Bekenntnis zur konfessionalistisch agierenden DNVP allgemein wurde. Freilich entstand dann spätestens nach dem Hitlerprozeß 1924 unter den dezidierten Lutheranern ein völkischer Flügel. Dort sah man die "schon ihrer Zahl nach nicht entfernt dem evangelischen Bevölkerungsanteil“

166 Vgl. die beiden Zeitungsausschnitte „Evangelischer Bund (1929)“, in: LkAN Bestand Personen XXV (Steinlein) Nr. 33.

${ }^{167}$ Vgl. Bericht über die Zwischenvisitation in Veitsweiler, 1. 11. 1932, in: LkAN Dek. Dinkelsbühl, Nr. 123.

${ }^{168} \mathrm{Zu}$ den Ereignissen vgl. Fränkische Zeitung, 10. 5. 1928; HStAM HMB, 3. 4. 1928.

${ }^{169}$ Siehe die öffentliche Erklärung zum Lutherfilm in der Germania, 17. 2. 1928; vgl. auch Münchner Neueste Nachrichten, 24. 2.1928.

170 W. Fleischmann-Bisten, Der Evangelische Bund, 1989, S. 194, 188.

${ }^{171}$ Vgl. das Manuskript „Zur Kritik des Lutherfilms in ,Christentum und Wirklichkeit“", in: LkAN Bestand Personen XXV (Steinlein) Nr. 33. 
entsprechenden protestantischen deutschnationalen Landtagsabgeordeten durch ihr Regierungsbündnis mit der BVP „politisch lahmgelegt“ und die „evangelischen Belange" infolgedessen mißachtet; das Konkordat zwischen evangelischer Landeskirche und bayerischem Staat 1925, so hieß es, sei nur ein "mechanischer Abklatsch" des katholischen Kirchenvertrags, da nach wie vor die lutherische Kirche weniger an Staatszuschuß erhalte, „als ihr bei der Durchführung der Rechtsgleichheit mit der römisch-katholischen Kirche, also nach dem Zahlenverhältnis der Kirchenangehörigen zukäme“172.

Zwischen „partei-völkischen Kreisen“ im Evangelischen Bund und deutschnational orientierten Protestanten entspann sich wegen der Zugehörigkeit einiger westmittelfränkischer Pfarrer zum monarchistischen Bayerischen Heimat- und Königsbund bald ein charakteristischer Streit, der unter anderem mit Flugblättern in den Dekanaten geführt wurde. Von „parteivölkisch“ geneigter Seite wurde gegen den Heimat- und Königsbund der Einfluß seines prominenten Mitglieds und BVP-Führers Heim ins Feld geführt, der einst angeblich „mit Deutschlands Todfeinden zum Zweck der Zerstückelung Deutschlands verhandelt" habe. Auch über die „Bedrückung der Protestanten“ unter Abel in den Jahren nach 1838 würde im überkonfessionellen Heimat- und Königsbund eine verharmlosende „hanebüchene Geschichtsfälschung" verbreitet. Gegen den Vorwurf, als Mitglieder des Heimat- und Königsbundes „das Erbe der Reformation mit vollem Bewußtsein preiszugeben “, so entgegneten drei westmittelfränkische Pfarrer, „brauchen wir evang. Geistlichen, zumal wir von der Neuendettelsauer Gesellschaft ... uns nicht zu wehren." Die "deutsch-protestantischen Interessen“ seien „unter dem Königtum“ jedenfalls viel besser gewahrt gewesen als unter der parlamentarischen Regierung. ${ }^{173}$

Schon in den ersten Wahlkampagnen der Weimarer Zeit 1919 war, wie oben gezeigt, der Appell an die protestantischen Grundüberzeugungen im Zweikampf zwischen Liberalen und deutschnationaler BMP unüberhörbar gewesen. Skepsis hatte obendrein geherrscht, ob sich die Einigung der christlichen Bauern „ohne Unterschied der Konfession" ins Werk setzen ließ ${ }^{174}$. Als die BMP in den frühen 1920er Jahren die alten konservativen Positionen gegen die Liberalen zurückerobert hatte, blieb ihre protestantische Zuverlässigkeit - bald in Konkurrenz zum fränkischen Nationalsozialismus - ein von den Funktionären, Mitgliedern, aber wohl auch den Wählern immer wieder vehement eingefordertes Schlüsselprädikat. Zumal die langjährige landespolitische Koalition der Deutschnationalen mit der BVP im Münchner Maximilianeum nicht nur bei wenigen eingefleischten Konfessionalisten zu schlimmen Befürchtungen Anlaß gab, sondern auch „weite protestantisch-bäuerliche Kreise“ einen scharfen Trennungsstrich „zwischen uns und der bayerischen Volkspartei“ ziehen wollten ${ }^{175}$. Der einflußreiche mittelfränkische Landbundführer und DNVP-Politiker Beckh hatte vor dem Hitlerputsch

${ }^{172}$ Hauptverein des Evangelischen Bundes in Bayern, Jahresbericht 1926, in: LkAN Bestand Personen XXV (Steinlein) Nr. 33.

${ }^{173}$ Flugblatt „Bayer. Heimat- und Königsbund“, unterschrieben von „Scholler-Bonnhof, ZindelElpersdorf, Fleischmann-Ammerndorf“, in: LkAN Bestand Personen XXV (Steinlein) Nr. 33.

174 BAP RLB 15: BdL-Geschäftsstelle Nürnberg an Roesicke, 16.11. 1919.

${ }^{175}$ C. Geuss an Hopp, 29. 2. 1924, in: BAK Nachlaß Weilnböck, Nr. 5a (1924). 
sogar für eine Verständigung mit der NSDAP plädiert, „damit wir uns gemeinsam gegen Heim und Schlittenbauer stellen können" "176.

Unter den kleinstädtischen DNVP-Honoratioren dominierte ebenfalls ein konfessionalistisches Weltbild, inspiriert von dem Wort über das „Heilige Evangelische Reich Deutscher Nation", das Adolf Stoecker, großes Vorbild des Erlanger Reichstagsabgeordneten Hermann Strathmann ${ }^{177}$, geprägt hatte. Bei einer Schwedenfeier auf dem Hesselberg, wo dem als protestantischen Helden verehrten König Gustav Adolf ein Denkmal enthüllt wurde, sprach der im Geist des deutschen evangelischen Pfarrhauses sozialisierte Dinkelsbühler DNVP-Bürgermeister Rudolf Götz ${ }^{178}$ über die „rohe Gewalt der Gegenreformation“ und fand sogar Verständnis für Gustav Adolfs Streben nach der deutschen Kaiserkrone: Womöglich habe den Schwedenkönig der Gedanke geleitet, „ein germanischer Fürst sei berufener zum Kaiser der Deutschen als ein spanisch-romanischer"179.

Konfessionalistisches Denken bestimmte nicht nur derartige Sonntagsreden, auch bei der Wahl Hindenburgs zum Reichspräsidenten 1925 war neben den Attributen der „Königstreue“ und Franzosenfeindschaft die konfessionelle Motivation mit ausschlaggebend ${ }^{180}$. Obwohl der populäre Heerführer des Ersten Weltkrieges auch von der BVP unterstützt wurde, stilisierte ihn vor allem der Evangelische Bund geradezu als „neuen Luther“. Der „schwer katholische“ Zentrumskandidat Wilhelm Marx blieb angesichts der vom rechten „Reichsblock“ gegen den angeblichen „Neo-Ultramontanismus“ erzeugten Kulturkampfstimmung zumindest bei den konfessionellen Lutheranern ohne Chance ${ }^{181}$. Denn daß „unser deutsches Vaterland zu einem Vasallenstaat des Papstes“ gemacht wird, wie der Evangelische Bund befürchtete ${ }^{182}$, schien überall dort eine unerträgliche Vorstellung, wo „die protestantischen Gefühle besonders erregbar“ waren, also etwa auch in Württemberg, Sachsen, Pommern und Mecklenburg ${ }^{183}$. In den fränkischen Bezirksämtern Ansbach, Rothenburg, Uffenheim und Gunzenhausen erhielt Hindenburg sogar mehr als $90 \%$ der Stimmen, wobei zahlreiche Dörfer sich nahezu einstimmig für den evangelischen General entschieden ${ }^{184}$. Auch in den Städten verliehen „imposante“ Siegesfeiern der allgemeinen Hindenburg-Euphorie Ausdruck ${ }^{185}$. Es entsprach der Realität, wenn bereits in der zeitgenössischen Publizistik der „Appell an das konfessionelle Bewußtsein der evangelischen Deutschen " als einer der wahlentscheidenden Faktoren hervorgehoben wurde ${ }^{186}$. Da der fränkische Protestantismus von „einem deutschen Mann, von einem Chri-

${ }^{176}$ Beckh an Weilnböck, 22. 5. 1923, in: BAK Nachlaß Weilnböck, Nr. 4b (1923). Sebastian Schlittenbauer war der Generalsekretär der Christlichen Bauernvereine.

177 Strathmann kam aus der geistlichen und kirchlichen Tradition Westfalens, wo Stoecker als Reichstagsabgeordneter gewählt worden war. Vgl. O. Hass, Hermann Strathmann, 1993, S. 4ff.

${ }^{178}$ H. Götz, Rudolf Götz, 1990, S. 39.

${ }^{179}$ Fränkische Zeitung, 1.7. und 5. 7. 1932.

${ }^{180}$ Der Freimund, 1925, S. 63, 67.

${ }^{181} \mathrm{~K}$. Holl, Konfessionalität, 1969, S. 275, $263 \mathrm{ff}$.

182 W. Fleischmann-Bisten, Der Evangelische Bund, 1989, S. 175.

${ }^{183}$ A. Lindt, Zeitalter des Totalitarismus, 1981, S. 85 (Zitat); zur katholischen Perspektive H. Hürten, Deutsche Katholiken, 1992, S. 88 f.; zur Persönlichkeit des katholischen Präsidentschaftskandidaten vgl. die Biographie von U. v. Hehl, Wilhelm Marx, 1987.

${ }^{184}$ R. Hambrecht, Aufstieg der NSDAP, 1976, S. 97, 457.

185 Vgl. StA Bad Windsheim: Stadtchronik vom 27. 4. 1925.

${ }^{186}$ R. Gaede, Stellung des deutschen Protestantismus, 1976, S. 397. 
sten, von einem evangelischen Christen" wie Hindenburg an der Staatsspitze nur das Beste erwarten konnte, hatte seine Wahl hier zunächst eine stabilisierende Wirkung für die Republik. Solange ein Hindenburg Präsident ist, kommentierte der Dettelsauer „Freimund“ seinen 80. Geburtstag (1927), „wird jeder gewaltsame Versuch, die bestehenden Verhältnisse zu ändern, auf eisernen Widerstand stoßen ..." ${ }^{\prime 187}$.

Die Konfessionalisierung der politischen Kultur Frankens spielte indes nicht nur in der großen Politik eine wichtige Rolle, sondern bis zum Ende der Weimarer Republik auch in der Kommunalpolitik. Ein Konflikt in der früheren Freien Reichsstadt Dinkelsbühl (BVP-Anteil 1930: 14\%), wo die "gereizten Protestanten" schon 1924 auf einem Gustav-Adolf-Bild als Ausgleich für einen angeblich katholischen Altar in der Kriegergedächtnishalle bestanden hatten ${ }^{188}$, machte dies im Sommer 1930 noch einmal schlaglichtartig deutlich. Der katholische Stadtrat und Verkehrsausschußvorsitzende Joseph Greiner hatte nach dem französischen Abzug aus dem Rheinland die Entfernung der an den vier Stadttoren angebrachten Mahntafeln gegen den „Schmachfrieden von Versailles“ beantragt, weil diese die Stadteinfahrten verunzierten und den Fremdenverkehr beeinträchtigten. Für die lokalen Gegner des Ultramontanismus bot diese Forderung nun eine willkommene Gelegenheit, nicht nur Greiners Patriotismus grundsätzlich in Zweifel zu ziehen, sondern auch die Tendenz seiner kommunalen Wirtschaftspolitik. Denn protestantische Geschäftsleute klagten seit einiger Zeit darüber, daß Greiner einseitig bestimmte, ihm konfessionell nahestehende Kreise bevorzuge. Nun konnten die Katholiken zwar geltend machen, daß die Mitglieder im städtischen Verkehrsausschuß „zumeist überzeugte Protestanten“ seien, doch war die Angelegenheit auch von der nationalliberalen Nürnberger Presse „ins konfessionelle Fahrwasser" gezogen worden und nur noch durch den Rücktritt Greiners aus dem Verkehrsausschuß zu lösen. In einer anderen Stadt, so kommentierte Greiner resignierend, wäre seine Austrittserklärung vielleicht wieder rückgängig zu machen gewesen, nicht aber „im politischen Klima Dinkelsbühls“, wo 11 Stadträte der plakativ konfessionell firmierenden „Evangelischen Bürgerpartei“, 2 Nationalsozialisten und auch einige Sozialdemokraten gegen ihn eingenommen seien. Und mit dem deutschnationalen Bürgermeister Götz war Greiner ohnehin schon wegen der Hakenkreuzfahnen bei NSDAP-Versammlungen im städtischen Schrannensaal zusammengestoßen ${ }^{189}$.

Aus der Analyse von politischem und alltäglichem Konfessionalismus während der 1920er Jahre erhellt, wie stabil die Kernschicht der nationalprotestantischen Milieumentalität in Westmittelfranken nach wie vor war und welch hoher Stellenwert religiös-kulturellen Faktoren als Motiv auch für das Wahlverhalten zukam. So waren die damaligen Erfolge der Deutschnationalen wie auch die späteren der NSDAP zu einem erheblichen Teil eine Folge des Konfessionalismus. Durch ihn

${ }^{187}$ Der Freimund, 1927, S. 358. Beim Gesang- und Musikverein in Feuchtwangen erwuchs damals „spontan aus der Hochstimmung" eines Festabends der Gedanke, dem Reichspräsidenten als dem "getreuen Ekkehard“ des deutschen Volkes ein Huldigungstelegramm zu senden. FSM: Festschrift 150 Jahre Gesang- und Musikverein Feuchtwangen, 1977, S. 33.

${ }^{188}$ Fränkische Tagespost, 18. 11. 1924.

189 Vgl. Fränkische Zeitung, 20. 9. 1930; Mittelfränkische Volkszeitung, 21. 7., 23. 9. und 25. 9. 1930; Alt-Dinkelsbühl, 1990; W. Bogenberger/M. Vogel, Dinkelsbühl, 1983. 
schien das politische Bewußtsein der Menschen im evangelischen Franken derart geprägt zu sein, daß sie - mit dem Begriff des Religionswissenschaftlers Wolfgang Philipp zu reden - gleichsam unter „Strukturzwang" handelten ${ }^{190}$.

Für die Wähler in der Corrèze galt ähnliches, freilich vor dem ganz anderen Hintergrund des Antiklerikalismus, der im Boden dieser Region mit seine tiefsten Wurzeln hatte. Die nervösen Ausschläge auf der Skala der tagespolitischen Konjunktur im Verhältnis von Staat und Kirche vermochten der in eineinviertel Jahrhunderten seit der Großen Revolution in immer neuen Schüben herangereiften antiklerikalen Mentalität so schnell nichts anzuhaben; die positiven Signale (Union sacrée, second ralliement, Krise der Action française) wirkten erst an der Oberfläche, begannen wohl schon in tiefere Schichten des politischen Bewußtseins einzusickern, hatten sich aber dort noch nicht fest abgelagert. Statt dessen entstanden aus dem in langen Zeiträumen gewachsenen Konfliktpotential selbst bei vergleichsweise marginal scheinenden Anlässen stets aufs neue kleinere und größere Reibereien, ohne daß bei den Kombattanten Anzeichen der Erschöpfung zu erkennen gewesen wären. Teilweise unbeirrt von den kirchenpolitischen Haupt- und Staatsaktionen im fernen Paris, folgte der „Kulturkampf von unten“ in der französischen Provinz seinen eigenen Gesetzen.

Für den corrézischen Antiklerikalismus in der Folgezeit der Union sacrée gilt der Befund, daß sich Elemente der Milieumentalität, selbst nach Wegfall für sie wesentlicher politisch-gesellschaftlicher Grundlagen, als Bestandteil des regionalen Wir-Gefühls im Kulturbewußtsein fortschreitend reproduzieren konnten und im übrigen wohl noch über die dargestellten Konflikte hinaus auf einer „subliterarischen "191 Ebene virulent blieben, zumal mentaler Wandel realem Wandel oft erst mit einer Verzögerung von ein, zwei Generationen folgt ${ }^{192}$. Da sich in Westmittelfranken der lutherisch-konfessionalistische Kern der regionalen Milieumentalität infolge des Umbruchs von 1918/19 eher noch verfestigte, weil der Nationalprotestantismus nach dem Ende des evangelisch bestimmten Kaiserreichs dazu überging, sich vor einem als bedrohlich empfundenen Katholizismus und einer sozialistischen "Gottlosenbewegung" gleichsam einzuigeln, konnte mentaler Wandel hier erst recht kaum Platz greifen. So wie in der regionalen politischen Kultur der Corrèze der (liberale) „Respekt vor der Laizität ... die Grenze nach rechts“ $\operatorname{zog}^{193}$, markierte im Westen Mittelfrankens eine spezifisch konservative lutherische Tradition weiterhin die Trennlinie nach links.

\section{Nationalismus nach Versailles}

Nationalprotestantische und republikanisch-laizistische Mentalität hatten sich in Westmittelfranken und in der Corrèze im 19. Jahrhundert herausgebildet, als lutherisch-konfessionalistische bzw. antiklerikale Kernschichten mit spezifischen Elementen von (antisemitischem) Nationalismus und (republikanischem) Libe-

190 W. Philipp, Religiöse Strömungen, 1963, S. 225.

${ }^{191} \mathrm{Vgl}$. Ch. Köhle-Hezinger, Evangelisch-katholisch, 1976, S. $79 \mathrm{ff}$.

192 Vgl. W. K. Blessing, Kirchenglocken für Eisner?, 1982, S. 268.

${ }^{193}$ So der corrézische Politiker Labrousse, zit. nach: Le Salut National, 8. 1. 1928. 
ralismus verschmolzen. Dabei war der Nationalismus als Integrationsideologie des Nationalstaates und der Massengesellschaft nicht nur in Deutschland seit der zweiten Hälfte des 19. Jahrhunderts zunehmend aggressiv aufgetreten; sein tendenziell totalitärer ${ }^{194}$ Appell an jeden einzelnen, einen Beitrag zur Größe der eigenen Nation zu leisten, hatte den europäischen Kontinent - nach den sozialdarwinistischen Ideen der Zeit - polarisiert und Menschen wie Staaten einem Pro$z e ß$ der $\mathrm{Ab}$ - und Ausgrenzung unterworfen ${ }^{195}$. In den Jahren nach dem Ersten Weltkrieg bildete der Nationalismus weiterhin, vielleicht sogar mehr noch als vor 1914, eine der gewaltigsten politischen Energien der Epoche ${ }^{196}$. So ähnlich indes die außen- und militärpolitischen Funktionen der europäischen Nationalismen waren, so unterschiedlich wirkten sie nach innen im Kontext regionaler Milieumentalitäten in den einzelnen Ländern.

Auch in der Corrèze war zunächst jener epochenspezifische europäische Normal-Nationalismus ${ }^{197}$ zu beobachten, der in einer Art „Konvergenz der Patriotismen" ${ }^{198}$ sogar die Grenzen von linksrepublikanischem und klerikal-konservativem Lager zu überspringen vermochte. So trafen sich die „zwei Frankreich“ in der Verehrung einiger großer nationaler Symbolgestalten, zumindest wenn diese so ambivalent gedeutet werden konnten wie Jeanne d'Arc oder Henri IV ${ }^{199}$. Auch das Begräbnis des corrézischen Kolonial-Unteroffiziers Charles Lovy, des Helden von Kzar-el-Azoudj, nahm 1904 in Tulle die Form einer patriotischen Massendemonstration $a^{200}$. Neben den im Ergebnis von 1870/71 kaum verwunderlichen Vorbehalten gegenüber Deutschland waren gerade im Limousin, einst Schauplatz des Hundertjährigen Krieges gegen die englische Krone, auch lange noch Animositäten gegenüber dem "perfiden Albion“201 lebendig.

Gleichzeitig gewannen internationalistische Gedanken - in der fränkischen Provinz allenfalls von einer schwachen Sozialdemokratie in den Kleinstädten verbreitet - im Limousin schon vor 1914 einen höheren Stellenwert. Nicht nur die Tuller Sozialisten verschrieben sich ausdrücklich dem „Antipatriotismus und Kollektivismus“ und der Menschheit als „der einzigen Partei“202; auch in der

194 Theodor Schieder sah die "Ideologie eines totalitären Nationalstaats" bereits in der demokratischen Identitätslehre Rousseaus angelegt. T. Schieder, Probleme der Nationalismusforschung, 1991, S. 107.

195 Auch die neuere sozialwissenschaftliche Forschung unterstreicht, wie stark nicht nur kultur-, sondern auch staatsnationales Gruppenbewußtsein durch eine „intern bindende und extern abstoßende Komponente" gekennzeichnet sei. Vgl. H. Esser, Ethnische Differenzierung und moderne Gesellschaft, 1988, S. 236.

${ }^{196}$ Norbert Elias bezeichnete Nationalismus als „eines der mächtigsten, wenn nicht das mächtigste soziale Glaubenssystem des 19. und 20. Jahrhunderts". Siehe N. Elias, Ein Exkurs über Nationalismus, 1989, S. 196. Aus der reichhaltigen Literatur zur Nationalismusproblematik sind darüber hinaus besonders empfehlenswert H. A. Winkler, Nationalismus, 1985, H. Schulze, Staat und Nation, 1995, sowie E. J. Hobsbawm, Nationen und Nationalismus, 1991.

197 Vgl. auch E. Weber, The Nationalist Revival in France, 1959.

198 Maurice Agulhon, in: Histoire de la France rurale, Bd. 3, 1976, S. 500; Raoul Girardet interpretiert diese nationalistische Konvergenz als "sentimentalen und mythischen Synkretismus“. Vgl. R. Girardet, Le nationalisme, 1966, S. 25.

199 Vgl. G. Dauger, Aux origines du Front populaire, 1986, S. 82 f.

200 ADC, 2 Fi Tulle 221, sowie Le Corrézien, 29. 3. 1904.

201 (Lemouzi 1895). Zit. nach M. Zorzi, La conscience régionale, 1996, S. 99.

202 Vgl. den Polizeibericht über eine politische Versammlung in Tulle vom 12. 9. 1907, in: La Corrèze à la Belle Epoque, 1983, S. 37. 
Volksschullehrerschaft pflegte man internationalistisches Gedankengut, weshalb klerikal-konservative Kreise in der Corrèze warnend von einer „Krise des Patriotismus an der Schule“ sprachen ${ }^{203}$. Dabei war es vor allem eine kräftige pazifistische Strömung, die den Nationalismus immer wieder in Frage stellte und seiner Radikalisierung entgegenstand.

Als in Frankreich zu Beginn des Ersten Weltkriegs der Geist der Union sacrée auch im sozialistischen Lager Einzug hielt, erklangen nirgendwo so - unzeitgemäß - pazifistische Töne wie in der limousinischen SFIO-Presse; leiser wurden sie erst unter dem doppelten Druck der Pariser Parteiführung und der Militärzen$\operatorname{sur}^{204}$. Völlig verstummte die sozialistische Friedenspropaganda in der Region aber während des ganzen Krieges nicht: in Tulle beschlagnahmte die Polizei eine verbotene Broschüre, die von einem Volksschullehrerehepaar verfaßt worden war. Freilich erfaßte diese Strömung, nach allem, was wir wissen, zunächst vor allem die Arbeiterschaft, nachdem die bäuerliche Bevölkerung von Maßnahmen wie etwa der Lebensmittelrationierung ohnehin weniger in Mitleidenschaft gezogen wurde und die corrézische Landwirtschaft sich in den Kriegsjahren vielmehr stabilisierte $^{205}$.

Auch wenn das Klischee vom Hurrapatriotismus der Augusttage 1914 die viel differenziertere, zwischen trauriger Resignation und Enthusiasmus schwankende Stimmung in der französischen Provinz verzeichnet ${ }^{206}$, war im Limousin, trotz pazifistischer Tendenzen, antideutscher Chauvinismus weit verbreitet; ebenso begegnete man an den Bahnhöfen jubelnden Mengen, die sich umarmten, nationale Lieder intonierten oder den Zug aus Ussel begrüßten, auf dem ein Spruchband eine Vergnügungsreise nach Berlin ankündigte ${ }^{207}$. In seinen Erscheinungsformen war dieser corrézische Nationalismus des Weltkriegs dem fränkischen sehr ähnlich ${ }^{208}$. In Städten wie Ansbach wurde der Krieg von der Bürgerschaft sehr begrüßt, vor allem nach den erfolgreichen Schlachten der ersten Monate kam es immer wieder zu spontanen Massendemonstrationen ${ }^{209}$. Draußen auf den Bauernhöfen in der Agrarprovinz war das „Augusterlebnis“ zwar stärker von der Sorge darüber bestimmt, wer die Ernte einbringen solle, doch glaubte man ebenfalls an die "gerechte deutsche Sache ${ }^{210}$; und der Bund der Landwirte impfte den staatstreu-monarchisch gesinnten Bauern jahrelang ein, daß angesichts des Ver-

${ }^{203} \mathrm{La}$ Croix de la Corrèze, 4. 6. 1905.

${ }^{204}$ G. Dauger/D. Dayen, Histoire du Limousin contemporain, 1988, S. $124 \mathrm{f}$.

${ }^{205}$ Ebd., S. $126 \mathrm{f}$.

${ }^{206}$ Vgl. J.-J. Becker, 1914: Comment les Français sont entrés dans la guerre, 1977, S. 282, 298, $306 \mathrm{f}$.

${ }^{207}$ Le Corrézien, 5. 8. 1914; G. Dauger, Aux origines du Front populaire, 1986, S. 82.

${ }^{208}$ Vgl. hierzu die Berichte über die bemerkenswerte "trinationale“ Ausstellung der Regionen Limousin, Mittelfranken und Westböhmen zum „Alltag im Ersten Weltkrieg“ in: Windsheimer Zeitung, 17./18. 7. 1999, u. Le Populaire, 27. 10. 1998, sowie das vom Bezirk Mittelfranken freundlicherweise zur Verfügung gestellte Manuskript des Grußworts von Bezirksheimatpfleger Kurt Töppner bei der Ausstellungseröffnung in Châteauponsac am 17.7. 1998. Töppner spricht von „überquellender allgemeiner Kriegsbegeisterung“, die aber im Laufe des Krieges umschlug. Auch zwischen den Erklärungen des deutschen Kaisers und des französischen Präsidenten Poincaré zum Kriegsbeginn gibt es im übrigen eine frappierende Parallelität. Vgl. O. Dann, Nation und Nationalismus in Deutschland, 1993, S. 214.

${ }^{209}$ F. Menges, Die Ansbacher Jahre, 1973/74, S. 146, 154.

${ }^{210}$ Vgl. hierzu die ausgesprochen dichte Regionalstudie zum ländlichen Ostwestfalen von H.-U. Kammeier, Der Landkreis Lübbecke, 1998, sowie G. Hirschfeld/G. Krumeich/D. Langewiesche/ H.-P. Ullmann, Kriegserfahrungen. Studien zur Mentalitätsgeschichte des Ersten Weltkriegs, 1997. 
nichtungswillens der Gegner nur ein Festlandssieg die Sicherheit und Unabhängigkeit Deutschlands gewährleisten könne ${ }^{211}$.

Je länger indes der Krieg dauerte und je härtere Belastungen er mit sich brachte, desto schlechter wurde die Stimmung. Die Einberufung von Bauern und Knechten erschwerte die Feldarbeit für die wenigen am Hof Zurückgebliebenen, zumal die Ablieferungsquoten zu festgesetzten Höchstpreisen stiegen. Besonders schlimm waren in Mittelfranken die „mit äußerster Rücksichtslosigkeit“212 auftretenden, oft Hunderte von Personen zählenden Züge städtischer Hamsterer; vor allem aber die ständigen Todesnachrichten von der Front zermürbten die bäuerliche Bevölkerung. Am stärksten entwickelte sich eine Mißstimmung, die Preußen für den ganzen Krieg verantwortlich machte, im katholischen Milieu. Überzeugt davon, vom Bezirksamt schikanöser kontrolliert zu werden als die protestantischen Nachbargemeinden, beschlossen Bauernverein und Ortsklerus im katholischen Herrieden, eine anstehende Kriegsanleihe zu boykottieren. Den katholischen Bauern sei es gleich, „ob sie russisch oder französisch würden “213. Daß sich ähnliches in protestantischen Dörfern nicht ereignete, indiziert die höhere Ausgangstemperatur des dort vorherrschenden Nationalismus. Die führenden Repräsentanten des Bunds der Landwirte im evangelischen Franken schlossen sich denn auch 1917 der Deutschen Vaterlandspartei an, die wegen ihres preußisch-hohenzollerschen Einschlags im ganzen übrigen Bayern nicht Fuß fassen konnte ${ }^{214}$. Doch selbst in der Agrarprovinz wurde die alte Ordung durch den Weltkrieg und seine Begleiterscheinungen spätestens in den Jahren 1917/18 immer mehr in Frage gestellt ${ }^{215}$; vor allem "manche Fehler" in der Kriegswirtschaft hatten auch den nationalprotestantischen Bauern sehr "weh getan“ und ihren „vaterländischen“ Geist alles andere als gestärkt ${ }^{216}$.

\section{Versailles-Syndrom und völkisches Denken in Westmittelfranken}

Hatte sich selbst in Frankreich nach der Niederlage von 1871 in einem Teil der Gesellschaft integraler Nationalismus herausgebildet, so kam es nach dem verlorenen Weltkrieg in Deutschland zu einer noch extremeren Radikalisierung. Im Geist von Sedan siegreich geformt, bedeutete für den deutschen Nationalismus die Niederlage 1918 einen besonderen Schock, auf den er explosionsartig reagierte. Und die evangelische Agrarprovinz war von ihrer mentalen Lage her besonders offen für den jetzt von allen Richtungen her einströmenden „Nationalismus der Niederlage ${ }^{\text {“217. }}$. Zwischen seiner eher deutsch-nationalen Variante in den

211 W. Mattes, Die bayerischen Bauernräte, 1921, S. 57.

212 K.-L. Ay, Die Entstehung einer Revolution, 1968, S. 116.

${ }^{213}$ Ebd., S. 118 (Zitat), 134-147.

${ }^{214}$ Siehe H. Hagenlücke, Deutsche Vaterlandspartei, 1997, S. 236.

${ }^{215}$ Vgl. auch R. Hambrecht, Geschichte im 20. Jahrhundert, 1982, S. 381.

216 Als die 8. Kriegsanleihe ihre Forderungen „besonders an die Landleute“ stellte, solidarisierte sich der Pfarrer von Flachslanden mit seinen Bauern und setzte ein Flugblatt in Umlauf: „Erst hat man die jungen Schweine markenlos den Kriegsgewinnlern in den Magen geliefert; und jetzt, nachdem der große Schweinemord vorüber ist, müßt ihr die jungen Schweine zu unerhörten Preisen kaufen. "Siehe das Flugblatt „Abwarten! 1. Aufruf an die Bauern zur 8. Kriegsanleihe“ von Otto Mehrmann, Pfarrer in Flachslanden, in: LkAN Personen XXV (Steinlein, Nr. 32).

${ }^{217}$ K. Nowak, Konfession und Nation, 1993, S. 24; die Verbindungen zwischen Protestantismus und 
evangelischen Pfarrhäusern, dem „demokratischen Nationalismus“218 des liberalen Teils der Volksschullehrer und den stärker völkischen Tendenzen im Bund der Landwirte und in weiten Teilen des Vereinswesens bestand insofern kein erheblicher Unterschied, als sämtliche Richtungen das Trauma Versailles im Bewußtsein der Landbevölkerung vertieften. Dies vermochten sie um so eher, als die von der Front zurückkehrenden Bauern und Knechte von einem nationalen Gemeinschaftserlebnis geprägt waren und mit ihren über den provinziellen Horizont hinausreichenden Erfahrungen die Agrargesellschaft daheim maßgeblich beeinfluß$\operatorname{ten}^{219}$.

Alles, was über die materiellen Konsequenzen des Pariser Friedensvertrages für Deutschland zu Recht relativierend gesagt worden ist - wenngleich auch die Reparationszahlungen einen "nicht unerheblichen Betrag“ der Staatsausgaben ausmachten $^{220}$-, hebt nicht auf, daß Versailles besonders in der evangelischen Provinz zum beherrschenden politisch-mentalen Bezugshorizont wurde. Die Anfänge dieser Grundstimmung während der entscheidenden Sommermonate 1919 in wesentlichen Teilen der ländlichen Gesellschaft sind oben bereits skizziert worden. Die mentalitätsgeschichtliche Wirkung des Versailler Vertrags in der fränkischen Region wurde dann wenige Jahre später, im Ruhrkampf 1923, durch ein zweites nationales Ereignis nochmals entscheidend vertieft, das nicht zufällig auf der parteipolitischen Ebene mit dem ersten Wetterleuchten der völkischen Bewegung zusammenfiel $\mathrm{l}^{221}$.

An der drückenden Schwüle des nationalistischen Klimas, verstärkt durch die auch von den Kanzeln weiter verkündete Dolchstoßlegende ${ }^{222}$, sollte sich trotz Stresemanns Verständigungspolitik in der zweiten Hälfte der 1920er Jahre kaum etwas ändern. In der Volksschullehrerschaft hielt man das, was in Versailles „einem Volke von der Größe und dem Wert des deutschen Volkes zugemutet wurde“, noch 1932 für „schlechterdings unerhört, unerträglich, schamlos, sinnlos, eine Schande für die ganze Menschheit“ - und: „die Jugend muß es immer wieder neu lernen"223. DNVP224 und Landbund setzten sich ebenso wie viele andere Vereine und Verbände „unentwegt ... in den nationalen Fragen ein“225. Allein in einem einspaltigen Bericht über eine Turnvereinsversammlung zu Ehren heimgekehrter Krieger fand sich zehnmal das Wort „Vaterland“226. Die führende Lokal-

Nationalismus beleuchtet aus französischer Sicht - anhand repräsentativer Gestalten des evangelischen Deutschland - R. Thalmann, Protestantisme et nationalisme, 1976.

${ }^{218}$ Vgl. J. C. Hess, Das ganze Deutschland soll es sein, 1977; vgl. auch U. Heinemann, Die verdrängte Niederlage, 1983, S. $240 \mathrm{ff}$.

${ }^{219}$ Kurt Sontheimer hat herausgearbeitet, wie die Bezugnahme auf das Weltkriegserlebnis nach 1918 generell zu einer fast unabdingbaren Redefloskel wurde. Vgl. K. Sontheimer, Antidemokratisches Denken in der Weimarer Republik, 1992, S. 93.

220 So Harold James im Blick darauf, daß etwa im ersten Standardjahr des Dawes-Planes 1928/29 die Reparationszahlungen einen Anteil von 12,4 Prozent an den deutschen Staatsausgaben erreichten. H. James, The German Slump, 1986, S. 21.

${ }^{221}$ Vgl. hierzu in ereignisgeschichtlicher Perspektive die Untersuchung im fünften Kapitel.

222 Siehe etwa die "inhaltsschwere Rede“ des Windsheimer Dekans zum 10. Jahrestag des Versailler Vertrags 1929. In der Kirche erinnerte der lutherische Geistliche „an die Kriegsschuldlüge und die anhaltenden Belastungen“. StA Bad Windsheim, Stadtchronik, Bd. 7, 1926-1933, S. $302 \mathrm{ff}$.

223 Bayerische Lehrerzeitung, 1932, S. 554.

${ }^{224}$ Vgl. hierzu U. Heinemann, Die verdrängte Niederlage, 1983, S. $249 \mathrm{f}$.

${ }^{225} \mathrm{~K}$. Heller, Der Bund der Landwirte, 1936, S. 49, 57 f., 66 (Zitat).

${ }^{226}$ Fränkische Zeitung, 15. 2. 1919A. 
zeitung, ein Blatt mit liberal-freisinniger Tradition, bot dem nicht nur einen Resonanzkörper, sondern marschierte an der Spitze der nationalistischen Bewegung. Mit - unwidersprochen bleibenden - Kommentaren wie „Herriot und McDonalds geeinigt an Deutschlands Kehle" scheint sie ihren Lesern noch 1932 aus der Seele gesprochen zu haben: „Es gibt keine deutsch-französische Verständigung, es gibt nur einen Kampf zwischen Deutschland und Frankreich auf Leben und Tod.“227

Im politischen Klima Westmittelfrankens war es auch für die SPD offensichtlich besonders wichtig, "nicht unnational“ aufzutreten, sondern zu beweisen, daß man "national und doch international eingestellt sein“ könne ${ }^{228}$. Wer politisch orientiert sein wolle, so wurde Rothenburger SPD-Mitgliedern empfohlen, müsse jeden Abend einen Paragraphen des Versailler Vertrags studieren. In dem Werk könne jeder Genosse das Schicksal seines Volkes auf Jahrzehnte hinaus erkennen; in dem „mit Blut und Boden“ geschriebenen Vertrag sei nicht weniger gesagt, „als daß wir Heloten werden und bleiben ... "229. So schwankten die Sozialdemokraten zwischen - wohl nicht nur defensiv-taktisch gemeinten - vaterländischen Paro${ }^{l e}{ }^{230}$ und ihren internationalistischen Überzeugungen. Nahmen SPD-Ortsvereine und Reichsbanner an einer vaterländischen Feier einmal nicht teil oder blieben Sozialdemokraten einer national motivierten Festsitzung des Stadtrats „unentschuldigt fern “231, so war dies für den Nationalismus der bürgerlichen Mehrheit eher noch ein Ansporn zu verstärkter Aktivität.

Häufig aber einten nationale Anlässe in Westmittelfranken „Angehörige der verschiedensten Parteien und Stände ... im gleichen Gedenken " und ließen, wie manche Pfalzbefreiungsfeier 1930, „alles Trennende vergessen“232. Die stets nach einem ähnlichen Schema, in Regie von Bürgermeistern und Lehrern, unter dem Glockenklang der Dorfkirchen ablaufende nationalistische Mobilisierung trug Züge jener "Volksgemeinschaft" ${ }^{\text {"233 }}$, die sich im Weltkrieg bis in die Arbeiterschaft hinein als neuer Begriff eingeprägt hatte und als politisches Schlagwort hohe Suggestivkraft behielt ${ }^{234}$. Der revisionistische Grundkonsens der Weimarer Gesellschaft, den der sozialdemokratische Reichspräsident Ebert 1922 zum Erschrecken des Auslandes sanktioniert hatte, indem er das Deutschlandlied („von der Maas bis an die Memel ...") zur Nationalhymne der demokratischen Republik proklamierte ${ }^{235}$, hatte - von den Gebieten an der deutschen Grenze einmal abgesehen kaum irgendwo festere Fundamente als in Westmittelfranken. Über die zwischen

227 Ebd., 2. 7. 1932.

228 Ebd., 24. 1., 13. 2. 1923.

${ }^{229}$ Ebd., 11. 2. 1920.

230 Nach U. Heinemann (Die verdrängte Niederlage, 1983, S. 245 ff.) unterschied sich „das Gros der Sozialdemokraten“ in seinem moralischen Verdikt über den Versailler Vertrag „nicht im mindesten von den sonst in der öffentlichen Meinung Deutschlands vertretenen Ansichten ... Die SPD unternahm nichts, um den deutschen Arbeitern, klaren Wein' über die Verantwortlichkeit am Weltkrieg einzuschenken“. So habe ihr ",halbherziges Schwanken“ zwischen nationaler Realpolitik und "deklamatorischem Internationalismus ... Wasser auf die Mühlen der antirepublikanischen Propaganda von rechts" geleitet" (ebd., S. 249).

231 StAN Pol. Nü-Fü, Nr. 361.

232 Fränkische Zeitung, 1. 7. u. 3. 7. 1930.

${ }^{233} \mathrm{Vgl}$. auch Fränkische Zeitung, 5. 7. 1930.

${ }^{234}$ Vgl. O. Dann, Nation und Nationalismus, 1993, S. 213.

235 Ebd., S. 262. 
Dinkelsbühl und Gunzenhausen gelegene markante Erhebung des Hesselbergs ließ ein Heimatroman den Schwedenkönig Gustav Adolf die bezeichnenden Worte sagen: „Mir kommt es vor, als hätte Gott von diesem Berge aus das halbe deutsche Reich geschaffen" ${ }^{236}$.

Vor dem Hintergrund eines das gesamte politische Spektrum umfassenden Versailles-Syndroms gerieten die Wahlkämpfe innerhalb des bürgerlichen Lagers oft zu einem Überbietungswettbewerb in Sachen Nationalismus, nicht selten verbunden mit den bekannten konfessionalistischen Argumentationsmustern. Je schärfer man sich gegen auch nur vermeintliche Anzeichen von Ultramontanismus wandte, gegen „das alte internationale Zentrum“237, desto mehr vaterländische Glaubwürdigkeit hoffte man dadurch zu gewinnen. Die BVP selbst wies solche Kritik empört zurück, überzeugt davon, „ihre nationale Gesinnung hunderttausendmal bewiesen zu haben“238. Aber der Anspruch, „im Dienst des nationalen Gedankens" ${ }^{\prime 239}$ gegen den Ultramontanismus zu stehen, durchzog besonders bei den bürgerlich-protestantischen Parteien doch die ganze Weimarer Zeit. Der Ende der 1920er Jahre beginnende Niedergang der DNVP resultierte schließlich auch daraus, daß ihr die nationalistische Meinungsführerschaft im Reich wie in Franken zunehmend streitig gemacht wurde. In der Agrarprovinz tat dies zunächst am erfolgreichsten die Christlich-Nationale Bauern- und Landvolkpartei: „Es gibt keine nationale Politik ohne uns. In unserem Lager ist Deutschland“240. Den radikalsten Nationalismus aber propagierte die NSDAP, der die völkische Aufladung des Nationalismus im Gefolge von Versailles und Ruhrkampf in Franken besonders zugute kam.

Die Wurzeln für die Massenwirksamkeit des völkischen Denkens lagen in einer schon vor 1914 verbreiteten volksbürgerlichen Literatur um Paul de Lagarde und Julius Langbehn, die Volk, Nation und Vaterland religiös interpretierte, sozialdarwinistische Elemente aufgriff und im Gegensatz zu Bismarcks kleindeutscher Reichslösung den Zusammenschluß der gesamten deutschen oder gar germanischen Sprach- und Kulturgemeinschaft forderte ${ }^{241}$. Das Adjektiv „völkisch“ soll 1875 von dem Germanisten Hermann von Pfister als Ersatzwort für "national“ eingeführt worden sein. Als Ideologie blieb das „Völkische“ „schillernd und verschwommen, undefinierbar und nur zu umschreiben“, nicht aus dem Rationalen, sondern aus dem Irrationalen bezog es seine stärkste Kraft, gefühlsbeladen „bis zur Leidenschaftlichkeit" ${ }^{\text {"242 }}$. Eingebettet in die völkisch orientierte Kulturkritik waren in Bayern schon seit den 1890er Jahren pädagogische Bemühungen, die breite Bevölkerung über die Volksschule zum deutschen „Wesen“ zu führen. Re-

${ }^{236}$ Siehe den Bericht in der Fränkischen Zeitung (14. 7. 1932) über Heinrich Grimms neuen Heimatroman "Menschen um den Berg".

${ }^{237}$ Fränkische Zeitung, 10. 1. 1919Vm; vgl. auch den Bericht in der Mittelfränkischen Volkszeitung (9. 9. 1930) über die Wühlarbeit des nationalliberalen Fränkischen Kuriers gegen die BVP wegen angeblich mangelnder Zuverlässigkeit in nationaler und christlicher Beziehung.

${ }^{238}$ Mittelfränkische Volkszeitung, 6.9.1930.

${ }^{239}$ So die DNVP laut Fränkischer Zeitung, 20. 8. 1930.

${ }^{240}$ So der Abgeordnete Brügel auf einer Landbundversammlung, Fränkische Zeitung, 12. 9. 1930.

${ }^{241}$ W. Tilgner, Nation und Vaterland im protestantischen Denken, 1970, S. 146-150. Zu Langbehn, de Lagarde und weiteren Wegbereitern des völkischen Gedankens wie Houston Stewart Chamberlain vgl. P. E. Becker, Sozialdarwinismus, 1990.

${ }^{242}$ P. E. Becker, Sozialdarwinismus, 1990, S. 573. 
formatorische, klassische, romantische und idealistische Traditionselemente, antikapitalistische und antisozialistische, antimaterialistische, antiintellektualistische und antiindividualistische Ideen verbanden sich damals zu dem Gedanken, Deutschland wieder auf den Weg seiner völkischen Bestimmung zwischen „welscher Zivilsation“ und „slawischer Barbarei“ zu führen ${ }^{243}$.

Vor diesem Hintergrund wäre es falsch, die völkische Bewegung bis 1918 bloß als die "Sache einer Handvoll von Agitatoren " 244 zu beschreiben. Sicher waren die Völkischen in eine Vielzahl von Gruppierungen mit unterschiedlichstem Organisationsgrad zersplittert ${ }^{245}$, und speziell die aus der Übernahme der Gobineauschen Rassenlehre resultierende Verbindung von völkischer Idee und Antisemitismus hat im Kaiserreich keine ernstzunehmende gesellschaftliche und parteipolitische Bedeutung besessen. Aber ohne das bis in die Dörfer hinaus wirkende allgemeine national-völkische Bildungsprogramm, ohne die frühe Disposition der sozial aufsteigenden Volksschullehrerschaft für Konfliktlösungen im Geiste einer kooperativen „Volksgemeinschaft" ${ }^{246}$ wäre der rasche völkische Durchbruch in Bayern nach dem Ersten Weltkrieg schwerlich zu erklären ${ }^{247}$. Als Staat und Monarchie 1918 zusammenbrachen, trat der ideelle Gehalt des Volkes nur noch intensiver ins Bewußtsein, das vaterländische Erlebnis des „einen Volkes“ aus den Augusttagen von 1914 wirkte wie ein Mythos fort ${ }^{248}$.

Freilich war die Konjunktur des volksnationalen Denkens am Ende des Ersten Weltkriegs, der schließlich als ein Krieg der Völker, nicht mehr nur als ein Krieg der Armeen ausgefochten wurde, nichts spezifisch Deutsches. Bekanntlich machte US-Präsident Wilson damals das "Selbstbestimmungsrecht der Völker“ zum internationalen Leitbegriff. Aber obwohl das - auch auf dem linken Parteienspektrum anzutreffende - volksdeutsche Denken in der Weimarer Republik nicht immer nationalistisch war ${ }^{249}$, förderte es doch einen Zeitgeist, von dem die Radikalvölkischen am meisten profitierten. Denn es war trotz bestehender Unterschiede ziemlich schwierig, "normale“ Volkstumsideologie und den vagen Begriff des Völkischen ganz auseinanderzuhalten.

Das völkische Denken in der Weimarer Republik bedeutete, mit Martin Broszat zu reden, zunächst „die Verdrängung alldeutscher Machtpolitik auf die Ebene des Gefühls"250. Explizit gegen den westlichen Rationalismus und den universalistisch-französischen Begriff der „Nation“ gerichtet ${ }^{251}$, sahen die Völkischen in der ethnischen Reinheit des deutschen Volkes den Zielpunkt ihrer Weltanschau-

\footnotetext{
${ }^{243}$ W. K. Blessing, Staat und Kirche, 1982, S. 219 f.

${ }^{244}$ K. Scholder, Die Kirchen und das Dritte Reich, Bd. 1, 1986, S. 94 f.

${ }^{245}$ Siehe U. Puschner/W. Schmitz/J. H. Ulbricht, Handbuch zur „Völkischen Bewegung“, 1996, S. XII.

${ }^{246}$ W. K. Blessing, Staat und Kirche, 1982, S. 219 f.

247 Ähnlich die Argumentation bei George L. Mosse, Die völkische Revolution, 1991, S. 251.

${ }^{248}$ W. Tilgner, Nation und Vaterland im protestantischen Denken, 1970, S. 160 f.; in Gustav Sondermanns Schlüsselroman über den westmittelfränkischen Bund Oberland „Türme über der Stadt" ist vom "Geist dieser entschlossenen Kameradschaft" die Rede, „der wie der ernstere, durch Wissen gereifte Bruder des jubelnden Jünglings vom August 1914“ wirke. G. Sondermann, Türme über der Stadt, 1938, S. 18.

249 O. Dann, Nation und Nationalismus, 1993, S. 264-267.

${ }^{250}$ M. Broszat, Die völkische Ideologie, 1958, S. 60.

${ }^{251}$ W. Bökenkamp, Frankreichs Universalismus, 1940, S. 33 f.
} 
ung. Für geistige Differenzierungen war in diesem manichäischen Denken kein Platz, Deutsches stand gegen Undeutsches, Rassereinheit gegen Rassenvermischung, und vor allem Jude gegen Arier. So primitiv und geistlos einem das völkische Denken in seiner krassen Ausprägung heute vorkommt ${ }^{252}$, ist doch unverkennbar und zum Verständnis der daraus entstehenden nationalsozialistischen Begeisterung in Westmittelfranken unerläßlich, „daß dahinter auch der Anspruch und die Überzeugung standen, auf der Seite des Guten gegen das Böse zu kämpfen “253. Der Glaube an Deutschlands Mission im Kampf gegen Alljuda war ebenso tief und leidenschaftlich, wie er falsch und verhängnisvoll war.

Innerhalb der eklektizistischen völkischen Weltanschauung erlangte der Antisemitismus jetzt eine zentrale Funktion, erklärte er doch auf einfache Weise die Ursachen und Folgen der deutschen Niederlage ${ }^{254}$. So mancher, der eine jüdische Weltverschwörung „in den sicheren Ordnungen des Kaiserreiches noch als Hirngespinst abgetan hatte", mochte angesichts der unvorstellbaren Verwirrung der Nachkriegsjahre in dieser absurden Idee plötzlich Plausibilität erkennen. Und wer sich "einmal auf diesen Gedanken eingelassen hatte, der fand bald auf Schritt und Tritt" bei den Juden in den Reihen der Siegermächte, in der deutschen Politik oder an der deutschen Börse die Belege dafür ${ }^{255}$.

In der mittelfränkischen Provinz konnte sich die völkische Bewegung aber nur dann breit entfalten, wenn die evangelischen Pfarrer ein tragfähiges Verhältnis zu ihr fanden. Hierfür schuf die Krise des verlorenen Weltkrieges günstige Voraussetzungen, da sie die nationale Idee ebenso erschütterte wie den symbiotisch damit verbundenen Protestantismus. Die völkische Bewegung schien in ihrem Bemühen, den alten nationalen Gedanken in einer neuen Form zu beleben, also ein natürlicher Bundesgenosse des notleidenden Luthertums zu sein. Das hieß zwar nicht, daß radikalvölkische Vorstellungen von arischem Jesus und arischer Religion für eine auch nur bedeutende Minderheit der Pfarrer akzeptabel wurden, führte aber doch vor allem bei einer Reihe jüngerer lutherischer Theologen zur Entdeckung des Volkes als eines neuen ethischen Bezugspunkts. Während Kulturgesellschaft und Staat als neben der Familie wichtigste Felder christlichen Tätigwerdens im Krieg zerbrochen bzw. fragwürdig geworden waren, hatte einzig das Volk offenbar überdauert. In dieser neuen politischen Theologie, die von einigen der bedeutendsten Gelehrten der Zeit entwickelt wurde, trat an die Stelle der alten Formel von Thron und Altar jetzt die Wendung von Gott und Volk ${ }^{256}$.

Die an der Universität Erlangen unter Paul Althaus und Werner Elert sich besonders ausprägende nationale Theologie sah es als ihre Aufgabe, dem deutschen Volk nach der Niederlage im Krieg seine von Gott gegebene und gewollte Stellung wieder zu verschaffen. Denn: „Wir waren ein Weltvolk, ein adeliges Volk, viel-

${ }^{252} \mathrm{Vgl}$. K. Sontheimer, Antidemokratisches Denken, 1992, S. $131 \mathrm{ff}$.

${ }^{253}$ K. Scholder, Die Kirchen und das Dritte Reich, Bd. 1, 1986, S. 94.

${ }^{254}$ Ebd., S. $97 \mathrm{ff}$.

${ }^{255}$ Ebd., S. 98 f.; allgemein zur Position der Juden in der Weimarer Republik: W. Grab/J. H. Schoeps, Juden, 1986; E. Hamburger, Jews, Democracy and Weimar Germany, 1986; W. E. Mosse, Deutsches Judentum in Krieg und Revolution 1916-1923, 1971; W. E. Mosse, Entscheidungsjahr 1932. Zur Judenfrage in der Endphase der Weimarer Republik, 1965.

${ }^{256} \mathrm{Vgl}$. K. Scholder, Die Kirchen und das Dritte Reich, Bd. 1, 1986, S. $124 \mathrm{f}$. 
leicht das blühendste von allen" ${ }^{257}$. Die Lehre des „jungen nationalen Luthertums ${ }^{\text {"258 }}$ und ihr mindestens semi-völkischer Nationalismus wurden auch in den - von Erlangen inspirierten - fränkischen Pfarrhäusern weithin akzeptiert und ließen die völkische Bewegung mindestens partiell zustimmungsfähig scheinen ${ }^{259}$. Die Vorbehalte gegen deren "Radauantisemitismus" hielten zwar an, aber nach Paul Althaus“ Vortrag über „Kirche und Volkstum“ auf dem deutschen „Vaterländischen Kirchentag" in Königsberg 1927 konnte das Prinzip der völkischen Bewegung endgültig als christlich legitimiert gelten ${ }^{260}$. Zumal die nationalkonservative Strömung im Protestantismus dazu überging, den Antisemitismus nicht mehr zu bekämpfen, sondern eine sittliche Aufgabe in der antisemitischen Bewegung wahrzunehmen, also dafür Sorge zu tragen, daß sie sich nicht radikal entlud, sondern "in geordeten rechtlichen Bahnen“" vollzog ${ }^{261}$. Für diese Taktik schien auch zu sprechen, daß die - von "radikalvölkischer" Seite erneut zu erwartenden „schwersten Verfolgungen“ des Judentums dessen Widerstandskraft in seiner dreitausendjährigen Geschichte nur gestählt hatten; so blieb als beste Lösung die Bekehrung der Juden zum christlichen Glauben ${ }^{262}$.

Nicht nur wegen des Erlanger Einflusses war das evangelische Mittelfranken für den völkischen Nationalismus besonders disponiert. Hinzu kam die Ausstrahlung der nahe Windsheim gelegenen Burg und völkischen Tagungsstätte Hoheneck. Schon vor dem Ersten Weltkrieg hatte die Burg der bündischen Jugend und dem Christlichen Verein Junger Männer als Ort der Begegnung gedient, Anfang der 1920er Jahre kaufte sie dann der Münchner Verleger Julius Friedrich Lehmann, der bis zu seinem Übertritt zur NSDAP 1931 der DNVP angehörte; sein Schwiegersohn, der Tierarzt Friedrich Weber, war Führer des „Bundes Oberland", dessen Zentrum Burg Hoheneck bis 1927 blieb. 1928 wurde Hoheneck zur SA-Schulungsburg für Süddeutschland und wiederholt Ort von NSDAP-Großveranstaltungen ${ }^{263}$. Aber bereits Anfang der 1920er Jahre begann hier der Dialog zwischen völkischer Bewegung und von der Jugendbewegung herkommenden Pfarrern, wobei gemäßigte Vertreter der Völkischen die abstoßenden Elemente ihrer Ideologie gegenüber den Geistlichen als „Schlacken der Kampfesweise“ abzutun suchten, die der „schon eingesetzte Reinigungsprozeß mit der Zeit ausscheiden wird“264.

Am Evangelischen Bund hatten die Völkischen einen weiteren frühen und lautstarken Sympathisanten. Der Vorsitzende des mittelfränkischen Zweigvereins

${ }^{257}$ So der Kirchengeschichtler und Althaus-Freund Emanuel Hirsch, zit. nach F. Kühnel, Hans Schemm, 1985, S. 191.

${ }^{258}$ W. Tilgner, Nation und Vaterland im protestantischen Denken, 1970, S. 165.

${ }^{259}$ K. Scholder, Die Kirchen und das Dritte Reich, Bd. 1, 1986, S. 133; W. Allgaier, Die Pastoren und die Völkischen, 1990, S. $35 \mathrm{f}$.

${ }^{260}$ Vgl. K. Scholder, Die Kirchen und das Dritte Reich, Bd. 1, 1986, S. 139f., 142. Vgl. aber auch das Gesamturteil zum Königsberger Kirchentag von K. Nowak (Geschichte des Christentums, 1995, S. 229), der die sogenannte "Vaterländische Kundgebung" als Etappensieg der Vernunftrepublikaner unter den evangelischen Kirchenführern wertet.

${ }^{261} \mathrm{~K}$. Scholder, Die Kirchen und das Dritte Reich, Bd. 1, 1986, S. 146.

${ }^{262}$ Der Freimund, 1929, S. 256 f.; 1930, S. 278.

${ }^{263}$ C. Rückert, Ipsheim, 1989, S. $84 \mathrm{ff}$.

${ }^{264} \mathrm{~K}$. Th. Bach, Das Verhältnis der evangelisch-lutherischen Kirche in Bayern zum Nationalsozialismus, 1982, S. 50; W. Allgaier, Die Pastoren und die Völkischen, 1990, S. 36. 
hielt die Völkischen wegen ihres von vielen als göttliches Gebot empfundenen „deutschen Lebenswillens" bereits 1924 für eine religiöse Bewegung; der Protestantismus müsse sie nur christlich durchdringen, um dann gemeinsam den Kampf gegen den Ultramontanismus aufnehmen zu können ${ }^{265}$.

Nicht nur in den kirchlichen, auch in den Pädagogennationalismus waren von Beginn der Weimarer Republik an zunehmend völkische Ideen hineingemischt. Um endlich als "Weltvolk“ geboren werden zu können, so lautete die Überzeugung, müßten die „braven, gutmütigen und michelhaften" Deutschen erst noch nach „völkischem festen Wesen, nach sicherer Form“ tasten. „Völkischer Stolz“ galt den nationalliberalen Lehrern gerade in der Stunde der Niederlage 1918 als Rezept gegen die stete deutsche Neigung „zu politischer Knochenerweichung “266. Das Bewußtsein, mit dem Volk „auf Gedeih und Verderb“ zusammenzugehören, stärker als die an Prestige und Einkommen privilegierten Studienräte mit ihrem humanistischen Bildungsauftrag ${ }^{267}$, verband sich Mitte der 1920er Jahre mit einer Abneigung gegen die konservativ-klerikale Kulturpolitik in München, so daß der Bayerische Lehrerverein das "ungeheure Anschwellen“ des Völkischen Blocks bei den Landtagswahlen 1924 als „auch von unserem Standpunkt aus begrüßenswert“ kommentierte ${ }^{268}$. In den Jahren danach wurden Fragen „hinsichtlich der Einbettung der Volksschule in das völkische Gesamtleben " für die mittelfränkischen Lehrer immer „brennender “269, vor allem für die in prekären ökonomischen Verhältnissen lebenden Junglehrer, die gegen ständische Interessengegensätze, für "Staat und Volksgemeinschaft" kämpften ${ }^{270}$.

Die Spuren des in Schulstuben und Pfarrhäusern verbreiteten völkischen $\mathrm{Na}$ tionalismus begegneten einem im politischen Leben der fränkischen Agrarprovinz während der $1920 \mathrm{er} \mathrm{Jahre} \mathrm{auf} \mathrm{Schritt} \mathrm{und} \mathrm{Tritt.} \mathrm{So} \mathrm{stieß} \mathrm{der} \mathrm{von} \mathrm{völkischem} \mathrm{Den-}$ ken republikweit zu einer Massenorganisation mit zwei Millionen Mitgliedern emporgetragene Verein für das Deutschtum im Ausland auf reges Interesse. Bei seinen Werbewochen in der Region wurde an den Landschulen Geld gesammelt, und wenn etwa in Uffenheim oder Feuchtwangen über die Verfolgung des Deutschtums in Böhmen und Südtirol informiert wurde, trat eine große Zahl neuer Mitglieder dem Verband bei ${ }^{271}$. Die Neustädter Sänger unternahmen aus Anteilnahme am Schicksal der Auslandsdeutschen in den 1920er Jahren mehrere „Grenzlandfahrten“ nach Südtirol, Dänemark und Böhmen ${ }^{272}$; und die Sängervereinigung Ansbach vollzog mit durchreisenden Sudetendeutschen, die sich auf einer der damals beliebten Rheinlandfahrten befanden, gar einen „Akt völkischer Verbrüderung “273. Das im Gefolge der territorialen Bestimmungen der Pariser Friedensverträge wachsende Verantwortungsgefühl für die nach Millionen zäh-

${ }^{265}$ Vgl. K. Scholder, Die Kirchen und das Dritte Reich, Bd. 1, 1986, S. $134 \mathrm{ff.}$

${ }^{266}$ Bayerische Lehrerzeitung, 1918, S. 197, 225.

${ }^{267}$ Ebd., 1918, S. 225; 1919, S. 121.

${ }^{268}$ Ebd., 1924, S. 132.

${ }^{269} \mathrm{Vgl}$. hierzu den Bericht über die Tagung des Bayerischen Lehrervereins in Weißenburg. Fränkische Zeitung, 22. 7. 1932.

${ }^{270}$ Vgl. die Tagung der Arbeitsgemeinschaft der bayerischen Junglehrer in Nürnberg. Fränkische Zeitung, 28. 8. 1930 .

${ }^{271}$ HStAM HMB, 5. 5. 1926, 5. 1. 1931.

${ }^{272}$ M. Döllner, Entwicklungsgeschichte, 1950.

${ }^{273}$ Der Bayerische Sänger, 1. 2. 1931, S. 33. 
lenden Deutschen im Ausland wirkte offensichtlich auf das Nationsverständnis im Reich zurück; es verstärkte die in allen politischen Lagern spürbare Umprägung der Begriffe Volk und Nation ${ }^{274}$.

Die eigentlichen Katalysatoren des völkischen Denkens waren in einem weiten Bogen auf der politischen Rechten angesiedelt. Als sich die fränkischen Nationalliberalen wegen der „Linksentwicklung“ der DVP im Reich im Herbst 1923 von der Partei abspalteten, hieß es zur Begründung: Deutschland solle wieder deutsch werden, indem unser Volk völkisch selbstbewußt werde ${ }^{275}$. Dabei betonten die Nationalliberalen, daß es eine Verständigung mit den Ideen von 1789 , wie sie sie vor dem Weltkrieg versucht hätten, jetzt nicht mehr geben könne, „daß vielmehr der deutsche Geist gegen jeden Kosmopolitismus aufgerufen werden müsse“276.

Auch im Landbund, dem mit Abstand wichtigsten Verband in der Region, herrschte die Überzeugung: „Bauernpolitik ist völkische Politik, darum muß völkische Politik in erster Linie Bauernpolitik sein ..." ${ }^{\text {277 }}$. Besonders dem aktivistischen Junglandbund lag der völkische Gedanke am Herzen, wobei die „Bekämpfung des jüdisch-marxistischen Geistes " $z u$ den Kernzielen zählte ${ }^{278}$. Der bäuerliche Bereich galt im übrigen schon im Anschluß an die Forschungen der Gebrüder Grimm als Kernbestandteil völkischer Kultur ${ }^{279}$. Wichtigstes Rekrutierungsfeld der völkischen Bewegung wurden indes die nationalen (Wehr-)Verbände wie Bund Oberland, Reichsflagge, Stahlhelm und Blücherbund, die sich nach der Auflösung der Einwohnerwehren 1921 und vor allem im Nationalisierungsschub des Ruhrkampfs 1923 auch in Westmittelfranken sprunghaft vermehrten. Die aktivistischen Gruppen veranstalteten „vaterländische Abende“, inszenierten Theaterstücke wie den „Rütlischwur" ${ }^{\text {“280 }}$ und erfreuten sich der tatkräftigen Unterstützung einflußreicher deutschnationaler Honoratioren ${ }^{281}$.

Denn die Pflege des völkischen Gedankens war ein Kernstück in der parteipolitischen Programmatik und Strategie der bayerischen DNVP. Auf dem Parteitag von 1921 hatte der Erlanger Professor Friedrich Brunstäd in einem Grundsatzreferat die deutschnationale Parteibildung „als eine notwendige Funktion innerhalb der völkisch-nationalen Erneuerung" bezeichnet und das "Ergriffensein“ von der Idee der „nationalen Volksgemeinschaft“ als Gründungsimpuls der aus ganz verschiedenen Lagern kommenden Partei herausgestellt ${ }^{282}$. Angesichts der völkischen Stimmung in den mittelfränkischen Hochburgen ebenso wie in der

274 Vgl. O. Dann, Nation und Nationalismus, 1993, S. 265 f.

${ }^{275}$ Fränkische Zeitung, 10. 10. 1923; die Ideen Eisners und Liebknechts zur internationalen Völkerbeglückung hatte man im Nationalliberalismus schon immer für naiv gehalten. Vgl. Fränkische Zeitung, 9.1.1919Vm.

${ }^{276}$ H. Fenske, Konservativismus und Rechtsradikalismus in Bayern, 1969, S. 74.

277 Der Bund der Landwirte in Bayern, 17. 2. 1924.

278 Abschrift „Die Ziele des Bayerischen Junglandbundes“ im Privatarchiv des einstigen Junglandbundmitglieds und späteren Kreisrats Friedrich Trump, Bottenweiler (Landkreis Ansbach).

${ }^{279}$ K. von See, Die Ideen von 1789 und die Ideen von 1914, 1975, S. 27.

${ }^{280}$ Vgl. die Berichte über die Reichsflagge Leutershausen und Windsbach, Fränkische Zeitung, 10. 1., 3. 11. 1923; R. Hambrecht, Der Aufstieg, 1976, S. $16 \mathrm{ff}$.

${ }^{281}$ Bei einer „Übung unter Gewehr" ausgerechnet im roten Schopfloch zog die Reichsflagge unter Leitung des Dinkelsbühler Bürgermeisters und des Bezirksamtmanns in den Ort ein. Fränkische Zeitung, 24. 11. 1923.

${ }^{282}$ Friedrich Brunstäd, Völkisch-nationale Erneuerung (Deutschnationale Flugschrift Nr. 119), 1921, S. 2 f. 
Münchner DNVP legten die deutschnationalen Funktionäre größten Wert darauf, den völkischen Gedanken angenommen zu haben, „schon bevor er zum Schlagwort wurde" 283 . Zu Recht hat George L. Mosse in der DNVP einen der „Hauptvermittler des völkischen Denkens “ gesehen, dessen Wirken nicht zuletzt deshalb „besonders tückisch“ war, weil es in einem so bürgerlichen „ehrbaren Gewande“ auftrat ${ }^{284}$.

Den Anspruch, gegenüber der NSDAP das völkische Original darzustellen, konnte die DNVP aber nach dem Ausscheiden ihrer extremvölkischen Teile $1922^{285}$ und dem Hitlerputsch 1923 immer weniger plausibel machen. Statt dessen geriet sie ins Lavieren, kritisierte zwar Hitlers „Mittel und Wege“, an der Kooperation „aller national und völkisch Denkender“ indes hielt sie auch nach dem Putsch fest, um das gemeinsame „hohe Ziel“ zu erreichen ${ }^{286}$. Als die radikalere völkische Variante, viel weniger restaurativ orientiert als der „alte Nationalismus“ der DNVP, profilierte sich die NSDAP. Sie übersetzte den neuen Nationalismus der Konservativen Revolutionäre, die „den eigentlich produktiven Kern des antidemokratischen Denkens in der Weimarer Republik “287 ausmachten, vom Intellektuellen ins Populär-Politische und trug entscheidend dazu bei, weite Teile der ländlichen Bevölkerung mit der Sehnsucht nach einer neuen Staatsordnung zu erfüllen. Die agitatorische Effizienz, mit der die Nationalsozialisten alten und neuen Nationalismus synthetisierten, nötigte selbst der DNVP Respekt $\mathrm{ab}^{288}$.

In ihrer zentralen antisemitischen Propaganda konnten die Nationalsozialisten in Westmittelfranken auf den Aktivitäten aufbauen, die Julius Streicher vor seinem NSDAP-Beitritt - noch in Konkurrenz zu Hitler - in diversen Splittergruppen wie dem Deutschvölkischen Schutz- und Trutzbund oder der Deutschen Werkgemeinschaft entfaltet hatte ${ }^{289}$. Aufgrund ihrer Radikalität gelang es der NSDAP auch, sich an die Spitze der „Arbeitsgemeinschaft der Vaterländischen Kampfverbände" zu setzen, die Ernst Röhm im Januar 1923 initiiert hatte und in der zahlenmäßig die Reichsflagge und der Bund Oberland viel stärker vertreten waren als die SA. Die nach dem legendären Coburger Vorbild im Frühjahr und Sommer 1923 auch in einer Reihe westmittelfränkischer Städte gemeinsam veranstalteten Deutschen Tage, also parademäßige Aufmärsche und Kundgebungen der Wehrverbände, wurden zu Heerschauen der völkischen Bewegung und legten ein Bekenntnis ab „zum völkisch-großdeutschen Gedanken “290.

Parallel dazu häuften sich an den Brennpunkten völkischer Propaganda die antisemitischen Ausschreitungen, die in Gegenden mit hohem jüdischen Bevölkerungsanteil, etwa im oberen Aischgrund, schon seit Jahren die mosaische Glaubensgemeinschaft beunruhigten. Die Völkischen rühmten sich, daß (1922) am Schluß einer stürmischen Versammlung in Neustadt „auf dem Buckel eines fre-

${ }^{283}$ Fränkische Zeitung, 12. 12. 1923.

${ }^{284}$ G. L. Mosse, Die völkische Revolution, 1991, S. 266.

${ }^{285}$ Vgl. J. Striesow, Die Deutschnationale Volkspartei, 1981, S. 451-471.

${ }^{286}$ Vgl. den Bericht über die Ansbacher BMP-Versammlung in: Fränkische Zeitung, 17. 11. 1923.

${ }^{287}$ K. Sontheimer, Antidemokratisches Denken, 1992, S. 37.

${ }^{288}$ Fränkische Zeitung, 14. 12. 1923.

${ }^{289}$ U. Lohalm, Völkischer Radikalismus, 1970, S. 308 ff.; R. Hambrecht, Der Aufstieg, 1976, S. 28 f.

${ }^{290}$ So der Aufruf zum Deutschen Tag in Ansbach, Fränkische Zeitung, 24. 9. 1923. 
chen feigen Juden ein bäuerlicher Eichenstock in Stücke" gegangen war ${ }^{291}$. Und sogar bei einer öffentlichen Versammlung der SPD verprügelten sie einen Juden und warfen ihn hinaus, nachdem dieser sich gegen den Vorwurf der Drückebergerei im Krieg verwahrt hatte ${ }^{292}$.

Die Ehrabschneidung der jüdischen Soldaten, die zur Infamie des völkischen Antisemitismus gehörte, brauchte nicht erst von der NSDAP initiiert zu werden. So betonte z. B. bei einer "namentlich von der Landbevölkerung“ stark besuchten Veranstaltung der Reichsflagge im Gau Feuchtwangen auch der Festredner Hauptmann Heiß, daß sein Verband keine Juden aufnehme, weil „der Jude im allgemeinen international, nicht national denke". Gewiß hätten auch Juden im Weltkrieg ihre Pflicht als Soldaten getan, aber hinsichtlich ihrer Beteiligung werde stark übertrieben; so sei es vorgekommen, daß auf eine Ehrentafel für gefallene Juden auch der Name eines Mannes gesetzt wurde, der von der Straßenbahn überfahren worden sei. Isidor Stern, Vorstand der Israelitischen Kultusgemeinde in Feuchtwangen, verwahrte sich zwar gegen diese Demagogie ${ }^{293}$; und die Diespekker Juden errichteten auf ihrem Friedhof sogar ein Kriegerdenkmal „in treuem Gedenken an ihre fürs Vaterland gefallenen Söhne “294. Aber noch so viele Zeichen von deutsch-jüdischem Patriotismus vermochten dem dumpfen Antisemitismus der Völkischen offenbar nichts anzuhaben.

Im Gefolge des Hitlerputsches 1923 kulminierte die Entwicklung, nachdem ein fränkischer SA-Führer den - kurze Zeit später widerrufenen - Befehl ausgegeben hatte, für das Hitlerblut müsse Judenblut fließen. In Sugenheim kam es bei der Erstürmung eines jüdischen Hauses durch bewaffnete Nationalsozialisten zu einer Schießerei und Mißhandlungen, in Burghaslach wurden Fenster eingeworfen und eine unbewohnte jüdische Villa ausgeräumt. Daß die Völkischen mit ihren antisemitischen Aktionen auf Sympathie bei der Landbevölkerung rechnen konnten, zeigte sich etwa daran, daß manche Bauern damals an Juden keine Milch und Butter mehr abgaben ${ }^{295}$. Zwar war nicht klar zu erkennen, welche Rolle für den ländlichen Antisemitismus rassische Motive spielten, eine gewisse Offenheit ist aber zu unterstellen, da bei Bauernversammlungen die „Rassenfrage“ jedenfalls angesprochen wurde ${ }^{296}$ und auch unter den meinungsführenden evangelischen Geistlichen das Thema „War Jesus ein Jude?" lebhaftes Echo fand. Zwar wurde die "Rassenvergötzung" abgelehnt, aber damit doch „niemals die Ablehnung des Rassengedankens überhaupt" verbunden ${ }^{297}$.

Die Enttabuisierung der Rassenfrage spielte zweifelsohne den Radikalvölkischen in die Hände, aber wichtiger noch waren für die Wahrnehmung der kleinen

${ }^{291}$ S. Strauß-Morawitzki, Die Entwicklung der NSDAP, 1979, S. $11 \mathrm{f}$.

292 Ebd.

${ }^{293}$ Er bezeichnete es angesichts des Ruhrkampfs als Gebot der Stunde, ,jeden Bruderzwist zu begraben“, weil ansonsten „unser geliebtes Vaterland“ noch länger „wehrlos am Boden liegen“ werde. StAN Pol. Nü-Fü, Nr. 953; BA Feuchtwangen an Reg. von Mfr., 26. 1. 1923.

${ }^{294}$ Vgl. den Bericht „Elf Diespecker Juden starben einst für ihr deutsches Vaterland“, in: Fränkische Landeszeitung, 16.5. 1996.

${ }^{295}$ R. Hambrecht, Der Aufstieg, 1976, S. 57.

${ }^{296}$ So informierte z. B. bei einer BLB-Veranstaltung in Leutershausen ein landwirtschaftlicher Arbeiter über die „Rassenfrage“. StAN Pol. Nü-Fü, Nr. 361: Gendarmerie Leutershausen an Bezirksamt Ansbach, 13. 12. 1927.

${ }^{297}$ W. Allgaier, Die Pastoren und die Völkischen, 1990, S. 36. 
Leute in der Provinz die Gefahren, die von der unheilvollen wirtschaftlichen Entwicklung ausgingen, verbunden mit der Tatsache, daß die deutschen Juden in den oberen Schichten der Gesellschaft überdurchschnittlich, in den minderprivilegierten Schichten unterdurchschnittlich vertreten waren ${ }^{298}$. Wie schon während der Großen Depression der Bismarckzeit wurden die Juden in den 1920er Jahren erneut zum Sündenbock für die Krise der Landwirtschaft. Daß in Kleinstädten wie Leutershausen von 17 jüdischen Familienoberhäuptern 16 Geschäftsleute, darunter elf Viehhändler, waren ${ }^{299}$ - bei Verschuldung und Zwangsversteigerung von Höfen häufig involviert - entlarvte sie in den Augen vieler Bauern als Hauptprofiteure der wirtschaftlichen Not. Sogar für die allgemeine Inflation glaubte man die Juden verantwortlich machen zu können ${ }^{300}$. Vergegenwärtigt man die „Konjunkturabhängigkeit des Antisemitismus" ${ }^{\text {"301, }}$, so wird nachvollziehbar, weshalb es angesichts der dauerhaft kritischen (land-)wirtschaftlichen Situation Westmittelfrankens zu einer entscheidenden Abschwächung der Ressentiments gegen die Juden nie kam ${ }^{302}$. Am meisten Besorgnis mußte erregen, daß neben der großen Beteiligung aus den Landgemeinden sich von Anfang an besonders viele Jugendliche, darunter zahlreiche Junglehrer, für die antisemitischen Versammlungen interessierten ${ }^{303}$.

So wie sich der junge völkische Nationalismus in Westmittelfranken darstellte, besaß er eine ureigene basisgeleitete Dynamik und war weit mehr als nur das Objekt von Instrumentalisierungsstrategien privilegierter Oberschichten ${ }^{304}$. Pfarrer, Lehrer und bäuerliche Antisemiten scheinen sich eher wechselseitig radikalisiert zu haben. Nach Versailles gelang es den protestantisch-konservativen Kräften - in scharfer Abgrenzung zum Zentrum und zur Sozialdemokratie - zunächst noch, den zunehmend völkischen Nationalismus für sich zu nutzen. Im Gefolge von Ruhr- und Inflationskrise aber sollte dies immer schwieriger werden. Und je mehr die Menschen in Westmittelfranken in den Bann völkischer Ideen gerieten, desto weiter entfernten sie sich von der Republik. Die Gestaltung politischer Gedenktage oder die „Flaggenfrage“ boten reiches Anschauungsmaterial dafür, daß die Inflation des Begriffes „Vaterland“ 305 sich nicht zuletzt gegen die gegenwärtige Weimarer Verfassung richtete.

${ }^{298}$ H. A. Winkler, Die deutsche Gesellschaft, 1991, S. 183.

${ }^{299}$ B. Z. Ophir/F. Wiesemann, Die jüdischen Gemeinden in Bayern, 1979, S. 195.

${ }^{300} \mathrm{Vgl}$. die Rede des Vorsitzenden des Blücherbundes in Ansbach, Fränkische Zeitung, 5. 11. 1923.

${ }^{301}$ H. A. Winkler, Die deutsche Gesellschaft, 1991, S. 181.

302 Der Befund H. A. Winklers (Die deutsche Gesellschaft, 1991, S. 187) über den anhaltenden Antisemitismus bei Kleinhändlern und Akademikern läßt sich auf das bäuerliche Westmittelfranken übertragen.

${ }^{303}$ Vgl. BA Neustadt an Reg. von Mfr., KdI, 25. 4. 1922, in: StAN KdI, II, Nr. 714.

${ }^{304}$ Vgl. dagegen H. Mommsen, Nationalismus in der Weimarer Republik, 1994, S. 85. Hinter dem Instrumentalisierungsansatz scheint im übrigen die Frage nach dem Sinn des Nationalismus zu schlummern, die aber selbst dann, wenn man sie - mit Bertolt Brecht - moralisch für berechtigt hält, analytisch nicht weiterführt: „Der Nationalismus der großen Herrn nützt den großen Herrn. Der Nationalismus der armen Leute nützt den großen Herrn. Der Nationalismus wird nicht besser dadurch, daß er in armen Leuten steckt; dadurch wird er nur ganz und gar unsinnig." B. Brecht, Meti. Buch der Wendungen, 1965, S. 77.

${ }^{305}$ Vgl. hierzu K. Nowak, Konfession und Nation, 1993, S. 35; O. Dann, Nation und Nationalismus, 1993, S. 269. 
So gingen die Verfassungsfeiern zum 11. August fast nur von der SPD aus, und zwar lediglich an einigen kleineren, namentlich Industrieplätzen sowie wenigstens in den meisten kreisunmittelbaren Städten wie Ansbach und Rothenburg. Auf dem Lande dagegen, wo man sich an vaterländischen, schwarz-weiß-roten Ereignissen wie den Deutschen Tagen oder den Reichsgründungstagen am 18. Januar nicht genug berauschen konnte, fanden die schwarz-rot-goldenen Termine keine Beachtung ${ }^{306}$. In Dinkelsbühl entbrannte bei der Aufführung des historischen Festspiels „Die Kinderzeche" eine charakteristische Fehde um das Mitführen schwarz-rot-goldener Fahnen im Festzug ${ }^{307}$. Und am zehnten Jahrestag der Weimarer Verfassung (1929) trat beim „Ring Schwarz-Weiß-Rot“ in Weißenburg der DNVP-Reichstagsabgeordnete Strathmann auf und begründete unter Hinweis auf den „Parteienstaat“ und den Versailler Vertrag, der Deutschland zum „Konzentrationslager" gemacht habe, weshalb es an diesem Tag nichts zu feiern gäbe ${ }^{308}$. Zwar erinnerte die SPD in Rothenburg daran, daß die Bürgerschaft der Freien Reichsstadt traditionell von „viel republikanischem Geiste durchdrungen“ gewesen sei und Altbürgermeister Nusch in dem Festspiel "Der Meistertrunk" bekannte: „Du Republik, du sollst mein alles sein“309. Doch der Versuch, eine republikanisch-demokratische Tradition zu erfinden, mußte an der mental nachwirkenden Koinzidenz von militärischer Niederlage, revolutionärer Republikgründung und Versailler Vertrag scheitern ${ }^{310}$. Auch die anderen alten Reichsstädte in der Region scheinen nach 1918 geradezu „ihre Ehre darein“ gesetzt zu haben, Vertreter „eines oft ganz extremen Nationalismus“311 zu werden. Rückwärtsgewandt hielt das evangelische Franken gegen die Weimarer Demokratie an seiner schwarz-weiß-roten Identität fest.

Das Ende des monarchischen Machtstaates 1918 hatte die evangelische Provinz so sehr auf die Idee des Volkes wie auf einen mentalen Rettungsanker zurückverwiesen, daß ihre seit den Befreiungskriegen gewachsene kulturnationale Tradition sich in einem gewaltigen antirepublikanisch wirkenden Schub ins Völkische transponierte. Im nachhinein gewann von hier aus sogar die ziemlich diffuse akademische Konstruktion der volksgemeinschaftlich-autoritär verstandenen „Ideen von $1914^{\text {“312 }}$, die zu Kriegsbeginn den individualistisch-demokratischen "Ideen von 1789 “ entgegengestellt worden waren, einige Plausibilität. Denn die Entwicklungslinien der politischen Kulturen Westmittelfrankens und der Corrèze gingen jetzt an dem zentralen Punkt des Nationalismus weiter auseinander, als sie es bis 1914/18 jemals gewesen waren. Während im militärisch unterlegenen Deutsch-

${ }^{306}$ HStAM HMB, 16. 8. 1924, 4. 2. 1926, 18. 8. 1927, 20. 8. 1929; Fränkische Zeitung, 22. 1. 1920. Die allgemeinen Befunde J. Bergmanns in einer Untersuchung über politische Identität und nationale Gedenktage im agrarischen Milieu während der Weimarer Republik („Das Land steht rechts, 1989, v. a. S. $205 \mathrm{f}$.) finden sich für Westmittelfranken bestätigt: eine "tiefe emotionale Bindung an die Welt des Kaiserreiches“ sowie "ein hohes Maß an Intransigenz und Feindseligkeit gegenüber dem demokratischen System" (ebd., S. 184, 205).

${ }^{307}$ HStAM HMB, 4. 7. 1925.

308 Windsheimer Zeitung, 12. 8. 1929.

${ }^{309}$ Fränkische Tagespost, 19. 11. 1924.

310 Nach Megerle wurde der Versailler Vertrag „quasi zur zweiten Konstitution der Weimarer Republik“, vgl. K. Megerle, Element nationaler Integration, 1990, S. 249.

${ }^{311}$ Fränkische Tagespost, 15. 7.1930.

${ }^{312}$ Vgl. Th. Raithel, Das "Wunder" der inneren Einheit, 1996, S. $506 \mathrm{f}$. 
land die kulturnationalen Konzepte im Völkischen Urständ feierten, zementierte der Sieg von 1918 in Frankreich die staatsnationalen Überzeugungen.

\section{Die Apotheose der siegreichen Republik in der Corrèze}

Bis weit hinein in das Lager des Katholizismus mit seiner alten Skepsis gegenüber der Dritten Republik reichte 1918/19 die Meinung, daß die „siegreich aus diesem schrecklichen fünfjährigen Kampf hervorgehende Republik heute von niemandem mehr ernstlich in Frage gestellt wird“313. Die Stimmung geschickt nutzend, ließ die französische Regierung am 11. November 1920 landesweit das 50. Jubiläum der Republik zusammen mit dem zweiten Jahrestag des Waffenstillstandes feiern, um allen Bürgern die Möglichkeit zu geben, „die unauflösliche Verbindung des siegreichen Vaterlandes und der Republik“ zu bezeugen ${ }^{314}$. „Republik, Soldat und Sieg", diese drei Worte sah etwa der Vizebürgermeister von Ussel in einer "Apotheose des Ruhms und der Dankbarkeit" vereinigt ${ }^{315}$.

Wie in Ussel so waren auch in Tulle an einem strahlenden Herbsttag nicht nur die öffentlichen Gebäude, sondern eine ganze Reihe privater Häuser mit Fahnen geschmückt; selten hatte man die Straßen so belebt gesehen. Veteranen- und Kriegsopferverbände, unter ihnen die Ehemaligen von 1870, und vor allem Schuljugend prägten das Bild der großen Feiern. In Tulle verlas der Präfekt eine Rede, die der Staatspräsident im Pantheon gehalten hatte, und erinnerte an die Gründerväter der Republik ${ }^{316}$. Gambetta, dessen Herz von ebensoviel Patriotismus erfüllt gewesen sei wie das des französischen Weltkriegssoldaten, stand auch im Mittelpunkt der Rede des Unterpräfekten in Ussel. Nach einem Rekurs auf die schwierigen Anfänge der Republik in den 1870er Jahren ließ der Staatsbeamte das "grandiose Werk von 50 Jahren Freiheit" noch einmal Revue passieren, wobei er besonders die Bedeutung des laizistischen Schulwesens für die zivilisatorische Mission Frankreichs würdigte, aber auch die kolonialen Erfolge der Republik nicht ver$\mathrm{gaß}^{317}$.

Der Präfekt der Corrèze - überzeugt davon, daß es seinen Bürgermeistern und Volksschullehrern ein Herzensanliegen sein müßte, dieser "großen Demonstration nationaler Einheit" den ganzen wünschenswerten Glanz zu geben - hatte den republikanischen Stützen des Departements noch einmal persönlich ins Stammbuch geschrieben, worum es am 11. November 1920 ging $^{318}$ : Danach hatte die Republik aus den kraftlos gewordenen Händen des Kaiserreichs 1870 ein in der Schmach der Niederlage isoliertes Frankreich übernommen, ,in seinem Ansehen und in seinem Territorium vermindert" und einer ungewissen Zukunft entgegensehend. Dann aber hatte die Republik - dank der Energie und des Glaubens ihrer Gründer, „dank ihrer hohen Konzeption der Freiheit“ und ihrer Fürsorge um die

${ }^{313}$ La Croix de la Corrèze, 7. 9. 1919.

${ }^{314}$ ADC 1 M 108: Präfekt an die Herren Bürgermeister, Damen und Herren Volksschullehrer, Tulle, 1. 11.1920.

${ }^{315}$ La Montagne Corrézienne, 21. 11. 1920.

${ }^{316}$ L'Action Républicaine de la Corrèze, 13.11. 1920.

${ }^{317}$ La Montagne Corrézienne, 21. 11. 1920.

${ }^{318}$ ADC 1 M 108: Präfekt an die Herren Bürgermeister, Damen und Herren Volksschullehrer, Tulle, 1. 11.1920. 
fleißigen Massen des Landes - die Zuneigung des Volkes und die Zustimmung aller freien Geister gewonnen. Schließlich hatte sie gerade ihr Werk gekrönt, indem sie „durch den reinsten der Siege“ die territoriale Einheit des Vaterlandes verwirklichte. Die Republik hatte - noch einmal mit den Worten des corrézischen Präfekten zu reden - „das Vaterland in seinem uralten Umfang wiederhergestellt“. Hier lag der fundamentale, in seiner Tragweite gar nicht hoch genug zu veranschlagende Unterschied zur deutschen Situation nach 1918, wo die Republik - nach nationalprotestantischer Überzeugung - das Vaterland innerlich und äußerlich zerstört hatte. Sicher hatte die Weimarer Republik dennoch ihre Chance; wie klein diese aber mentalitätsgeschichtlich gesehen war, zeigt kaum etwas drastischer als der Vergleich mit der für eine stabile demokratische Entwicklung unendlich viel günstigeren Ausgangsposition in Frankreich nach dem Krieg.

Richten wir zunächst den Blick auf die Struktur des Nationalismus im kirchlich gebundenen Teil der Gesellschaft. Die Niederlage gegen das "protestantische“ Deutschland 1870/71 war auch von den französischen Katholiken, die ihre Religion für einen besonders authentischen Teil des vaterländischen Erbes hielten, als nationale Demütigung empfunden worden ${ }^{319}$. Am Vorabend des Ersten Weltkrieges hatten dann verschiedene außenpolitische Manöver des Deutschen Kaiserreiches die nationalistischen Emotionen selbst unter den dezidiert antilaizistischen französischen Katholiken verstärkt. Während des Krieges (1915) äußerte sich der Bischof von Versailles überzeugt, daß das lutherische und preußische Deutschland nicht der Vorbote der christlichen Zivilisation in der Welt sei, noch auch sein könne ${ }^{320}$. Wie wichtig ein antideutsch bestimmter Nationalismus für die Integration des französischen Katholizismus in die laizistische Republik wurde, klang auch bei einem Plädoyer des Bischofs von Tulle Ende 1918 durch, angesichts der großen nationalen Aufgabe jede Erinnerung an die bedauerliche Vergangenheit „in den Seelen unserer guten Bürger“" verschwinden zu lassen: Gott wolle Frankreich an der Spitze der Nationen haben ${ }^{321}$, wer aber könne „uns versprechen, daß Deutschland nicht einen weiteren Wilhelm II. hervorbringt?"322. Um einmal mehr den „Patriotismus der Kirche Frankreichs“ unter Beweis zu stellen ${ }^{323}$, begann der corrézische Klerus wenige Monate nach Kriegsende damit, ein "Goldenes Buch“ zu verfassen, in dem alle gefallenen oder verwundeten Priester und Seminaristen aus der Region verzeichnet wurden.

Auch im anhaltenden Konflikt mit dem laizistischen Staat spielten die Katholiken verstärkt auf der Klaviatur des Nationalismus und versuchten, die kirchenfeindlichen Gesetze als antinational und antirepublikanisch zu brandmarken. Bismarck persönlich, so die These, habe der Dritten Republik in den 1870er Jahren den antiklerikalen Virus infundiert, nachdem er den Kulturkampf im eigenen Land mit Rücksicht auf den inneren deutschen Einigungsprozeß wieder aufgegeben hatte. Nur um Frankreich zu schwächen, habe der deutsche Reichskanzler

${ }^{319}$ A. Lindt, Das Zeitalter, 1981, S. 72, 235.

${ }^{320}$ Ebd., S. 242.

${ }^{321} \mathrm{La}$ Croix de la Corrèze, 3.11. 1918.

322 Ebd., 7. 9. 1919.

${ }^{323}$ La Semaine Religieuse du Diocèse de Tulle, 1919, S. 106. 
Gambetta veranlaßt, dem Klerikalismus den Krieg zu erklären ${ }^{324}$. Der anhaltende Kampf der Kirche für eine andere Kulturpolitik richtete sich erkennbar nicht mehr gegen die Republik selbst, die auch von katholischer Seite zunehmend mit der Nation identifiziert wurde. Die entschiedensten Befürworter einer christlichen Demokratie entwickelten sogar eine politische Theologie, die Jesus Christus als "den herausragenden Republikaner" und ersten Demokraten deutete ${ }^{325}$. Im Blick auf Perversionen der völkischen Theologie in Deutschland und ihre Behauptung eines arischen Jesus erscheint diese republikanische Interpretation besonders bemerkenswert.

Wenn schon der Patriotismus der französischen Kirche nach 1918 immer republikanischer wurde, so mußte dies für die Haltung der Volksschullehrer erst recht gelten. Da die Instituteurs aufgrund ihrer ideologischen Ausbildung die Dritte Republik seit jeher als Tochter der glorifizierten Revolution von 1789 verehr$\operatorname{ten}^{326}$, kam es ihnen nach der erfolgreichen Bewährungsprobe dieses Staatswesens - und seiner Pädagogen - im Weltkrieg mehr denn je darauf an, „die Republik mit den Lehrern und die Lehrer mit der Republik zu verteidigen“: beide „solidarische und unzertrennliche Kräfte" seien existentiell aufeinander angewiesen ${ }^{327}$. Der 50. Jahrestag der laizistischen Schule 1931 und das Pathos, mit dem sich corrézische Lehrer und Dritte Republik an diesem Tag selbst inszenierten, ist für diese Entwicklung besonders aufschlußreich.

Kein zweiter Vortrag bei dem großen Bankett in Tulle wurde so enthusiastisch aufgenommen wie der des Inspektors der Lehrerakademie. Dessen als seit langem „schönste republikanische Demonstration“ in der Corrèze empfundene, „ermutigende" Rede ließ die Seelen erbeben und verwischte angeblich sogar "für einen Augenblick die Grenzen der Parteien". Ermöglicht hatte dies ein zutiefst emotionaler Appell des alten Akademieinspektors an die demokratischen und laizistischen Empfindungen des überwiegend aus dem Erziehungswesen, bis aus den entlegensten Weilern der Corrèze gekommenen Publikums. Denn der betagte Pädagoge gehörte zu denen, "die sich noch daran erinnern, wie der Schatten des Dorfpfarrers sich im Klassenzimmer abgezeichnet hat ...". Aber ebenso wie im Mittelalter der religiöse Glaube das Land mit einem weißen Mantel an Kirchen überdeckt habe, gebe es seit einem halben Jahrhundert einen neuen laizistischen, aus der Revolution hervorgegangenen Glauben, der die Zahl der Dorfschulen vervielfacht und alle Herzen mit dem Traum von der Emanzipation des Geistes beseelt habe ${ }^{328}$.

Kein Zweifel, der Begriff der Republik war in der corrézischen Mentalität weithin affektiv besetzt, und er hatte eine ähnlich emotionalisierende Wirkung wie das Vaterländische für die Menschen in Westmittelfranken. Neben der funktionalen gab es aber auch eine inhaltliche Parallele, denn in den fortschrittlichen Klang des Republikanismus mischten sich "klassische“ Töne eines normalen europäischen

${ }^{324}$ Zur historischen Unhaltbarkeit dieser These vgl. L. Capéran, Histoire contemporaine, 1957, S. $105 \mathrm{ff}$.

${ }^{325}$ M. Montuclard, Conscience religieuse et démocratie, 1963, S. 168.

${ }^{326} \mathrm{~J}$. Girault, Instituteurs syndiqués, 1984, S. 147.

327 Siehe den Artikel „Les instituteurs et la République“ in: Revue de l'Enseignement Primaire et Primaire Supérieur, 4. 10. 1925.

${ }^{328}$ Vgl. die Dokumente und Zeitungsausschnitte vom Juni 1931 in: ADC 1 M 111. 
Abgrenzungsnationalismus. Symptomatisch war etwa die Kritik aus den Reihen der Volksschullehrer an Friedrich Ebert und der deutschen Sozialdemokratie: Während der einzige und wahre Pazifist Jean Jaurès den Sozialismus idealistisch mit der menschlichen Vernunft verbunden habe, sei Eberts "Realismus" an den animalischen Instinkt gekoppelt und habe so einen Krieg ermöglicht, zu dem die Deutschen wie Tiere zur Schlachtbank gegangen seien. Die Positionen Eberts und Jaurès' markierten in dieser Argumentation die typische Grenze zwischen dem deutschen politischen Mittelmaß und der Überlegenheit des französischen „Ge-

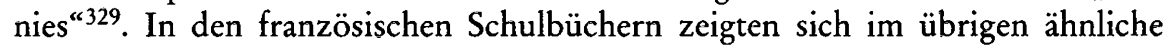
nationalistische Tendenzen: dem "friedlichen", "großen" und "gerechten" Frankreich wurde ein "kriegerisches“, "barabarisches" und „brutales" Deutschland gegenübergestellt ${ }^{330}$. Offensichtlich zählte der Nationalismus so sehr zur ideologischen Grundausstattung der europäischen $Z$ wischenkriegsepoche, daß er selbst in seiner republikanischen französischen Umprägung noch deutliche Spuren hinterließ.

Nicht einmal der Versailler Vertrag entsprach deshalb „dem tiefen Sehnen der

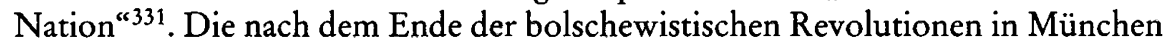
und Budapest 1919 im corrézischen Nationalismus keimende Hoffnung, nun könne die Gefahr eines roten Deutschland bei den laufenden Friedensverhandlungen den Weimarer Politikern nicht mehr als Argument dienen, um die Angloamerikaner für sich einzunehmen, sah sich bitter enttäuscht ${ }^{332}$. Nicht nur in den Augen der corrézischen Konservativen wurde in Versailles allenfalls ein "Minimum" jener Reparationszahlungen durchgesetzt, auf die das verwüstete Frankreich Anspruch zu haben glaubte ${ }^{333}$. Ferner blieb in der öffentlichen Meinung der Corrèze umstritten, ob der Vertrag genügend Garantien gegen Deutschland enthalte, zumal manche Beobachter - gestützt auf Berichte der deutschen Presse - in der Weimarer Republik immer noch das alte Deutschland erkannten, in dem trotz demokratischer Fassade der Geist des autoritären Regimes lebendig sei. Sogar im sozialdemokratisch geführten preußischen Innenministerium, so hieß es, trieben reaktionäre Beamte ihr Unwesen ${ }^{334}$.

Skepsis gegenüber Deutschland und dem Versailler Vertrag prägte später auch die Reaktion der Corréziens auf die Ruhrbesetzung ${ }^{335}$. Ein konservativer Politiker fühlte sich dadurch motiviert, einen Antrag im Conseil général einzubringen, um Poincaré zu seinem „acte d'énergie“ zu beglückwünschen. Die linke Mehrheit in dem kommunalen Gremium setzte aber im Juni 1923 eine differenziertere und diplomatische Stellungnahme durch, die von der Legitimität der französischen Reparationsforderungen ausging und sich gleichzeitig zufrieden darüber äußerte,

${ }^{329}$ Vgl. den Artikel „Comment faire la paix?“, in: Revue de l'Enseignement Primaire et Primaire Supérieur, 16. 2. 1919.

${ }^{330}$ J. H. C. Hayes, France. A Nation of Patriots, 1930, S. 54.

331 G. Dauger/D. Dayen, Histoire du Limousin contemporain, 1988, S. 131.

${ }^{332}$ La Montagne Corrézienne, 11. 5. 1919.

${ }^{333}$ Liste d'Union Républicaine et de Défense Agricole et Sociale, Aufruf zu den Wahlen vom 16.11. 1919, in: ADC 3 M 195; vgl. zum nationalen Kontext P. Miquel, La paix de Versailles, 1971.

${ }^{334}$ La Montagne Corrézienne, 14. 9. 1919.

${ }^{335}$ ADC 10 M 67: Präfektenbericht, Tulle, 12. 3. 1923. 
daß die Regierung nunmehr eine internationale Verhandlungslösung anstrebte ${ }^{336}$. Massiver zogen lediglich die Kommunisten gegen die Ruhrbesetzung zu Felde ${ }^{337}$.

Bei anderen Anlässen stießen freilich auch die corrézischen Sozialisten immer wieder mit dem im liberalen und konservativen Spektrum verbreiteten Nationalismus zusammen; etwa als sie eine Wahlversammlung mit dem Deputierten Longuet, dem Enkel eines Deutschen, ankündigten und provokativ von einem "quart de boche" sprachen. Einen so "notorischen Defätisten " ${ }^{338}$ einzuladen, fand die Croix de la Corrèze ebenso empörend wie den Gruß des corrézischen Sozialistenführers Spinasse an seine „deutschen Kameraden“. Spinasse hatte im November 1923 im „Worwaerts“ (gemeint: Der Vorwärts) Poincarés Ruhrpolitik kritisiert, die die deutsche Arbeiterklasse ökonomisch ruiniere, und an sie appelliert, den Kampf der französischen Sozialisten gegen Poincaré zu unterstützen. Die nationalistischen Katholiken fanden dies unerhört: Der „Boche“ habe kein Geld, um die Reparationen zu bezahlen, aber er sammle, um die französischen Wahlen zu sabotieren ${ }^{339}$. Die schändliche Kooperation der deutschen und französischen Sozialisten gegen Poincaré gehörte von nun an zum argumentativen Arsenal des französischen Nationalismus. Bei einer SFIO-Versammlung in Brive löste der prominente rechte Debattenredner Henri Kerillis noch Jahre später „große Emotion im Saal" aus, als er den bekannten Vorwärts-Artikel aus der Tasche zog, um den Patriotismus der Sozialisten in Frage zu stellen ${ }^{340}$.

Die vermeintlichen nationalen Defizite der französischen Linken erregten nicht nur die konservativen Katholiken, sondern fast mehr noch die rechtsgerichteten Weltkriegsveteranen. Wenn man schon 1918 weniger der „Humanitätsduselei Wilsons" gefolgt wäre, sondern dem Boche "das Maul gestopft" hätte, so kommentierte der UNC-Vorsitzende von St-Salvadour den Ruhrkampf, dann wäre die deutsche Gefahr heute geringer. Über die französische Gutgläubigkeit würden sich die Deutschen nur ins Fäustchen lachen ${ }^{341}$. Später in der Zeit der Wirtschaftskrise empfahl Le Combattant Corrèzien, nur noch französische Produkte zu kaufen, und beschwor die Solidarität der Schützengräben als Allheilmittel gegen innere Schwierigkeiten ${ }^{342}$.

Während aber der typische Nationalismus der Weltkriegssoldaten in den fränkischen Wehrverbänden eine völkische Dynamik gegen den Weimarer Staat entwickelte, blieb er in der Corrèze republikanisch domestiziert. Le Combattant Corrèzien warnte in den 1930er Jahren ausdrücklich „einige Fischer im trüben Wasser" davor, die schlechte Stimmung infolge spektakulärer Korruptionsskandale als eine Abkehr von den republikanischen Institutionen zu deuten: „... sie

${ }^{336}$ Le Travailleur de la terre, Juni 1923.

${ }^{337}$ Im Travailleur de la terre (Mai 1923) war mit Bezug auf die Ruhrbesetzung von der „Lüge des Nationalismus" die Rede. Vgl. auch G. Dauger/D. Dayen, Histoire du Limousin contemporain, 1988, S. 143.

${ }^{338} \mathrm{La}$ Croix de la Corrèze, 26. 10. 1919.

339 Ebd., 27. 4. 1924.

${ }^{340}$ In der hier beispielhaft erwähnten Briver Veranstaltung hieß es demgegenüber, daß die französischen Sozialisten nicht aus Deutschland, sondern nur aus Österreich, Belgien und Schweden Geld bekommen hätten. La Croix de la Corrèze, 25. 3. 1928.

${ }^{341}$ Le Combattant Corrézien, 26. 7. 1924.

${ }^{342}$ Ebd., 16. 1. 1932. 
irren sich, die Masse des Volkes ist von Grund auf republikanisch“343. Von niemandem wollte sich die Union National des Combattants in der Corrèze „Lektionen in Sachen Staatsgesinnung “ (civism) geben lassen, hatte sie doch ,in Krieg und Frieden ihre Treue zum demokratischen Ideal bewiesen "344. Erst recht galt dies für die linksgerichtete Veteranenorganisation der Union fédérale, die auch zum Nationalismus viel weiter Abstand hielt und den "negativen“ exaltierten Patriotismus als eine dauernde Verunglimpfung, eine moralische Beleidigung, eine törichte Herausforderung für die anderen Länder deutete; der Geisteszustand des Nationalismus erzeuge stupide Kränkungen der Selbstachtung und schließlich Feindschaft zwischen den Völkern mit all ihren gefährlichen Folgen ${ }^{345}$.

Nur auf der äußersten, in der Region freilich bedeutungslos bleibenden politischen Rechten kannte der Nationalismus kaum noch republikanische Grenzen ${ }^{346}$ und berauschte sich - etwa bei einer der seltenen Massenkundgebungen der Croix de feu in Limoges - an dem "herrlichen“, seit 20 Jahren, „seit dem Sieg vergessenen Gefühl: dem Gefühl, wieder Franzose geworden zu sein". Zwar sprach der Hauptredner Oberst de la Rocque so patriotisch über Frankreich, das Volk der Sieger, "daß aus vielen Augen Tränen flossen“ und sich dann der Gesang der Marseillaise "wie ein Gebet in den Himmel“ erhob; aber die Wirkung dieser Rhetorik auf die republikanische Mehrheit war gering, mochte der Limoger Croix de feuFührer Le Tanneuer noch so heftig gegen die „alten Männer der Republik“ zu Felde ziehen, die nichts mehr von dem Wollen der französischen Jugend verstün$\operatorname{den}^{347}$. Schließlich bekam der französische Nationalismus nach 1933 auch an dem Punkt nicht recht, wo er im nachhinein betrachtet einige Argumente auf seiner Seite hatte: mit der Warnung vor dem aggressiven und revanchistischen Nationalismus Hitler-Deutschlands. Denn während die französische Linke die Nationalisten im eigenen Land scharf bekämpfte, wurden deutsche Nationalsozialisten an hoher Stelle mit allen Ehren empfangen und bekamen als Touristen von französischen Bürgermeistern kostenlose Unterkunft gestellt ${ }^{348}$.

Das Paradoxon bestätigte aber nur, wie spiegelverkehrt die Entwicklung des Nationalismus auf beiden Seiten des Rheins verlief. So wie in Westmittelfranken die zunehmend völkisch-antirepublikanisch definierte Kulturnation als regulative Idee wirkte, die im Begriff des "Vaterlandes" das allgemein verbindliche gesellschaftliche Ideal vorgab, so richtete sich die politische Kultur der Corrèze von den Volksschullehrern über die alten Kämpfer bis hin zu den gemäßigten Katholiken nach 1918 noch stärker auf die französische Staatsnation aus. Deren sakrosankte Chiffre war die „Republik“, die in der Corrèze während der gesamten Zwischenkriegszeit fast einem modernen Totem vergleichbare Funktionen eines Stammeszeichens mit übernatürlicher Kraft behielt. In Leserbriefen bekannte man sich als „alter Republikaner" ${ }^{439}$; auch in der Jugend gab es Initiativen zur Verteidigung der

\footnotetext{
343 Ebd., 20. 1. 1934.

344 Ebd., 14. 4. 1935.

345 Le Mutilé du Limousin, November 1930.

346 Vgl. auch E. Weber, La fièvre de la raison, 1958.

${ }^{347}$ Le Réveil du Bas-Limousin, 6. 6. 1935.

348 Le Salut National, 11. 5. 1933.

${ }^{349} \mathrm{La}$ Croix de la Corrèze, 2. 11. 1919.
} 


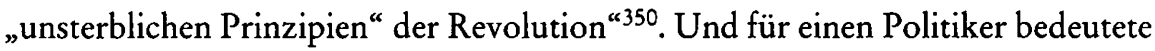
es einen unschätzbaren Vorteil, wenn sein Vater - vielleicht sogar als Volksschullehrer - in der "großen Epoche der republikanischen Kämpfe" hervorgetreten war, also zu denen gehörte, „die soviel gekämpft und gelitten haben für die Demokratie $^{\text {«351. }}$.

Als Gralshüter der Republik agierte der Parti radical. Von jeher waren die Radicaux symbiotisch mit der Republik verbunden und partizipierten, worauf die Funktionäre auch immer wieder hinwiesen, „seit einem halben Jahrhundert an der Fundamentierung der Demokratie“352. Der Tuller Bürgermeister Jacques de Chammard, der 1928 als Républicain Radical-Socialiste für das Parlament kandidierte, bekannte sich gleich im ersten Satz seines Wahlaufrufs ausdrücklich zu seinem „Stolz, der großen republikanischen Partei anzugehören, deren Charta die unsterblichen Prinzipien “ der Menschenrechtserklärung seien ${ }^{353}$. In der Nationalversammlung übernahm Henri Queuille 1929 den Vorsitz einer neugegründeten, 200 Parlamentarier umfassenden Groupe Républicaine de défense de la Démocratie rurale ${ }^{354}$. Die „Wahlbekenntnisse“ der Radicaux waren fast immer plakativ mit „République Française - Liberté - Égalité - Fraternité “ überschrieben, so als ob es sich dabei um amtliche staatliche Dokumente handelte ${ }^{355}$. Auch bei Stichwahlen zählte der Appell an die „Disziplin aller echten Republikaner“ zu den propagandistischen Topoi des Parti radica ${ }^{356}$.

Offensichtlich war der republikanische Alleinvertretungsanspruch der Radicaux so wählerwirksam, daß der politische Gegner es für ratsam hielt, ihn anzufechten. Dem PRS-Kandidaten Jaubert wurde gar öffentlich vorgeworfen, ein "Reaktionär" zu sein, weil er die Republik als Monopol des Parti radical darstelle; die Wähler, so Jauberts Kritiker, ließen sich durch solche Worthülsen aber nicht mehr täuschen: „... ich halte mich für ebenso republikanisch wie Sie, ohne Radikalsozialist zu sein “357. Als der PRS-Generalrat Laumond auf großen Plakaten eine „republikanische Bauernversammlung“ in seinem Kanton ankündigte, ironisierte die Croix: „Was für eine Freude für die Kälber, Kühe, Schweine ..., zu lernen - denn sie werden es schließlich auch noch begreifen -, daß daß sie Republikaner sind und sogar Radikalsozialisten ${ }^{\prime 358}$. Philippe Vachal scheint die Stimmung gekannt zu haben, als er schon am Ende der 1920er Jahre seinen Wahlaufruf nicht mehr einfach mit der obligatorischen Floskel „Es lebe Frankreich! Es lebe die Republik" schloß, sondern ausdrücklich ergänzte, das sei für ihn mehr als eine „banale Formel“359.

${ }^{350}$ L'Effort Républicain pour l'Union des Gauches, 30. 3., 6. 4. 1924.

351 So die Zeitung France über den Kandidaten Lortholary aus Lubersac, zit. nach: Le Salut National, 8.1. 1928.

${ }^{352}$ So der Parlamentskandidat Jaubert, zit. nach: La Croix de la Corrèze, 22. 1. 1928. Ähnlich Philippe Vachal in seiner Profession de foi zu den Wahlen vom 22. 4. 1928, in: ADC 3 M 197.

${ }^{353}$ Profession de foi zu den Wahlen vom 22. 4. 1928, in: ADC 3 M 198.

${ }^{354}$ La Défense Paysanne de la Corrèze, 31. 7. 1929.

${ }^{355} \mathrm{Vgl}$. die Professions de foi, in: ADC 3 M $195 \mathrm{ff}$.

${ }^{356}$ Henri Queuille, „Aux Électeurs“ (vor den Stichwahlen am 29. 4. 1928), in: ADC 3 M 197.

${ }^{357} \mathrm{La}$ Croix de la Corrèze, 22. 4. 1932.

358 Ebd., 21. 9. 1930.

${ }^{359}$ Philippe Vachal, „Aux électeurs de la circonscription de Tulle-Sud“ (Wahlen vom 22. 4. 1928), in: ADC 3 M 197. 
Die Wirksamkeit der radikalsozialistischen Propaganda beruhte darauf, daß sie die typisch französische Verbindung von Republikanismus und Nationalismus besonders glaubwürdig darstellte. Schon im 19. Jahrhundert hatten die Radicaux den kämpferischen Republikanismus als Teil der nationalen Identität Frankreichs begriffen ${ }^{360}$. Und auch in der Zwischenkriegszeit blieb die Union von Republik und Vaterland ein Eckstein im parteipolitischen Selbstverständnis der Radikalsozialisten, wie zeitgenössische Äußerungen belegen. Der Abgeordnete de Chammard beendete etwa seinen Wahlaufruf an die „Bürger“ von Tulle-Süd mit dem Versprechen, auch künftig zur Union der Republikaner beizutragen, „die in einem gleichen Kult das Vaterland und die Republik vereinigen “361.

Von hier aus war auch eine Brücke zu den konservativ-nationalistischen Kräften in der Corrèze geschlagen, die zwar wegen des unabänderlichen germanischen Nationalcharakters eine härtere Deutschlandpolitik verlangten und Reparationen „bis zum letzten Centime“ einforderten, die Republik aber wegen der Weihen des Sieges von 1918 doch für „unberührbar“ hielten ${ }^{362}$. Die Aufrufe der konservativen Liste d'Union Républicaine et de Défense Agricole et sociale waren infolgedessen ebenso mit dem staatstragenden „République Française“ überschrieben wie die Bekenntnisse unabhängiger bürgerlicher Kandidaten. Alle warben sie damit, die "echten“ (sincères) oder "wahren Republikaner" zu sein, oder distanzierten sich gar von einigen Radikalsozialisten, die sich "gestern noch weigerten“, „es lebe die

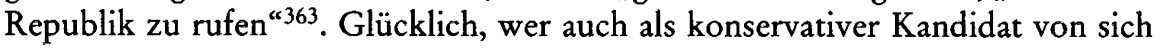
sagen konnte, daß Vater und Großvater sich schon zu einem Zeitpunkt als Republikaner bekannten, „als das noch gefährlich war"364. Am bemerkenswertesten aber war die Einsicht eines Kommunalpolitikers, der (1929) „den republikanischen Prinzipien eine solche Kraft", der Republik eine so stabilisierende Funktion für das Land zutraute, daß Frankreich deswegen „den Krisen der Nachkriegszeit besser widerstanden" habe als die anderen Nationen ${ }^{365}$.

Der in der politischen Mitte verbreitete „nationalisme de synthèse républicaine " 366 nahm auf der linken Seite des französischen Parteienspektrums spürbar ab. Stand die Republik für politische Gleichheit, so beanspruchte der Sozialismus soziale Gerechtigkeit; trotz gemeinsamer Bezüge waren beide Prinzipien doch nicht ganz äquivalent. Obwohl dieses Spannungspotential in der SFIO jedenfalls bis zur Volksfrontbewegung erhalten blieb, war es überlagert von einer grundsätzlich republikanischen Energie, die sich während der Dreyfus-Affäre in der Kooperation von Arbeiterbewegung und liberalem Bürgertum aufgebaut hatte. In Anbetracht der Teilerfolge der nationalen republikanischen Geschichte mußten die französischen Sozialisten die Revolution nicht mehr ex nihilo machen, sondern brauchten sie nur noch innerhalb des bestehenden parlamentarischen

${ }^{360} \mathrm{Vgl}$. J. F. Stone, La république et la patrie, 1991.

${ }^{361}$ Profession de foi zu den Wahlen vom 22. 4. 1928, in: ADC 3 M 198.

${ }^{362}$ Liste d'Union Républicaine et de Défense Agricole et Sociale, Wahlen vom 16. 11. 1919, in: ADC 3 M 195; vgl. auch R. A. Höhne, Faktoren, 1972, S. 67 f.

${ }^{363} \mathrm{Vgl}$. Aufrufe zu den Wahlen vom 16. 11. 1919 und vom 11. 5. 1924, in: ADC 3 M 195 u. 3 M 196.

${ }^{364}$ So im Aufruf von Philippe Vachal, Bürgermeister von Argentat, zu den Senatswahlen vom 20.10. 1929, in: ADC 3 M 229.

${ }^{365}$ Aufruf von Philippe Vachal zu den Senatswahlen vom 20. 10. 1929, in: ADC 3 M 229.

${ }^{366} \mathrm{Zu}$ dem von Jean Touchard stammenden Begriff siehe R. A. Höhne, Faktoren, 1972, S. 66, 211. 
Systems zu vollenden ${ }^{367}$. Im Wahlkampf 1919 sprachen die Sozialisten davon, durch einen Sieg die "wahre Republik" zu etablieren, da im bestehenden Staat die angebliche politische Gleichheit „durch wirtschaftliche Ungleichheiten zur Lüge" werde ${ }^{368}$. Dementsprechend waren auch die Professions de foi nicht mit „République Française“, sondern mit „Sozialistische Partei - S.F.I.O.“ überschrieben; sie betonten den großen verfassungspolitischen und gesellschaftlichen

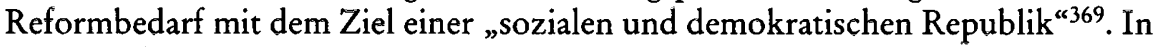
der Zeit der Linksbündnisse mit den Radicaux mahnten die Sozialisten dann in den 1920er Jahren „alle Republikaner" zur Einheit, um die sozialen und demokratischen Errungenschaften zu sichern ${ }^{370}$.

Daß die Idee des Republikanismus zumindest integralen Nationalismus in der Corrèze so gut in Schach halten konnte, lag auch - wie schon vor 1914 - an der im Vergleich zu Westmittelfranken ganz untergeordneten Bedeutung des Antisemitismus. Zwar wurde die Frage der „Kriegsgewinnler“ auch im siegreichen Frankreich nach 1918 zum Wahlkampfthema ${ }^{371}$. Aber der - seit Dreyfus - anhaltende antirepublikanische Geruch des Antisemitismus sowie der gleichbleibend geringe jüdische Bevölkerungsanteil in der Corrèze verhinderten, daß der Typus des Kriegsgewinnlers mit „dem“ Juden identifiziert wurde ${ }^{372}$. Spuren dumpfen Ressentiments waren zwar gelegentlich bis hinein in den sozialistischen Le Travailleur de la Corrèze zu entdecken, der an die sprichwörtliche Schläue der Menschen in der Nachbarregion erinnerte: ein Auvergnac, so sage man, würde drei Juden übers Ohr hauen ${ }^{373}$. Aber aufs Ganze gesehen blieb der Antisemitismus in der Corrèze wie im übrigen Frankreich während der 1920er Jahre doch ein randständiges Phänomen ${ }^{374}$. Die katholische Kirche hatte seit der Verurteilung der Action Française 1926 „endgültig mit antijüdischen Vorurteilen gebrochen" ${ }^{\text {" } 375}$.

Lediglich auf der französischen Rechten sah man im Antisemitismus nach wie vor ein geeignetes Mittel, das ideologisch tief zerklüftete Land zu integrieren ${ }^{376}$; und als die Dritte Republik ab 1932 immer tiefer in die Krise geriet, erlebte Frankreich eine antisemitische Welle, die in ihrer propagandistischen Wucht manchen an die Dreyfus-Affäre erinnerte ${ }^{377}$. Während der Zeit der Volksfront richtete sich der Judenhaß dann zunehmend gegen die Person Léon Blums ${ }^{378}$, der jüdischer

${ }^{367}$ Vgl. A. Bergounioux, Socialisme et République avant 1914, 1992, S. 117, 127 f., sowie M. Winock, Le mythe fondateur, 1992, S. $141 \mathrm{f}$.

${ }^{368}$ Le Travailleur de la Corrèze, Numéro spécial zur Wahl im November 1919.

${ }^{369}$ Vgl. die Aufrufe der SFIO zu den Senatswahlen vom 20.10. 1929 (Docteur A. Verdeaux) und zu den Parlamentswahlen 1932 (Léger Faure), in: ADC 3 M 229 bzw. 3 M 200.

${ }^{370}$ Vgl. die Profession de foi von Spinasse zu den Wahlen vom 29. 4. 1928, in: ADC 3 M 197.

${ }^{371}$ Vgl. La Croix de la Corrèze, 19.10. 1919, 27. 4. 1924. So galt etwa der Radikalsozialist Jaubert als Kriegsgewinnler und seine Kandidatur als Belastung für die gesamte Liste Henri Queuilles.

${ }^{372} \mathrm{Vgl}$. auch Z. Sternhell, The Roots of Popular Antisemitism, 1985, S. 121, 129.

${ }^{373}$ Le Travailleur de la Corrèze, 29. 9. 1919.

${ }^{374}$ L. Poliakov, Histoire de l'antisémitisme, Bd. IV, 1977, S. $307 \mathrm{ff}$.

${ }^{375}$ R. Rémond, Frankreich im 20. Jahrhundert, 1994, S. 229; vgl. auch L. Landau, Juifs et catholiques en France de 1919 à 1939, 1980.

${ }^{376}$ Vgl. Z. Sternhell, The Roots of Popular Antisemitism, 1985, S. 111, 115.

${ }^{377}$ R. Schor, L'antisémitisme en France, 1992, S. 11; R. Milllman, La question juive, 1992, S. 298; vgl. auch P. J. Kingston, Anti-semitism in France during the 1930s, 1983.

${ }^{378}$ S. A. Schuker, Origins of the "Jewish Problem" in the Third Republic, 1985, S. 161. 
Abstammung war. In der politischen Kultur der Corrèze haben aber auch diese nationalen antisemitischen Schübe keine spürbare Wirkung gezeitigt.

Selbst für die Agitation der regionalen Action Française spielte antisemitische Kritik - etwa am „jüdisch-republikanischen“ Scheidungsrecht ${ }^{379}$ oder an der Spezialausbildung linker Lehrer durch die ,jüdische Freimaurerei“ in den Ecoles normales ${ }^{380}$ - eine untergeordnete Rolle. Offensichtlich wurde dieses Argumentationsmuster als nicht besonders wirkungsvoll erachtet, denn bei intellektuellen Vordenkern der Action Française im Limousin, wie Albert Pestour, waren "die Juden und ihre roten Lakaien“ durchaus als „Profiteure der Schlächterei“ im Ersten Weltkrieg benannt worden ${ }^{381}$. Erst im Kontext der Volksfront wuchs auch am rechten Rand der Corrèze die Neigung, eine "gemeinsame jüdisch-freimaurerische und sozialistisch-kommunistische Front" als Gefahr zu beschwören. Schon den Weltkrieg hatten danach die Machenschaften des internationalen Judentums verschuldet: der serbische Jude Gabriel Princip sei zwei Jahre lang von einer jüdischen Freimaurerloge auf das Attentat von 1914 vorbereitet worden ${ }^{382}$. Dennoch konnten diese antisemitischen Parolen mangels konkreten regionalen Agitationsstoffs nicht über kleine rechte Zirkel hinausdringen.

Wie die Entwicklung verlaufen wäre, wenn das Landjudentum in der Corrèze eine größere Rolle gespielt hätte, ist schwer zu beantworten. Die hypothetische Frage scheint aber doch zumindest gestellt werden zu müssen, weil die Vorwürfe gegen nicht-jüdische Händler in der Corrèze der antisemitisch gefärbten Kritik der fränkischen Bauern in manchem sehr ähnelten. Als Beispiel angeführt sei hier nur die an den radikalsozialistischen Bauernverbandsvorsitzenden Faure gerichtete Klage eines Landwirts über die Dreistigkeit und Falschheit skrupelloser Händler. So habe einer, wenige Wochen nachdem er ein Rind gekauft hatte, behauptet, es sei an Tuberkulose gestorben, und vom Bauern die Rückzahlung des Geldes verlangt. Schon um zu vermeiden, daß andernfalls der Tierarzt mehrfach den gesamten Viehbestand impfen müsse und sie diese Kosten zusätzlich zu tragen hätten, würden die Bauern in solchen Fällen die Kaufsumme zurückerstatten. Die Wut über die „ausbeuterischen Blutsauger ${ }^{\text {“ }} 383$ des französischen Bauern konnte sich allerdings auch während der Agrarkrise nicht in einer Sündenbocktheorie gegen eine nach religiösen oder ethnischen Kriterien näher zu definierende Minderheit verdichten - so wie dies in Westmittelfranken Ende der 1920er Jahre mehr und mehr geschah, als Juden zwangsversteigerte Bauernhöfe aufkauften.

Nimmt man die regionalen Ausprägungen des französischen und deutschen Nationalismus in den politischen Kulturen Westmittelfrankens und der Corrèze noch einmal zusammenfassend in den Blick, so fällt vor allem der scharfe Kontrast ins Auge zwischen der fränkischen Entwicklung, die von der „völkischen Revolution" in Deutschland nach 1918 maßgeblich geprägt wurde, und der evolutionären Verfestigung des republikanischen Mythos in der Corrèze. Während in Westmit-

${ }^{379}$ Le Salut National, 20. 3. 1927.

380 Ebd., 27. 2. 1927.

${ }^{381}$ Vgl. das Gedicht "L'appel au roi“ in dem gleichnamigen Gedichtband von Albert Pestour (L'appel au roi, 1933, S. 7).

${ }^{382}$ Le Réveil du Bas-Limousin, 7. 6. 1934 u. 27. 2. 1936. Das in Brive erscheinende Blatt fühlte sich der Fédération républicaine verbunden.

${ }^{383}$ La Défense Paysanne, 15. 6. 1929. 
telfranken auch nur anscheinend vaterlandslose Gesellen zunehmend in die argumentative Defensive gerieten, waren in der Corrèze die vermeintlichen Gegner oder auch nur Skeptiker der Republik in einer immer schwierigeren Position, weil sich im Ergebnis der historischen Zäsur von 1918 die unterschiedlichen Strukturen der nationalprotestantischen bzw. republikanisch-laizistischen Milieumentalitäten weiter vertiefen konnten. In Frankreich blieb für (revanchistischen) Chauvinismus nach der Rückeroberung Elsaß-Lothringens nicht mehr viel Platz ${ }^{384}$, rückten auch die lange zögernden Katholiken immer näher an die siegreiche Republik heran, wohingegen Deutschland in den Teufelskreis von Versailles stürzte und besonders die Nationalprotestanten in beklemmender Geschwindigkeit über den revisionistischen Nationalismus zum völkischen Antirepublikanismus abdrifteten.

\section{Militarismus der Besiegten - „patriotischer Pazifismus“ der Sieger}

Max Weber hat Nation als eine „spezifische Art von Pathos“ bezeichnet, „welches sich in einer durch Sprach-, Konfessions-, Sitten- oder Schicksalsgemeinschaft verbundenen Menschengruppe mit dem Gedanken einer ihr eigenen ... Machtorganisation verbindet ${ }^{385}$. Nicht minder wichtig als die Maximierung militärischer Macht nach außen war die damit oft einhergehende Militarisierung des innenpolitischen Lebens. Wo nationalistische Mentalitätsschichten sich militaristisch ausbuchteten, konnte dies zu einem zusätzlichen Belastungsfaktor für die Zwischenkriegsdemokratien werden, wie für die Weimarer Republik allgemein aufgezeigt worden ist ${ }^{386}$; die gegenläufige Strömung des Pazifismus scheint zwar paradoxerweise in Frankreich die militärische Verteidigungsbereitschaft beeinträchtigt und das außenpolitische Ende der Dritten Republik beschleunigt zu haben, vorher aber trug sie 1936 zum Sieg der Volksfront bei, die sich eindeutig demokratischen Spielregeln unterwarf ${ }^{387}$. Daß in Frankreich auf die Nationalisierung des Krieges nicht wie in Deutschland die forcierte Militarisierung der Nation folgte, war freilich in erster Linie, wenn auch nicht ausschließlich, eine Folge des Sieges von 1918. Am Beispiel Westmittelfrankens und der Corrèze wird dies besonders deutlich.

${ }^{384}$ Vgl. M. Winnock, Nationalisme, antisémitisme et fascisme, 1990, S. 29; G. L. Mosse, Rassismus, 1978, S. 177. Jedenfalls kehrte der französische Nationalismus, wie es Klaus Harpprecht treffend formuliert hat, immer wieder „mit einem unschuldigen Lächeln ... zu den Normen der westlichen Zivilisation zurück“. K. Harpprecht, Mein Frankreich, 1999, S. 118.

${ }^{385} \mathrm{M}$. Weber, Wirtschaft und Gesellschaft, 1964, S. 316.

386 Vgl. K.-J. Müller/E. Opitz, Militär und Militarismus in der Weimarer Republik, 1978; teils ins 19. Jahrhundert zurückgreifend V. R. Berghahn, Militarismus, Köln 1975.

${ }^{387}$ Daß die Veteranenverbände in Frankreich ein Faktor politischer und sozialer Stabilität waren, während sie in Deutschland zur Destabilisierung der Republik beitrugen, ist eine These, die etwa bereits K.-J. Müller (La mémoire des guerres, 1993, S. 68) in einem anregenden Vortrag zur „politischen Kultur der Rechten“ vertreten hat. 


\section{Das pazifistische Meinungsklima der Corrèze}

Auch in Frankreich hatte es vor 1914 „Militarismus als politische Kultur" gegeben $^{388}$, der nach der klassischen Definition von Alfred Vagts alle Denk- und Wertsysteme sowie alle Gefühlskomplexe umfaßte, „die militärischen Institutionen und Formen höher" stellte als zivile Lebensformen und dabei „eine militärische Mentalität sowie Handlungs- und Entscheidungsweisen in die zivile Sphäre“ $\operatorname{trug}^{389}$. Schulbücher und nationalistische Verbände orientierten auf Kriegsgesinnung, der Elsaß-Lothringen-Kult verstärkte sich mehr und mehr, in Turn-, Fechtund Schützenvereinen fand paramilitärische Ausbildung statt ${ }^{390}$. Wie weit dies auch in der linksrepublikanischen Corrèze die Gesellschaft erfaßte, zeigten etwa Veranstaltungen des Schützenvereins „La Tulliste“ mit eigenem Wettschießen für Frauen am Karabiner ${ }^{391}$. Geistige Beiträge zur Pflege militärischer Werte lieferte immer wieder die regionalistische Publizistik ${ }^{392}$. Angesichts einer bedrohlichen außenpolitischen Konstellation schien es gerade in den Jahren vor dem Weltkrieg die erste Pflicht eines guten französischen Bürgers zu sein, wie Raymond Poincaré 1911 vor der "Jeunesse laïque" verkündete, „ein tapferer und gehorsamer Soldat" zu werden ${ }^{393}$.

Der vorherige, fast ein Jahrzehnt währende „Tiefstand bei Moral und Prestige der Armee ${ }^{394}$ im Ergebnis der Dreyfus-Affäre war allerdings mehr als eine Episode geblieben. So hatte sich eine pazifistische Strömung entwickelt, die zunächst von den Sozialisten der Haute Vienne und Kreisen der Volksschullehrerschaft ausging, aber auch in der Corrèze ${ }^{395}$ bereits Massen mobilisierte. Annähernd 500 Besucher aus Tulle und Umgebung strömten 1909 zu der Versammlung mit dem berühmten Antimilitaristen Gustave Hervé396. Der ehemalige Lehrer spielte geschickt mit den laizistischen Emotionen seines corrézischen Auditoriums und stellte die "militärischen Prozessionen“ in eine Reihe mit den endlich abgeschafften „klerikalen Prozessionen“: „Staatsbürger, man macht aus Euch Kälberherden für die Metzgerei ... Deutsche und französische Arbeiterklassen müssen sich zusammenschließen ..." Auch in anderen Erscheinungsformen des corrézischen Vorkriegspazifismus tauchten wesentliche Themen bereits auf, die nach 1918 ver-

${ }^{388}$ Vgl. J. Vogel, Militärfeiern in Deutschland und Frankreich, 1995, v. a. S. 209f.; vertiefend J. Vogel, Nationen im Gleichschritt, 1997, sowie die ebenfalls vergleichend angelegte Studie von M. Ingenlath, „Mentale Aufrüstung“, 1998.

${ }^{389}$ Zur Militarismus-Definition von Alfred Vagts aus den 1930er Jahren vgl. W. von Bredow, Moderner Militarismus, 1983, S. 23; zur marxistischen Perspektive P. Bachmann/K. Zeisler, Der deutsche Militarismus, Bd. I, 1986, v. a. S. 5, 7.

390 W. von Bredow, Moderner Militarismus, 1983, S. 41, sowie M. Christadler, Kriegserziehung durch das Jugendbuch in Deutschland und Frankreich, 1976, S. $19 \mathrm{ff}$.; zur Militarisierung der französischen Lehrerschaft vgl. die deutschnationale Polemik von J. Kühn, Der Nationalismus im Leben der dritten Republik, 1920, S. 59.

${ }^{391} \mathrm{La}$ Corrèze à la Belle Époque, 1983, S. 39.

${ }^{392}$ M. Zorzi, La conscience régionale, 1996, S. 98.

${ }^{393}$ Zit. nach J. Kühn, Der Nationalismus im Leben der dritten Republik, S. 59.

394 W. L. Shirer, Der Zusammenbruch Frankreichs, 1970, S. 71.

${ }^{395}$ Die Mitglieder der SFIO-Sektion Tulle waren satzungsgemäß verpflichtet, den internationalen Frieden als die wesentliche Bedingung für das Werden der künftigen Gesellschaft zu betrachten. Siehe: Feuille d'adhésion à la section de Tulle du Parti socialiste de Paul Reliaud (1917), in: ADC 1 M 66.

${ }^{396}$ Zu Hervés Aktivitäten J. Vogel, Nationen im Gleichschritt, 1997, S. 245 ff. 
mehrt angeschlagen wurden. In Brive klebten antimilitaristische Flugzettel gegen das Bündnis von „Säbel und Weihrauchwedel“ oder gegen die Soldatenuniform als "Livree des Henkers“, oder man agitierte gegen die Verlängerung des Wehrdienstes auf drei Jahre, die schließlich die Arbeiterklasse am schärfsten träfe, und nicht die zum Krieg drängenden Elemente in der nationalistischen Studentenschaft $^{397}$. In Tulle traten sogar die in der CGT organisierten Arbeiter der Waffenfabrik mit pazifistischen Aktionen hervor ${ }^{398}$.

Vor allem eine breiter werdende sozialistische Strömung in der Volksschullehrerschaft vermochte den Pazifismus nach 1918 noch weiter in die corrézische Gesellschaft hineinzutragen. Wie weit insgesamt der Einfluß der Lehrer reichte, wird weiter unten noch näher zu beleuchten sein. Ohne das Bewußtsein der Lehrer, ,in vorderster Front “ für den Frieden zu kämpfen ${ }^{399}$, wären die antimilitaristischen Elemente in der politischen Kultur jedenfalls kaum zu erklären. Ebenso galt dies für die Haltung der Anciens Combattants (AC), die in jedem Dorf zahlreich von der Realität des Großen Krieges berichten konnten. Gleich nach dem radikalsozialistisch orientierten Bauernverband bildeten sie mit ca. 15000 Mitgliedern die zweitgrößte organisierte Interessengruppe in der Corrèze. Gewiß, nur die knappe Hälfte gehörte der linksrepublikanisch ausgerichteten Union Fédérative (UF) an, die Mehrheit der als konservativ geltenden Union Nationale des Combattants (UNC) ${ }^{400}$, aber dem Gesamtgewicht der AC im Departement war dies nicht abträglich, da parteipolitische Fragen von beiden zumindest bis zum Februar 1934 peinlichst vermieden wurden, um die in den Schützengräben gewachsene Einheit - und die Durchschlagskraft ihrer sozialen Forderungen - nicht zu gefährden. So bildeten UC und UNC gemeinsam mit den übrigen Kriegsopferorganisationen (der Lungenverletzten, Orientkämpfer, Witwen, Pfarrer, Lehrer und ehemaligen Kriegsgefangenen) ein "Comitée d'entente ${ }^{\text {"401 }}$ und arbeiteten etwa Fragenkataloge zum Wahlkampf aus.

Die geringe Bedeutung parteiideologischer Fragen erklärt auch den zunächst erstaunlichen Befund, daß ausgerechnet die rechte UNC in der linken Corrèze am stärksten Wurzeln schlug. Wie in anderen Departements folgte der Beitritt der alten Frontkämpfer zu diesem oder jenem Verband keiner soziologischen oder politischen Logik, sondern gehorchte eher dem General Zufall. In der Regel gab es nur in den größeren Städten konkurrierende Organisationen. Die Kleinstädte waren meistens Sitz entweder einer UF- oder UNC-Sektion, die auf den ganzen Kanton ausstrahlte und so als "die" lokale AC-Gruppe schlechthin erschien. Auf dem flachen Land schließlich gehörte der Boden erst recht dem Verband, der ihn zuerst betrat, wobei dessen politische Grundrichtung keine Rolle spielte, ja manchmal nahm man nicht einmal den Namen der nationalen Dachorganisation richtig zur Kenntnis. Die meisten corrézischen Bauern gingen zweifelsohne zu der Gruppe, von der sie zuerst etwas gehört hatten, und blieben ihr dann ebenso

${ }^{397} \mathrm{La}$ Corrèze à la Belle Époque, 1983, S. $40 \mathrm{f}$.

${ }^{398}$ AN F 7/13358: Betr. Usines de guerre, Corrèze, Bericht des Commissaire spéciale an den Tuller Präfekten, 6. 8. 1917.

${ }^{399}$ SNI Bulletin Mensuel de la Corrèze, Mai/Juni 1934, S. 30.

${ }^{400}$ Die UF wuchs von 4613 Mitgliedern (1928) auf 6819 (1933/35), die UNC im gleichen Zeitraum von 5000 auf 7629 . A. Prost, Les anciens combattants, 1977, Bd. 2, S. $61 \mathrm{ff}$.

${ }^{401}$ Le Combattant Corrézien, 28. 4. 1932, 15. 2. 1936. 
treu wie der Feuerwehr oder dem landwirtschaftlichen Unterstützungsverein. Auch dem Habitus ihrer Vereins- und Festkultur nach fügten sich die AC-Gruppen bruchlos in die ländliche Gesellschaft ein, ja wurden als Bereicherung des ereignisarmen Alltags empfunden ${ }^{402}$.

Obwohl an der Arbeit der UNC-Sektionen auffallend häufig die „großen Familien " der Corrèze führend beteiligt waren ${ }^{403}$, mußten eventuell vorhandenene konservative Instrumentalisierungsabsichten von vornherein an der Realität des vehement unpolitischen Grundanspruchs der Alten Kämpfer scheitern. Angesichts der linksrepublikanischen Traditionen der Corrèze hatte die an der Spitze rechtsgerichtete UNC besondere Zurückhaltung zu üben und „allen loyal die Hand zu reichen ${ }^{\text {404. }}$. Vor den Wahlen 1924 gab das UNC-Blatt sogar dem Direktor der linken UF das Wort, um die parteipolitische Unabhängigkeit beider Organisationen zu unterstreichen. $\mathrm{Da}$ die zu lösenden Aufgaben weder der Rechten, der Mitte, noch der Linken gehörten, Patrioten und Kriegsprofiteure auf den meisten Listen gleichzeitig vertreten seien, beschwor man statt dessen den „esprit combattant“. UNC-Vorstandsmitglieder, die für ein Mandat kandidieren wollten, hatten ihr Amt abzugeben, und auch in die Wahlkomitees der Parteien durften UNC-Mitglieder nur ohne Hinweis auf ihre Zugehörigkeit zum Verband eintreten $^{405}$. Selbst das Verhältnis zwischen UNC und corrézischen Sozialisten war infolgedessen bis in die frühen 1930er Jahre hinein recht sachlich ${ }^{406}$.

Die Distanz zur Parteipolitik kam in dem eigentümlichen Begriff der „Action civique" zum Ausdruck, die im Juni 1923 auch in Brive beschlossen wurde, nachdem die "schönen Versprechungen von 1919“" nur zum geringsten Teil erfüllt worden waren. Mit der "Action civique“ glaubten die Alten Kämpfer aber immer noch, nicht selbst Politik zu machen, sondern diese gleichsam nur zu kontrollieren $^{407}$. Ging es dabei meist „nur“ um Sozialpolitik, vor allem um Renten und Versorgungsfragen ${ }^{408}$, so hieß das nicht, daß die AC-Verbände - über die „Action civique" hinaus - zu anderen Themen keine politische Meinung hatten. Aufgrund ihrer persönlichen Betroffenheit nahmen die Veteranen vor allem an den Fragen um Krieg und Frieden regen Anteil.

Über die politischen Lager hinweg von der UF bis zur UNC herrschte bei den Alten Kämpfern Konsens, daß sich Pazifismus und Patriotismus nicht ausschlössen, sondern ganz im Gegenteil wechselseitig bedingten und ergänzten. Die übliche Unterscheidung zwischen Patrioten, die wie Poincaré eine harte Linie in der Deutschland- und Sicherheitspolitik verfochten, und den auf deutsch-französische Versöhnung und internationale Zusammenarbeit ausgerichteten Pazifisten um Briand wurde von den wenigsten Alten Kämpfern so nachvollzogen; vielmehr markierten diese Positionen für sie zwei Pole, von denen gleichzeitig Anziehungs-

${ }^{402}$ A. Prost, Les anciens combattants, 1977, Bd. 2, S. $132 \mathrm{ff} .$, 176, 181, 198.

${ }^{403}$ G. Dauger/D. Dayen, Histoire du Limousin contemporain, 1988, S. 140.

${ }^{404}$ Le Combattant Corrézien, 6. 1. 1934.

${ }^{405}$ Ebd., 12. 4., 26. 4. 1924.

${ }^{406}$ Vgl. den Bericht über den UNC-Kongreß in Uzerche. La Voix Corrézienne, 20. 3. 1932; ihre Verbandsnachrichten publizierte die UNC-Sektion auch in der radikalsozialistischen La Montagne Corrézienne (z. B. 14. 1.1934).

${ }^{407}$ Le Combattant Corrézien, 12. 1. 1924.

${ }^{408}$ Vgl. ebd., 23. 2. 1924. 
kraft ausging, wobei deren Stärke je nach Problemlage, von Versailles über die Ruhrbesetzung bis zur vorzeitigen Räumung des Rheinlandes, unterschiedlich stark sein konnte. Die Bewegung der ehemaligen Frontkämpfer wollte im Grunde beides: Reparationen und Versöhnung. Militärische Sicherheit hoffte sie vor allem über den Völkerbund und den Ausbau der „internationalen Friedensarbeit“ zu erreichen ${ }^{409}$, wobei ihre Haltung weniger einer Ideologie entsprang als der emotionalen Kriegserfahrung. Schließlich waren sowohl Vaterland als auch Frieden die Werte gewesen, die dem Leben und Sterben der „poilus “ ${ }^{\text {“410 }}$ Sinn gegeben hat$\operatorname{ten}^{411}$.

Allerdings nahm die Bedeutung des nationalistischen Patriotismus infolge des Sieges und der territorialen Satisfaktion Frankreichs nach 1918 ab, zumal viele Soldaten ihrem Selbstverständnis nach nicht eigentlich gegen Deutschland gekämpft hatten, sondern gegen den deutschen Militarismus und Imperialismus. Nach dessen vermeintlichem Ende gab es für sie keinen vernünftigen Grund mehr, den Konflikt fortzusetzen. Der - im Gegensatz zum Vaterland - universelle Wert des Friedens schien allein geeignet, die Nationen zu versöhnen. Darüber hinaus entwickelte sich nicht nur unter linken, sondern zum Teil auch unter konservativen Veteranen eine starke Abneigung gegen die „Bellizisten“, also gegen die Männer in der Etappe, die den Krieg selbst nicht kannten, sich aber als "Superpatrioten" ${ }^{412}$ gerierten und den Geist des Krieges wachhielten; vor allem einige publizistische Vertreter von Großindustrie und Großhandel erschienen in dieser Perspektive als „Profiteure“413.

$\mathrm{Daß}$ im breiten politischen Spektrum der corrézischen UNC auch scharfer antideutscher Nationalismus eine Heimstatt hatte und sich nach 1933 aus gegebenem Anlaß verdichtete, ist bereits erwähnt worden; aber entscheidend war doch, daß selbst in diesem rechtsgerichteten Soldatenverband die pazifistische Strömung, das „Vertrauen in den Völkerbund und die Politik des großen Pazifisten Briand “414 sowie der „Protest gegen den zu vernehmenden Kriegslärm“415, eine enorme Stärke erreichte. Die Zäsur der Februar-Unruhen 1934, an denen die Pariser UNC beteiligt war, sollte zwar auch die AC-Organisationen in der Corrèze politisch polarisieren, an der maßgeblich von ihr miterzeugten pazifistischen Grundstimmung in der Region änderte dies aber nicht viel.

Kaum irgendwo in der französischen Agrarprovinz war das Bewußtsein, einen außergewöhnlich hohen Kriegstribut entrichtet zu haben, weiter verbreitet als bei den Corréziens. Frankreichs führender Bauernpolitiker Méline schlug deshalb einen gerne gehörten Ton an, als er 1923 den 11. Internationalen Landwirtschaftskongreß eröffnete und seine Rede zu einer Hommage an den Pazifismus nutzte. Die „bäuerliche Welt" der Corrèze, die „unter dem Krieg so sehr zu leiden hatte“, daß sie jetzt nach Frieden dürstete, dankte Méline in bewegten Worten für sein

\footnotetext{
${ }^{409}$ Le Combattant Corrézien, 31. 12. 1924, 13. 2. 1932.

${ }^{410}$ Bezeichnung für die Soldaten des Ersten Weltkriegs.

${ }^{411}$ Vgl. A. Prost, Les anciens combattants, Bd. 3, 1977, S. $77 \mathrm{ff}$.

${ }^{412}$ Ebd., S. 81.

${ }^{413}$ Le Combattant Corrézien, 27. 2. 1932.

${ }^{414}$ Ebd.

${ }^{415}$ Ebd., 13. 2. 1932.
} 
pazifistisches Plädoyer ${ }^{416}$. Auch bei den Anciens combattants, in deren Reihen die bäuerlichen Mitglieder den größten Anteil stellten, stand die Erinnerung an das besondere Opfer der Landbevölkerung mit im Zentrum der verbandlichen Arbeit $^{417}$.

Als nach Locarno und dem Abschluß des Briand-Kellogg-Paktes 1928 der Frieden konsolidiert schien, herrschte Euphorie, weil die Bauern der Corrèze den Krieg, in dem sie „stets den größten Blutzoll zu zahlen“ hatten, „tief verabscheuten“. "Gott sei Dank“, so hieß es, müßten "unsere Kinder nun nicht mehr die mörderische Geißel des Krieges fürchten “418. Die Diskussionen um den BriandKellogg-Pakt im Parlament begleitete man mit pazifistischen Kommentaren ${ }^{419}$. Und selbst die wachsenden außenpolitischen Gefahren seit Anfang der 1930er Jahre führten im bäuerlichen Massenverband der Fédération Faure nicht zu einer Militarisierung des politischen Denkens.

Ein Landwirt aus Mante de St Clément umriß noch im September 1934 den wahren „Esprit syndicaliste“, also den Geist des Verbandes, mit den Worten: er wolle nicht nur bessere Preise für die Landwirtschaft, vielmehr hasse er den Krieg, der die Menschen dazu veranlasse, sich gegenseitig umzubringen, und nur zu Leid und Elend führe. Weiterhin pries der corrézische Agrarpazifist das „hohe Ideal der sozialen Gerechtigkeit und der menschlichen Brüderlichkeit“, wie es der Sozialist Albert Thomas in seiner "Hymne à la terre“ artikuliert hatte. Danach waren die Bauern in der Weltgeschichte von jeher die „friedliebenden Bevölkerungen“, die vermöge ihrer Arbeit und ihres Wesens den Frieden in der Welt geschaffen hät$\operatorname{ten}^{420}$. Der Agrarpazifismus wurde schließlich so kräftig, daß die in der Fédération Faure zusammengeschlossenen corrézischen Bauern, „die mehr als alle anderen die Schrecken des Krieges kennengelernt haben“, während Mussolinis ÄthiopienAbenteuer wörtlich forderten, den Frieden „um jeden Preis zu erhalten“421. Auch im Verhältnis zum Staat Hitlers trübte der pazifistische Voluntarismus seit 1933 den Blick, so daß etwa ein von Friedensrhetorik bestimmtes Antwortschreiben der längst nationalsozialistisch dominierten deutschen Soldatenvereine an die Anciens Combattants als Beweis gewertet wurde, daß „auf beiden Seiten der Grenze alle den Frieden wollen, der den Bauern so teuer" sei.422.

Für den Pazifismus der Fédération Faure bietet sich neben der endogenen Erklärung auch eine exogene an: die Konkurrenz der Kommunistischen Partei. Diese rückte antimilitaristische Elemente nicht nur innerhalb ihrer Agrararbeit in den Vordergrund, etwa mit Hinweis auf „Das Budget des ,Bloc National' “ (43\% für Schuldendienst, 25,5\% für Krieg und Marine, 0,60\% für die Landwirtschaft) ${ }^{423}$, sondern war darüber hinaus bemüht, die von ihr gelenkte Association Républicaine des Anciens Combattants (ARAC) gegen die, wie es hieß, von Gene-

${ }^{416}$ La Défense Paysanne de la Corrèze, Juni 1923; A. Prost, Les anciens combattants, Bd. 2, 1977, S. $160 \mathrm{ff}$.

${ }^{417}$ Vgl. Le Combattant Corrézien, 23. 12. 1923.

${ }^{418}$ La Défense Paysanne de la Corrèze, 30. 9. 1928.

${ }^{419}$ Ebd., 15. 4. 1929.

${ }^{420}$ Ebd., 15. 9. 1934.

${ }^{421}$ Ebd., 30. 11. 1935.

422 Ebd., 15. 6. 1936.

${ }^{423}$ Le Travailleur de la terre, Mai 1921. 
rälen und Großbourgeois beherrschte UNC in Stellung zu bringen und ein Netz von ARAC-Ortsgruppen in der Corrèze aufzubauen ${ }^{424}$.

Die allseitigen Anstrengungen, das Thema für sich zu besetzen, lassen Rückschlüsse auf dessen außerordentliche Wirksamkeit beim ländlichen Publikum zu. Immer wieder auch traten Bauern selbst als pazifistische Aktivisten in Erscheinung, sei es beim spektakulären Protest Hunderter von Jungbauern gegen die Verlängerung des Wehrdienstes 1935 in Seilhac ${ }^{425}$ oder in Brive, wo im gleichen Jahr Soldaten in einem Restaurant über ihren Vorgesetzten schimpften und Bauern am Nachbartisch ihnen offen beipflichteten: der Krieg habe die Mentalität der Offiziere nicht verändert. Einer der aus den Dörfern der Umgebung stammenden Landwirte zog daraufhin ein Bündel mit antimilitaristischen Flugblättern aus der Tasche und überließ sie den Soldaten zur weiteren Verteilung ${ }^{426}$.

$\mathrm{Daß}$ Sozialisten und Kommunisten von dieser pazifistischen Grundhaltung der corrézischen Bauern profitieren könnten, hatte lokalen Autoritäten schon 1919 Sorgen bereitet. Spätere KP-Hochburgen wie die Kantone Bugeat und Seilhac zählten zu den Gegenden der Corrèze, wo überdurchschnittlich viele der eingezogenen Soldaten $\left(61,6 \%\right.$ bzw. 54,5\%) im Krieg umgekommen waren ${ }^{427}$. Ein erheblicher Teil der überlebenden männlichen Bevölkerung war kriegsverletzt und hatte mit den physischen Folgen des Krieges zurechtzukommen - von den psychischen Verwundungen ganz zu schweigen. Die verständliche Depression unter den jungen Kriegsveteranen - auch wenn ihre materielle Lage in den Nachkriegsjahren nicht schlecht war - zog die Stimmung der ganzen Landbevölkerung in Mitleidenschaft. Da die meisten Familien zumindest einen Frontkämpfer in ihren Reihen hatten, stand das gesamte corrézische Dorf unter ihrem tendenziell pazifistischen Einfluß ${ }^{428}$.

$\mathrm{Zu}$ einer Heroisierung der "Stahlgewitter" konnte es in dieser Atmosphäre kaum kommen; überdies fehlten entsprechende Impulse von der nationalen Ebene, wo dem Kommunismus nahestehende Literaten wie Romain Rolland oder Henri Barbusse (Träger des Nobelpreises bzw. des Prix Goncourt) das Klima mitprägten. Der aus dem Limousin stammende Jean Giraudoux ließ in seinem 1935 erschienenen „La guerre de Troie n'aura pas lieu“ den Helden Hektor sagen: Der Krieg scheint mir das schmutzigste und scheinheiligste Rezept zu sein, um alle Menschen gleich zu machen ${ }^{429}$.

Auch im politischen "Totenkult" der Corrèze spiegelte sich diese pazifistische Grundhaltung; ob im kleinen St Aulaire oder in Tulle, meist stand bei den Gedenkfeierlichkeiten die Schreckensseite des Krieges im Vordergrund, die Einsicht etwa, daß „der moderne Krieg den Höhepunkt des Martyriums“ bilde. Die Toten, so hieß es, seien in der Gewißheit gefallen, daß der Krieg, dem sie ihr Leben opferten,

${ }^{424}$ Ebd., Juli/August 1922, sowie Dezember 1921 („Kameraden, alle in die ARAC“); vgl. auch L. S. Boswell, Rural Communisme, 1988, S. 463; R. J. Soucy, France: Veterans' Politics Between the Wars, 1975, S. 61, 64.

425 L. S. Boswell, Rural Communisme, 1988, S. 468.

426 Präfekt an Innenminister, Tulle, 30.4. 1935. ADC 1 M 68.

${ }^{427}$ R. Fourche, STO, Le refus corrézien, 1995, S. 101.

${ }^{428}$ Vgl. L. S. Boswell, Rural Communisme, 1988, S. 391 f., $396 \mathrm{ff}$.

${ }^{429} \mathrm{~J}$. Defrasne, Le pacifisme en France, 1994, S. $134 \mathrm{ff}$.; J. Lestocquoy, Histoire du patriotisme, 1968, S. 229. 
der letzte wäre. Für die Überlebenden wurde daraus die Verpflichtung abgeleitet, „an der Organisation des inneren und äußeren Friedens" mitzuwirken ${ }^{430}$. An den Inschriften der in den 1920er Jahren fast überall im Limousin eingeweihten Kriegerdenkmäler konnte man die pazifistische Mentalität ebenfalls ablesen. Je stärker vor allem der sozialistische und kommunistische Einfluß in den Gemeinden war, desto seltener wurde an die „für Frankreich“ bzw. „für das Vaterland“ gefallenen Soldaten erinnert, sondern schlicht „an unsere Toten“ oder „an unsere Kinder, Opfer des Krieges“431. Auf dem Kriegerdenkmal von Gentioux hieß es sogar: „Verflucht sei der Krieg“432. Und in den von kommunistischen Gemeinderäten geführten Orten Lagraulière und Toy-Viam wurde überhaupt kein Denkmal errichtet, war man doch überzeugt, die Opfer des kapitalistischen Krieges nicht durch teure Monumente, sondern durch entschiedenen Pazifismus am besten zu ehren $^{433}$.

Die kritische Stimmung gegenüber dem Militär ließ das Departement 1924 zu einem bevorzugten Zielgebiet für den deutsch-französischen Redneraustausch werden, den Pazifisten beider Länder organisiert hatten. Während der Auftritt eines Franzosen in Nürnberg von der bayerischen Regierung verboten und die Ersatzveranstaltung in Potsdam von den Rechtsparteien zu einem Skandalon gemacht wurde, kam Robert René Kuczynski und anderen deutschen Pazifisten selbst in der tiefsten französischen Provinz die tolerante Diskussionskultur des Landes zugute. Trotz des Protests einer Gruppe rechter Frontkämpfer - die Deutschen sollten lieber in Deutschland den Frieden predigen als in Frankreich - nahmen etwa an einer Veranstaltung im städtischen Theater von Brive 1000 Zuhörer teil, wobei der deutsche Gast und die Action Française in Rede und Gegenrede aufeinandertrafen ${ }^{434}$.

Im Meinungsklima der Corrèze war auch für AF-Aktivisten die Friedenspolitik ein besonders wichtiges Thema. Élie Jacquet, der limousinische AF-Generalsekretär, warnte bei der Briver Versammlung 1924 davor, dem deutschen Pazifismus zu trauen, da zehn Jahre vorher Millionen deutscher Sozialisten die Waffen gegen Frankreich erhoben hätten. Bereits 1928 brachte die AF an den Mauern von Brive Plakate an mit der drohenden Überschrift: „Der Krieg läuft sich warm“ oder „Die Republik bedeutet Krieg“. Der Text endete mit dem Aufruf: „Für den Frieden. Es

${ }^{430}$ Le Combattant Corrézien, 28. 9., 13. 12. 1924, 16. 1. 1932.

${ }^{431}$ G. Monédiaire, Intersection politique d'espaces, 1985/86, S. $81 \mathrm{ff}$. Demnach kann der Einschätzung in dem anregenden Beitrag von M. Jeismann und R. Westheider nicht gefolgt werden, wonach der Zusammenhang zwischen der politischen Haltung eines Departements und der dort anzutreffenden Denkmalsgestaltung „eher schwach ausgeprägt zu sein“ schien. Vgl. M. Jeismann/ R. Westheider, Wofür stirbt der Bürger? Nationaler Totenkult und Staatsbürgertum in Deutschland und Frankreich, 1994, S. 39.

${ }^{432}$ ADC 2 Fi Monuments $1^{\circ}$ G.M. 11 sowie J 1984/1; G. Monédiaire, Intersection politique d'espaces, 1985/86, S. 98; nur sechsmal trugen Denkmäler auf französischem Boden solch „wahrhaft pazifistische Aussagen“. A. Becker, Der Kult der Erinnerung nach dem Großen Krieg, 1994, S. 322. Vgl. auch: A. Becker, Les monuments aux morts, 1988, sowie dies., La Guerre et la foi, 1994.

${ }^{433} \mathrm{G}$. Monédiaire, Intersection politique d'espaces, 1985/86, S. 98 f.; L. S. Boswell, Rural Communisme, 1988, S. 464; literarisch hierzu der auf dem Plateau de Millevaches spielende Roman von Didier Daenenckx, Le der des ders, 1986, sowie E. Bilal/ P. Christin, Les Phalanges de l'ordre noir, 1979.

${ }^{434}$ O. Jung, Unterschiedliche politische Kulturen, 1990, S. 257, 276, 280; hierzu auch der Bestand $\mathrm{F} 7 / 12884$ in den AN. 
lebe der König“. Zweifel an der republikanischen Sicherheitspolitik bestimmten in den 1930er Jahren verstärkt die Agitation der Action Française. Nach Hitlers Machtergreifung war man bei der corrézischen AF mehr denn je überzeugt, daß der nächste Krieg unmittelbar bevorstehe, weil Deutschland aufrüste, während die französische Regierung Abrüstung propagiere und zudem mit der vorzeitigen Räumung des Rheinlands Hitler begünstigt habe ${ }^{435}$.

Bei den Katholisch-Konservativen links von der AF wurde der pazifistische Grundakzent ebenfalls, etwas weniger stark, aber immer noch spürbar, von nationalistischen oder patriotischen Elementen durchdrungen. Hier hielt sich am ehesten der Sinn für Paraden und Militärkapellen, für die Armee als politische und soziale Ordnungsmacht und überhaupt der ganze Kult der heroischen Größe des „poilu“436. In den Aufrufen der Tuller Bistumszeitung, etwa zum Tag von Verdun 1927 („Die Corrèze war dort; sie hat dort gekämpft; sie hat dort geblutet“), schwang stets die allgemeine kirchenpolitische Hoffnung mit, die Erinnerung an die „unsterbliche Seele der Verteidiger von Verdun“ könne die Union sacrée festigen bzw. beleben ${ }^{437}$. Katholische Kleriker, die teilweise selbst am Krieg teilgenommen hatten, nutzten auch einmal die Messe, um panegyrische Reden auf den Soldaten des Großen Krieges zu halten. Allerdings wurden sie in den betont laizistischen Gemeinden der Corrèze nicht in die lokale Gedenkkultur einbezogen, was die Reichweite dieser Bekenntnisse einschränkte ${ }^{438}$.

Selbst im katholisch-konservativen Verbandswesen waren in den als "heilige Aufgabe" verstandenen Patriotismus starke pazifistische Grundüberzeugungen hineingemischt. Die kirchliche Jugend im Departement hielt zwar den verlängerten Wehrdienst 1935 noch für eine „Verpflichtung gegenüber dem Vaterland“439. Andererseits hatte sich die Fédération Nationale Catholique der Festigung des Friedens durch „brüderliche Zusammenarbeit der Völker" verschrieben und unterstützte alle Maßnahmen, um durch die Organisationen kollektiver Sicherheit „die Herrschaft des Friedens in der Welt" zu sichern ${ }^{440}$. Unsicheres Schwanken zwischen Pazifismus und Patriotismus kennzeichnete insgesamt die Haltung der konservativeren Kräfte in der Corrèze. Statt entschieden den illusionären Charakter des reinen Gesinnungspazifismus bloßzulegen, meinten sie dem in der Region besonders mächtigen Zeitgeist taktisch Tribut zollen zu müssen oder waren selbst von ihm erfaßt. Auf der einen Seite warf La Croix de la Corrèze den Radicaux ihre Zustimmung zu Briands Friedenspolitik vor und warnte, daß nach den PRSWahlsiegen 1914 und 1924 jeweils Kriege ausgebrochen seien ${ }^{441}$. Neben solch kämpferischen Tönen waren aber auf der anderen Seite, vor allem in der

${ }^{435}$ Unterpräfekt an Präfekten, Brive, 14. 4. 1928, in: ADC 3 M 198 (Zitat); Präfekt an Innenminister, Tulle, 17. 5. 1933, in: ADC 1 M 67.

${ }^{436}$ Vgl. R. Girardet, La Société Militaire dans la France Contemporaine, 1953, S. $314 \mathrm{f}$.

${ }^{437}$ La Semaine Religieuse du Diocèse de Tulle, 1927, S. 23.

${ }^{438}$ Vgl. Le Combattant Corrézien, 28. 6. 1924 (Lagarde-Enval), 28. 9. 1924 (Bar), 15. 10. 1924 (Brignac-La-Plaine, St-Bonnet-Elvert), 13.12. 1924 (Tulle), 16. 5. 1925 (Perpezac-Le-Blanc, Champacnac-La-Prune), 16. 1.1932 (St-Aulaire).

${ }^{439}$ So La Jeune Corrèze, November 1935, bei der Verabschiedung eines Kameraden der katholischen Jugendgruppe in Bassignac-Le-Haut zur Infanterie.

440 Vgl. das Programm der FNC vom Januar 1936 (Nachlaß de Chammard. ADC $41 \mathrm{~J}$ ).

${ }^{441}$ Damit spielte die Zeitung - neben dem Weltkrieg - auf die Kolonialkriege in Marokko und Syrien an. La Croix de la Corrèze, 3. 4. 1932. 
„Triumphepoche des Briandismus“442 1925-1932, ganz andere Klänge zu hören, die auf den Beifall des Agrarpazifismus schielten.

Wichtigster Grund für die Entvölkerung des Landes, so behauptete (1929) der Senatskandidat Philippe Vachal, wäre die Dauer des Wehrdienstes, der den jungen Landmann von der Heimat und von der Landfrau trenne; „Frieden unter den Völkern" nannte Vachal deshalb als oberstes Ziel in seinem Programm ${ }^{443}$. Der konservative Parlamentskandidat Joseph Escande (Républicain Démocrate de Gauche) sprach sich 1928 für einen „auf das unbedingt notwendige Minimum“ reduzierten Wehrdienst und eine kürzere Reservistenzeit aus. Darüber hinaus sollten während der landwirtschaftlichen Saat- und Erntezeit keine Bauern zu Wehrübungen heranzogen werden ${ }^{44}$. Auch wer als Konservativer die sicherheitspolitische Lage in Europa skeptischer einschätzte, das Rheinland nicht ohne Friedensgarantien räumen wollte oder es einfach für unzureichend hielt, nur „zu sagen, daß man den Frieden will“, verband diese Position doch so gut wie immer mit einem allgemeinen Bekenntnis zu Völkerbund, Rüstungsbegrenzung, internationaler Schiedsgerichtsbarkeit und Weltfrieden ${ }^{445}$.

Noch stärker in Richtung Pazifismus verschoben waren die Gewichte bei den corrézischen Radicaux. Auch wenn sie in den ersten Nachkriegsjahren der intransigenten Deutschlandpolitik der Rechten nicht fernstanden, gewann doch Mitte der 1920er Jahre Briands Verständigungspolitik immer mehr Anhänger in einer Partei, deren Gründervater Léon Bourgeois die Idee des Völkerbundes in Frankreich eingeführt hatte ${ }^{446}$. Schon 1919 erwarteten die corrézischen Radicaux in „fester Verbundenheit mit dem Frieden“, daß eines Tages dank des Völkerbundes allgemein abgerüstet werde. Zwar wollte der PRS die militärischen Aufgaben „in Ehren halten“, aber er verurteilte doch alle Anzeichen von Militarismus ${ }^{447}$. Briands Diktum: „Das republikanische Frankreich ist ganz und gar friedlich“448, mußte in einem Departement auf offene Ohren stoßen, wo auch der rechte Flügel der Radicaux das Ideal des Friedens stolz zur Charta seiner "großen republikanischen Partei" rechnete ${ }^{449}$.

Indem der corrézische PRS die Politik Briands unterstützte, beanspruchte er, „der französischen Nation ihr friedliches Gesicht zurückzugeben“, die nationalen Egoismen zu bekämpfen, die in allen Ländern den tiefen Sehnsüchten der Völker

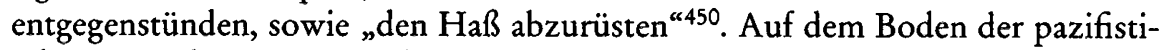
schen Grundstimmung in der Region, von der sie getragen wurden und die sie zum Teil selbst mit schufen, verfehlte im Wahlkampf kaum einer der etablierten Radicaux den Hinweis, mit Briand für die europäische Versöhnung gearbeitet zu

442 R. Girardet, La Société Militaire dans la France Contemporaine, 1953, S. 315.

${ }^{443}$ Siehe Vachals Profession de foi zu den Senatswahlen vom 20.10. 1929, in: ADC 3 M 229.

${ }^{444}$ Siehe Escandes Profession de foi zu den Parlamentswahlen vom 22. 4. 1928, in: ADC 3 M 197.

${ }^{445}$ ADC 3 M 196: Liste d'Union républicaine et de défense agricole zu den Wahlen vom 11. 5. 1924; 3 M 197: René Lafarge (Candidat d'Union républicaine et de défense agricole) zu den Wahlen vom 22. 4. 1928; 3 M 202: Docteur G. Lafarge (Candidat de Concentration Républicaine) zu den Wahlen vom 26.4. 1936 (Zitat).

${ }^{446}$ S. Berstein, Histoire du Parti radical, Bd. 1, 1980, S. 100.

${ }^{447}$ ADC 3 M 195: Liste Queuille zu den Wahlen am 16.11. 1919.

448 J. Defrasne, Le pacifisme en France, 1994, S. 156.

449 ADC 3 M 198: De Chammard zu den Wahlen vom 22. 4. 1928.

450 Ebd. 
haben oder das "große Werk der Befriedung Europas" an der Seite von Briand, Herriot und Poincaré fortsetzen zu wollen ${ }^{451}$. Verkürzung des Wehrdienstes, strenge Kontrolle der Rüstungsausgaben und Weiterentwicklung des Völkerbundes, so lauteten in der Hochphase der Verständigungspolitik die Forderungen des PRS, um „schließlich einen endgültigen Frieden unter den Völkern herstellen“ zu können ${ }^{452}$.

Je dunkleres Gewölk in den 1930er Jahren am Horizont der internationalen Beziehungen aufzog, desto emphatischer wurde auch der Pazifismus im Lager der corrézischen Radikalsozialisten. Typisch war etwa die Rede Henry de Jouvenels ${ }^{453}$ vor den ehemaligen Frontkämpfern in Neuvic, in die der corrézische Außenpolitiker sein ganzes „Herzblut" legte und alle Anwesenden einlud, im Geiste abzurüsten, damit auch die Fäuste abgerüstet werden könnten und eine bessere Welt entstünde ${ }^{454}$. Die erste Aufgabe der Politiker sei es, so Henry Queuille in seinem Senatswahlkampf Ende 1935, „unermüdlich, treu, von ganzem Herzen für den Frieden zu arbeiten", um der französischen Republik eine friedliche Zukunft zu sichern ${ }^{455}$. Die nicht nur rhetorische, sondern tief emotionale Bindung der Radicaux an den Pazifismus wird nur dann verständlich, wenn man sie im Zusammenhang mit den republikanischen Grundüberzeugungen der Partei sieht. Steeg brachte es 1931 auf den Begriff: Je glühender demokratisch wir Radikalsozialisten sind, desto entschiedener pazifistisch sind wir auch ${ }^{456}$.

Für die Sozialisten in der Region, die sich auf eine besonders ausgeprägte pazifistische Tradition berufen konnten, war das Thema Frieden eher noch wichti$\operatorname{ger}^{457}$ : nur sie hätten vor 1914 den Krieg kommen sehen und bekämpft, nur sie dem Versailler Vertrag die Ratifizierung verweigert, weil dieses Abkommen den Militarismus in Deutschland stärkte und Annexionen verfügte, die die Quelle neuer Konflikte seien. Krieg als „höchster Grad der Unvernunft“, so forderten die corrézischen Sozialisten, müsse vollständig aus den Köpfen vertrieben werden. Immer wieder erinnerte die SFIO ihre Landsleute daran, daß der „mörderische Kapitalismus" in Europa seinen ausbeuterischen Zwecken in fünf Jahren 20 Millionen Menschen geopfert habe ${ }^{458}$. Vor dem Hintergrund der Locarno-Politik kam sogar die Hoffnung auf, Deutschland und Frankreich könnten sich intellektuell ergänzen und die vereinigten Staaten von Europa vorbereiten. Als die Verständigungspolitik ins Stocken geriet, bezeichneten corrézische SFIO-Kandidaten unverdrossen den Frieden als oberstes Ziel aller zivilisierten Völker, die endlich in einem großen universellen Vaterland zu versöhnen seien, oder forderten ,in Erwartung der Abrüstung“, die Wehrpflicht um sechs Monate zu verkürzen ${ }^{459}$.

${ }^{451}$ ADC 3 M 197: Queuille zur Stichwahl vom 29. 4. 1928; ADC 3 M 229: François Labrousse zu den Senatswahlen vom 20.10. 1929.

452 ADC 3 M 197: Alexis Jaubert und Jean B. Laumond zu den Wahlen vom 22. 4. 1928.

${ }^{453} \mathrm{Zu}$ dessen politischem Gesamtprofil vgl. C. Manigand, Henry de Jouvenel et le courant radical, 1992.

${ }^{454}$ La Montagne Corrézienne, 24. 4. 1932.

${ }^{455}$ ADC 3 M 233: Queuille zur Senatswahl vom 8.12. 1935.

456 J. Defrasne, Le pacifisme, 1983, S. 97.

457 P. Hanen, Le P.C.F. et la S.F.I.O., 1975, S. 52, 124.

${ }^{458}$ ADC 3 M 229: SFIO zu den Senatswahlen vom 20.10. 1929.

459 ADC 3 M 200: SFIO (Léger Faure) zu den Wahlen von 1932, sowie SFIO (René Cabannes) zu den Wahlen vom 1. Mai 1932. 
Vor allem die ehemaligen Frontkämpfer wurden vom sozialistischen Pazifismus emotional angesprochen; das Votum für die SFIO könne verhindern, daß „Eure Kinder erneut zu Märtyrern werden “ 460 . Aus Gründen pazifistischer Glaubwürdigkeit und weil sie 1919 sehr unter dem Vorwurf der Drückebergerei gelitten hatten, legten die sozialistischen Parlamentskandidaten auch größten Nachdruck auf ihre Vergangenheit als Frontkämpfer. Spinasse, der führende Mann der corrézischen SFIO, spielte in dieser Frage eine herausragende Rolle ${ }^{461}$; in seinem Stimmkreis war er 1928 der einzige Kandidat, der vier Jahre lang in einer infanteristischen Kampfeinheit am Krieg teilgenommem hatte. Dreimal verwundet, präsentierte sich Spinasse den Frontkämpfern als einer der Ihren, der ihr „Martyrium und die Schrecken des Krieges" ebenso kannte wie ihren „Willen zum Frieden" ${ }^{462}$. Damit war ein Grundstock an Integrität aufgebaut, der Spinasse bei seinen regelmäßigen Auftritten vor den Frontkämpfern, auch denen der UNC, immer wieder zugute kam. Bald zählte der corrézische Sozialistenführer auch auf der nationalen Bühne zu den profiliertesten pazifistischen Außenpolitikern seiner Partei.

Die kommunistischen Erfolge in der Region wurzelten ebenfalls, und wohl noch tiefer, in der mehrheitlich militärskeptischen Mentalität der Corréziens, der schon die Gründungsmotivation der SFIC entgegengekommen war: Ressentiments gegen den sozialistischen Eintritt in die Union sacrée 1914 und Enthusiasmus für die bolschewistische Revolution, die „den kriegshetzerischen Kapitalismus liquidiert" habe ${ }^{463}$. Da der Kommunismus in der Corrèze nach dem Trennungskongreß von Tours 1920 den Großteil des organisatorischen und personellen Erbes der SFIO antrat, konnte er deren militaristischen Sündenfall von 1914 kritisieren, aber doch gleichzeitig die positiven pazifistischen Traditionselemente aufgreifen ${ }^{464}$. Fortgesetzt sprach die corrézische KP von der „Ausbeutung des Todes" durch eine reiche kapitalistische Klasse, der sie auch die Verantwortung dafür zuschob, daß sich Frankreich, obschon siegreich aus dem Krieg hervorgegangen, in einem ebenso miserablen Zustand befinde wie der Besiegte ${ }^{465}$.

Die SFIC leitete selbst ihr Agrarprogramm 1921 mit der - zutreffenden - Erkenntnis ein, daß die zur Partei gestoßenen ländlichen Mitglieder im Kommunismus vor allem eine Bastion gegen den Krieg sahen. Tatsächlich bestanden die Sekretariate mancher corrézischer KP-Zellen sämtlich aus Veteranen. Wenn Invaliden an der Folge von Kriegsverletzungen starben, war dies immer wieder in der KP-Presse zu lesen und hielt die antimilitaristischen Emotionen ebenso wach wie die Grabreden, in denen der Horror der Schlachtfelder ein ums andere Mal evoziert wurde. Sogar im Kommunalwahlkampf, den die anderen Parteien meist mit örtlichen Themen bestritten, stellte sich die SFIC im Limousin vor allem als pazifistisches Bollwerk dar. Daran vermochte in der ersten Hälfte der 1920er Jahre auch Moskaus ideologisches Verdammungsurteil gegen pazifistische Kommuni-

460 ADC 3 M 195: Le travailleur de la Corrèze, Numéro Spécial zur Wahl am 16. 11. 1919.

461 Vgl. auch D. Faugeras, Recherches, 1986, S. 376.

462 ADC 3 M 197: SFIO (Spinasse) zu den Wahlen vom 22. 4. 1928.

${ }^{463} \mathrm{~J}$. Defrasne, Le pacifisme en France, 1994, S. 85.

464 L. S. Boswell, Rural Communisme, 1988, S. 431.

${ }^{465}$ Le Travailleur de la terre, April 1921; vgl. hierin auch den Aufsatz von Vazeilles („Für den nächsten letzten Krieg“); zur kommunistischen Position allgemein J. Rabaut, Lantimilitarisme en France, 1975 , S. $135-170$. 
sten nichts zu ändern, deren „kleinbürgerliche“ Konzeption angeblich den legitimen revolutionären Krieg zur Verwirklichung der kommunistischen Gesellschaft in Frage stellte ${ }^{466}$. Der Antimilitarismus blieb trotzdem das wohl populärste Thema der KP auf dern Land, mit dem sie - wie der Briver Unterpräfekt 1925 sorgenvoll konstatierte - selbst Soldaten aus integren corrézischen Bauernfamilien anzusprechen vermochte ${ }^{467}$.

Angesichts der kommunistischen Propaganda hatten die Garnisonen in Brive und Tulle keinen leichten Stand. An Bäumen klebende Flugblätter oder in Kasernennähe angebrachte Spruchbänder mit antimilitaristischem Inhalt sorgten immer wieder für Unruhe ${ }^{468}$. Gleiches galt für Broschüren über „Die Leiden und Kämpfe der Soldaten ", die von der KP in Brive auf Versammlungen besprochen und verkauft wurden ${ }^{469}$, oder die kommunistische Agitation unter wehrübenden Reservisten ${ }^{470}$. Die KP-Jugend tat sich dabei besonders hervor. In Brive behauptete z.B. ein Funktionär der Jungen Kommunisten nach einer Grippewelle, die in Frankreich ausschließlich im Militär Todesopfer gefordert hatte, Soldaten würden generell zu schlecht ernährt und müßten zu exzessiv exerzieren ${ }^{471}$. Selbst innerhalb des 126. Infanterieregiments in Brive war - der leninistischen Infiltrationsstrategie folgend ${ }^{472}$ - eine kommunistische Zelle aktiv, die unter anderem eine „Zeitung zur Verteidigung der Soldaten“" publizierte ${ }^{473}$. Die Auswirkungen solcher Propaganda zeigten sich in einer Phase wachsender Spannungen Mitte der 1930er Jahre, als einige Soldaten ihrer Unzufriedenheit über den härteren sicherheitspolitischen Kurs der Regierung mit klassenkämpferischen Parolen und dem Singen der Internationale Luft machten ${ }^{474}$.

Zusammenfassend läßt sich sagen, daß nach dem Sieg im Weltkrieg im ganzen Land eine Friedenssehnsucht gewachsen war, die offensichtlich besonders stark Gegenden mit älteren pazifistischen Traditionen erfaßte. Auch in der politischen Kultur der Corrèze waren die militaristischen Elemente weiter zugunsten der pazifistischen abgebaut worden. Wenn die Politiker hier Wert darauf legten, Frontkämpfer gewesen zu sein ${ }^{475}$, dann weniger aus heroischen Gründen, sondern zur Erhöhung ihrer pazifistischen Glaubwürdigkeit. Im Rahmen dieser Mentalität gewannen vor allem die sozialpolitischen Folgen des Krieges, Versorgungs- und Rentenfragen oder das Schicksal der Kriegerwitwen, einen hohen Stellenwert. Wahlen konnten nur die Parteien für sich entscheiden, die Antworten auf diese

${ }^{466}$ L. S. Boswell, Rural Communisme, 1988, S. 456, 459ff., 463; J. Defrasne, Le pacifisme en France, 1994, S. 90, 92, 97.

467 ADC 1 M 68: Unterpräfekt an Präfekten, Brive, 18. 11. 1925.

${ }^{468}$ ADC 1 M 76: Präfekt an Innenminister, 2. 10. 1934; 1 M 68: Präfekt an Innenminister, 15. 4. 1935; 1 M 68: Präfekt an Innenminister, Tulle, 13. 3. 1925.

${ }^{469}$ ADC 1 M 70: Unterpräfekt an Präfekten, Brive, 2. 8. 1933.

470 ADC 1 M 68: Unterpräfekt an Präfekten, Brive, 31. 8. 1927.

471 ADC 1 M 76: Präfekt an Innenminister, Tulle, 23. 3. 1935.

472 Paul Vaillant-Couturier hatte 1925 in der Humanité einen Appell an die Einberufenen gerichtet und sie aufgerufen, nicht zu desertieren, da man ohne Armee keine Revolution machen könne. Vgl. N. Faucier, Pacifisme et antimilitarisme dans l'entre-deux-guerres, 1983, S. $57 \mathrm{f}$.

${ }^{473}$ ADC 1 M 68: La riposte des biffins du 126ème Régiment d'Infanterie, no 1, avril 1931.

${ }^{474}$ ADC 1 M 68: Präfekt an Innenminister, Tulle, 8. 4. 1935.

475 Vgl. etwa den Bericht über eine Veranstaltung mit dem Regimentsarzt Queuille, der seine Pflicht an der Front erfüllt habe, in: La Montagne Corrézienne, 1.5. 1932. 
Fragen versprachen ${ }^{476}$, nicht wer mit militärischen Titeln prahlte ${ }^{477}$. Dafür sorgte neben den Frontkämpfer- und Agrarverbänden ein ganzes Netz pazifistischer Organisationen von der Republikanischen Jugend bis zu den Jungen Pazifisten, vielfach von den corrézischen Lehrern geknüpft, die bis in die Dörfer hinein die thematischen Schwerpunkte in der politischen Diskussion setzten ${ }^{478}$. Darüber hinaus war der Pazifismus auch in den älteren politisch mentalitätsprägenden Organisationen wie den Freimaurerlogen, der Menschenrechtsliga, den Gewerkschaften oder den laizistischen Freundeskreisen im Vorfeld der Schulen einflußreich $^{479}$. Uniformierte Kampfverbände, die das politische Leben militarisierten, konnten auf diesem Boden - in Konkurrenz zu den dominierenden AC-Organisationen - kaum gedeihen, auch wenn sie in anderen Regionen Frankreichs vor allem in der Krise seit 1934 eine gewisse Rolle spielten ${ }^{480}$.

\section{Militarismus und Webrverbände in Westmittelfranken}

Sowenig Chancen paramilitärische Verbände in der Corrèze nach dem Weltkrieg hatten, so sehr florierten sie in der Weimarer Republik, und für den Westen Mittelfrankens galt dies besonders. Die nach 1870/71 entstandenen klassischen Veteranenorganisationen verloren demgegenüber an Bedeutung, blieben aber ein so ubiquitäres Phänomen, daß ohne sie der „Militarismus der ,kleinen Leute “ “481 auf dem Land ebensowenig zu verstehen wäre wie die Geschichte der darauf gründenden Wehrverbände selbst. In den Kriegervereinen, seit 1899 in der föderativen Zentralinstanz des Kyffhäuserbundes reichsweit zusammengeschlossen, hatte sich der Glaube an die ewige Gültigkeit militärischer Ordnungsprinzipien mit betont nationalen Empfindungen nachgerade „zu einem spezifischen Lebensstil vereint, der meist behäbig-gemütlich unter der alten Regimentsfahne an den Stammtischen provinzieller Wirtshäuser gepflegt wurde ${ }^{\star 4882}$.

Hinter der Fassade ländlicher Beschaulichkeit verbarg sich schon vor 1914 ein latent politisches Denken, das die Normaltemperatur des deutschen Nationalbewußtseins an der Euphorie der Reichsgründungszeit 1870/71 maß, infolgedessen das allgemeine nationale Empfinden stets in Gefahr sah und danach strebte, es immer wieder zu heben ${ }^{483}$. Daneben spielte die Frage nach der Moralität des Krieges eine wichtige, aber wechselnde Rolle. Die zeitweilig stärker sozialdarwinistischen Begründungen des Krieges als Grundlage menschlicher Existenz und die Über-

476 Vgl. die Analyse des Vorwahlkampfes und der Chancen eines von Frontkämpfern unterstützten Kandidaten in: ADC 3 M 198, Unterpräfekt an Präfekten, 21.11.1927.

477 Vgl. ADC 3 M 198: Unterpräfekt an Präfekten, 2. 1.1928 (auf dem Schriftstück ist irrtümlicherweise das Datum 2.1.1938 vermerkt).

${ }^{478}$ Vgl. etwa ADC 1 M 76: Unterpräfekt an Präfekten, 30. 3. 1934 (Bericht über die auf einem corrézischen Dorf stattfindende Generalversammlung der Jungen Pazifisten), oder L'Effort républicain, 20. 4. 1924 (Rede des Vorsitzenden der Republikanischen Jugend): „Wir haben alle eine tiefe Abneigung gegen den Krieg ..."

479 J. Defrasne, Le pacifisme en France, 1983, S. 98.

${ }^{480}$ Zur Entwicklung während der Krise der Dritten Republik in den 1930er Jahren vgl. die Darstellung unten im sechsten Kapitel (III.5.).

${ }^{481} \mathrm{Vgl}$. Th. Rohkrämer, Der Militarismus der „kleinen Leute“, 1990.

${ }^{482}$ V. R. Berghahn, Der Stahlhelm, 1966, S. 5.

${ }^{483}$ Th. Rohkrämer, Der Militarismus der „kleinen Leute“, 1990, S. 193. 
zeugungen von der Unausweichlichkeit des baldigen Kampfs um Deutschlands „Platz an der Sonne“ wichen im Verlaufe des Krieges ab 1914 wieder einer mehr moralisierenden Haltung, die den Gegner schlicht als böse, die eigene Seite als gut interpretierte. Im Bewußtsein eines gerechten Krieges hielten die KyffhäusserVerbände den deutschen Pazifismus damals für einen Ausdruck moralischer Dekadenz; er symbolisierte für sie gleichermaßen die Zersetzung der soldatischen Tugenden von Tapferkeit und Pflichterfüllung wie den „jämmerlichen weibischen Zug" der neuen Zeit ${ }^{484}$.

Die Erfahrungen des Weltkriegs, der Revolution und der innenpolitischen Entwicklung seit 1918 vermochten der nationalistisch-militaristischen Vorstellungswelt der Kriegervereine nichts anzuhaben. Bis ans Ende der Weimarer Republik bedeutete das deutsche Vaterland für sie „die höchste Ehre“; hier lebte schließlich „das kulturfähigste, bisher moralisch gesündeste, geistig hochveranlagte, wehrhafte und friedfertigste Volk der Erde“, dem man, „wenn es sein muß, mit dem Tode“, zu dienen entschlossen war. Unter Rekurs auf die sozialdarwinistischen Tendenzen von vor 1914 bejahte der Kyffhäuserbund „das Naturgesetz des ewigen Kampfes“ als gesundes Prinzip „völkischen Opfersinns“. In der Verewigung des Status quo durch den Pazifismus erblickte er dagegen eine rückschrittliche „feige Lebensauffassung “485. Die schon im Kaiserreich vertretene standes- und konfessionenübergreifende Gemeinschaftsideologie der Kyffhäuservereine hatte sich in der „Frontgemeinschaft“ des Krieges verdichtet und wurde nun dem Weimarer Parlamentarismus als ideales Gesellschaftsmodell entgegengehalten. Aus der Frontkameradschaft sollte gleichsam die „Volkskameradschaft" erwachsen ${ }^{486}$.

Daraus erhellt, daß viele Soldaten auch in den Jahren nach 1918 mental im Kriegszustand verharrten, nachdem der Frieden von Versailles den politischen Vorstellungen, für die sie seit 1914 gekämpft hatten, so diametral widersprach. Mochte der französische "poilu“ nach dem Sieg von 1918 in den Schrecken des Krieges doch einen Sinn sehen, wenn jetzt nur endgültig die Befestigung des für Frankreich günstigen Friedens gelang, so scheinen sich die deutschen Soldaten vielfach auf weitere Kämpfe eingestellt zu haben, damit die Jahre von 1914 bis 1918 für sie nicht sinnlos blieben, sondern letztlich noch in einem „Endsieg“ ihre Rechtfertigung fanden. „In Wahrheit ist der Krieg noch nicht beendigt und damit noch nicht verloren "487, so brachte ein fränkischer Nationalsozialist 1922 eine Stimmung auf den Begriff, die zweifelsohne weit über die NS-Bewegung hinausging.

Zur Verhärtung dieser Denkpositionen trug die jahrelang prekär bleibende, im Ruhrkampf gipfelnde außenpolitische Konstellation ebenso bei wie die Erinnnerung an die bürgerkriegsähnlichen Auseinandersetzungen im Inneren, die die Deutschen und besonders die Bayern unmittelbar im Anschluß an den Waffenstillstand erlebt hatten. Gleich nach der Niederschlagung der Räterepublik Mitte 1919 begann der organisatorische Zusammenschluß der bestehenden lokalen

${ }^{484}$ Ebd., S. 250, $256 \mathrm{ff}$.

${ }^{485}$ Die Zitate aus der Kyffhäuserpresse nach K. Führer, Der Deutsche Reichskriegerbund Kyffhäuser, 1984, S. 65 f.

${ }^{486}$ Ebd., sowie Th. Rohkrämer, Der Militarismus der „kleinen Leute“, 1990, S. 206.

${ }^{487}$ R. Hambrecht, Der Aufstieg, 1976, S. 15. 
Volkswehrgruppen zu einer bayerischen Einwohnerwehr unter Forstrat Georg Escherich $^{488}$. Der Forstrat stützte sich vor allem auf das konservative Land und kooperierte im evangelischen Franken eng mit der $\mathrm{BMP}^{489}$ und dem Bund der Landwirte ${ }^{490}$. So war etwa der Oberdachstetter Brauereibesitzer Gabriel Haag als Gauleiter der Einwohnerwehren mit Aufklärungsversammlungen so überlastet, $\mathrm{daß}$ er nicht an der Landesversammlung des BdL teilnehmen konnte ${ }^{491}$. In der bald "sehr wichtigen Frage der Erhaltung der Einwohnerwehren" verlangte der BdL 1920 von der bayerischen Regierung „bestimmt“, daß sie die von den Siegermächten verlangte Auflösung "unter allen Umständen ablehnt“, da Bayern sonst „dem Bolschewismus unrettbar verfallen müßte ${ }^{\text {«492 }}$.

Die staatlichen Behörden selbst hatten zum Schutz vor den Räterevolutionären im April 1919 in nahezu allen Gemeinden Westmittelfrankens aus ortsansässigen Zeitfreiwilligen eine „Militär-Landpolizei“ organisiert, an die allein im Bezirksamt Uffenheim 1200 Gewehre ausgegeben wurden. Auch die Finanzierung der Einwohnerwehren - im „Gau Neustadt a. d. Aisch - Scheinfeld“ 120 Ortswehren mit 4000 Wehrmännern - übernahmen teilweise die Gemeinden. Obwohl die - nicht selten vom fränkischen Adel geführten - Einwohnerwehren bis zu ihrer erzwungenen Auflösung 1921 nur einmal während des Kapp-Putsches zur Sicherung einer Bahnlinie aufgeboten wurden, kann ihre Bedeutung für den fortgesetzten Militarismus kaum überschätzt werden. Die noch dazu mit Hilfe von kommunaler Verwaltung und Reichswehr aufgebauten paramilitärischen Organisationen knüpften ein Netz kameradschaftlicher Kontakte und brachten große Bestände an Militärwaffen unter die Bevölkerung, die nicht alle wieder eingezogen werden konnten. Die Wehrverbände und später die SA bauten hier auf ${ }^{493}$.

Die erzwungene materielle Abrüstung zunächst der Reichswehr, dann auch noch der Einwohnerwehren beantwortete ein erheblicher Teil des Landvolks in Westmittelfranken mit geistiger Aufrüstung. Die einfachen Mitglieder der Kriegervereine "glaubten wohl mit geringerer Stringenz und Intensität ${ }^{\text {‘494 }}$ an Vaterland und Volksgemeinschaft als ihre Verbandsfunktionäre und -redakteure, doch waren Nationalismus und Militarismus zumindest unterbewußt zentrale Bestandteile ihrer Weltanschauung und Identität, die sie vor Ort in Festen und Feiern, Versammlungen und Beerdigungen ein ums andere Mal zum Ausdruck brachten. Einem verstorbenen Königsulanen in Großhaslach rief sein Militär- und Kampfgenossenverein nach, er sei „bis an sein Lebensende von militärischem Geist be-

${ }^{488} \mathrm{Vgl}$. D. J. Large, The Politics of Law and Order, 1980; H. Nußer, Konservative Wehrverbände, 1973 (zu Escherich Bd. 1, S. 17-74), sowie die ebenso umfassende wie apologetische frühe Darstellung von R. Kanzler, Bayerns Kampf gegen den Bolschewismus, 1931, v. a. S. 9-51.

${ }^{489}$ Der Gauhauptmann der Einwohnerwehren für Dinkelsbühl-Wassertrüdingen, Frhr. v. Süßkind aus Dennenlohe, war zeitweilig auch Vorsitzender der 70 Mitglieder starken BMP-Ortsgruppe Wassertrüdingen; der Rothenburger Gauhauptmann, General v. Staudt, war ebenfalls BMP-Mitglied. Vgl. J. Striesow, Die Deutschnationale Volkspartei, 1981, S. 590.

$490 \mathrm{Vgl}$. das Schreiben Escherichs an Weilnböck, in: IfZ Schober, MS 28, 74, sowie B. Steger, Berufssoldaten oder Prätorianer, 1980, S. 124f.

491 BAK NI Weilnböck, Nr. 49c, Gabriel Haag an Brügel, Abschrift, 14. 11. 1919.

${ }^{492}$ BAK NI Weilnböck, Nr. 14b: Undatierte BdL-Pressemitteilung (1920).

${ }^{493} \mathrm{Vgl}$. R. Hambrecht, Geschichte im 20. Jahrhundert, 1982, S. 382 f., sowie B. Steger, Berufssoldaten oder Prätorianer, 1980, S. $137 \mathrm{ff}$.

${ }^{494}$ So Th. Rohkrämer (Der Militarismus der „kleinen Leute“, 1990, S. 268) im Blick auf den Bezug der „kleinen Leute“ zu Kaiser, Reich und Armee in der Wilhelminischen Zeit. 
seelt" gewesen ${ }^{495}$. Und in den anderen Dörfern und Kleinstädten Westmittelfrankens wurde in den "Veteranen- und Kampfgenossenvereinen“ ebenfalls nicht nur „manches Kriegerlebnis wieder wachgerufen“, sondern auch am Ausbau der Ortsgruppen „in national-vaterländischem Geiste“ gearbeitet ${ }^{496}$.

Dies lag ganz auf der Linie, die die Bundesführungen in Berlin und München vorgezeichnet hatten: nämlich formell auf "parteipolitisch neutraler Grundlage“ zu agieren, schon um staatlich sanktionierte Kontakte mit der Reichswehr unterhalten zu können, aber gleichzeitig als „Verband nationalgesinnter ehemaliger Angehöriger des alten Heeres“ aufzutreten, der es selbstverständlich ablehnte, politisch linksstehende Vereine zu seinen Veranstaltungen einzuladen ${ }^{497}$. Als sich die „nationalen Kräfte“ im Volksbegehren gegen den Young-Plan 1929 erstmals zum Kampf gegen die Republik sammelten, wurde spürbar, wie schwer es der Führung des Kyffhäuserbundes fiel, wirklich neutral zu bleiben. Seinen Vereinen „als solchen", so die Parole, sei der Eintritt in die örtlichen Komitees des Volksbegehrens nicht gestattet, und die Funktionäre sollten sich ebenfalls zurückhalten, der Betätigung einzelner Mitglieder werde dadurch aber ,in keiner Weise vorgegriffen “498. Die Kompromißformel wird verständlich, wenn man bedenkt, daß sich das Volksbegehren gegen die „Große Koalition“ in Berlin richtete; an ihr war damals auch das Zentrum beteiligt, der Kyffhäuserbund hatte also Rücksicht auf seine Vereine in den katholischen Gegenden Deutschlands zu nehmen ${ }^{499}$.

Wie anders die Verhältnisse aber bei den Veteranenverbänden im protestantischen Westmittelfranken lagen, deren Mitglieder oft gleichzeitig den politisierenden Wehrverbänden angehörten ${ }^{500}$, zeigte sich erneut nach dem Treffen der „nationalen Opposition" in Bad Harzburg im Oktober 1931. Auf zahlreichen Herbstversammlungen erörterten die Kriegervereine nun eingehend die Frage ihrer Stellung zur NSDAP. Obwohl dabei nach wie vor jede parteipolitische Bindung der Kriegervereine abgelehnt wurde, war doch zu erkennen, daß ein großer Teil der Vereine aus den protestantischen Gemeinden des Bezirks „nicht übel Lust hätte, sich in die Harzburger Front einzufügen "501. Ob dies noch überwiegend auf die Nähe zu den Deutschnationalen, nicht schon zur NSDAP zurückzuführen war, fiel immer schwerer zu beurteilen. Den militärischen Vereinen Windsheims jedenfalls genehmigte der Stadtrat eine öffentliche Versammlung „Für Deutschlands Freiheit und Sicherheit“ im Januar 1932 nur mit der bezeichnenden Auflage, den NSDAP-Politiker Stegmann keinesfalls auftreten zu las$\operatorname{sen}^{502}$.

An der Bedeutung des Kyffhäuserbundes für den Weg in die Diktatur besteht kein Zweifel. Er war mit 29000 Vereinen und über zwei Millionen Mitgliedern im

495 Fränkische Zeitung, 7. 10. 1932.

${ }^{496}$ Ebd., 25. 1. 1933 (Leutershausen); 20. 10. 1932 (Petersaurach); hierzu auch das Protokollbuch des Frontkriegerbundes im GA Petersaurach, B 29a.

${ }^{497}$ Vgl. die Erklärung des Bayerischen Kriegerbundes im Fränkischen Kurier, 8. 12. 1927, sowie

K. Führer, Der Deutsche Reichskriegerbund Kyffhäuser, 1984, S. 57.

${ }^{498}$ Ebd., S. 58, sowie Fränkische Zeitung, 19. 8. 1929.

${ }^{499} \mathrm{Vgl} \mathrm{C}$. J. Elliot, The Kriegervereine and the Weimar Republic, 1975, S. 118.

${ }^{500}$ Der Bayerische Stahlhelm, 1. 8. 1929.

${ }^{501}$ HStAM HMB, 19. 11. 1931.

${ }^{502}$ StA Bad Windsheim VII 65/2: Bescheinigung über die erfolgte Anmeldung einer öffentlichen Versammlung, 20.1.1932. 
Reich (davon 325000 in Bayern) der bei weitem größte Soldatenverband der Weimarer Republik ${ }^{503}$. Die Dichte seines - teilweise von Volksschullehrern geknüpften - organisatorischen Netzes noch in den bäuerlichsten Bezirksämtern Westmittelfrankens war beeindruckend ${ }^{504}$. So trugen die militaristischen und nationalistischen Denkkategorien der Kriegervereine ihren Teil dazu bei, daß die parlamentarische Demokratie vom Landvolk nicht akzeptiert wurde und daß es zunächst für die Agitation der politisierenden Wehrverbände, dann für nationalsozialistische Parolen anfällig werden konnte.

Begünstigt wurde der Gesinnungsmilitarismus in Deutschland obendrein durch einen - im Vergleich zu Frankreich - niedrigeren politischen Stellenwert der Kriegsopferversorgung. Während in Frankreich die entsprechenden Gesetze nach einer langen und emotionalen politischen Kampagne schließlich im Parlament strittig verabschiedet wurden, fehlten dem deutschen Reichsversorgungsgesetz, das auf Referentenentwürfe im Arbeitsministerium zurückging und in den letzten Sitzungstagen des Reichstags 1920 nach knapper allgemeiner Debatte beschlossen wurde, „der politische Atem und das politische Engagement ${ }^{\text {“505. Indem }}$ Regierung und Parteien die Militärversorgung lediglich als ein Verteilungsproblem verstanden, verwiesen sie die Kriegsbeschädigten auf die Rolle einer Interessenbewegung ohne eigene politische Identität, mit der Folge, daß ihre Verbände $\mathrm{zu}$ „unwirtlichen Vereinen " ${ }^{\text {"506 }}$ wurden, was immer sie im einzelnen für ihre Klientel erreichten.

Die französischen "mutilés" sahen sich indessen von einem eigenen Pensionsministerium und departementalen Zweigstellen der Versorgungsverwaltung als eine besondere soziale Gruppe staatlich angesprochen und auch als Wählerschicht mit hohem Symbolwert lebhaft umworben ${ }^{507}$. Obwohl ihre materielle Situation nicht schlechter war als die der deutschen Kriegsopfer, obwohl in beiden Ländern schon bald nach 1918 das soziale System der Fürsorge ausgebaut und ein Rechtsanspruch auf Unterstützung begründet worden war, standen die „bred-andbutter issues" bei den französischen Frontkämpferverbänden anhaltend im Vordergrund; in Deutschland war ihr (sozial-)politischer Sprengstoff offenbar viel geringer ${ }^{508}$ oder kam nicht zur Entladung, weil die größeren militärpolitischen Themen im Ergebnis des Versailler Vertrages dies verhinderten. Als im Gefolge der Weltwirtschaftskrise ab 1929 auch die Versorgung der Kriegsopfer prekärer wurde und manche Protestversammlung des vom Anspruch her neutralen „Reichsverbandes der Kriegsbeschädigten“ zu einer „Reklameversammlung für

${ }^{503}$ Hierzu K. Führer, Der Deutsche Reichskriegerbund Kyffhäuser, 1984, S, 57, sowie Fränkischer Kurier, 8. 12. 1927.

${ }^{504}$ Vgl. die Berichte in der Fränkischen Zeitung, 4. 5. 1928, 10. 9. 1929; demnach bestätigt sich der frühere Befund Th. Rohkrämers (Der Militarismus der "kleinen Leute“, 1990, S. 34 f.) insoweit, als die Vorsitzenden der Kriegervereine eher aus den höher gebildeten Schichten stammten; daß insgesamt Landwirte wegen Freizeitmangels in den Kriegervereinen unterrepräsentiert waren, läßt sich im Blick auf die kleinbäuerlichen Gegenden Westmittelfrankens nicht bestätigen.

${ }^{505} \mathrm{M}$. Geyer, Ein Vorbote des Wohlfahrtsstaats. Die Kriegsopferversorgung in Frankreich, Deutschland und Großbritannien, 1983, S. 255; vgl auch A. Prost, Die Demobilmachung, 1983.

${ }^{506}$ M. Geyer, Ein Vorbote des Wohlfahrtsstaats, 1983, S. 256.

${ }^{507}$ Ebd., S. $269 \mathrm{f}$.

${ }^{508}$ J. M. Diehl, Germany: Veteran Politics under Three flags, 1975, S. 151, 156, 169. 
die Nazi“509, war die Entwicklung der Vorjahre nicht mehr rückgängig zu machen. Die lange zufriedenstellend geregelte Fürsorge $e^{510}$ zu verdanken wesentlich der SPD und dem ihr nahestehenden "Reichsbund der Kriegsbeschädigten, Kriegsteilnehmer und Hinterbliebenen " - hatte den politischen Handlungsbedarf in den Augen der links und in der Mitte stehenden Veteranenverbände gelähmt und das Augenmerk der rechten Kräfte ganz auf ihre unbefriedigten ideellen Ziele gerichtet ${ }^{511}$. Dankbarkeit gegenüber den sozialen Leistungen der Republik stellte sich in diesen Kreisen nicht ein, statt dessen Ablehnung der neuen Staatsform, die sie mit den militärpolitischen Folgen des verlorenen Krieges identifizierten.

Neben dem als erniedrigend empfundenen Kriegsschuldartikel war es vor allem die in Versailles erzwungene Abrüstung auf ein 100000-Mann-Heer, die gravierende Folgen für die Mentalitäten zeitigte und alles Militärische nun stärker denn je zu einer Frage des nationalen Prestiges machte. Auch auf dem fränkischen Land gewann die arg zusammengeschrumpfte Armee noch an Geltung ${ }^{512}$. So wurden etwa Herbstmanöver der Reichswehr im Raum Ansbach-Dinkelsbühl-Gunzenhausen überall „freudigst begrüßt“. Ihre "große Anziehungskraft auf die weitesten Kreise der Bevölkerung" zeigte sich besonders bei Einquartierungen der übenden Truppe, die „große Begeisterung bei alt und jung“ auslösten und Klagen über Manöverschäden bei den Bauern kaum laut werden ließen ${ }^{513}$.

Die nicht zuletzt von der Literatengruppe um Ernst Jünger ausgehende, auch in einer Beilage der Stahlhelm-Zeitung verbreitete Hypostasierung des Krieges zur schicksalsmächtigen Naturerscheinung fand in Westmittelfranken offene Ohren. Überzeugt davon, daß das Fronterleben „Männer von Memmen, Kerle von Kreaturen, Helden von Händlern “514 schied, beließ man es nicht dabei, auch „die fröhliche Seite des Soldatenlebens im alten Heer vor dem Krieg “515 herauszustellen, sondern zeigte sich begeistert, wenn ein Offizier bei den Ehemaligen des $10 \mathrm{er}$ Infanterieregiments - als Einstimmung auf das Theaterstück „Andreas Hofer" die Einsätze im Weltkrieg schilderte. Die Lokalzeitung traf die verbreitete Mentalität mit der Formulierung: die Zuhörer „durften die schweren Kämpfe im Geiste durchleben "516. An der SA störte infolgedessen weniger ihr rabiates Auftreten, als daß sie an ihrem Ansbacher Gautag beim Fackelzug "militärische Pünktlichkeit“ habe vermissen lassen ${ }^{517}$. Und eine als „widerlich“ empfundene „Kriegskrüppelausstellung " im roten Nürnberg konnte man sich nur als Produkt sozialistischer Politik erklären ${ }^{518}$.

${ }^{509}$ Vgl. Fränkische Zeitung, 5. 9., 16. 9. 1929, 4. 10. 1932; Fränkische Tagespost, 2. 9. 1930 (Zitat), 19.4. 1932.

${ }^{510}$ Hierzu der Bericht über die Kriegsbeschädigtenversammlung in Merkendorf. Fränkische Zeitung, 18.5. 1928 .

511 Vgl. J. M. Diehl, Germany: Veteran Politics under Three flags, 1975, S. $149 \mathrm{f}$.

512 Zur kulturellen Bedeutung des Militärs im Bayern des 19. Jahrhunderts vgl. W. K. Blessing, Disziplinierung und Qualifizierung, 1991.

${ }^{513}$ HStAM HMB, 19. 9. 1930; Fränkische Zeitung, 22. 9. 1932.

${ }^{514}$ H.-J. Mauch, Nationalistische Wehrorganisationen, 1982, S. 97.

${ }^{515}$ Fränkische Zeitung, 1.2. 1933.

${ }^{516}$ Ebd., 17. 10. 1923.

517 Ebd., 28. 10.1929.

${ }^{518}$ Vgl. die Kontroverse zwischen Fränkischem Kurier und Fränkischer Tagespost, in: Fränkische Tagespost, 31. 12. 1918. 
Militärischer Geist herrschte auch in den fränkischen Landschulstuben und Pfarrhäusern. Als um die Jahrhundertwende im deutschen Kaiserreich die Obrigkeit den Volksschullehrern aus militärpolitischen Erwägungen die Laufbahn des Reserveoffiziers ermöglichte, nutzten in Bayern über $90 \%$ aller Pädagogen - fast doppelt soviel wie im Reichsdurchschnitt - die mit dem einjährig-freiwilligen Dienst verbundene Chance, zur „besseren Gesellschaft “ aufzurücken ${ }^{519}$. Pazifismus war für diese Lehrer kein Thema, nach 1918 kehrten viele als Leutnant oder Hauptmann aus dem Krieg zurück und brachten verstärkt militärische Umgangsformen in ihre Schulklassen hinein. Die für eine kirchenfromme Bevölkerung unerläßlichen theologischen Begründungen der deutschen Wehrhaftigkeit lieferten schließlich die protestantischen Pfarrer, so daß die spezifische Verbindung von Militarismus, Nationalismus und Religion über 1918 hinaus weiterwirken konnte ${ }^{520}$.

Das Beispiel der Lehrer und die Appelle der Pfarrer scheinen ihre Wirkung auf die mehrheitlich landwirtschaftliche Bevölkerung nicht verfehlt zu haben, die Haltung des Landbundes war jedenfalls ganz eindeutig ${ }^{521}$. Die „Wehrhaftmachung des deutschen Volkes" zählte auch zu den fünf Kernzielen der BLB-Nachwuchsorganisation, die Bewegung und Schießsport in ihrer Arbeit großschrieb ${ }^{\mathbf{5 2 2}}$. Auf den „Bundeskampfruf“: „Laßt kämpfen uns, laßt kämpfen. Macht blank das Schwert, macht blank den Pflug", nahmen die Bauernpolitiker in der Region nur zu gerne Bezug ${ }^{523}$, gingen sie doch davon aus, daß Wehrstand und Nährstand ein unzertrennliches Ganzes bildeten ${ }^{524}$ : „Neben dem Pfluge über die Scholle müsse der Wehrgedanke marschieren ..." ${ }^{525}$. Außerdem sahen sie in dem angestrebten größeren Volksheer den „besten Abnehmer für die Landwirtschaft “526, was die Bedeutung der Wehrfrage für sie noch erhöhte; und schließlich spielten nationalistische Überlegungen eine Rolle, d.h. die Erwartung, als Nation erst dann erneut Macht zu haben, "wenn das Eisen, das Gott wachsen ließ, wieder zum Schwert geschmiedet wird“. "Gegenüber der pazifistisch international eingestellten Weltanschauung, die nicht den deutschen Belangen Rechnung tragen will“, müsse man, so der Westheimer Landwirt und Reichstagsabgeordnete Bachmann, für ein freies, unabhängiges Vaterland eintreten ${ }^{527}$. Um die als notwendig erachtete "geschlossene Front gegen Marxismus-Internationalismus, Pazifismus und Separatismus“ zu errichten, appellierte der Landbund vor allem an die „Frontkämpfer: wacht auf" ${ }^{428}$.

${ }^{519}$ R. Bölling, Volksschullehrer und Politik, 1978, S. 26.

${ }^{520}$ Die Problematik des Militarismus in der westmittelfränkischen Pfarrer- und Lehrerschaft wird unten im Vierten Kapitel (II. Pfarrer - Lehrer - Republik) vertieft.

${ }^{521}$ Vgl. auch - mit ostelbischem Schwerpunkt - J. Flemming, Die Bewaffnung des Landvolks, 1979, S. 7-36.

${ }^{522}$ Die Ziele des Bay. Junglandbundes, Abschrift, Privatarchiv Trump.

${ }^{523}$ Vgl. z. B.: Der Bund der Landwirte in Bayern, 11. 11. 1923 (Brügel bei BdL-Versammlung in Ansbach).

${ }^{524} \mathrm{Vgl}$. die Rede des Deßmannsdorfer Bauernführers Arnold in: Fränkische Zeitung, 22. 2. 1933.

${ }^{525}$ So Stahlhelmführer Heiß in der Ansbacher Rezathalle auf einer BdL-Massenveranstaltung, als er beim Blick in die Reihen der Besucher erkannt haben wollte, wie viele Frontkämpfer „, heute wieder hinter dem Pfluge" stünden. Fränkische Zeitung, 8. 2. 1933.

${ }^{526}$ Fränkische Zeitung, 1. 3. 1933.

${ }^{527}$ Ebd., 15. 5. 1928.

${ }^{528}$ Der Bund der Landwirte in Bayern, 30. 3., 7. 12. 1924. 
Mit ihrem Gesinnungsmilitarismus standen die Bauern aber nicht allein; nicht nur in den Dorfschaften des Junglandbundes hatte man Mitte der 1920er Jahre verstärktes Interesse am Kleinkaliberschießen ${ }^{529}$, sondern auch andere "politisch eingestellte Vereine“ wie etwa der „Notbund Windsbach“ oder zahlreiche Reichsflaggen-Ortsgruppen hielten regelmäßige Schießübungen $\mathrm{ab}^{530}$. Die mittelfränkischen Katholiken schätzten es, wenn die "Christusjugend marschiert", und betonten (1932), daß die Bayernwacht immer noch stärker sei als die SA ${ }^{531}$. Die liberale DDP hielt es ebenfalls für werbewirksam, eine Versammlung in Weidenbach mit dem Hinweis anzukündigen, der Redner, Ritter von Rudolph, sei Inhaber der höchsten bayerischen Tapferkeitsauszeichnung, „des bayerischen Militär-MaxJosefsordens ${ }^{\text {"532. }}$. Überhaupt wurden sämtliche politische Fragen zunehmend in Begriffen des Kampfes gedacht. So erfreute sich der „Deutsche Kampfbund gegen die Kriegsschuldlüge" in der Region großer Beliebtheit; dem Bayerischen Ehrenausschuß gehörten selbstverständlich die fränkischen Bauernführer an, und auch der mittelfränkische Regierungspräsident unterstützte den Bund ostentativ mit einer „Kampfspende“533. Daß den Nationalsozialisten diese allgemeine Wertschätzung des Militärischen in Westmittelfranken entgegenkam, war offensichtlich. Im Kampf gegen die Regierung Papen stellten sie etwa eine Veranstaltung unter das Motto "Etappenbrüder gegen Frontkämpfer“ und verglichen „das große Erlebnis der Frontkämpfer mit den bescheidenen Eindrücken, die Papen und die um ihn Versammelten vom Kriege gewonnen hätten“"534.

Selbst in der SPD polemisierte man im Wahlkampf schon einmal gegen einen konservativen Politiker, der sich dem Kriegsdienst entzogen hatte ${ }^{535}$, unterschrieb an der Seite Bürgerlicher Werbeaufrufe für ein regionales Freikorps ${ }^{536}$ oder begeisterte sich für die "schneidigen Marschweisen“ einer Kapelle des Reichsbanners ${ }^{537}$. Der „Waffenmeister" der Reichsflagge in Gebsattel versteckte gar unter dem Fußboden seiner Wohnung „eine Anzahl Infanteriegewehre“ ${ }^{\text {“538. Allerdings }}$ ist nicht zu übersehen, daß die maßgeblich von der SPD betriebene Gründung des Reichsbanners Schwarz-Rot-Gold ${ }^{39}$, also faktisch einer sozialdemokratischen Variante des Wehrverbandes, auch in Westmittelfranken 1924/25 im wesentlichen nur eine Reaktion auf das seit Jahren bestehende Phänomen des Paramilitarismus

${ }^{529}$ StAN KdI, II, Nr. 687, Bayerischer Junglandbund, Nürnberg, an KdI, 10. 10. 1926.

${ }^{530}$ StAN KdI, II, Nr. 687, BA Ansbach, 31. 8. 1926, an KdI.

${ }^{531}$ Mittelfränkische Volkszeitung, 7. 7., 11. 7. 1932.

${ }^{532}$ Fränkische Zeitung, 25. 4. 1928.

${ }^{533}$ StAN KdI II, Nr. 2 (Deutscher Kampfbund gegen die Kriegsschuldlüge).

${ }^{534}$ Fränkische Zeitung, 13. 10. 1932.

${ }^{535}$ Fränkische Tagespost, 10. 12. 1918. Vgl. auch die spätere Kontroverse zwischen dem Rothenburger SPD-Ortsverein und dem Nationalsozialisten Stegmann, der auf einer Bauernversammlung 1931 behauptet hatte, die NSDAP-Reichstagsfraktion habe mehr als als doppelt so viele Frontkämpfer in ihren Reihen wie alle anderen Parteien zusammengenommen. 70 Prozent der männlichen Mitglieder der SPD-Fraktion, so die Replik der Sozialdemokraten, hätten „ihre militärische Pflicht während des Krieges erfüllt". Fränkischer Anzeiger, 6. 7. 1931.

${ }^{536}$ G. Gradenegger, Die Entwicklung der Rechtsparteien, 1973, S. 22.

${ }^{537}$ Vgl. den Bericht über die Kundgebung der Eisernen Front in Ansbach: Fränkische Tagespost, 23. 2. 1932.

${ }^{538}$ Fränkische Tagespost, 11. 4. 1932.

${ }^{539}$ Vgl. K. Rohe, Das Reichsbanner Schwarz Rot Gold, 1966; auch beim Reichsbanner wurde das Bekenntnis zum Wehrgedanken und die Kritik des Pazifismus bis Anfang der 30er Jahre immer deutlicher. Vgl. ebd., S. 182. 
bedeutete. Die SPD blieb doch auch die einzige, schwache Kraft in der Region sieht man von den Ansbacher Esperantisten einmal $a^{540}$-, die internationalistisches und pazifistisches Gedankengut kultivierte ${ }^{541}$. Militarismus erzeugte nach sozialdemokratischer Ansicht nichts weiter als tiefe Verbitterung und sei der Nährboden für neuen Volkshaß, wenn auch leider keine „spezifische Angelegenheit unserer Nation", wie z. B. die belgischen Besatzungssoldaten am Niederrhein demonstrierten, vor denen deutsche Zivilisten den Hut abzunehmen hätten ${ }^{542}$.

Mit ihrer überwiegend antimilitaristischen Haltung bewegten sich die Sozialdemokraten in Westmittelfranken weitab von der Hauptmasse, deren „Militärfrömmigkeit" ${ }^{453}$ schließlich am stärksten in den Wehrverbänden kondensierte. Diese waren den traditionellen Kriegervereinen zwar in vaterländischem Geist verbunden, doch konnten sie sich mit deren kontemplativer Militärnostalgie und formeller politischer Neutralität nicht recht anfreunden, sondern drängten stärker zur Tat; und als Freikorps und Einwohnerwehren Anfang der 1920er Jahre aufgelöst werden mußten, suchten sie nach neuen Formen soldatischer Politik. In Struktur und politischer Zielsetzung verwirrend vielfältig, schwankten die Wehrverbände meist zwischen völkisch-radikaler und nationalkonservativer Orientierung ${ }^{544}$; gemeinsam aber waren ihnen militärähnliche Organisationsstrukturen, hierarchische Gliederung, Befehl und Gehorsam, Führerprinzip, Uniformen, militärische Bewaffnung und Ausrüstung sowie nicht zuletzt Gewaltbereitschaft gegenüber dem politischen Feind ${ }^{545}$. Daneben prägte die Wehrverbände, in Franken nicht anders als im Reich, vor allem ein autoritätsgläubiger Hurra-Patriotismus, der ihren Mitgliedern „die Anpassung an das Leben einer demokratischen Republik unend-

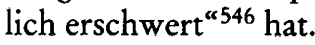

Nur von hier aus ist die politische Kultur in Westmittelfranken zu verstehen, wo unter den zahlreichen Wehrverbänden die Reichsflagge lange die dominierende Rolle spielte. Sie entwickelte sich aus dem „Bataillon Nürnberg“, das der noch zur Reichswehr gehörende Hauptmann Adolf Heiß im Frühsommer 1919 organisiert und in die Einwohnerwehr eingebracht hatte, um die rote Hochburg Nürnberg in Schach zu halten ${ }^{547}$. Die Reichswehr protegierte damals eine ganze Reihe neugegründeter rechtsgerichteter paramilitärischer Verbände, um im Falle von inneren Unruhen oder Grenzkonflikten nicht auf ihre eigenen schwachen Kräfte angewiesen zu sein. Nach Auflösung der Einwohnerwehren 1921 lehnte Heiß einen Anschluß an deren bayerisch-föderalistisch orientierte Nachfolgeorganisation ab. Vielmehr entwickelte sich die selbständig bleibende Reichsflagge

${ }^{540}$ Vgl. Fränkische Zeitung, 14. 9. 1929.

${ }^{541}$ Zum Pazifismus in der SPD vgl. auch K. Megerle, Element nationaler Integration und politischer Konsensstiftung?, 1990, S. 232.

${ }^{542}$ Fränkische Tagespost, 6. 12. 1918.

${ }^{543} \mathrm{G}$. Ritter, Staatskunst und Kriegshandwerk, 1960, S. $123 \mathrm{ff}$.

${ }^{544}$ Zur Typologisierung der Wehrverbände und generell zur Klassifizierung der „nationalen“ Verbände vgl. A. Klotzbücher, Der politische Weg des Stahlhelm, 1964, S. XIIIf.

${ }^{545} \mathrm{Zu}$ den Kennzeichen paramilitärischer Verbände vgl. W. E. Williams: Paramilitarism in Inter-State Relations, 1965.

${ }^{546}$ V. R. Berghahn, Der Stahlhelm, 1966, S. 6; vgl. auch A. Klotzbücher, Der politische Weg des Stahlhelm, 1964, S. XIII.

${ }^{547} \mathrm{Vgl}$. hierzu und zum folgenden R. Hambrecht, Der Aufstieg, 1976, S. 15 ff., H. Fenske, Konservatismus und Rechtsradikalismus, 1969, S. $166 \mathrm{f}$. 
unter dem - wie es hieß „tüchtigen“ - Hauptmann Heiß zu einem „Wehrverband reinster Prägung“, „aktivistisch, kampffreudig und waffengeschult“, dessen „innere Geschlossenheit und militärische Tauglichkeit" unter den bayerischen Organisationen „ihresgleichen suchte "548. Da Heiß seinen Dienstsitz in Nürnberg hatte, wurde in erster Linie Mittelfranken zum Einzugsgebiet der Reichsflagge, die in Nordbayern 1923 etwa 12000 Mann stark gewesen sein soll.

„In fast allen Orten und Dörfern“ Westmittelfrankens unterhielt der Wehrverband Ortsgruppen, „insbesondere die landwirtschaftliche Bevölkerung “ schloß sich - unter den wohlwollenden Blicken des Landbundes - der Reichsflagge an ${ }^{549}$. In den Bauerndörfern der alten Rothenburger Landwehr wie Adelshofen oder Insingen gehörte ihr jeder dritte Mann an, allein in ihrem kleinen Hesselberger Bezirk hatte sie 300 Mitglieder, in der 4000-Einwohner-Stadt Dinkelsbühl $200^{550}$. Nicht nur in der einstmals freien Reichsstadt, deren Bürgermeister im Ehrenamt Reichsflaggenführer war, profitierte der Wehrverband von der Sympathie der nationalkonservativ gestimmten Honoratioren, sondern auch auf dem flachen Land. So berief in Habelsee der Bürgermeister selbst die Gründungsversammlung ein. Am Hesselberg war es der Dennenloher Baron von Süßkind, andernorts ein aus dem Krieg als Reserveoffizier zurückgekehrter Landarzt oder Apotheker, aber auch einmal ein „besserer“ Landwirt, der die Initiative ergriff ${ }^{551}$.

Die Ortsgruppen beließen es nicht dabei, an vaterländischen Abenden nationale Theaterstücke $\mathrm{zu}$ inszenieren ${ }^{552}$, vielmehr trugen sie mit ihren häufigen Geländeübungen und Gepäckmärschen ${ }^{553}$ zur Militarisierung des regionalen Alltags bei. Immer wieder kam es an den Punkten mit sozialdemokratischer Präsenz zu Krawallen zwischen Reichsflagge und „Arbeiterjugend“554. Über die Schießübungen der Reichsflagge im Steinachtal waren die wenigen Rothenburger Kommunisten so beunruhigt ${ }^{555}$, daß sie bei größerer Stärke wohl tatsächlich die für notwendig erachteten „Abwehrhundertschaften“ (zusammen mit der USP) gebildet hätten ${ }^{556}$. Als in der aufgeladenen Stimmung nach dem Hitlerputsch die Reichsflagge ihre Mitglieder in dem Arbeiterdorf Schopfloch von einem bevorstehenden proletarischen Überfall bedroht wähnte, marschierte sie „unter Gewehr" in den Ort ein. Der örtliche Arbeitersekretär hielt schon die wenigen einheimischen Reichsflaggenleute für eine Provokation; statt des angekündigten „Blutvergießens“ endete die Auseinandersetzung aber lediglich in einem wilden Handgemenge und 17 Verhaftungen ${ }^{557}$.

${ }^{548}$ H. Fenske, Konservatismus und Rechtsradikalismus, 1969, S. $166 \mathrm{f}$.

${ }^{549}$ HStAM HMB, 20. 6. 1923; vgl. auch StAN Rep. 218, Nr. 584.

${ }^{550}$ StAN Rep. 218, Nr. 583. Pol. Nü-Fü, Mitgliederstärken von Parteien und Verbänden Mitte der 1920er Jahre.

${ }^{551}$ StAN Rep. 218, Nr. 391, Gend. Hartershofen an BA Rothenburg, 1. 6. 1923; KdI, II, Nr. 248, BA Dinkelsbühl, 15. 5. 1923, an Reg. von Mfr.; Gespräche mit F. Trump und A. Kolb; I. Metzner, Der Aufstieg, 1981, S. 8f., 75.

552 Fränkische Zeitung, 10. 1., 3. 11. 1923.

${ }^{553}$ HStAM HMB, 19. 10. 1926, 6. 10. 1927.

${ }^{554}$ Ebd., 20. 3. 1923, 5. 12.1923.

${ }_{555}$ I. Metzner, Der Aufstieg, 1981, S. 75.

${ }^{556}$ StAN Rep. 218, Nr. 391, Stadtrat Rothenburg an Reg. von Mfr., 16. 5. 1923.

${ }^{557}$ Fränkische Zeitung, 24. 11. 1923. 
Fast bis in die Tage des Hitlerputschs hinein arbeitete die Reichsflagge auch mit der NSDAP zusammen, vor allem seit der Ruhrkampf „alle vaterländisch Gesinnten aufgerüttelt" und die radikalsten Wehrorganisationen in einer lockeren „Arbeitsgemeinschaft der vaterländischen Verbände" bayernweit vereinigt hatte ${ }^{558}$. Höhepunkte dieser letztlich auf einen politischen Umsturz abzielenden Kooperation waren die gemeinsame Sonnwendfeier auf Burg Hoheneck 1923 und der Deutsche Tag Anfang September 1923 in Nürnberg mit dem festeren Zusammenschluß zum „Deutschen Kampfbund “559. Auch Reichsflaggenredner in der westmittelfränkischen Provinz schwadronierten nun öffentlich über den Marsch auf Berlin und bewegten sich eine Zeitlang "ganz in Mussolinischen Gedankengängen. Demnächst ginge es los, ... wer sich den Verbänden nicht anschließe, werde Gewalt spüren" ${ }^{660}$. Derart eingestimmt, standen Teile der Reichsflaggenbasis nach dem Bekanntwerden der Münchner Vorgänge im November 1923 bewaffnet und marschbereit ${ }^{561}$.

Einsatzbefehle von Heiß allerdings blieben aus, da dieser sich gerade noch rechtzeitig im Oktober gegen Hitler und für den etwas gemäßigteren Generalstaatskommissar Kahr entschieden hatt ${ }^{562}$, so daß die Reichsflagge nach dem gescheiterten Putsch von der Verbotskrise der Völkischen profitieren konnte und immer stärker zu einer DNVP-nahen nationalkonservativen Vereinigung wurde $^{563}$ : monarchisch, antisemitisch, anti-ultramontan, antisozialistisch, in bezug auf den Versailler Vertrag scharf revisionistisch und reaktionär darauf aus, die Bismarcksche Reichsverfassung wiederherzustellen. Die politische Ideologie mit ihrer Polemik gegen die schwarz-rot-goldenen Farben „der Deserteure und Meuterer “564 war in Verbindung mit paramilitärischer Aktivität in Westmittelfranken so attraktiv, daß die Reichsflagge - im Zeichen der gepanzerten Faust und der schwarz-weiß-roten Fahne - jahrelang sogar der nationalsozialistischen SA vielerorts das Wasser abgrub ${ }^{565}$.

Mit dem in den Hitler-Putsch verstrickten und daraufhin verbotenen Bund Oberland war die Reichsflagge Ende 1923 auch ihres einzigen ernsthaften Konkurrenten unter den Wehrverbänden ledig, der ihr vorher in einigen Bezirken

${ }^{558}$ Vgl. H. Fenske, Konservatismus und Rechtsradikalismus, 1969, S. $188 \mathrm{ff}$.

${ }^{559} \mathrm{StA}$ Bad Windsheim LR I/1/2: Kurzgefaßter Entwurf zu einer Parteigeschichte der NSDAP im Kreisabschnitt Windsheim (ohne Seitennumerierung).

${ }^{560}$ HStAM HMB, 5. 1. 1923.

${ }^{561}$ R. Hambrecht, Der Aufstieg, 1976, S. 56.

562 Die Polizeidirektion Nürnberg-Fürth attestierte Heiß, gegen den der Oberreichsanwalt wegen Hochverrats ermittelte, „bei und nach den Vorgängen des 8./9. 11 (1923) eine durchaus staatstreue

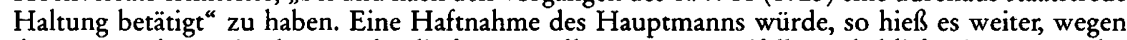
dessen Ansehens ,in der vaterländischen Bevölkerung ... zweifellos erhebliche Störungen der öffentlichen Ruhe hervorrufen“. Pol. Nü-Fü, 3.6. 1924, an „Herrn Oberreichsanwalt“", in: StAN Pol. Nü-Fü, Nr. 953; H. Fenske, Konservatismus und Rechtsradikalismus, 1969, S. 215; zur völkischen Kritik vgl. die Polemik von H. Preiß, Die Anfänge der völkischen Bewegung, 1937, S. 87 f.

${ }^{563}$ Nur ein kleiner Teil der Mitglieder mochte diese Entwicklung nicht mitvollziehen und spaltete sich als Alt-Reichsflagge ab, um „den deutsch-völkischen Gedanken mehr im nationalsozialistischen Sinne betonen" und sich vom Generalstaatskommissar weiter distanzieren zu können. Vgl. HStAM HMB, 5. 1. 1924.

${ }^{564}$ Fränkischer Kurier, 10. 1.1929; Bayerische Volkszeitung, 7. 2. 1929.

${ }^{565}$ R. Hambrecht, Der Aufstieg, 1976, S. 102 f.; IfZ Epp-Papers MA 144/5: Reichsflagge, Grundlagen und Ziele; sowie die Denkschrift "Unsere Organisation“, Mittelfranken, 12.2. 1922, Bl. 93799391, 9579-9604. 
Westmittelfrankens, besonders im Süden zwischen Dinkelsbühl und Weißenburg, arg zugesetzt hatte. Denn auch „Oberlands Stärke“ lag in seinen „dortigen Bau-

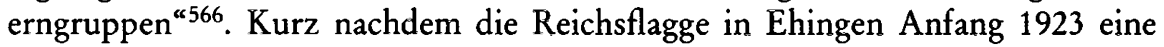
Ortsgruppe gegründet hatte, beraumte der Bund Oberland eine eigene Veranstaltung an, wozu alle Bürger "mit Ausnahme von Juden, Kriegsgewinnlern, Schiebern und Wucherern" eingeladen waren. Angesichts der organisatorischen Zersplitterung der ideologisch verwandten Wehrverbände klagte der Bürgermeister: „... man wisse jetzt wirklich nicht mehr, wo ein und wo aus. Die jungen Leute auf

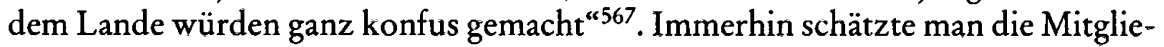
derzahl des Bunds Oberland im benachbarten Städtchen Wassertrüdingen (1600 Einwohner) auf 250, im angrenzenden Bezirksamt Gunzenhausen auf 600-700568. Wie schwer es der Reichsflagge fiel, sich durchzusetzen, wenn eine Ortsgruppe des Bundes Oberland - schwarz-weiß-rot mit Edelweiß - unter einer schlagkräftigen Führung agierte, zeigte sich in Schillingsfürst, wo die Reichsflagge keine zwei Dutzend Anhänger um sich scharte, während der spätere NS-Landtagsabgeordnete Otto Roth schon seit 1922 „alle völkisch gesinnten Volksgenossen“ in einer Ortsgruppe des Bundes Oberland sammelte ${ }^{569}$.

Aus dem Freikorps Oberland hervorgegangen, das bei der Niederwerfung der Münchner Räterepublik und in Oberschlesien eingesetzt war, vereinigte der Bund Oberland von Anbeginn sehr heterogene, bürgerliche, soldatische und jugendbewegte Strömungen ${ }^{570}$. Einige Mitglieder kamen vom Sozialismus her und entwickelten sich in nationalbolschewistischer Richtung ${ }^{571}$; die Masse der westmittelfränkischen Bündler aber stand parteipolitisch irgendwo zwischen Deutschnationalen und Nationalsozialisten, mancher stärker auf eine Partei hin orientiert, mancher im Niemandsland. Der aktive Kreisleiter von Mittelfranken-Süd, ein Westheimer Dorfschullehrer, wird etwa als „jugendlicher Schwärmer" charakterisiert, zwar von "glühender Vaterlandsliebe und bestem Wollen beseelt", aber „politisch ... unreif und urteilslos" $" 572$.

Bemerkenswert und ebenfalls kennzeichnend für einen idealistischen Grundansatz war das soziale Engagement des Bundes für seine arbeitslosen Mitglieder in der Wirtschaftskrise von 1923. Dabei sollte „jeder Oberland-Bauer und Gütler“, welche schon früher "große Opferwilligkeit bewiesen“ hatten, „einen unverschuldet arbeitslosen Kameraden den Winter über auf seinen Hof" nehmen. Denn ein Mann, so die Überlegung, konnte im Winter selbst in kleinen Betrieben zur Arbeit gebraucht und als Gegenleistung mitverpflegt werden ${ }^{573}$. Generell schlossen sich die „kleinen unter den Bauern, die Gütler“, dem Bund Oberland „am verständnisvollsten“ an, aber auch die Arbeiter „aus den kleinen, der Großstadt noch ferne

${ }^{566}$ StAN KdI, Abg. 1968, II, Nr. 248: Oberland e.V. an von Kahr, München, 24. 10. 1923.

${ }^{567}$ HStAM HMB, 5. 1. 1923, 5. 3. 1923.

${ }^{568}$ StAN Rep. 218, Nr. 583, Pol. Nü-Fü, Mitgliederstärken von Parteien und Verbänden.

${ }^{569}$ Die Entwicklung der NSDAP im Kreis Rothenburg ob der Tauber, in: Fränkischer Anzeiger, 3. 11. 1937.

${ }^{570}$ H. Fenske, Konservatismus und Rechtsradikalismus, 1969, S. $159 \mathrm{ff}$.

${ }^{571}$ H. J. Kuron, Freikorps und Bund Oberland, 1960, S. 191 ff. H. Fenske, Konservatismus und Rechtsradikalismus, 1969, S. $248 \mathrm{f}$.

${ }^{572}$ StAN KdI, Abg. 1968, II, Nr. 248: „Vormerkung“ in Sachen Lehrer Voginauer, Ansbach, 22. 2. 1924.

${ }^{573}$ StAN KdI, Abg. 1968, II, Nr. 248: Oberland e.V. an von Kahr, München, 24. 10.1923. 
liegenden Landstädten “; während die größeren Landwirte und insgesamt die etabliertere ältere - deutschnationale - Generation den tendenziell radikalvölkischen Bestrebungen des Bundes eher mißtrauten ${ }^{574}$.

Es war kein Zufall, daß die Mehrzahl der 1000 Personen, die im März 1923 die erste NS-Versammlung in Gunzenhausen besuchte, dem Bund Oberland angehörte ${ }^{575}$. Die Schillingsfürster „Oberländer“ lösten sich ganz „von den Deutschnationalen" und überführten im Oktober 1925 die komplette Ortsgruppe in die neu gegründete $\mathrm{SA}^{576}$. Im Verbandsblatt „Das Dritte Reich“, redigiert von dem "geistigen Vorkämpfer" ${ }^{\text {" }} 77$ des Bundes, Gustav Sondermann aus Westmittelfranken, war klargestellt, daß ideenmäßig „uns die nationalsozialistische Bewegung besonders nahe" stehe. "Gemeinsames Schicksal in schwerer Zeit", also das Verbot beider Organisationen nach dem November-Putsch 1923, wirkte zusätzlich verbindend ${ }^{578}$. Nur in den kleinstädtischen Ortsgruppen, so scheint es, überwog das deutschnationale Element, so daß die Ansbacher Bündler ganz zum DNVPnahen Stahlhelm übertraten ${ }^{579}$, während die „im Bund Oberland getarnt gewesenen Nationalsozialisten “ Windsheims sich 1930 „dort abzweigten“ und auch formell NSDAP-Mitglied wurden ${ }^{580}$.

Bei allen parteipolitischen Gegensätzen einte die Mitglieder des Bunds Oberland eine gemeinsame Mentalität, zu deren wichtigsten Elementen Militärfrömmigkeit, Nationalismus und Antisemitismus gehörten. Das 1925 an der Ipsheimer Oberland-Hochburg aufgeführte Festspiel "Arnold von Hoheneck" hatte „bei einer ausgesprochen nationalen Tendenz" einen so starken „völkischen und judenfeindlichen Einschlag“, daß die in diesen Fragen keineswegs zimperliche Regierung von Mittelfranken dem Protest jüdischer Kreise stattgab und die bereits erteilte Genehmigung zum Besuch des Theaterstücks durch Schulkinder wieder zurückzog ${ }^{581}$. Ähnlich reserviert zeigten sich die Behörden hinsichtlich der „militärischen Übungen“, die nach der Wiederzulassung des Bundes im Februar 1925 , teils als Wanderungen oder Märsche getarnt, durchgeführt wurden ${ }^{582}$. Auch auf der Ostertagung, so meldete der Regierungspräsident im April, „soll viel exerziert worden sein"; sogar am Ostersonntag übten die Führer, darunter viele ehemalige Offiziere, in geschlossenem Verband auf einem Gelände hinter der Burg, und abends wurde ihnen, soweit sie noch nicht vereidigt waren, „das Gelübde durch Handschlag und Berührung der Fahne" abgenommen ${ }^{583}$.

Daß der Bund Oberland nach der Aufhebung des Verbots dennoch nicht wieder zu alter Stärke zurückfand, hatte mehrere Gründe. Zum einen war die

${ }^{574}$ Kritische Bemerkungen und Vorschläge zur völkischen Bewegung (Eine Denkschrift), von G. Sondermann, 21. 2. 1925, in: IfZ MA 1292 35/700, S. 20.

575 HStAM HMB, 20. 3. 1923.

${ }^{576}$ Die Entwicklung der NSDAP im Kreis Rothenburg ob der Tauber, in: Fränkischer Anzeiger, 3. 11. 1937.

577 HStAM MA 101238/1.

578 Das Dritte Reich, 15. 3. 1927.

${ }^{579}$ HSt AM HMB, 19. 1. 1931.

${ }^{580}$ StA Bad Windsheim LR I/1/2: Kurzgefaßter Entwurf zu einer Parteigeschichte der NSDAP im Kreisabschnitt Windsheim (ohne Seitennumerierung).

${ }^{581}$ HStAM HMB, 4. 7. 1925.

${ }^{582}$ StAN Reg. von Mfr., KdI, Abg. 1968, II, Nr. 685: BA Uffenheim an Reg. von Mfr., 15. 5. 1925.

${ }^{583}$ HStAM HMB, 20. 4. 1925. 
NSDAP nach der Schlappe der Reichspräsidentenwahl 1925 bemüht, ein schärferes Eigenprofil zu gewinnen und sich von den ganzen vaterländischen Organisationen einschließlich der Wehrverbände deutlicher abzugrenzen; die dennoch anhaltenden, aber einseitigen Freundschaftsbezeugungen seitens des Bundes wirkten deshalb anachronistisch. Außerdem zog sich der Oberland-Führer Friedrich Weber 1927 aus der Politik zurück, um eine Arztpraxis aufzubauen; die schon vorher begonnene Wandlung des Bundes in einen romantisch-intellektuellen Diskussionszirkel mit immer weniger national- und immer mehr sozialrevolutionärer Tendenz verstärkte sich nun, und je weiter gleichzeitig der „reale Wehrgedanke“ in den Hintergrund trat, desto mehr verlor der Bund Oberland in Westmittelfranken an Breitenwirkung ${ }^{584}$. Sondermann hatte schon 1925 jene kritisiert, die sich in ihrer Militärbegeisterung wirklich einbildeten, „schon Soldaten zu sein, wenn sie ein paarmal eine Windjacke anhatten und ein Gewehr sahen"; dagegen sei die Reichswehr der einzig bedeutende Waffenträger. Wer so dachte, dem genügte es wohl nicht, nur den „Gedanken an die Würde und Verantwortlichkeit des Kriegerkleides“ 585 wachzuhalten oder sich turnerisch zu betätigen. Und schließlich fanden viele in den Sturmabteilungen der NSDAP, bei dem alten Oberländer und späteren fränkischen SA-Gruppenführer Stegmann, was sie in ihrem Bund immer schmerzlicher vermißten ${ }^{586}$.

Von Anfang an war Oberland mit seiner überkonfessionellen Ausrichtung und seinem über Mittelfranken hinaus auch stark ins Altbayerische reichenden Einzugsbereich dem regionalen Milieu weniger gut angepaßt gewesen als die Reichsflagge $e^{587}$. Aber auch diese verlor in der Konsolidierungsphase nach dem Sommer 1924, als die Zeit des Putschismus und der Psychose von 1923 allmählich vorüberging ${ }^{588}$ und die rechtsgerichtete BVP/DNVP/BBB-Regierung in Bayern „strikt auf Loyalität" der vaterländischen Organisationen drang, an politischem Gewicht. Das neue "friedliche Nebeneinander" der Wehrverbände war bald von ständigen Versuchen begleitet, den schleichenden Bedeutungsverlust durch einen Zusammenschluß aufzuhalten ${ }^{59}$. Daß dieser lange nicht zustande kam, hat die wachsende „Interesselosigkeit des Bürgertums“ an den Wehrverbänden ebenso verstärkt wie die Abwanderung der jüngeren Generation, die, wo nicht schon in

${ }^{584}$ R. Hambrecht, Der Aufstieg, 1976, S. 101 f., H. Fenske, Konservatismus und Rechtsradikalismus, 1969, S. $248 \mathrm{f}$.

${ }^{585}$ Kritische Bemerkungen und Vorschläge zur völkischen Bewegung (Eine Denkschrift), von G. Sondermann, 21. 2. 1925, in: IfZ MA 1292 35/700, S. 10, 17.

${ }^{586}$ Neben Stegmann kamen eine ganze Reihe prominenter Nationalsozialisten in den fränkischen $\mathrm{Be}-$ zirksämtern, so etwa auch der Dinkelsbühler Kreisleiter Ernst Ittameier, vom Bund Oberland. Vgl. R. Hambrecht, Der Aufstieg, 1976, S. 427. Ab 1931 verstärkte die „große Mehrheit der Oberländer" die Reihen der NS-Bewegung. Vgl. H.-J. Mauch, Nationalistische Wehrorganisationen, 1982, S. 69.

${ }^{587}$ Daran vermochten auch die wenigen sächsischen und württembergischen Einheiten der Reichsflagge nichts zu ändern; vgl. J. M. Diehl, Paramilitary Politics in Weimar Germany, 1977, S. 232. Vielmehr war die Selbststilisierung der Reichsflagge als Brücke zwischen den vaterländischen Kräften Bayerns und des übrigen Reichs ein charakteristischer Topos des fränkischen Regionalismus.

588 Ähnlich hatte es Jungdo-Hochmeister Arthur Maraun formuliert. Vgl. HStAM MA 101238/2, Lagebericht Nr. 127/II 28, 2. 4. 1928.

${ }^{589}$ Vgl. H. Fenske, Konservatismus und Rechtsradikalismus, 1969, S. 246. 
der SA, dann in den großen Rahmenorganisationen der Sport- und Schützenverbände genügend Gelegenheit zur Betätigung fand ${ }^{590}$.

Dem „dauernden Abbröckeln besonders der ländlichen Mitglieder“ versuchte die Reichsflagge mit ihrem Dinkelsbühler Wehrsporttag im September $1927 \mathrm{zu}$ begegnen; doch als die "Wiederbelebung der stark zurückgegangenen fränkischen

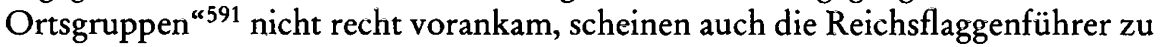
der Erkenntnis gelangt zu sein, daß die Zeit der "Soldatenspielerei“ und des "Landsknechtstums" endgültig überholt sei. Die - jedenfalls im Vergleich zu früher - „eingezogene Nüchternheit in der politischen Denkweise" sowie "die immer zwingendere Notwendigkeit, nunmehr auch positive Ergebnisse an Stelle der bisherigen negativen Kritiken den Anhängern vorzuweisen“, bewirkte einen langsamen Klimawandel hin zum "bewußt politischen"592.

Die regionale Begrenztheit der Reichsflagge erwies sich in dieser Situation als nachteilig, da eine irgendwie bedeutendere nationalpolitische Rolle mit den fränkischen Kräften allein nicht zu spielen war. Nach langem Schwanken und dem Scheitern einer bayerischen Arbeitsgemeinschaft der vaterländischen Verbände entschloß sich die - auch finanziell in Schwierigkeiten geratene - Reichsflagge endlich im Herbst 1927 zum Anschluß an den politisch schlagkräftigsten soldatischen Verband im Reich: den von Magdeburg aus geführten, aber auf die föderalistische Sehnsucht seines bayerischen Landesverbandes immerhin Rücksicht nehmenden Stahlhelm ${ }^{593}$. Dieser hatte mit der Parole "Hinein in den Staat" im Oktober 1926 die erfolgreichste Antwort auf die alle Wehrverbände beschäftigende Frage gefunden, wie sich paramilitärisches Machtpotential in ruhigeren Zeiten in politischen Einfluß umsetzen ließe; dabei ging es nicht um Zusammenarbeit zum Wohle der Republik, sondern um deren Durchdringung und Wandlung zum

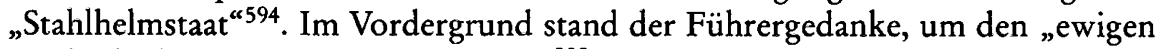
Wechsel“ der Regierungen zu beenden ${ }^{595}$. Der Anschluß der Reichsflagge an den Stahlhelm „als geschlossene Formation unter Wahrung ihrer Selbständigkeit" war um so leichter möglich, als zwischen den „Kampfgenossen aus großem Krieg und stürmischer Nachkriegszeit“ seit Jahren "herzliche Freundschaft" bestand; beide erstrebten die ,innere und äußere Befreiung unseres Vaterlandes“, beider Endziel war "das Großdeutschland“, und beides waren „straffe, scharf durchdisziplinierte Organisationen " 596 .

Der bisher in Bayern und Franken relativ schwach vertretene Stahlhelm begann seitdem „allmählich an Boden zu gewinnen " ${ }^{\text {c97 }}$. Von der schon länger bestehenden Ortsgruppe in Ansbach aus kam es in den Jahren 1928 bis 1932 in ganz Westmittelfranken zu einer Serie von Neu- bzw. Umgründungen unter der Bezeichnung

${ }^{590}$ HStAM MA 101238/2, Lagebericht Nr. $127 /$ II 28, 2. 4. 1928, sowie Lagebericht Nr. 138/II 28, 15. 12.1928.

${ }^{591}$ HStAM MA 101238/2, Lagebericht Nr. 127/II 28, 2. 4. 1928.

592 HStAM MA 101238/2, Lagebericht Nr. 138/II 28, 15. 12. 1928.

${ }^{593}$ Ebd.

${ }^{594}$ Vgl. H.-J. Mauch, Nationalistische Wehrorganisationen, 1982, S. 66; V. R. Berghahn, Der Stahlhelm, 1966, S. 103; HStAM MA 101237/2.

595 So der mittelfränkische Stahlhelm-Stabschef Dechant. Fränkische Zeitung, 1. 2. 1933.

${ }^{596}$ Der Bayerische Stahlhelm, 1.11. 1927.

${ }^{597}$ HStAM MA 101237/2 (Bericht über Deutschen Tag des Stahlhelm in Ansbach). 
„Reichsflagge im Stahlhelm"598. An der Gauführerbesprechung in Ansbach im Dezember 1928 hatten bereits 23 lokale Vorsitzende aus der ländlichen Umgebung teilgenommen ${ }^{599}$; bis in die kleinsten, nur wenige hundert Einwohner zählenden Dörfer hinein reichte das Netz der Ortsgruppen. Landwirte stellten vor allem, aber nicht nur hier, den Führer. Insgesamt deckten Vorstände und Mitglieder des Stahlhelm das soziale Spektrum der Provinzgesellschaft nahezu in seiner ganzen Breite ab. In der Führung der Ortsgruppen waren - wie schon in der alten Reichsflagge - neben den Landwirten die Handwerksmeister und Volksschullehrer besonders vertreten, in den Kleinstädten und auf Bezirksebene vor allem auch Ärzte, Apotheker, Studienräte und Landadel. Unter den einfachen Mitgliedern überwogen „Bauern und Bauernburschen “600.

Denn die Aktivitäten des mitgliederstarken Wehrverbandes ${ }^{601}$ waren eng auf die mentalen Bedürfnisse der ruralen Klientel zugeschnitten und aus dem provinziellen Alltag bald nicht mehr wegzudenken. So gab es Werbeabende mit vaterländischen Theaterstücken ${ }^{602}$, in Ansbach eine eigene Stahlhelm-Frauengruppe, die sich dem Thema Segelfliegen widmete ${ }^{603}$, und vor allem in den größeren Ortsgruppen entstanden auch Stahlhelmkapellen, die nicht nur bei den Verbands-Versammlungen in Erscheinung traten, sondern den „Rhythmus vergangener Zeiten, der nun im Stahlhelm seine Wiedererstehung feiert" ${ }^{\text {"604 }}$, landauf, landab bei den Heimatfesten immer wieder werbend in Erinnerung riefen ${ }^{605}$. Ein Vikar, der die Posaunen des Kirchenchores der Stahlhelmkapelle vorenthalten wollte - ,aus diesen Posaunen kämen nur kirchliche Töne ${ }^{\prime 606}$-, war keineswegs repräsentativ für die Einstellung der Pfarrerschaft, die statt dessen nur zu gerne bei den massenhaft besuchten Feldgottesdiensten des Stahlhelm zelebrierte ${ }^{607}$.

Schließlich gründete der Stahlhelm „nicht auf rein verstandesmäßigen Erwägungen“, sondern schöpfte „seine Wurzeln und seine Kraft aus dem christlichen Glauben“. Ganz im Gegensatz zur wachsenden "Gottlosigkeit" in der deutschen Jugend der Weimarer Zeit forderte auch die Nachwuchsorganisation des Wehrverbandes gleich im ersten ihrer „10 Jungstahlhelm-Gebote“: „Sei ein gläubiger und kämpfender Christ. Die göttliche Kraft wird nur in dem Kämpfenden leben-

${ }^{598}$ Auch Prinz Wilhelm von Preußen, Gastredner bei der Weihnachtsfeier des Ansbacher Stahlhelm 1928, mahnte, die Einigung der rechtsstehenden Verbände sei ein Gebot der Stunde. HStAM HMB, 19. 12. 1928.

${ }^{599}$ Fränkische Tagespost, 18. 12. 1928.

600 Vielleicht gehörte es sogar zum Erfolgsrezept des mittelfränkischen Stahlhelm, daß die "geistige Veranlagung" seines Führers, des Ansbacher Regierungsassistenten Saumweber, nach einem internen Bericht als „nur für ländliche Bevölkerung ausreichend“ eingeschätzt wurde. BAP 61 Sta 1 Landesverband Bayern, 68: Geheimer Bericht an den Ersten Bundesführer über dic Inspektionsreise vom 25. Sept. bis 5. Oktober (1932) im Großgau Franken/Landesverband Bayern, sowie Bl. 179 ff. (Neue Ortsgruppen); Der Bayerische Stahlhelm, 5. 10., 27. 10, 20. 12. 1928, 1. 12. 1929; Fränkische Zeitung, 21. 11. 1929; HStAM HMB, 4. 4. 1929, 6. 3. 1930.

${ }^{601}$ Für die Ortsgruppen Wassertrüdingen und Lichtenau ließen sich in den genannten Archivalien Zahlen ermitteln. Danach gehörten dort - bei einer Einwohnerzahl von 1660 bzw. 930 Seelen - 100 bzw. 90 mehrheitlich junge Männer dem Stahlhelm an.

${ }^{602}$ Fränkische Zeitung, 28. 10. 1932.

${ }^{603}$ Der Bayerische Stahlhelm, 16. 8. 1930.

${ }^{604}$ Fränkische Zeitung, 9. 2. 1933.

${ }^{605}$ Ebd., 13. 9. 1929 (Schillingsfürst).

${ }^{606}$ Gespräch mit A. Kolb.

${ }^{607}$ StAN Rep. 218, Nr. 953, Pol. Nü-Fü, Gend. Uffenheim, 19. 5. 1930. 
dig. ${ }^{4008}$ Zwar legte der Stahlhelm Wert auf überkonfessionelle Kameradschaft, wollte mit Kritik an "Rom“ nicht die katholische Kirche oder den Papst gemeint wissen, gab aber doch dem Zentrum wegen seiner rezidivierenden Bündnisse mit der SPD ganz offen eine Mitschuld an der "marxistischen Verseuchung“ Deutschlands ${ }^{609}$ und operierte so häufig mit Schlagwörtern wie "Ultramontanismus" und "Jesuitentum "610, daß sich der Wehrverband nahtlos in das nationalprotestantische Milieu Westmittelfrankens einfügte.

Angesichts seiner Beiträge zur biederen lokalen Festkultur darf nicht übersehen werden, welche Rolle das militärische Element in der Ideologie wie in den Aktionsformen des politisierten Wehrverbandes anhaltend spielte. $\mathrm{Zu}$ größeren Versammlungen in den Nachbarorten starteten die Stahlhelm-Ortsgruppen mit ihren „Motorstürmen“, beliebt waren auch Veranstaltungen „zum Gedenken an die deutsche Mobilmachung “ oder Filmvorführungen zum Weltkrieg, etwa über "Douaumont“, da dieser Tonfilm das "ungeheuere Weltbrandgeschehen “ in den Augen der Stahlhelmer ohne „sentimentale Manöverpoesie“ oder gar „pazifistisches Gesäusel“ darstellte ${ }^{611}$. Ludwig Quiddes Gesellschaft der Friedensfreunde galt schlicht als „eine Gruppe von Idioten“612, wollte sie doch angeblich das „Ehrbewußtsein des deutschen Volkes durch Verzicht auf Wehrrecht und Wehrwillen schwächen“; demgegenüber sagte der Stahlhelm "jeder Weichlichkeit und Feigheit" den Kampf an ${ }^{613}$.

Daß dies eben nicht nur die Sprache der höheren Verbandsfunktionäre war, sondern bis hinunter an die ländlichste Basis von Menschen, die sich als „Idealisten "614 verstanden, so empfunden wurde, wird exemplarisch an einem Gedicht deutlich, das ein 20-jähriger Jungstahlhelmer aus einer christlich-bäuerlichen, später zur Bekennenden Kirche haltenden Familie 1930 für einen Stahlhelmabend verfaßte: "Jungdeutschland soll leben im Sonnenschein, hat lange im Schatten gestanden/ wieder das erste der Völker sein und prachten in allen Landen/ wer will mit schaffen neue Bahn, wer will das Werk mit fassen an: hier ist Jungdeutschland! .../ Noch sind wir da, noch lebt unser Herz/ hart und gereinigt in Blut und Schmerz/ Wir leben und sterben für Deutschlands Tag/ wohl dem, der mit uns kämpfen mag: Für Deutschland. “615

Die Geschichte der mittelfränkischen Wehrverbände kann nicht hell genug beleuchtet werden, wenn man den Aufstieg des Nationalsozialismus in der Region verstehen will. Reichsflagge und Bund Oberland, später dann der Stahlhelm mobilisierten im Zeichen einer nationalistisch und religiös aufgeladenen Wehrutopie breite bäuerliche und bürgerlich-mittelständische Schichten in der Agrarpro-

${ }^{608}$ Der Bayerische Stahlhelm, 1. 7. 1930.

${ }^{609}$ Ebd., 1. 7., 17. 8. 1930.

${ }^{610}$ Nach Berghahn sah der Stahlhelm in der katholischen Kirche - neben Reichsbanner und Juden seinen wichtigsten Gegner. Vgl. V. R. Berghahn, Der Stahlhelm, 1966, S. 64, sowie W. Vogel, Katholische Kirche und nationale Kampfverbände, 1989, S. 27 f.

${ }^{611}$ Fränkische Zeitung, 3. 10. 1932, 9. 2. 1933; Der Bayerische Stahlhelm, 20. 8. 1929, 10. 1. 1931.

${ }^{612}$ Der Bayerische Stahlhelm, 15. 4. 1928.

${ }^{613}$ V. R. Berghahn, Der Stahlhelm, 1966, S. $105 \mathrm{f}$.

${ }^{614}$ Vgl. die fettgedruckten (!) „Gedanken eines Idealisten“ gegen den Young-Plan, in: Fränkische Zeitung, 19. 8. 1929.

${ }^{615}$ Gedicht "Jung-Deutschland" im Privatarchiv Kolb. 
vinz $z^{616}$ - und zwar für eine Entwicklung, von deren Ziel sie keine genaueren Vorstellungen hatten ${ }^{617}$. Aufgrund ihrer heterogenen Mitgliederstruktur trugen die Wehrverbände erheblich dazu bei, die Unterschiede zwischen Deutschnationalem und Nationalsozialistischem zu verwischen. Auch die Biographien führender NSDAP-Funktionäre in der Region, die in den Wehrverbänden begonnen hatten, belegen dies ${ }^{618}$.

Darüber hinaus verstanden es die Nationalsozialisten "meisterhaft", in die Organisationen der Kriegervereine „einzudringen“, auf die sie es - jedenfalls bis 1930 - von allen Verbänden „am meisten ... abgesehen“ hatten. In manchen Bezirken gelang es ihnen, die Kriegervereine zu „Zentralen der nationalsozialistischen Agitation" zu machen ${ }^{619}$. So war etwa der Gunzenhausener NSDAP-Bezirksleiter Appler auch Kreisführer des mittelfränkischen Frontkriegerbundes ${ }^{620}$.

Angesichts des völkischen Einflusses auf den Traditionsmilitarismus der Kyffhäuservereine kann für Westmittelfranken kaum von einer erst 1929 einsetzenden „Remilitarisierung der öffentlichen Meinung“ gesprochen werden, wie sie im Hinblick auf die nationale Diskussion konstatiert worden ist; vielmehr stießen hier schon lange vor der Gegenbewegung auf Erich Maria Remarques pazifistisches Buch „Im Westen nichts Neues“ die Überzeugungen des soldatischen Nationalismus auf Resonanz ${ }^{621}$. Den stärksten Impuls bezog der anhaltende Militarismus zweifelsohne aus dem nachkriegsdeutschen Nationalismus, der seinen Alptraum Versailles während der ganzen 1920er Jahre - von der Abtretung Oberschlesiens über den Ruhrkampf bis zum Young-Plan - ein ums andere Mal durchlitt. Nächst der Bibel muß der Vertrag von Versailles das verbreitetste und gelesenste Volksbuch der Deutschen sein, hatte es 1922 in einer Denkschrift des Jungdeutschen Ordens geheißen ${ }^{622}$. Daß es in Westmittelfranken tatsächlich dahin kam, zeigten nicht nur die stupenden Erfolge der großen Wehrverbände, sondern auch die unübersehbare Fülle kleinerer und kleinster Gruppen ähnlicher ideologischer Observanz, durch persönliche Ambitionen ihrer Führer zwar vielfach zersplittert, aber doch allesamt gespeist aus der einen großen Quelle des Hasses auf den Versailler Vertrag. Hierzu zählten der schwerpunktmäßig in Oberfranken aktive Jungdeutsche Orden ${ }^{623}$, der auch in den Landstädten Westmittelfrankens einige Ortsgruppen hatte ${ }^{624}$, ebenso wie der Deutschvölkische Schutz- und Trutzbund (bis 1923), Altreichsflagge, Bund Wiking, Blücherbund oder der Sturmtrupp „Frankenland“625, um nur einige Beispiele zu nennen.

${ }^{616}$ Vgl. H.-J. Mauch, Nationalistische Wehrorganisationen, 1982, S. 71.

${ }_{617}$ Vgl. L. Albertin, Stahlhelm und Reichsbanner, 1968, S. 461.

${ }^{618}$ R. Hambrecht, Der Aufstieg, 1976, S. 17.

${ }^{619}$ Fränkische Tagespost, 20. 8. 1930.

${ }^{620}$ A. Hinzmann, Entstehung und Entwicklung der NSDAP, 1982, S. 78.

621 W. Wette: Von Kellogg bis Hitler, 1980, S. 253, 256; K. Sontheimer, Antidemokratisches Denken, 1992, S. 94, 107; K. Prümm, Die Literatur des soldatischen Nationalismus, 1974.

${ }^{622}$ Vgl. K. Finker, Die militaristischen Wehrverbände, 1966, S. 363.

${ }^{623}$ Vgl. K. Hornung, Der Jungdeutsche Orden, 1959.

${ }^{624}$ StAN KdI, II, Nr. 684, Pol. Nü-Fü, 12. 8. 1924, an Staatsministerium des Inneren. Der Jungdo in Rothenburg - unter der Führung eines Apothekerassistenten - umfaßte etwa 35 Mann, spielte in der Region aber dann, wohl auch wegen seiner Versöhnungstendenzen Frankreich gegenüber und seiner Annäherung an die Weimarer Republik, keine Rolle mehr.

${ }^{625}$ HStAM HMB, 18. 5. 1923; StAN Rep. 218, Nr. 391, Gend. Hartershofen an BA Rothenburg, 1. 6. 1923. 
An Kriegerdenkmäler mit pazifistischer Aussage war in einem solchen Klima nicht zu denken ${ }^{626}$. Anders als in Frankreich, wo die Initiative zu den Mahnmalen stets von kommunalen Gremien ausging, gaben in Deutschland zumeist Regiments- und Kriegervereine ${ }^{627}$ oder auch die Kirchengemeinde den Anstoß. Im westmittelfränkischen Markt Berolzheim wurde Anfang der 1920er Jahre auf dem Dorfplatz vor der evangelischen Pfarrkirche ein Brunnendenkmal mit einer Achtecksäule errichtet, auf der ein Adler mit ausgebreiteten Schwingen eine Beute schlug, in Nennslingen war seit 1923 ein sich aufbäumendes Pferd zu sehen, dessen Reiter sein Schwert zog $^{628}$. Nationalistischer Heroismus, oft christlich verbrämt ${ }^{629}$, der die Niederlage verdrängte oder gar in einen Sieg umdeutete, herrschte also vor, demokratische Bekenntnisse waren nicht denkmalsfähig ${ }^{630}$. Charakteristisch hierfür wurde eine Auseinandersetzung in Rothenburg, wo die Sozialdemokraten vergeblich das Gefallenendenkmal in der alten Burg kritisierten, das für sie den "Geist des Kriegführens in Verbindung mit der Anrufung Gottes" verkörperte und geradezu "nach einem kommenden Kriege schreit" ${ }^{\text {“631. }}$.

Angesichts einer - in der nationalprotestantischen Provinz nur besonders ausgeprägten - nationalistisch-militaristischen Grundströmung blieb der Pazifismus in der Weimarer Republik so gut wie ohnmächtig. Selbst in den republikanischen Parteien war die in der Deutschen Friedensgesellschaft zentral organisierte Bewegung umstritten ${ }^{632}$. Obwohl sie sich vom Versailler Diktat distanzierte, wurde ihr das Vertragswerk von der Rechten ständig angelastet, die darin geradezu das Musterbeispiel pazifistischer Politik sah ${ }^{633}$. Demgegenüber traf für das siegreiche Frankreich spätestens in den frühen 1930er Jahren die Einschätzung des bekannten Friedenskämpfers Charles Richet wohl zu, daß Frankreich das am stärksten pazifistische aller Völker sei6 ${ }^{634}$. Der französische Pazifismus, zwar balkanisiert und zersplittert ${ }^{635}$, wirkte gesellschaftlich in die Tiefe, bedurfte der festen Organisation nicht einmal, sondern entwickelte sich seit Ende der 1920er Jahre - im gleichen Zeitraum, in dem die deutsche Friedensbewegung zerfiel ${ }^{636}-$ bis in die Provinz hinein immer mehr in Richtung auf einen „integralen“637, also kämpfe-

${ }^{626}$ In vergleichender deutsch-französischer Perspektive hierzu R. Koselleck, Zur politischen Ikonologie des gewaltsamen Todes, 1998.

${ }^{627}$ Vgl. etwa N. Ott, Wassertrüdingen unter Krone und Kanzler, 1987, S. 530.

${ }^{628}$ Mahnmale für den Frieden, 1988, S. 102 f., 116.

${ }^{629}$ Ein Anfang der 1920er Jahre bei der evangelischen Kirche in Meinheim errichtetes Denkmal trug z.B. die Aufschrift: „Niemand hat größere Liebe, denn die, daß er sein Leben läßt für seine Freunde. Joh. 15, Vers 13“. Mahnmale für den Frieden, 1988, S. 106.

${ }^{630}$ M. Jeismann/R. Westheider, Wofür stirbt der Bürger?, 1994, S. 29, 35; vgl. auch G. L. Mosse, Soldatenfriedhöfe und nationale Wiedergeburt, 1980, S. 241-261.

${ }^{631}$ Fränkische Tagespost, 15. 7. 1930.

${ }^{632} \mathrm{~K}$. Holl, Pazifismus in Deutschland, 1988, S. 148, 180.

${ }^{633}$ Ebd., S. 142; siehe auch den Bericht eines abtrünnigen Mitglieds der Deutschen Friedensgesellschaft, das bezeugte, daß der deutsche Pazifismus vom Ausland bezahlt werde, in: Der Bayerische Stahlhelm, 16. 8. 1930; auch Mosse sieht im Versailler Vertrag das große Hindernis für eine Zusammenarbeit von deutschen und französischen oder englischen Pazifisten. G. L. Mosse, Gefallen für das Vaterland, 1993.

${ }^{634} \mathrm{~N}$. Ingram, The politics of dissent, 1991, S. 3.

${ }^{635}$ Ebd., S. 2.

${ }^{636}$ K. Holl, Pazifismus in Deutschland, 1988, S. 189.

${ }^{637}$ Zur Prägung des Begriffs „integraler Pazifismus“ am Vorabend des Weltkriegs 1913 vgl. M. Dreyfus, Pacifistes socialistes et humanistes, 1988, S. 462; zum Stellenwert des Phänomens in der SFIO vgl. M. Bilis, Socialistes et pacifistes, 1979, S. $103 \mathrm{ff}$. 
risch-radikalen Pazifismus ${ }^{638}$. Dieser trug - maßgeblich von republikanisch-laizistischen Organisationen gefördert - einiges dazu bei, Frankreich vor den von rechts kommenden Erschütterungen der Demokratie zu bewahren. Nach 1933 dann vertraten gerade die integralen Pazifisten die nicht ganz falsche Ansicht, das deutsche Volk werde Hitler so lange folgen, bis endlich eine Revision des Versailler Vertrages stattgefunden habe ${ }^{639}$. Denn von den verbundenen geistigen Strömungen des Nationalismus und des Militarismus ging in Franken wie im gesamten Deutschen Reich tatsächlich mit der stärkste mentale Sog in Richtung Drittes Reich aus.

Gegen Tendenzen in der neueren Forschung, die zu sehr den in beiden Ländern vor 1914 allgemein verbreiteten „Folkloremilitarismus“ in den Blick nehmen ${ }^{640}$, sind grundlegende Entwicklungsunterschiede auch bereits in der Zeit vor dem Ersten Weltkrieg zu betonen. Wenn damals auf den Straßen Frankreichs dem Ruf „Vive l'armée“ von sozialistischer Seite entgegengehalten wurde „Vive la république“, während die deutsche Arbeiterbewegung "den unpolitischen Nimbus der nationalen Militärfeiern" weitgehend respektierte ${ }^{641}$, so hat dies mentalitätsgeschichtliche Erklärungskraft. Gewiß war später keine Nation imstande, der Brutalisierung der Politik nach dem Krieg völlig zu entgehen, politische Militanz und auch Kriminalität nahmen in weiten Teilen Europas nach 1919 sprunghaft zu, doch konnten die Siegernationen, anders als die Verlierer, den „Prozeß der Brutalisierung weitgehend oder gänzlich unter Kontrolle halten"642. Und eine Region wie die Corrèze blieb von der Militarisierung der politischen Kultur und schließlich bürgerkriegsähnlichen Auseinandersetzungen, wie sie Westmittelfranken in den letzten Weimarer Jahren erschüttern sollten, so gut wie ganz verschont, nicht zuletzt weil hier die traditionell andere Militärkultur Frankreichs besonders wirksam war.

Immer noch bemerkenswert scheinen in diesem Zusammenhang die zeitgenössischen Beobachtungen Friedrich Sieburgs, der den „unauslöschlichen $\mathrm{Haß}$ “ des Franzosen gegen den deutschen Militarismus damit erklärte, daß Uniformen, $\mathrm{Ka}$ sernenjargon und strammer Drill der individualistischen und humanistischen Auffassung von Menschenwürde zuwiderliefen: Niemals könne ein Franzose es fassen, „daß ein freier Mann Lust hat, sich mit Millionen in eine Einheitsfrisur zu teilen ..." ${ }^{643}$. Französische Deutschlandreisende registrierten umgekehrt, wie aus-

${ }^{638} \mathrm{Vgl}$. etwa die radikalpazifistische Massenversammlung in Limoges mit über 2000 Besuchern. N. Ingram, The politics of dissent, 1991, S. 14, 165; zu den pazifistischen Organisationen in Frankreich auch die Skizze bei M. Dreyfus, Pacifistes socialistes et humanistes, 1988, S. $465 \mathrm{ff}$.

${ }^{639}$ So Goulven-Mazéas in der pazifistischen Wochenzeitung La Patrie bumaine, 3. 11. 1933, zit. nach: F. Taubert, Das Deutschlandbild der französischen Linken, 1992, S. 338.

${ }^{640} \mathrm{~J}$. Vogel, Nationen im Gleichschritt, 1997, S. $275 \mathrm{ff} ., 288$. Allerdings ist dem Verfasser der anregenden komparatistischen Studie zuzustimmen, wenn er resümierend die These vom deutschen Sonderweg problematisiert und die „spezifischen Eigentümlichkeiten des republikanischen Frankreichs" unterstreicht. Ebd., S. 290.

${ }^{641}$ Ebd., S. 240 f., 255.

642 G. L. Mosse, Gefallen für das Vaterland, 1993, S. 195.

${ }^{643}$ Ein Pariser Briefträger an einem Sommertag böte, so Sieburg, „einen wahren Anschauungsunterricht. „Die Art, wie er die Uniform aufgeknöpft, die Mütze in den Nacken geschoben hat und die Hose über das höchst eigenwillige Schuhzeug hängen läßt, verrät den Stolz eines Menschen, der sich keinen Augenblick als einer von zehntausend Beamten fühlt, sondern sich immer seines unangreifbaren Privatlebens bewußt bleibt." F. Sieburg, Gott in Frankreich, 1932, S. $147 \mathrm{ff}$. 
geprägt das Standesbewußtsein der deutschen Offiziere im Vergleich zu dem der französischen war, wie sehr in den Städten die Uniform das öffentliche Leben prägte. Diese schon vor 1918 vorhandenen Unterschiede zwischen dem französischen Militärwesen - mit seinem bürgerlich-republikanischen Zug - und dem deutschen - mit seiner überwiegend antidemokratischen Richtung - haben sich in den 1920er Jahren eher noch verschärft ${ }^{644}$; denn der Schmerz der Niederlage überlagerte in Deutschland die Schrecken des Krieges und nährte einen „Militarismus der Besiegten", wohingegen in Frankreich die Leiden während der Jahre des Großen Krieges das Bewußtsein - bis hin zu einem „Pazifismus der Sieger" - viel stärker bestimmten. Welch bedeutende Rolle der Militarismus der Wehrverbände in Westmittelfranken für den Durchbruch des Nationalsozialismus, die pazifistische Mentalität für den Triumph der Volksfront in der Corrèze spielten, wird bei der Analyse der Staats- und Wirtschaftskrise später nochmals zu vertiefen sein.

\section{Landflucht, Großstadtfeindschaft und Modernisierungsskepsis}

Die verschiedenen Ausprägungen von Militarismus und Pazifismus, Konfessionalismus und Antiklerikalismus, völkischem und republikanischem Nationalismus verfestigten nach dem Weltkrieg die traditionellen Differenzen zwischen den Milieumentalitäten in Westmittelfranken und der Corrèze dergestalt, daß eigentlich gemeineuropäische Reaktionen der Provinz auf den Modernisierungsprozeß dort weiterhin so unterschiedlich verliefen, wie sie sich im 19. Jahrhundert herausentwickelt hatten. Dabei waren die Zweifel an der Identität von Landwirtschaft und Landleben, das Gefühl, der große Verlierer im Prozeß von Industrialisierung und Urbanisierung $\mathrm{zu}$ sein, in beiden Regionen anzutreffen. Auch vom konkreten Problem der anhaltenden Landflucht, das in Frankreich wie in Deutschland gleichermaßen zu den sichtbarsten Phänomenen des gesellschaftlichen Strukturwandels der Zwischenkriegsprovinz zählte ${ }^{645}$, waren Westmittelfranken und die Corrèze besonders betroffen.

In nur eineinhalb Jahrzehnten von 1921 bis 1936 sank die Einwohnerzahl der Corrèze um weitere $5 \%$, wobei die Binnenwanderung innerhalb des Departements vom flachen Land in die kleinen Städte und Marktflecken noch zu berücksichtigen ist ${ }^{646}$, die ausschließlich den vier verkehrsgünstig gelegenen Kantonen Egletons, Larche, Ussel und vor allem Brive ein Wachstum einbrachte, während die restlichen 25 Kantone abnahmen und vor allem die landwirtschaftlich ertragsschwächsten Gemeinden um Bugeat, Sornac und Meymac auf dem Plateau de Millevaches und in der Xaintrie zum Teil über 20\% ihrer Bevölkerung verloren. Von hier aus gingen tausende Corréziens in die Industriezonen nach Paris, Bor-

${ }^{644}$ So auch H. Kaelble in seinem Beitrag über „Die französische und die deutsche Gesellschaft 19181933: Zeit der Divergenzen“, der voraussichtlich München 2000 in dem vom Institut für Zeitgeschichte herausgegeben Sammelband „Demokratie in der Zwischenkriegszeit. Deutschland und Frankreich im Vergleich" erscheinen wird.

${ }^{645}$ Zur gesamteuropäischen Entwicklung: H. Haufe, Die Bevölkerung Europas, 1936.

${ }^{646} \mathrm{Vgl}$. M. Robert, Considération sur l'exode rural et le rôle des chefs-lieux de cantons, 1967. 
deaux, Clermont-Ferrand und Marseille, um dort, nun zunehmend auch in den Fabriken, Arbeit zu suchen ${ }^{647}$. Begleiterscheinungen dieser Entwicklung waren eine - durch extrem niedrige Geburtenraten noch verstärkte - Überalterung der Bevölkerung sowie das allmähliche Verschwinden von Landarbeitern und Zwergbauern und damit des landwirtschaftlichen Kleinstbesitzes ${ }^{648}$.

Verschiebungen des regionalen Altersaufbaus, Abwandern vor allem von Tagelöhnerfamilien und Handwerkern und eine erhebliche Abnahme der Kleinstbetriebe kennzeichneten zwar auch die Landflucht in Westmittelfranken ${ }^{649}$, doch wurden hier die Wanderungsverluste zwischen 1919 und 1933 durch die natürliche Bevölkerungsvermehrung so gut wie ausgeglichen ${ }^{650}$; die sogenannte Geburtenfrequenz lag in Westmittelfranken ca. $50 \%$ über der in der Corrèze ${ }^{651}$. Dies hatte zur Folge, daß die Einwohnerzahl in den Bezirksämtern bei kleineren Schwankungen (den stärksten Zuwachs erzielte das BA Uffenheim mit plus $2 \%$, am meisten verlor das BA Rothenburg mit minus $4 \%$ ) insgesamt so gut wie konstant blieb ${ }^{652}$, bedeutete aber nicht, daß das in Frankreich als "ruraler Exodus" benannte Problem in Deutschland, und speziell in der fränkischen Agrarprovinz, weniger gravierend gewesen wäre. Denn der Stellenwert der Landfluchtfrage für die politische Mentalität in Franken wie im Limousin ist wohl nicht zu verstehen, ohne die in Deutschland generell viel tiefer reichenden Strömungen der „Agrarromantik und Großstadtfeindschaft ${ }^{“ 653}$ vom 19. Jahrhundert her in den Blick zu nehmen.

\section{Deutsche Agrarromantik und französischer "Agrarismus“}

Als die Landflucht in Westmittelfranken so wie im ganzen Reich in den 1890er Jahren einen Höhepunkt erreichte, brach in Deutschland „fast schlagartig“654 eine breite Diskussion los ${ }^{655}$. Nicht nur die Wissenschaften, von der Nationalökono-

${ }^{647}$ La Corrèze de 1919 à 1939, 1986, S. 9; H. Thomas, La vie politique en Corrèze, 1984/85, S. 41; G. Dauger/D. Dayen, Histoire du Limousin contemporain, 1988, S. 120.

${ }^{648}$ L. Bournazel, Histoire d'Uzerche, 1987, S. 172; M. Robert, Les limousins des années trente, 1989, S. 83; G. Dauger/D. Dayen, Histoire du Limousin contemporain, 1988, S. 142; allgemein zur Migrationsproblematik in Frankreich vgl. D. Courgeau, Etude sur la dynamique, 1982; daneben P. E. Ogden/P. E. White, Migrants in modern France, 1989, besonders S. 1-59, sowie zeitgenössisch E. Verhaeren, Les campagnes hallucinées, 1893; J. Bertillon, La dépopulation de la France, 1911; L. Wuarin, La crise des campagnes et des villes, 1900; W. Grotkopp, Das Problem der Landflucht in Frankreich, 1938. Zum Limousin: J.-P. Larivière, La population du Limousin, 1975, sowie J. Bergonnier, Le canton de Seilhac (Corrèze). Aspects, causes et conséquences de l'exode rural, 1970.

${ }^{649}$ In ganz Deutschland wanderten vor allem aus kleinstbäuerlichen Gruppen in den Realteilungsgebieten wegen weitverbreiteter Unterbeschäftigung einzelner Familienmitglieder gerade in den Betrieben unter 10 ha viele ab. Vgl. F. W. Henning, Landwirtschaft und ländliche Gesellschaft in Deutschland, Bd. 2, 1978, S. 159.

${ }^{650}$ Zum Verhältnis von Landflucht und Geburtenrate in Deutschland und Frankreich vgl. P. Quante, Die Flucht aus der Landwirtschaft, 1933, S. $263 \mathrm{f}$.

${ }^{651}$ Verhältnis ermittelt aufgrund der Zahlenangaben in: ZBSLA 55 (1923), S. 92 f., sowie H. Bernhard, Landbauzonen, ländliche Entvölkerung und landwirtschaftliche Einwanderung in Frankreich, 1927.

${ }^{652}$ K. Seiler/W. Hildebrandt, Die Landflucht, 1940, S. 24, 36 ff., 49, 80.

${ }^{653} \mathrm{Vgl}$. K. Bergmann, Agrarromantik und Großstadtfeindschaft, 1970.

${ }^{654}$ Ebd., S. 33.

${ }^{655}$ K. Seiler/W. Hildebrandt, Die Landflucht, 1940, S. 23. 
mie bis zur Medizin, beschäftigten sich nun intensiv mit den Prozessen der Binnenwanderung und Verstädterung, auch Tages- und Traktätchenliteratur, agrarpolitische Reden und Schriften der gerade jetzt aus dem Boden schießenden Agrarverbände thematisierten - oft genug politisch-agitatorisch verzerrt, aber massenwirksam - den wirtschaftlichen und sozialen Strukturwandel. Angesichts des „eingeborenen Erdcharakters des deutschen Volkes“, den Julius August Langbehn 1890 reklamiert hatte, war es von Bismarck bis zum Bund der Landwirte Konsens, daß der Bauernstand als Rückgrat der Nation zu erhalten sei ${ }^{656}$.

Damit knüpfte man inhaltlich an den Agrarromantiker Wilhelm Heinrich Riehl an, dessen aus den 1850er Jahren stammendes CEuvre, vor allem „Land und Leute“ sowie „Die bürgerliche Gesellschaft", jetzt gleichsam „wiederentdeckt" wurde. Riehl, ein Schüler Ernst Moritz Arndts, hatte es mit einer Sprache von hoher Suggestivkraft verstanden, seine Ideen, nicht zuletzt auf Wandervorträgen vor Hunderttausenden von Menschen zu popularisieren und agrarkonservatives Denken bis weit in das 20. Jahrhundert hinein zu befruchten. Seine Großstadtfeindschaft resultierte wesentlich aus der Beobachtung, daß das traditionslose Proletariat als zentrale Kraft der gesellschaftlichen Bewegung fast ausschließlich in der Großstadt zu finden sei ${ }^{657}$. Von der Notwendigkeit „organischen “, langsamen Wachstums aus "natürlichen Bedingungen“ heraus überzeugt, erschien Riehl das explosionsartige Anwachsen der Großstädte künstlich und monströs, zumal er sie von arbeitsscheuen Existenzen, parasitären Luxusarbeitern, Spekulanten und Tagelöhnern bevölkert sah, die in der großen Stadt hofften ernten zu können, ohne gesät zu haben ${ }^{658}$. Wegen seiner weitreichenden Wirkung galt Riehl in Deutschland manchen als der ,ideologisch wohl bedeutsamste Antipode seiner Zeitgenossen Marx und Engels ${ }^{\text {"659, }}$, zeigte er doch auf seine Art, wie sich die von den Kommunisten geforderte soziale Revolution gemäß der Erkenntnis Georg Büchners verhindern lasse: „Mästen Sie die Bauern und die Revolution bekommt die Apoplexie.“660

Den Ansatz Riehls, das Bauerntum als politisches Gegengewicht zum typisch großstädtischen „socialistische(n) Geist der Gleichmacherei“661 zu erhalten, griff zu Beginn der 1890er Jahre vor allem Heinrich Sohnrey auf. Der ehemalige Dorfschullehrer wurde mit seiner 1893 begründeten Zeitschrift „Das Land“ zum auch von den Nationalsozialisten später offiziell geehrten - „Vater des deutschen Landvolkes"662. Da Sohnrey aus eigenem Erleben um den Einfluß von Pfarrern und Lehrern auf dem Lande wußte, sprach er diese lokalen Multiplikatoren, neben einem „willig hörenden“ bäuerlichen Leserkreis, mit seiner Zeitschrift zielgerichtet an und machte Front gegen die ausdrücklich als „Feind“ angesprochene Sozialdemokratie ${ }^{663}$.

${ }^{656}$ K. Bergmann, Agrarromantik und Großstadtfeindschaft, 1970, S. 33, 35.

${ }^{657}$ Ebd., S. $38 \mathrm{ff} ., 49$.

${ }^{658}$ W. H. Riehl, Land und Leute, 1854, S. 11, 75 f.; zur Kritik der Riehlschen Großstadtkritik vgl. H. P. Bahrdt, Die moderne Großstadt, 1961, S. 12 ff.

${ }^{659}$ K. Bergmann, Agrarromantik und Großstadtfeindschaft, 1970, S. 40; zur Bewertung Riehls jetzt auch kritisch Th. Fliege, Bauernfamilien zwischen Tradition und Moderne, 1998, S. 28-32.

${ }^{660} \mathrm{G}$. Büchner/L. Weidig, Der hessische Landbote, 1965, S. 81.

661 W. H. Riehl, Land und Leute, 1854, S. 9.

${ }^{662}$ K. Bergmann, Agrarromantik und Großstadtfeindschaft, 1970, S. $63 \mathrm{f}$.

${ }^{663}$ Ebd., S. $76 \mathrm{ff}$. 
Blickt man nach Frankreich, aus dessen „ewig eiternde(m) Geschwür“ (Paris) schon Riehl den Sozialismus vornehmlich hatte hervorgehen sehen ${ }^{664}$, so fällt auf, daß die Großstadtkritik hier deutlich schwächer ausgeprägt war ${ }^{665}$. Eine antimodernistische und naturromantische Jugendbewegung, eine industriekritische Heilpraktikerbewegung oder eine oft antistädtische Lebensreformbewegung, wie sie in Deutschland damals entstanden, fehlten in Frankreich fast völlig. Auch die Widerstandskraft gegen den partiell großstadtfeindlich begründeten Antisemitismus war im intellektuellen Leben Frankreichs stärker ${ }^{666}$. Und selbst der konservative Schriftsteller Gustave Le Bon richtete 1895 seine kulturpessimistische Deutung der Psychologie der Massen nicht explizit gegen die Stadt ${ }^{667}$. Die in Frankreich ohnehin ganz auf Paris konzentrierte Großstadtproblematik war während des 19. Jahrhunderts von Victor Hugo (Les misérables) bis Baudelaire (etwa: Le spleen de Paris) ziemlich ambivalent diskutiert worden ${ }^{668}$. Parallel dazu hatten Alfred Zola und Guy de Maupassant im Anschluß an Honoré de Balzac auch die Archaismen des Landlebens reflektiert, die Agrarprovinz als geschlossene Gesellschaft in ihren ungeschliffenen Manieren und rauhen Sitten geschildert. Erst nach der Jahrhundertwende zwischen 1900 und 1914 zeichneten die „romans rustiques" ein freundlicheres Bild der Bauernlandschaften. Ohne das rurale Leben notwendigerweise zu idyllisieren, vermittelten Eugène le Roy (Jacquou le Croquant) oder René Bazin (La terre qui meurt) weniger den Eindruck einer bedrohlichen als den einer bedrohten Welt auf dem Lande ${ }^{669}$.

Der Stadt-Land-Gegensatz wurde in Frankreich nicht nur insgesamt facettenreicher diskutiert, er war damit auch weniger ideologieanfällig als in Deutschland. So reichte die vergleichsweise gemäßigte Großstadtskepsis politisch von der französischen Linken bis zur Rechten ${ }^{670}$. Die Bedrohung des flachen Landes durch die Anziehungskraft der Stadt war für den konservativen Christen ebenso bedauerlich wie für den Sozialisten, der den Landflüchtigen nur eine Zukunft als ausgebeutete städtische Proletarier zu prophezeien vermochte, oder für den überzeugten Republikaner, der in der Agrargesellschaft einen Kraftquell der neuen Staatsgesinnung sah. Schließlich hatte kein Geringerer als Jules Ferry angesichts einer unabänderlichen politischen Fäulnis der Städte (1890) proklamiert: Unser Sieg wird auf dem Lande errungen, nicht in der Stadt ${ }^{671}$. Den von Maurice Agulhon konstatierten Konsensus des politischen Frankreich hinsichtlich der Stadt-LandProblematik $^{672}$ wird man aber gerade im Blick auf laizistische Traditionsräume wie die Corrèze insofern zu relativieren haben, als die - oben erwähnte - kirchli-

664 W. H. Riehl, Land und Leute, 1854, S. 75.

${ }^{665}$ Ralf Dahrendorf hat die Großstadtfeindschaft in den größeren Zusammenhang des Kulturpessimismus gestellt, der in Deutschland ein breiteres Echo gefunden habe als bei anderen Industrienationen. Vgl. das Vorwort R. Dahrendorfs in: F. Stern, Kulturpessimismus als politische Gefahr, 1963, S. IX.

${ }^{666}$ H. Kaelble, Nachbarn am Rhein, 1991, S. 35.

${ }^{667}$ A. Lees, Cities Perceived, 1985, S. 171.

${ }^{668}$ Ebd., S. 69 ff., 75, 81.

${ }^{669}$ P. Barral, Les agrariens français, 1968, S. $130 \mathrm{ff.;}$. P. Rémy, Les images de la paysannerie, 1977, S. $68 \mathrm{f}$; Histoire de la France rurale, Bd. 3, 1976, S. $489 \mathrm{f}$.

${ }^{670}$ Vgl. Histoire de la France rurale, Bd. 3, 1976, S. 489.

671 Ebd., S. 354.

672 Ebd., S. 489. 
che Propaganda gegen die Großstadt und ihre Versuchungen manche Bauern eher mißtrauisch machte. Wenn ein Landsmann, der in Holzpantoffeln und grobem Wollkleid nach Paris aufgebrochen war, in feinem Tuch und Lackschuhen zurückkehrte ${ }^{673}$, löste dies nicht nur Neidgefühle aus; vielmehr hatten die Menschen im Limousin aufgrund der älteren Tradition saisonaler Abwanderung oft seit langem ein ziemlich realistisches Bild von Vorzügen und Nachteilen des großstädtischen Lebens, und sie waren infolgedessen wohl schon vom Ansatz her etwas weniger anfällig für antiurbane Parolen als die Bauern im Fränkischen. Dort waren, sieht man von Sonderfällen wie Schopfloch einmal ab, zumindest bis zur Jahrhundertwende überwiegend ganze Familien ausgewandert, die danach kaum mehr Beziehungen zu ihrem Heimatdorf unterhielten ${ }^{674}$.

Zwar entfaltete sich auch in Frankreich am Ende des 19. Jahrhunderts eine Ideologie des "Agrarismus“, die der industriellen Welt neben den ernährungspolitischen Funktionen des Landes vor allem dessen hehre moralische Werte entgegensetzte $^{675}$ und die schichtenübergreifende Einheit des Landvolks proklamierte $^{676}$, zu einer konservativ geprägten Agrarromantik wie in Deutschland wuchs sie sich aber nicht aus. Der stärker politisch-ideologische, konservativantimarxistische Kern, den die Agrarromantik in Deutschland enthielt, erhärtete sich obendrein noch während des Ersten Weltkriegs in der Gleichsetzung von Landflucht und Fahnenflucht. Nicht nur die objektive Notwendigkeit der LandStadt-Binnenwanderung wurde also bezweifelt, Abwanderer galten vielmehr als schlechte Patrioten ${ }^{677}$.

Die im Vergleich zu Frankreich erheblich raschere Urbanisierung und die damit spürbareren Schattenseiten der industriellen Expansion trugen in Deutschland viel zu der besonders tiefen Irritation und Skepsis gegenüber der Großstadt bei ${ }^{678}$. Hinzu kam der im ganzen stärker bürgerlich-liberale Charakter der Politik in der französischen Provinz, eine Folge ihrer tieferen geistigen Urbanisierung. Ländlicher Grundbesitz war hier im 19. Jahrhundert nicht nur für den Amtsadel, sondern auch für die Industrie- und Handelsbourgeoisie zu einer Frage des sozialen Prestiges geworden ${ }^{679}$, Stadt und Land wurden also auch personal verklammert, urbane Weltoffenheit in die provinzielle Selbstgenügsamkeit hineingetragen; in Deutschland entstand dagegen keine Notabelnschicht, die mit den französischen „propriétaires rentiers" vergleichbar gewesen wäre ${ }^{680}$.

Auf der anderen Seite aber war die französische Provinz seit Jahrhunderten zugunsten der Metropole Paris besonders stark verkümmert und spätestens seit der Epoche des Sonnenkönigtums in der zweiten Hälfte des 17. Jahrhunderts zu einem bloßen Ort herabgesunken, von dem aus - mit der Formulierung von La

${ }^{673}$ Vgl. die entsprechende Schilderung eines Pfarrers bei P. Vallin, Paysans rouges, 1985, S. 77.

${ }^{674} \mathrm{Vgl}$. H. Schorr, Untersuchung der Lebensverhältnisse in kleinbäuerlichen Dörfern, 1953, S. 215.

${ }^{675}$ Vgl. H.-G. Haupt, Sozialgeschichte Frankreichs, 1989, S. 216.

676 Vgl. P. Barral, Les agrariens français, 1968, S. $128 \mathrm{ff}$.

${ }^{677}$ K. Bergmann, Agrarromantik und Großstadtfeindschaft, 1970, S. 17.

${ }^{678}$ Kaelble verweist etwa auf die am Ende des 19. Jahrhunderts schlechtere medizinische Versorgung, die höhere Kinder- und Frauensterblichkeit, die höhere Gewaltkriminalität oder die schlechtere Wohnungssituation in den deutschen Großstädten. H. Kaelble, Nachbarn am Rhein, 1991, S. $36 \mathrm{f}$. ${ }^{679}$ G. Friedmann, Villes et campagnes, 1953, S. XVII.

${ }^{680}$ W. Mager, Landwirtschaft und ländliche Gesellschaft, 1989, S. 98. 
Bruyère zu reden - der Hof bewunderungswürdig schien; auch in der Literatur hatte "Provinz“, nicht nur bei Molière, einen pejorativen Anklang bekommen ${ }^{681}$. So machten Mitte des 19. Jahrhunderts die im Gefängnis geschriebenen Erinnerungen einer jungen Pariserin Furore, die einen derben corrézischen Landmann geheiratet und mit Arsen vergiftet hatte, angeblich weil sie die Öde des sozialen Lebens und die Spießigkeit des Kleinbürgertums in Ussel und Tulle nicht länger ertragen konnte ${ }^{682}$.

In Deutschland dagegen gab es nicht nur Wien, vielmehr hatten sich eine ganze Reihe höfischer Residenzen mit gesellschaftlichem Leben, Vergnügen, Kultur und Luxus herausgebildet. Außerhalb dieser Kapitalen wurde die Provinz „mit ihrer Langeweile, gesellschaftlicher Isolation und den Moden, Gedanken und Lebensformen von vorgestern " $z$ war zu einem Synonym für Rückständigkeit ${ }^{683}$, aber schon die Vielfalt an Zentren ließ den Gegensatz zwischen Metropole und Peripherie historisch weniger tief einwurzeln als auf der anderen Seite des Rheins ${ }^{684}$.

$\mathrm{Da}$ in Deutschland die Fixierung auf eine einzige Metropole unterblieb, vielmehr selbstbewußte regionale Territorien ihre Modernisierung selbst in Angriff nahmen, bildete sich im nationalen Provinzialismus eine besondere Identität aus. Den dominierenden kleinstädtisch-kleinbürgerlichen Zug hat Heinrich Heine in seinem „Philister" sozial typisiert. Die anhaltende Geltung der Kirche vergrößerte noch den Abstand zu Frankreich, denn da dem Stadtleben allgemein eine schädliche Wirkung auf den christlichen Glauben zugeschrieben wurde ${ }^{685}$, vertrat der Durchschnittstyp des Geistlichen ein „idealisiert agrarisch-patriarchalisches Menschen- und Gesellschaftsbild"686 im Sinne der Riehlschen Gesellschaftkritik. Eine Summe von Faktoren also führte in der deutschen Provinz schon bis $1914 \mathrm{zu}$ einer breiteren Großstadtfeindschaft und zu dezidiert konservativer Agrarromantik, die den Bauern zu einem Garanten des traditionellen monarchischen Staatswesens werden ließ. Dagegen blieb es auf dem französischen Land bei einer Art HaßLiebe zu Paris und parteipolitisch kaum festzumachendem Agrarismus; vor allem aber schlug hier zu Buche, daß die selbstbewußten Republikaner im Konflikt mit den konservativen Agrariern selbst ,verländlichten ${ }^{4687}$ und die Bauern ihrerseits zum „sozialen Ideal der Dritten Republik“ erhoben.

${ }^{681}$ J. F. Gravier, Paris et le désert français, 1972, S. 7.

682 Mme Lafarge, Mémoires, 1867, v. a. S. $214 \mathrm{ff}$.

${ }^{683}$ D. Bellmann/W. Hein/W. Trapp/G. Zang, ,Provinz“ als politisches Problem, 1975, S. 81; vgl. auch J. Blaschke, Handbuch der westeuropäischen Regionalbewegungen, 1980, S. $17 \mathrm{f}$.

${ }^{684}$ Selbst in einem großen Staat wie Preußen hat Berlin nie die identifikatorische Bedeutung für das ganze Land gewonnen, die in Frankreich Paris erreichte. Vgl. R. von Thadden, Les relations entre Berlin et les provinces prussiennes, 1988, S. $75 \mathrm{ff}$.

${ }^{685}$ Vgl. etwa L. Heitmann, Großstadt und Religion, 1913, S. 8, 39-46.

686 W. K. Blessing, Staat und Kirche, 1982, S. 253.

${ }^{687}$ E. Plenel, L'état et l'école, 1985, S. 298: „Les républicains ... se sont à leur tour ruralisés“. 


\section{Westmittelfranken: Agrarromantische Wendung gegen den Weimarer Sozialstaat}

In der wirtschaftlichen und sozialen Krise nach dem Krieg sollten sich die Gegensätze zwischen Stadt und Land in Franken noch verschärfen. Bei den Not leidenden Städtern entstand zum Teil blanker Haß, weil sie ihre Lage von bäuerlichen "Wucher- und Schiebergeschäften“ mit Lebensmitteln ausgenutzt sahen. Das christliche (!) Gewerkschaftskartell in einer einstigen freien Reichsstadt drohte den Getreidewucherern unverhohlen, daß die Geduld der städtischen Bevölkerung „auch einmal ein Ende hat“. Die „Herrschaften“ möchten sich nicht wundern, „wenn schließlich das Volk zur Selbsthilfe greift und vor dem Eingang eines jeden Bauerndorfes einen Galgen errichtet für alle diejenigen, die es verdient haben"688. Die Bauern ihrerseits sahen auf den städtischen Arbeiter herab, dessen geringere, nun auf acht Stunden täglich reduzierte Arbeitsleistung ihnen, die vom frühen Morgen bis zum späten Abend tätig waren, indirekt „die Lebensbedürfnisse verteuert". Von der Realität, wie sie damals in einem Polizeibericht vermerkt wurde: „Intra muros peccatur et extra“, nahmen Stadt- und Landbevölkerung wohl nur die für sie günstigere Hälfte zur Kenntnis. Nach einer zeitgenössischen polizeilichen Einschätzung war es deshalb nicht auszuschließen, daß dieser $\mathrm{Ge}$ gensatz „einestags zu einer gewaltsamen Auseinandersetzung führt “689.

Konfliktverschärfend hatte es gewirkt, daß der Drang in die Stadt infolge des Krieges spürbar zunahm. Mehr als die Häfte der vom fränkischen Land stammenden Soldaten meldeten sich bei ihrem Ausscheiden aus dem Militärdienst beim Arbeitsamt, bewarben sich um einen anderen Beruf und wollten, wenn irgend möglich, nicht mehr zur Landarbeit zurückkehren ${ }^{690}$. Die im Rahmen der Demobilmachungsverordnungen seit 1919 geltenden Regelungen, die Gewerbe- und Industriebetriebe mit einer Geldstrafe bedrohten, falls sie landwirtschaftliche Arbeiter einstellten, wurden so oft unterlaufen, daß sich die Bauernschaft wiederholt zu Beschwerden veranlaßt sah. Den Gemeindebehörden mußte infolgedessen bezirksamtlich „eingeschärft" werden, in den Arbeitsbüchern und Invalidenquittungskarten der Dienstboten „unter allen Umständen stets die bisherige Stellung als landwirtschaftlicher Arbeiter" zu kennzeichnen und Anträge auf andere Berufsbezeichnungen, z.B. Hilfsarbeiter, entschieden abzulehnen ${ }^{691}$. Als die ohnehin nicht immer greifenden Verbotsbestimmungen - trotz Protests der Bayerischen Landesbauernkammer - 1922 sogar ganz aufgehoben wurden, wirkte sich dies gerade in Mittelfranken wegen der "starken Vermischung von Landwirtschaft und Industrie“ in einer Phase vorübergehender "Schein-Hochkonjunktur" vor allem in den Gebieten nahe des Nürnberger Ballungsraumes ungünstig für die Agarökonomie aus ${ }^{62}$. Auch bei den Arbeitgebern weiter „draußen“, etwa in der

${ }^{688}$ StAN Pol. Nü-Fü, Nr. 335, Allgemeiner Bericht Nr. 40/1921. Geheim!

${ }^{689}$ StAN Pol. Nü-Fü, Nr. 332, Wochenbericht der Polizeistelle für Nordbayern, 15.11. 1919; HStAM HMB, 6. 11. 1922.

690 K. Seiler/W. Hildebrandt, Die Landflucht, 1940, S. 122.

${ }^{691}$ StAN Landratsamt Ansbach, Abg. 1961, Nr. 4170, BA Ansbach, 10. 2. 1922, Betreff: Behebung des Arbeitermangels in der Landwirtschaft; Abdruck aus dem Amtsblatt des bayerischen Bezirksamtes Schwabach vom 8.11.1922.

${ }^{692}$ M. Hundmeyer, Arbeits- und Lohnverhältnisse in der mittelfränkischen Landwirtschaft, 1925, S. $28 \mathrm{ff}$., sowie HStAM HMB, 5. 6. 1923. 
Bechhofener Pinselindustrie oder der Windsheimer Maschinen- und Gipsindustrie, zeigte sich eine "gewisse Vorliebe für die Einstellung billig arbeitender und williger Arbeitskräfte aus der Landwirtschaft ${ }^{* 693}$. Sehr oft arbeiteten diese unter Tarif; und sie konnten es, weil sie Nebeneinkünfte aus landwirtschaftlicher Tätigkeit bezogen. In vielen Fällen lieferten sie ihrem Unternehmer auch noch eigene Agrarprodukte zu Vorzugspreisen ${ }^{694}$.

Als infolge der Währungskrise 1923 Arbeiter in großer Zahl entlassen wurden, waren zwar kurzzeitig Dienstboten sogar ohne Lohn, gegen freie Verpflegung und Bezahlung ihrer Sozialversicherung zu rekrutieren. Aber in der Krisensituation sahen sich viele kleine Landwirte nun außerstande, wenigstens diese Minimalentlohnung aufzubringen; selbst die mittleren Betriebe schränkten die Zahl ihrer Dienstboten ein ${ }^{695}$. Nach der kurzen Phase des Arbeitskräfteüberschusses bestimmte schon bald wieder die immer größer werdende "Leutenot" das Bild der Landwirtschaft in Westmittelfranken ${ }^{696}$. Aus dem Bezirksamt Rothenburg wanderten die Dienstboten vor allem in die württembergischen Industriegebiete ab, so daß im Sommer 1925 angesichts zahlreicher offener Stellen in der Landwirtschaft die Einbringung der Ernte gefährdet war ${ }^{697}$. Die Erbitterung unter den Bauern wuchs noch, als angesichts der Arbeitsmarktlage die Lohnforderungen von Knechten und Mägden erneut in die Höhe gingen, ja sogar einige mitten während der Ernte in den Streik traten. Nicht nur die streikenden Dienstboten von Obermögersheim verwiesen auf die Bezahlung der Arbeiter im Ruhrgebiet und drohten mit Abwanderung ${ }^{698}$, auch durch die Jugend von Elpersdorf bei Ansbach ging (1927) ein „Zug nach dem Ruhrgebiet“, seit ein Knecht Anfang des Jahres bei Krupp in Duisburg Arbeit gefunden hatte. Rasch hatte er Bekannte aus seiner Heimat nachgezogen, „und nun will eine ganze Anzahl junger Leute, darunter auch ein Bauernsohn, nach Duisburg “699.

Überhaupt waren es neben mittellosen Dienstboten sehr oft gerade die zweitgeborenen Söhne von Landwirten oder Gütler, die angaben, „um keinen Preis in der Landwirtschaft arbeiten zu wollen, weil nicht genügend bezahlt würde“700. Die fränkische Landflucht hing also auch damit zusammen, daß in Deutschland die revolutionäre Bewegung 1918/19 in eine Lohnbewegung umgelenkt worden war ${ }^{701}$ und insgesamt die sozialstaatliche Expansion der Weimarer Republik ein Ausmaß erreichte, das zwar den in der Industrie Beschäftigten zugute kam, aber für den Arbeitsfrieden in der Agrarprovinz nicht eben zuträglich war ${ }^{702}$. Speziell

${ }^{693}$ M. Hundmeyer, Arbeits- und Lohnverhältnisse, 1925, S. 43; auch HStAM HMB, 20. 10. 1922.

${ }^{694}$ HStAM HMB, 20. 4. 1922.

${ }^{695}$ So die Ergbnisse einer Rundfrage des Bezirksamtes Ansbach zur Arbeitsmarktlage nach M. Hundmeyer, Arbeits- und Lohnverhältnisse, 1925, S. $46 \mathrm{f}$.

${ }^{696} \mathrm{Vgl}$. HStAM HMB, 4. 2. 1928.

697 HStAM HMB, 18. 7. 1925.

${ }^{698}$ HStAM HMB, 19. 6. 1922, 4. 8. 1922, 19. 11. 1924, 18. 11. 1927, 4. 2. 1928.

${ }^{699}$ StAN Landratsamt Ansbach, Abg. 1961, Nr. 322: Evang.-Luth. Pfarramt Elpersdorf an BA Ansbach, 8. 11. 1927.

${ }^{700}$ HStAM HMB, 20. 4. 1922.

701 Vgl. hierzu: J. von Kruedener, Die Überforderung der Weimarer Republik als Sozialstaat, 1985, S. 376.

702 Vgl. in diesem Kontext die Kontroverse zwischen K. Borchardt und C.-L. Holtfrerich über die Frage der Lohnhöhe in der Weimarer Republik. K. Borchardt, Zwangslagen und Handlungsspielräume, 1982, sowie C.-L. Holtfrerich, Zu hohe Löhne in der Weimarer Republik?, 1984. 
das Thema der Erwerbslosen- und Krankenversicherung wurde für die fränkischen Bauern zu einem Quell nie versiegenden Ärgernisses, sahen sie doch hier ihre Pariarolle als Modernisierungsverlierer gleichsam materialisiert.

Als die Einführung der Gemeinlast für die Krankenkassen sich bei den Landkrankenkassen in Gestalt von Beitragsforderungen fühlbar machte (1923), entstand bei der bäuerlichen Bevölkerung im Bezirksamt Feuchtwangen eine Mißstimmung, weil sie fürchtete, daß damit auf Kosten des flachen Landes große Ortskrankenkassen im städtischen Bereich entlastet würden ${ }^{703}$. Überzeugt davon, daß „Faulheit und Liederlichkeit“ zu den Charakteristika der städtischen Industriearbeiterschaft zählten, war auf dem Lande wenig Neigung vorhanden, die urbanen Unterschichten via Krankenkassenbeitrag zu unterstützen ${ }^{704}$. In Ansbach verwahrten sich der „Bezirksverein“ des BdL und die „Viehverwertung“ in einer Resolution dagegen, landwirtschaftliche Arbeitgeber und Arbeitnehmer im Rahmen eines Zuschlags zum Krankenkassenbeitrag zur Erwerbslosenunterstützung heranzuziehen. In fünf ländlichen Bezirken Mittelfrankens, so wurde argumentiert, stünden 1572 Erwerbslosen anderer Berufsgruppen nur acht unterstützte Erwerbslose aus der Landwirtschaft gegenüber. Mindestens müsse die Inanspruchnahme der Kassenmittel künftig auf wirklich bedeutende Erkrankungsfälle begrenzt werden, wie dies in der Landwirtschaft ohnehin Praxis sei ${ }^{705}$.

Die Kritik an der als überhastet empfundenen Sozialgesetzgebung der Revolutions- und Nachrevolutionszeit hatte sich mit zunehmender „Leutenot“ bis 1926 soweit verdichtet, daß nun auch die Landesbauernkammer häufiger gegen weitere Sozialreformen protestierte. Um so fassungsloser reagierte die bäuerliche Bevölkerung deshalb, als am 1. Oktober 1927 auch noch eine Neuregelung der Arbeitsvermittlung und Arbeitslosenversicherung in Kraft trat, die den ländlichen Stellenmarkt weiter belastete ${ }^{706}$. Schon seit Anfang des Jahres, mit dem traditionellen Dienstbotenwechsel am Lichtmeßtag, hatte die Mißstimmung gegenüber der Erwerbslosenfürsorge verstärkt um sich gegriffen. Die Ansprüche von Knechten und Mägden waren „neuerdings erheblich gestiegen“, der Dienstbotenmangel insgesamt wieder sehr fühlbar geworden; und auf der anderen Seite fielen die in die Städte abgewanderten landwirtschaftlichen Arbeiter der Erwerbslosenfürsorge "vielfach nach kurzer Zeit" schon wieder zur Last ${ }^{707}$.

Als nun mit dem neuen Gesetz seit Herbst 1927 auch noch die Bedürftigkeitsprüfung für Erwerbslose entfiel, machten auf dem Lande namentlich Kleingütler und ihre Angehörigen den Rechtsanspruch auf Unterstützung geltend, was von vielen Bauern als eine "geradezu ungeheuerliche Geldverschwendung" empfunden wurde ${ }^{708}$. Der mittelfränkische Regierungspräsident bezweifelte indes, ob der abermals verschärften Lage durch gesetzliche Neuregelungen abzuhelfen sei; ihm lagen Berichte vor, wonach selbst die Einziehung der Erwerbslosenunterstützung frühere Dienstboten nicht dazu bestimmen konnte, wieder landwirtschaftliche

${ }^{703}$ HStAM HMB, 4. 7. 1925.

${ }^{704}$ HStAM HMB, 20. 2. 1930. Zur Kritik an als überhöht empfundenen Krankenkassenbeiträgen vgl. auch HStAM HMB, 19.12. 1923.

${ }^{705}$ Fränkische Zeitung, 7. 12. 1923.

706 W. Ratjen, Die bayerischen Bauernkammern, 1981, S. 105, 128.

707 HStAM HMB, 19. 1. 1927.

${ }^{708}$ HStAM HMB, 4. 2. 1928. 
Arbeitsstellen anzunehmen. Viele Mägde waren seit langem bestrebt, nachgerade „mit allen Mitteln“ in der Stadt unterzukommen. Außerdem gab es genügend auch "angesehene" Landwirte, die ein „schlechtes Beispiel“ gaben“, ihre eigenen Kinder in die Stadt schickten und versuchten, die Söhne bei der Reichswehr oder Landespolizei unterzubringen ${ }^{709}$. Der Regierungspräsident sprach deshalb von einer Teilschuld, die die Landwirte selbst an dem Leutemangel trügen ${ }^{710}$. Als schließlich die Weltwirtschaftskrise am Anfang der 1930er Jahre ein Abströmen der Arbeitskräfte vom Lande in die städtische Industrie zunehmend verhinderte, war auch die Situation bei den Agrariern so prekär geworden, daß sie ihre Dienstbotenhaltung einschränken mußten und nun plötzlich wieder ein Überangebot wenigstens an männlichen Arbeitskräften vorhanden war ${ }^{711}$.

In diesen Wechselfällen des Modernisierungsprozesses prägte sich immer mehr ein Paradoxon im Bewußtsein des fränkischen Landvolks aus: Großstadtfeindschaft und Großstadtsehnsucht, die widersprüchlich miteinander verbunden waren und sich wechselseitig verstärkten. Je häufiger Landbewohner der Anziehungskraft der Großstadt erlagen, desto kräftiger, so schien es, wurden bei den Bleibenden antiurbane Vorbehalte. Und zwar um so mehr, als der verlorene Weltkrieg, gedeutet als eine Niederlage der sinistren Kräfte des Industriezeitalters, die Rückkehr Deutschlands zum Agrarstaat zu gebieten schien, was der Provinz vorübergehend einen „enormen Zuwachs an Selbstbewußtsein“ verschaffte ${ }^{712}$.

Der bäuerliche Mißmut richtete sich vor diesem Hintergrund nicht einfach gegen die Großstadt, sondern im Grunde gegen alle Berufe, die sich der „beseelten " 713 bäuerlichen Arbeit entzogen hatten, die aus der strukturellen Einheit von Produktions- und Konsumsphäre ausgebrochen waren und die somit für die vorindustrielle Selbstversorgungsmentalität der Bauern etwas Fremdes darstellten, d.h. nicht nur gegen die Industriearbeiter, sondern ebenso gegen die - gleichfalls "unbeseelt" tätige - Beamtenschaft. „Charakteristisch für die durch die Not der Zeit und wohl auch durch radikale Hetze herbeigeführte Verwirrung der Gemüter" war ein Anfang 1926 beim Weißenburger Bezirksamt eingegangener anonymer Brief, in dem der Absender drohte, zusammen mit 20 „Bundesbrüdern“ den größten Teil der Beamten des Bezirks- und Finanzamts „zum gleichen Glockenschlag kalt" zu machen, wenn er sich auf seinem Bauernhof nicht mehr ehrlich und redlich ernähren könne. Zugleich wurden die Beamten aufgefordert, einen Teil ihres Gehalts an Bedürftige abzugeben und die Gabe in der Zeitung zu veröffentlichen ${ }^{714}$. Daß der Drohbrief um die Jahreswende geschrieben wurde, war wohl kaum zufällig, da nicht zuletzt die Weihnachtszulage der Beamten auf dem Lande einen Stein des Anstoßes darstellte ${ }^{715}$.

${ }^{709}$ HStAM HMB, 5. 3. 1928; vgl. auch HMB 20. 2. 1928, 4. 2. 1928.

710 Vgl. hierzu schon HStAM HMB, 5. 12. 1921.

711 Arbeitsamt Ansbach an Gemeinde Neuendettelsau, 11.6. 1930 u. 23. 5. 1931, in: GA Neuendettelsau 416/3.

${ }^{712}$ A. Wirsching, Bäuerliches Arbeitsethos und antiliberales Denken, 1990, S. 418 f.

${ }^{713}$ Den Begriff der „beseelten Arbeit “ hatte der in ländlichen Kreisen besonders geschätzte Werner Sombart (Der moderne Kapitalismus, 1928) geprägt. Bäuerliche Arbeit war demnach „kein ökonomisch berechenbarer, sondern ein moralischer Wert per se". Vgl. A. Wirsching, Bäuerliches Arbeitsethos und antiliberales Denken, 1990, S. 418.

714 HStAM HMB, 6. 1. 1926.

715 Vgl. HStAM HMB, 19. 1. 1927. 
Trotz aller Ressentiments gegen die anscheinend vom Weimarer Sozialstaat begünstigten städtischen Berufsgruppen war die Landbevölkerung während der Zwischenkriegszeit selbst einem Prozeß zunehmender „geistig-seelischer Verstädterung "716 ausgesetzt. Seit dem Ausbau der Verkehrswege nach der Mitte des 19. Jahrhunderts waren die Berührungsmöglichkeiten zwischen Stadt und Land stetig gewachsen, der städtische Ausflugsverkehr vermittelte den Dorfbewohnern einen Eindruck von urbaner Zivilisation, Kleidung, Ernährung und Manieren; und durch die so gegebenen Vergleichsmöglichkeiten konnte sich der Bauer seiner eigenen Lage, seines „arbeitsgekrümmten $\operatorname{Körper(s),~seine(r)~groben~Hände,~sei-~}$ ne(r) bäuerlichen Mundart", des an ihm "haftenden Stallgeruchs" und seiner geringeren „Welt- und Lebenskenntnisse“ erst richtig bewußt werden. Die offene Geringschätzung des Städters gegenüber dem Landbewohner verstärkte auf bäuerlicher Seite noch ein "deutliches Minderwertigkeitsgefühl“717. Als wichtigste „Propagandisten der Großstadt “"718 fungierten jene seit Anfang des Jahrhunderts vermehrt in die Stadt abgewanderten Einzelpersonen ${ }^{719}$, die über Sonntag bei den Verwandten zu Besuch kamen und erzählten, wie es ihnen im neuen Lebensbereich erging; es war nur allzu menschlich, wenn sie dabei vor allem ihre persönlichen Erfolge bei der Suche nach einem Arbeitsplatz oder einer Wohnung betonten. In ihnen, die nicht Fremde waren, sondern Bruder, Schwester oder Freund, verkörperte sich glaubwürdig die städtische Gegenwelt auf dem Lande, eröffnete sich den ländlichen Unterschichten eine Alternative zu ihrer eigenen Existenz, die sich schließlich in ihrer kollektiven Vorstellung verankern konnte.

Und dies gelang um so eher, als das von den - bürgerlichen - Agrarideologen gezeichnete romantische Bild der ländlichen Welt mit der Realität einer Landgemeinde oft nur wenig zu tun hatte ${ }^{720}$ : „Ein Tagelöhner, eigentlich Handwerksgeselle, mit acht Kindern, das Handwerk steht ganz still, und zu Tagelohn ist der Mann zu kränklich und wenig Gelegenheit vorhanden. Die Kinder sind im Dienst, die übrigen leben im größten Elend, hungernd und zerlumpt..."721. Bei etlichen Tagelöhnerfamilien verstärkten sich auch deshalb Hunger und Not, weil mit der landwirtschaftlichen Mechanisierung, vor allem mit der Einführung der Dreschmaschine, die Winterarbeit überall dort vollkommen wegfiel, wo kein oder wenig Wald vorhanden war ${ }^{722}$. Die Situation des Gesindes hatte sich im Zuge der Modernisierung ebenfalls kaum verbessert: „Früher hat der Knecht auf dem Hof ein ganz anderes Leben gehabt als heute. Nach dem Feierabend, der damals früher anfing als heute, weil es kein elektrisches Licht gegeben hat, und am Sonntag ist der Knecht in die Stube gegangen. Dort hat er mit seiner Herrschaft oder mit den Mägden geplaudert, ... Zeitung gelesen oder auch ein Buch in die Hand genommen. Heute darf er die Stube nicht mehr betreten. Die Bäuerin will heute, wie die Städter, eine

\footnotetext{
${ }^{716}$ K. Seiler/W. Hildebrandt, Die Landflucht, 1940, S. 120.

717 Ebd., S. 109, 124.

718 W. Kromer, Propagandisten der Großstadt, 1985, S. 17.

719 Vgl. H. Schorr, Untersuchung der Lebensverhältnisse in kleinbäuerlichen Dörfern, 1953, S. 215.

${ }^{720}$ Vgl. zu diesem Zwiespalt M. Mitterauer, Lebensformen und Lebensverhältnisse ländlicher Unterschichten, 1981.

721 W. Kromer, Propagandisten der Großstadt, 1985, S. 87.

${ }^{722}$ K. Bedal, Göpel und Dreschmaschine, 1981, S. 131.
} 
schöne Stube haben ... Nach dem Feierabend ... weiß der Knecht nicht wohin auf dem Hof ... Er muß entweder ins Bett gehen oder ins Wirtshaus. “723

Zur allgemein beklagten Versachlichung des Verhältnisses zwischen Herr und Knecht trug aber vor allem auch die kapitalistisch-rationalistische Durchdringung des ländlichen Lebens bei, also die mit dem Verkehrsausbau einhergehende Ablösung der dörflichen Autarkie und das Vordringen der Geldwirtschaft. Als die Bauern begannen, ihren Boden und Besitz „in Geld umzudenken“, waren sie nicht länger zufrieden, wenn der Hof nur die Familie ausreichend ernährte, sondern bestrebt, damit Geld zu verdienen. In der Folge versuchten viele Bauern durch Verwendung von Maschinen oder durch erhöhte Sparsamkeit, d.h. verstärkten Einsatz von Frauen und Kindern, die Zahl des Gesindes einzuschränken. Dies mochte zwar die Bargelderträge der Höfe erhöhen, führte aber auch zu einer "Überanstrengung und Ausnützung der Bauernkinder" wie des verbleibenden Gesindes ${ }^{724}$.

Gewiß gab es in der ländlichen Unterschicht noch immer Knechte und Mägde, die „, Bn Bauernarbeit Lebenserfüllung, am Bauernhof ein Zuhause und in der Bauernfamilie Partnerschaft fanden "725, insgesamt aber bedeutete diese Existenz für die meisten doch „mehr Dienen als Verdienen“ - von primitiven Arbeits- und Lebensbedingungen einmal ganz abgesehen ${ }^{726}$. Da die meisten Bauern zudem verheiratetes Gesinde nicht beschäftigen wollten („Ein verheirateter Knecht trägt dir den Hof davon"), wurde der Gesindeberuf zur lebensgeschichtlichen Sackgasse. Um eine Familie ernähren zu können, blieb vielfach nur die Abwanderung in die Stadt ${ }^{727}$, und auch sonst genügten bei Taglöhnern wie Gesinde oft „schon die bescheidensten mit dem Stadtleben verbundenen Hoffnungen " 728 , um von einer dörflichen Existenz Abschied zu nehmen, deren Alltag immer belastender empfunden wurde ${ }^{729}$.

Die kapitalistische Produktion war zwar nicht, wie Marx und Engels prophezeit hatten, "wie ein Eisenbahnzug über eine Schubkarre“ über die veralteten Kleinbetriebe hinweggegangen ${ }^{730}$, hatte sie aber doch in ihrer Substanz verändert. Und das Landvolk, konfrontiert mit der vielfach schmerzlichen Herausforderung, sich dem System einer modernen arbeitsteiligen Industriegesellschaft anzupassen, reagierte mit einer tiefen Bewußtseinskrise, schwankend zwischen Großstadtfeindschaft und Stadtbewunderung. Wenn der Elpersdorfer Pfarrer fürchtete, daß seine ins Ruhrgebiet abgewanderten jungen Leute "gelegentlich auch einmal auf die Straße gesetzt werden und dann, physisch und moralisch ruiniert, zur Land-

${ }^{723}$ So die Schilderung eines alten Bauern aus dem Uffenheimer Bezirksamt in den 1930er Jahren, nach: K. Seiler/W. Hildebrandt, Die Landflucht, 1940, S. 121.

${ }^{724}$ K. Seiler/W. Hildebrandt, Die Landflucht, 1940, S. 121.

${ }^{725}$ N. Ott, Wassertrüdingen unter Krone und Kanzler, 1987, S. 111.

${ }^{726}$ Zeitzeugen erinnern besonders die alten offenen Kamine, schlechte Fenster, unheimlich kalte Küchen: „... was haben die Frauen da mitgemacht“. G. Lang, Mein Dorf in Franken, 1983, S. 37, 42; vgl. auch L. Hefele, Geschichte der Pfarrei Veitsaurach, 1977, S. 128f., sowie zur allgemeinen Problematik R. Schulte, Bauernmägde in Bayern am Ende des 19. Jahrhunderts, 1983.

${ }^{727}$ K. Seiler/W. Hildebrandt, Die Landflucht, 1940, S. 122 f.

728 W. Kromer, Propagandisten der Großstadt, 1985, S. 87.

${ }^{729}$ Ebd., S. 110, 120 f.

${ }^{730}$ Zit. nach W. Abel, Die drei Epochen der deutschen Agrargeschichte, 1964, S. 120. 
arbeit nicht mehr taugen und das Heer der Arbeitslosen vermehren "731, so war damit sicher eine Grundstimmung bei den Seßhaften in Westmittelfranken artikuliert. Die zur Abwanderung Entschlossenen aber konnte dies nicht aufhalten, um so weniger als die von Pfarrern und Lehrern vermittelten negativen Stadtbilder wohl eher im Bereich einer moralisch-appellativen Unverbindlichkeit blieben und sich kaum in konkreten Bemühungen niederschlugen, einzelnen, meist auch materiell motivierten Fällen von Landflucht entgegenzuwirken ${ }^{732}$. Dennoch war die konservative Agrarromantik mehr als eine bürgerliche Ideologie über den Bauern, weil zumindest einige ihrer Bestandteile in die Mentalität der seßhaften Landbevölkerung eingingen, sie in ihren "natürlichen" Vorurteilen gegen das Städtische bestärkten.

„Es sprießt der Stamm der Riesen aus Bauernmark empor“, begann das Landwirtschaftskapitel im Grundsatzprogramm der bayerischen Deutschnationalen und pries das Bauerntum als das Mark „im Knochengerüste unseres Volkskörpers“. Noch jedesmal, wenn „unser deutsches Volk den jähen Sturz von der steilen Höhe des Glanzes und des Erfolges in die Tiefen der Schmach und des Elends getan - jeder so furchtbar, daß ihn kein anderes Volk überdauert hätte“, hätten „Bauerntrotz und Bürgersinn in zäher, unverdrossener Arbeit die Höhe wiedergewonnen"; zunächst, als die "staufische Reichsherrlichkeit in Trümmer sank" und dennoch "gewaltige Scharen deutscher Bauern und Bürger" die deutsche Ostkolonisation vollendeten, dann nach dem Dreißigjährigen Krieg und der „napoleonischen Schmach“, und nun nach „der tiefsten Erniedrigung unseres Volkes“ im „Versailler Sklavenfrieden“ ruhten abermals "unsere Hoffnung und Zukunft ... in der deutschen Scholle"733.

Als wichtiger Transmissionsriemen deutschnationaler Agrarromantik in Westmittelfranken fungierte der Landbund, der seinerseits einen „freien, besitzenden Bauernstand“ propagierte. Danach ergänzte die Bauernschaft „wie ein ewig fließender Jungbrunnen“ die „in den Großstädten verbrauchte Urkraft unseres Volkes immer wieder ..., wenn Schwindsucht, Geschlechtskrankheiten, Alkoholismus und Nervenkrankeiten auch noch so sehr im Großstadtwesen verheerend hausen"734. Aus der ,historischen" Analyse wurde politisch abgeleitet, daß die Agrarier „voraussichtlich in der Gesamtvolkswirtschaft in Zukunft eine weit größere Rolle spielen als in den letzten Jahrzehnten unseres industriellen Erfolges ${ }^{\text {“735. }}$.

Die deutschnationale Agrarromantik mußte sich an der ganz anderen Weimarer Realität immer wieder stoßen, und so war sie geeignet, jenen Grundwiderspruch zu vertiefen, der sich aus dem Gegensatz traditioneller Agrarideologie zur parallel erfolgenden „Propaganda der Großstadt" ohnehin ergab. Dies verstärkte noch das allenthalben auf dem Lande anzutreffende Gefühl, am Ende von generationenübergreifenden Gewißheiten zu stehen und nicht nur einen - in immer neuen Maschinen auf den Höfen täglich greifbaren - technischen Fortschritt mitzuerleben,

731 StAN Landratsamt Ansbach, Abg. 1961, Nr. 332, Ev.-luth. Pfarramt Elpersdorf, 8. 11. 1927.

732 W. Kromer, Propagandisten der Großstadt, 1985, S. 92, $331 \mathrm{f}$.

${ }^{733}$ BAP DNVP 26, Die Ziele der Bayerischen Mittelpartei, S. $22 \mathrm{ff}$.

${ }^{734}$ Der Bund der Landwirte in Bayern, 19. 1. 1919.

${ }^{735}$ BAP DNVP 26, Die Ziele der Bayerischen Mittelpartei, S. $22 \mathrm{ff}$. 
sondern generell an historisch bedeutsamen Wandlungen teilzunehmen ${ }^{736}$. Angesichts dieser „seelisch-geistigen Dispositionen “737 war der Boden für eine politische Kraft gedüngt, die nicht nur die ruralen Ressentiments gegen die Sozial- und Wirtschaftspolitik der Weimarer Republik romantisierend aufgriff, sondern neben einer Aufwertung der Agrarprovinz auch dessen Versöhnung mit der Großstadt verhieß, zu der zwischenzeitlich mannigfaltige verwandtschaftliche Kontakte bestanden. Den Paradoxa in der ländlichen Mentalität und ihren ambivalenten politischen Erwartungen scheint der Nationalsozialismus schließlich am ehesten entsprochen zu haben, indem er Tradition und Moderne eklektizistisch verband und Stadt und Land in einer großen Volksgemeinschaft zu vereinen versprach.

Dennoch steckte im modernen ländlichen Identitätsproblem nicht a priori ein unauflöslicher Widerspruch zum liberalen System der Weimarer Republik, eine „dem Staatswohl abträgliche Stimmung “738; die Spannung zwischen vorindustriellem Autarkiedenken und liberalen Marktprinzipien mußte nicht zwangsläufig mit einer Ablehnung des parlamentarischen Systems - und entsprechendem Wahlverhalten - verbunden sein ${ }^{739}$. Dies vermag der Vergleich mit der (partei-)politisch distinkten französischen Provinz zu zeigen, die nach 1918 ebenso schwer von den Phänomenen der Landflucht gezeichnet und von zunächst ganz ähnlichen agraristischen Ideologemen beherrscht war.

\section{Corrèze: Republikanische Einhegung des „Agrarismus“}

Die von Alain Corbin für das 19. Jahrhundert konstatierte „opposition globale ${ }^{740} z$ wischen den Mitgliedern der dörflichen und städtischen Gesellschaft im Limousin $^{741}$ blieb während der Zwischenkriegszeit für die Corrèze ebenso charakteristisch wie die parteipolitische Heterogenität des Agrarismus mit seinen republikanischen und katholischen Hauptvarianten. Allerdings wurde das Landflucht-Thema doch etwas stärker von rechts her besetzt. Die Union catholique appellierte eindringlich an den jungen „Pierre“, auf dem Dorfe zu bleiben, das seine Väter in christlicher Pflichterfüllung nie verlassen hatten. In der stark moralisierenden Argumentation wurde die Stadt dem Jungbauern als ein blendendes Trugbild voller eleganter, aber nicht heiratsfähiger Püppchen geschildert. Auf dem Dorfe dagegen würde einem Gott zur rechten Zeit „ein gutes, bescheidenes und gläubiges Mädchen“ zuführen, das den Kindern eine würdige Mutter sei und als „Mädchen der Scholle“ den nötigen Sinn für die bäuerliche Existenz mitbringe.

Als Hauptursachen für den Leutemangel auf dem Lande erkannten katholische Agraristen die Mängel im bäuerlichen Bildungswesen. Niemand verdeutliche den Agrariern den Nutzen ihrer Arbeit für das Gemeinwohl und den wissenschaftli-

${ }^{736}$ So belegen es Äußerungen alter Bauern seit dem 19. Jahrhundert. Vgl. K. Bedal, Göpel und Dreschmaschine, 1981, S. $131 \mathrm{f}$.

${ }_{737}$ Zum Begriff vgl. Th. Geiger, Die soziale Schichtung des deutschen Volkes, 1932, S. 77.

${ }^{738}$ So der mittelfränkische Regierungspräsident zur Landflucht; HStAM HMB, 18. 4. 1929.

739 Vgl. hierzu die Thesen A. Wirschings, Bäuerliches Arbeitsethos und antiliberales Denken, 1990, S. $422 \mathrm{f}$.

${ }^{740}$ A. Corbin, Archaisme, 1975, S. 1001.

${ }^{741} \mathrm{Zu}$ ihrer Ausdrucksform im Schimpfwort: G. E. Clancier, La vie quotidienne en Limousin, 1974. 
chen Charakter der Landwirtschaft, und niemand vor allem pflanze in ihr Herz die Liebe zur Erde ${ }^{742}$. Die katholische Jugendarbeit sah hier ein wichtiges Betätigungsfeld und organisierte große Landfluchtkongresse. Der Bischof und der Präsident der französischen Jungkatholiken führten 1926 in Tulle 400 Kindern und Jugendlichen eindringlich den "schwülen Dunst" der Städte vor Augen und plädierten für eine „intellektuelle Landwirtschaft" nach dänisch-belgischem Vorbild ${ }^{743}$. Die beliebte Anspielung auf antirurale Positionen der französischen Sozialisten durfte nicht fehlen; denn auf einem Parteikongreß (1909) hatte einer ihrer Funktionäre die seßhaft Bleibenden als geistig unbewegliche ,arme Bauernlümmel“ beschimpft, „voller Ignoranz und Alkohol“, und dazu verdammt, immer nur „zwischen Kirche und Wirtshaus hin- und herzuschwanken “744. Dergleichen wurde von der politischen Rechten gerne kolportiert und - auch von der Katholischen Jugend der Corrèze - voller Empörung zurückgewiesen: „Wir glauben nicht, daß nur all die auf der Scholle bleiben müssen, die nicht intelligent genug sind, um im öffentlichen Dienst zu arbeiten." ${ }^{\text {"745 }}$

In den Wahlkämpfen thematisierten konservativere Kandidaten wie Louis Aujol besonders nachdrücklich den Stadt-Land-Gegensatz und stellten die Frage: „Bauern! Was hat man für Euch getan?" Die schlechten Straßen und Transportverhältnisse, der teure Strom und die "schweren Sorgen“ der Landbevölkerung wurden mit dem „süßeren Leben“, der organisierten Freizeit, aber auch dem „kostenlosen Krankenhaus“ in den Städten kontrastiert. Der agrarkonservative Aujol, der nominell als „unabhängiger sozialistischer Republikaner zur Wahrung bäuerlicher Interessen“ auftrat, zielte mit dieser Kritik zwar "nicht ohne eine gewisse Bitterkeit" auf die „Berufspolitiker“ in Paris, die nur Reden gegen die Landflucht hielten, statt tatsächlich gegen sie vorzugehen, doch blieben seine Forderungen doch eindeutig systemimmanent darauf gerichtet, den „arbeitsamen Bauern“ endlich den ihnen zukommenden Platz „im parlamentarischen Konzert“ zu sichern ${ }^{746}$.

Was in der Corrèze nur von einer bewußt katholischen Minderheit gedacht wurde, war in weiten Teilen des konservativ-klerikalen französischen Landes breite Überzeugung: daß nämlich wesentliche Institutionen der laizistischen Republik wie Militärdienst und Schulpflicht für die Landflucht verantwortlich $\operatorname{seien}^{747}$. Danach hatten die allzu fortschrittlichen Lehrer ihre Ressentiments gegen die bäuerliche Welt gleichsam auf die Schüler übertragen und sie so unterrichtet, daß sie Schamgefühle ihrer Geburt und vor allem ihrer schmutzigen Arbeit wegen entwickelten ${ }^{748}$. Im republikanischen Lager dagegen wurde ein Wirkungszusammenhang zwischen laizistischer Politik und Landflucht ${ }^{79}$ so natürlich nicht gesehen. Jean Guillou beschrieb das Phänomen in seiner fundamentalen Untersuchung ohnehin als eine normale und natürliche Bewegung der zivilisierten Gesell-

${ }^{742}$ La Croix de la Corrèze, 29. 2. 1932.

${ }^{743}$ AN F 7/13219, Präfekt an Innenminister, Tulle, 7. 4. 1926.

${ }^{744}$ E. Weber, La fin, 1983, S. 415.

${ }^{745}$ Bericht des Präfekten an den Innenminister, Tulle, 7. 4. 1926, in: AN F 7/13219.

${ }^{746} \mathrm{Le}$ Cultivateur Républicain. Organe de Défense Agricole et de l'Artisanat Rural, 19.4. 1932 (ADC).

${ }^{747}$ Vgl. J. Pitié, L'exode rural, 1980, S. 65.

${ }^{748}$ D. Halévy, Visites aux paysans du Centre, 1921, S. 62.

${ }^{749}$ Vgl. J. Eysseric, Politique laïque et dépopulation, 1931. 
schaften unserer Zeit ${ }^{750}$, und Emile Vandervelde hielt der ewigen Klage „La terre manque de bras “751 den „unschätzbaren Vorteil“ entgegen, Millionen Individuen aus ihrer mentalen Trägheit herausgerissen zu haben ${ }^{752}$.

Speziell die marxistischen Parteien waren schon aufgrund ihrer starken Verankerung im städtischen Wählermilieu gar nicht in der Lage, ebenso scharf gegen die Urbanisierung zu polemisieren wie konservative Agrarideologen. In ihren „Briefen an einen Bauern" beklagten die corrézischen Sozialisten (1929) zwar die schlimme Entvölkerung des Landes, machten dafür aber in sachlicher Argumentation die „sich seit einem Jahrhundert unterschiedlich entwickelnden Lebensbedingungen zwischen landwirtschaftlicher und Arbeiterbevölkerung" verantwortlich $^{753}$. Dies verband sich allerdings mit einem besonders kritischen Blick auf den bäuerlichen Alltag und mit der daraus resultierenden Frage, ob das einzige Recht der Bauern denn wirklich nur darin bestehe, „das ganze Jahr über zu schwitzen und klaglos dieses Galeerenleben fortzusetzen?"“. Auf dem Höhepunkt der Wirtschaftskrise in den 1930er Jahren gipfelte die SFIO-Politik in der radikalen Forderung, "gegen die Hungerlöhne aufzustehen "754.

Entscheidenderes Gewicht als dem ziemlich unbedeutenden corrézischen Agrarsozialismus kam aber dem großen liberal-republikanischen Bauernverband der Fédération Faure zu, wo linker und rechter Agrarismus auf eine manchmal schwer zu durchschauende Weise ineinander übergingen und an Topoi der deutschen Agrarromantik erinnerten. Bauernverbandspräsident Faure selbst sah angesichts einer immer stärker werdenden Abwanderung (1923) „die Blüte unserer schönen Landjugend über die Städte herfallen“, angezogen "wie die Schmetterlinge vom Licht, das nur zu oft ihre Flügel verbrennt“. Daß die meisten „auf dem Boden unserer sonnigen Weiler" glücklicher lebten als in den gärenden Städten, „wo die Sittenlosigkeit und die Tuberkulose täglich Legionen von Opfern" forderten, stand für Faure außer Frage. In lyrischen Wendungen schilderte er das Schicksal eines jungen Landmädchens, das nach einer glücklichen Jugend inmitten ihrer Viehherden in die Stadt gegangen war, um nach wenigen Jahren Paris nervenkrank zu werden: „Ihr Leichnam wurde in einem Zustand fortgesetzter Verwesung in ihrer Behausung gefunden". Und um seinem offen erklärten Ziel gerecht zu werden, Illusionen über das Stadtleben zu zerstören, verdeutlichte Faure, $\mathrm{da}$ es sich dabei nicht um einen Einzelfall handelte. Erst vor wenigen Wochen sei ein weiteres, schwangeres Mädchen aus der Corrèze - ohne den abgeschnittenen Kopf - in der Seine gefunden worden ${ }^{755}$. Tatsächlich entsprangen derartige Schreckensgemälde nicht nur purer Ideologie, vielmehr beschrieben sie zumindest ausschnittweise eine schmerzliche soziale Realität, die schon vor dem Ersten Weltkrieg in der Corrèze zur Gründung eines Vereins geführt hatte, dessen Anliegen es war, jährlich um die 50 abgewanderte, aber in Paris gescheiterte Frauen zu "repatriieren“"756.

${ }_{750}^{75} \mathrm{~J}$. Guillou, L'émigration des campagnes vers les villes, 1905, S. 141.

751 J. Pitié, L'exode rural, 1980, S. 65.

752 E. Vandervelde, L'exode rural et le retour aux champs, 1903, S. 246.

753 La Voix Corrézienne, 10. 4. 1929.

${ }^{754}$ Ebd., 28. 1. 1934.

${ }^{755}$ La Défense Paysanne de la Corrèze, Dezember 1923.

${ }^{756} \mathrm{Ch}$. Fouchier, Essai sur l'abandon des campagnes, 1914, S. 225. 
Darüber hinaus waren die Agraristen im corrézischen Bauernverband bemüht, „bäuerlichen Stolz“ gezielt zu fördern, um zu verhindern, daß Landwirte „eine Beute der Fabrik" würden ${ }^{757}$. Übertrafen nicht die Landwirte in Frankreich zahlenmäßig immer noch jeden anderen Berufsstand? Und neben dem alten Argument der wirtschaftlichen Bedeutung erhielt seit 1918 vor allem der moralische Aspekt neues Gewicht: schließlich hatten die bäuerlichen Infanteristen in den Schützengräben, als „Prototypen des Nichtprofiteurs“, im Weltkrieg große Opfer gebracht ${ }^{758}$.

Rechte wie linke Großstadtkritik konzentrierte sich nach wie vor auf Paris, wobei offensive und defensive Elemente häufig ineinander übergingen. Denn die hauptstädtischen Medien, gerade auch die Handelsblätter, führten immer wieder „haßerfüllte Kampagnen“ gegen die Landwirtschaft, und die besonders agrarisch strukturierte Corrèze kam dabei mit am stärksten ins Kreuzfeuer. Der Euvre empörte sich (1921), daß das "ausschließlich von Bauern bewohnte Departement" ganze sechs Francs Steuern aus den bénéficiaires agricoles erbracht hatte: „Alle Ehre den Corréziens, eine derartige Summe zum Staatshaushalt beizutragen ..." Nachdem sich auch städtische Parlamentarier an der antibäuerlichen Kampagne beteiligten, sah sich der Schatzmeister des Bauernverbandes von Objat schließlich zu der Empfehlung veranlaßt, die betreffenden Abgeordneten sollten doch die „Hölle Paris“ verlassen und Bauer werden, an Arbeitsplätzen für Pächter und Dienstboten mangele es nicht, und die landwirtschaftliche Arbeit sei, wie die Parlamentarier wüßten, „ein Kinderspiel“759.

Die in Frankreich langsamere Entwicklung zum sozialen Interventionsstaat bot insgesamt zwar weniger Anlaß zu bäuerlichem Mißmut als in Deutschland, Ähnlichkeiten waren aber kaum zu übersehen. Bereits die Einführung des Achtstundentages unmittelbar nach dem Ersten Weltkrieg war für die französischen Bauern, die "schließlich während der Ernte 14, 15 Stunden arbeiteten“, ein Stein des Anstoßes, und die corrézischen Konservativen versäumten es nicht, publikumswirksam diese "Welle der Faulheit zu beklagen“, in die Frankreich sehr zum Schaden seiner Finanz- und Wirtschaftspolitik eingetaucht sei ${ }^{760}$. Wie in der deutschen Agrarideologie gaben darüber hinaus die Beamten, von denen es ohnehin "schon zu viele" gebe, die Kontrastfolie zur angeblich heilsamen bäuerlichen Arbeit ab, die allemal „einen gesunden Körper in einem gesunden Geist" garantiere $^{761}$. Verständnislos stand die corrézische Landwirtschaft auch anderen Erscheinungen der modernen Welt gegenüber, etwa den Krediten zur Finanzierung der Olympischen Spiele - wo man Leistungssport doch für gesundheitsschädlich hielt -, oder den gegen ihre staatliche Besteuerung protestierenden Theater- und Kinobesitzern. Diesen „Nutznießern“ zunehmender Freizeitkultur wurde das immer wiederkehrende Argument entgegengehalten, sie seien im Falle ihres Ruins „bequem in der Landwirtschaft unterzubringen "762.

${ }^{757}$ La Défense Paysanne de la Corrèze, 15. 1. 1932.

${ }^{758}$ Ebd.

759 Ebd., Februar 1923.

${ }^{760}$ La Croix de la Corrèze, 7. 9. 1919; vgl. später auch die Kritik Faures an der 40-Stunden-Woche in:

La Défense Paysanne de la Corrèze, 15. 10. 1934.

${ }^{761}$ L'Union Catholique de la Corrèze, November 1925.

${ }^{762}$ La Défense Paysanne de la Corrèze, 15. 3. 1929 u. 30. 10. 1929. 
Die agraristische Polemik trug ebensowenig zum Verständnis des Konflikts bei wie unverändert dürftige Landflucht-Analysen seitens hochrangiger Politiker ${ }^{763}$. Die (Groß-)Stadt der Zwischenkriegszeit, so lautete eine der nach wie vor unzureichenden Begründungen, habe in ihrem anderen Rhythmus eben etwas Faszinierendes für den Kleinbauern und Dorfhandwerker ${ }^{764}$. Jules Méline, über Jahrzehnte eine Art Chefideologe der ländlichen Welt und zwischen 1883 und 1916 oftmals Landwirtschaftsminister, hatte in seinem mehrfach wiederaufgelegten Werk über die „Rückkehr zum Boden“ sogar geschrieben, nicht die materielle Not, sondern die Hoffnung auf das süße Stadtleben würde die Landleute anziehen $^{765}$. Méline symbolisierte mit seiner allmählichen Wanderung von der linken Mitte zur republikanischen Rechten $^{766}$ aber gleichzeitig die parteipolitische Offenheit des französischen Agrarismus.

Darüber hinaus sorgten vor allem die Radicaux dafür, daß dieses Denken sich nicht auf eine konservative Agrarromantik verengte. Die Geschichte lehre, so propagierte der PRS, daß der bäuerliche Familienbetrieb dem Menschen ein Leben in guter Gesundheit und Freiheit ermögliche, die Gaben der Beobachtung, des Nachdenkens, des Maßes und der Geduld entwickele, Charakterbildung und Verantwortungsbewußtsein sichere. Der soziale, nationale und menschliche Wert der Landwirtschaft übersteige also ihren ökonomischen; die Leistungen, welche die Bauern der gesamten Nation erbrächten, seien für deren Leben unersetzlich. Auch auf die Verdienste im großen „bäuerlichen“ Krieg 1914 bis 1918 nahm man im PRS immer wieder Bezug ${ }^{767}$.

Führende Radikalsozialisten mahnten zudem, die Zahl der Verbraucher dürfe nicht immer weiter zu Lasten der Zahl der Produzenten anwachsen, andernfalls drohe „unser ganzes nationales Gleichgewicht“ zerstört zu werden ${ }^{768}$; und in der corrézischen PRS-Presse war die Forderung zu lesen, städtische Erwerbslose sollten als Bauern auf dem Land zwangsverpflichtet werden, „um die verfallenen Strohhütten wiederaufzubauen, die verlassenen Felder wiederzubewirtschaften und das notwendige Gleichgewicht zwischen Stadt und Land wiederherzustellen"769. Dabei richtete sich der radikalsozialistische Agrarismus natürlich nicht gegen die Republik, sondern öffnete dem provinziellen Ressentiment in der $\mathrm{Zu}$ spitzung der Kritik auf die Metropole Paris ein Ventil, um es gleichzeitig in demokratische Bahnen zu lenken. Erwähnt seien nur die aufschlußreichen Worte Alains: „Ach, meine Herren, wenn man die Kammer und die Regierung doch nur nach Tours oder Chateauroux verlegen könnte, dann würde die Politik sehr viel klarer werden, weniger parisienne, nationaler" 770 .

Insgesamt war es in Frankreich angesichts des „großen Schweigens der Bauern" nicht leichter als in Deutschland, die wirklichen Beweggründe der landflüchtigen Menschen zu erfassen, die zeitgenössisch meist nur von bürgerlicher

${ }^{763}$ J. Pitié, L'exode rural, 1980, S. 98 .

764 M. Robert, Les Limousins des années trente, 1989, S. 30, 45.

${ }^{765} \mathrm{~J}$. Méline, Le retour à la terre, 1905, hier zitiert nach der 6. Auflage von 1912, S. 110.

766 J.-Y. Mollier/J. George, La plus longue des républiques, 1994, S. 143.

767 L. Latty/J.-M. Royer, Les radicaux, 1958, S. 104.

${ }^{768}$ Édouard Herriot, zit. nach J. Pitié, L'exode rural, 1980, S. 268 f.

${ }^{769} \mathrm{La}$ Montagne Corrézienne, 12. 4. 1936.

770 J.-Th. Nordmann, Histoire des radicaux, 1974, S. $324 \mathrm{f}$. 
Seite, von Pfarrern, Lehrern, Ärzten, Anwälten oder Schriftstellern analysiert wurden - auch wenn etwa die Literaten des französischen Landes, von Mistral bis Bazin, sämtlich unter den Bauern gelebt, oft sensibel deren Mentalitäten erfaßt hatten und in der Zwischenkriegszeit mit Hilfe von schulischen und kirchlichen Bibliotheken oder Almanachen von der ländlichen Bevölkerung auch immer mehr gelesen wurden ${ }^{771}$. Nur vereinzelt indes war die Stimme derer zu vernehmen, die abwanderten und die jenseits aller Agrarmythologie sehr konkret wußten, wovon sie sprachen. In der französischen wie in der deutschen Provinz war es demnach nicht, oder jedenfalls nicht entscheidend, der Glanz der Stadt, sondern vielmehr das Elend des Landlebens, nicht zuletzt auch das der Bauersfrauen, das eine Familie zur Abwanderung bewog ${ }^{772}$, wobei sich materielle mit immateriellen Landflucht-Gründen mischten und der Einfluß bereits abgewanderter Verwandter maßgeblich war ${ }^{773}$. Daß die verhältnismäßig hohe Kulturreife des französischen Volkes, auch des bäuerlichen, es das "harte einsame Bauernleben besonders schwer empfinden " 774 ließ, dürfte demgegenüber empirisch kaum zu belegen sein.

Tatsächlich waren die Menschen in beiden Regionen gleichermaßen mit den ruralen Modernisierungsparadoxa von Großstadtfeindschaft und Großstadtsehnsucht konfrontiert. Daraus resultierte eine Desorientierung, die auf dem Boden traditionell unterschiedlicher Milieumentalitäten spezifische (partei-)politische Wirkungen entfaltete. Rechtskonservativ instrumentalisiert werden konnte sie am stärksten in Westmittelfranken, wo die insgesamt dominierende Richtung des deutschen Agrarkonservativismus (,ausgesprochen antibürgerlich, antiurban, antiliberal, antikapitalistisch und nicht zuletzt antisemitisch"775) schon im 19. Jahrhundert eine besondere Rolle spielte und nach 1918 dann der Liberalismus endgültig als städtisch-jüdisches Phänomen diskreditiert wurde ${ }^{776}$, so daß der deutschnationale Landbund mit seiner konservativen Agrarromantik das Feld zu beherrschen vermochte. In der Corrèze verhinderten vor allem der im Departement lange bestimmend bleibende Parti radical und die mit ihm verbundene Fédération Faure eine antiliberale und antibürgerliche Akzentierung des Agrarismus. Mit dem PRS bediente eine fest auf dem Fundament der parlamentarischen Republik ruhende Partei gerade auch die antiurbanen Affekte der ländlichen Klientel;

${ }^{771}$ P. Barral, Les agrariens français, 1968, S. 130; vgl. auch J. Pitié, L'exode rural, 1980, S. 114; Histoire de la France rurale, Bd. 4, 1977, S. 470.

772 Vgl. den Lebensbericht des Kleinbauern J. L. Vidal, Ils s'en vont. Pourquoi je ne suis pas resté petit cultivateur, 1927; daneben den von M. Thorez anhand der Verhältnisse im Limousin konzipierten Artikel „La femme au village“, in: L'Humanité, 3. 7. 1939, zit. bei J. Pitié, L'exode rural, 1980, S. 114 u. 268 f., sowie E. Guillaumin, Panorama de l'évolution paysanne, 1936, S. 67.

${ }^{773}$ Vgl. L. P. Moch, Paths to the city, 1983, S. 199; E. Weber, La fin, 1983, S. 414; La Croix de la Corrèze, 29. 2. 1932.

${ }_{774}$ P. Quante, Die Flucht aus der Landwirtschaft, 1933, S. $264 \mathrm{f}$.

775 W. Kaschuba, Dörfliche Kultur, 1990, S. 281. Eine bürgerliche Phase und bürgerliche Werte seien „im Übergang von altständischen zu berufsständisch/mittelständischen und völkisch-präfaschistischen Orientierungen“" gewissermaßen „übersprungen“" worden

776 Dennoch gab es auch in den bürgerlichen Mittel- und selbst den linksliberalen Parteien agrarromantisches Denken, was etwa Heinrich Brüning und Hermann Dietrich auf dem Höhepunkt der Weltwirtschaftskrise dazu verleiten sollte, angesichts einer vermeintlichen „Überindustrialisierung" Deutschlands Primitivsiedlungskonzepte zu entwerfen. Vgl. H. Mommsen, Nationalismus, 1994, S. 88. 
die Radicaux streuten zwar ebenfalls agrarpopulistische Parolen aus, auf der anderen Seite verwiesen sie republikanisch-konstruktiv auf die Erfolge regionaler Strukturpolitik ${ }^{777}$ und demonstrierten auch in einem "Comité de retour à la terre", das den Segen des Präfekten hatte, ihre politische Sensibilität ${ }^{778}$. So gelang es im Verlauf der Weltwirtschaftskrise faschistischen Kräften überhaupt nicht, den Kommunisten lediglich in den Landfluchtzonen der Nord-Corrèze, antikapitalistische und antietatistische Elemente des ideologisch disparaten Agrarismus stärker für sich nutzbar zu machen ${ }^{779}$, während in Westmittelfranken die NSDAP auf den rechtskonservativen Traditionen der nationalen Agrarromantik ${ }^{780}$ aufbauen konnte, als um 1929/30 in der deutschen Provinz die Großstadtfeindschaft „in nie gekannter Schärfe" aufflackerte ${ }^{781}$.

\section{Regionalistische Potentiale}

Waren Agrarromantik und Agrarismus nationale Phänomene der deutschen bzw. französischen politischen Kultur, die sich im Prozeß der ökonomischen und gesellschaftlichen Modernisierung vor dem Hintergrund traditionaler Milieumentalitäten in Westmittelfranken und der Corrèze nur spezifisch ausprägten, so wurde der klassische Konflikt zwischen Peripherie und Zentrum in der Provinz beider Länder mancherorts noch durch einen weiteren, im engeren Sinn regionalistischen Impuls mit bestimmt, der gleichzeitig wirtschaftlich wie ethnisch-kulturell und emotional motiviert sein konnte. Denn generell blieben die sozio-territorialen Bindungen der Menschen an ihren engeren Lebensraum auch in der Moderne ein wichtiger mentaler Bezugshorizont ${ }^{782}$, zumal für die, die sich gegen die Landflucht entschieden. Parallel zum Ausbau des National- und Industriestaates war am Ende des 19. Jahrhunderts ein Trend zum Regionalen gelaufen ${ }^{783}$; dabei hatte das Provinzproblem gegenüber früheren Provinzphänomenen einen grundlegend anderen Charakter "von der Quantität, der Qualität und dem Tempo her“ gewonnen ${ }^{784}$, d.h. die Unterschiede zwischen industrialisierten und agrarischen Regionen wurden immer größer ${ }^{785}$. Der für traditionale Gesellschaftsstrukturen besonders charakteristische Identifikationskomplex "Heimat" ${ }^{486}$, als Grundlage der gesellschaftlichen Existenz des einzelnen, konnte sich dabei zum einen kultur-

777 Siehe etwa: La Montagne Corrézienne, 12.3. 1928.

${ }^{778}$ Vgl. den Bericht in L'Union Républicaine de la Corrèze, 4. 3. 1923.

779 Vgl. P. Bitoun, Agriculture et politique, 1981, S. 74.

${ }^{780}$ Vgl. auch H.-J. Puhle, Stichworte, 1990, S. 281.

${ }^{781}$ K. Bergmann, Agrarromantik und Großstadtfeindschaft, 1970, S. 281.

782 P. Weichhart, Raumbezogene Identität, 1990, S. 27.

${ }^{783} \mathrm{~K}$. Möckl, Föderalismus und Regionalismus im Europa des 19. und 20. Jahrhunderts, 1983, S. 538; Maurice Agulhon meint sogar, der französische Regionalismus habe sich umgekehrt proportional zur Intensität des Nationalbewußtseins entwickelt, habe also von dessen Krisen profitiert. Vgl. M. Agulhon, Conscience nationale et conscience régionale en France, 1988.

${ }^{784}$ G. Zang, Provinzialisierung einer Region, 1978, S. 18.

785 Vgl. K. Duwe, Regionalismus in Europa, 1987; S. Pollard, Region und Industrialisierung, 1980.

${ }^{786}$ Vgl. auch L. Krappmann, Soziologische Dimensionen der Identität, 1973. 
landschaftlich äußern ${ }^{787}$, aber teilweise auch „zu einem politischen Selbstverständnis" drängen ${ }^{788}$.

\section{Historische Grundlagen}

Im Grunde genommen war das Handicap der Provinz „so alt wie die Stadt selbst "789; schon die athenischen Großstädter hatten ihre Witze über die Böotier gemacht. Jenseits dieses immerwährenden Strukturproblems aber waren die Ausgangsbedingungen für regionalistische Strömungen in Deutschland und Frankreich ganz unterschiedlich ${ }^{790}$. Das südfranzösische Okzitanien, zu dem das Limousin zählt, wurde bis zur Französischen Revolution in Paris sogar als „Ausland" bezeichnet ${ }^{791}$. Dem Ancien Régime war es bis zuletzt nicht gelungen, die alten territorialen Organisationsformen und die Fülle der Regionalsprachen zu vereinheitlichen ${ }^{792}$. Dies geschah erst ab 1789, nachdem die Jakobiner im Namen der Gleichheit und zur besseren Verbreitung der revolutionären Ideen immer stärker zentralistische Prinzipien durchgesetzt hatten. Französisch wurde nun zur Sprache des Fortschritts und der Freiheit, während Dialekte als rückständig identifiziert wurden ${ }^{793}$. Auf der administrativen Ebene krönte Napoleon die Machtausübung von Paris aus, indem er weisungsgebundene Präfekten für jedes der Departements - die neue Verwaltungseinheit seit 1790 - einsetzte ${ }^{794}$.

Aus einer antizentralistischen Gegenbewegung heraus bildete sich $1854 \mathrm{im}$ Bund des Félibrige eine Gruppe junger Intellektueller um den Dichter Frédéric Mistral ${ }^{795}$. Ausgehend von der engeren Provence erfaßte er den gesamten okzitanischen Raum mit seinem Anliegen, die regionale Sprache und Literatur zu erhalten bzw. wiederzubeleben, die damals nicht mehr geschrieben, immerhin aber noch als Mundart viel gesprochen wurde. Noch 1863 war die Mehrzahl der corré-

${ }^{787}$ Zum Begriff der „Kulturprovinzen“ als Schlußstein der historisch-landeskundlichen Arbeit bei Hermann Aubin vgl. ders., Grundlagen und Perspektiven geschichtlicher Kulturraumforschung, 1965, S. 24.

${ }^{788}$ K. Möckl, Föderalismus und Regionalismus, 1983, S. 546; Region ist nach Möckl (S. 530) mit der Bezeichnung n Geschichtslandschaft" identisch, geht aber darüber hinaus und ist von stärker historischer Begrifflichkeit. Vgl. ferner A. H. von Wallthor und H. Quirin, „Landschaft“ als interdisziplinäres Forschungsproblem, 1977; K.-G. Faber, Geschichtslandschaft - Région historique - Section in History, 1979.

${ }^{789}$ C. Améry, Die Provinz. Kritik einer Lebensform, 1966, S. 7; vgl. auch H. J. Priamus/R. Himmelmann, Stadt und Region - Region und Stadt, 1993.

790 Was M. Broszat zum Provinz-Thema gesagt hat, daß es sich nämlich aufgrund der Inkongruenz seiner Bezugsfelder und Konnotationen einer Systematisierung entziehe, gilt erst recht für die vergleichende interregionale Perspektive. Das folgende hat demzufolge, wenigstens streckenweise, den Charakter einer Annäherung. Vgl. das Geleitwort Broszats in G. Zang, Provinzialisierung einer Region, 1978, S. 9.

${ }^{791}$ A. Hense, Der okzitanische Regionalismus, 1980, S. 170.

792 Wie sehr der unitarisch-zentralistische Charakter des Ancien Régime überschätzt worden ist, hat Hedwig Hintze herausgearbeitet. Vgl. dies., Staatseinheit und Föderalismus im alten Frankreich und in der Revolution, 1989. Von einer „ambivalenten Bilanz “ des Ancien Régime spricht auch J. Revel, La région, 1992, S. 862.

${ }^{793}$ R. Brütting, Okzitanische Perspektiven des Regionalismus, 1981, S. 138; S. Deimel/K. Dittrich, Die Okzitaner, 1980, S. 217.

794 Zur Entstehungsgeschichte der Departements M. Roncayolo, Le département, 1992, sowie P. Barral, Le département, une réalite française, 1991.

${ }^{795}$ Zum Félibrige vgl. einführend P. Martel, Félibres et Félibrige, 1984; R. Jouveau, Histoire du Félibrige, 1977; R. Lafont, La revendication occitane, 1974. 
zischen Gemeinden nicht frankophon, und die breiten ländlichen Grundschichten hielten bis ins 20. Jahrhundert hinein - parallel zum allmählich vor allem bei der Schuljugend vordringenden Französisch - an ihrer regionalen Sprache fest ${ }^{796}$. Allerdings fanden die Menschen Okzitaniens, als sie am Ende des 19. Jahrhunderts - anhand des Französischen - Lesen und Schreiben lernten, die Lektüre ihres Dialekts sehr schwierig, um so mehr als sich mit französischer Orthographie der Klang der Langue d'oc nicht adäquat ausdrücken ließ und die teils archaisch anmutende okzidentalische Hochsprache den Entwicklungen der zahlreichen lokalen Einzeldialekte nicht Rechnung trug ${ }^{797}$. So blieb regionalistisches Engagement bis 1914 vor allem die Sache einer - in der Corrèze nur wenige hundert FélibreMitglieder umfassenden ${ }^{798}$ - kleinen Geburts-, Vermögens- oder Geisteselite, von der großen Volksmasse ebenso abgehoben wie von den wichtigsten Vertretern der „kapitalistischen Bourgeoisie“, die aufgrund ihrer ökonomischen Interessen viel zu sehr an die nationale Einheit gebunden war, als sich regionalistischen Träumen hinzugeben ${ }^{799}$.

War der von einer kulturellen Elite getragene Regionalismus im Frankreich des 19. Jahrhunderts vor allem sprachenpolitisch motiviert, so nahm er in Deutschland seinen Ausgang von den alten territorialen Traditionen, von dynastischen und nicht zuletzt konfessionellen Identitäten, die im Zuge der napoleonischen „Flurbereinigung“ 1803/06 oder durch die preußische Ausdehnungspolitik zwischen 1815 und 1870 verletzt worden waren. Daraus resultierten die regionalistischen Potentiale in den welfischen Kernlanden des Königreichs Hannover, in den katholischen Rheinlanden, auf spezifische Weise in Elsaß-Lothringen, in der „politischen Landschaft" des katholischen Oberschwaben ${ }^{800}$ und gerade auch im bayerisch gewordenen, evangelischen Teil Frankens.

Vor allem im Bereich der ehemaligen Markgraftümer Ansbach und Bayreuth gab es eine dynastische Anhänglichkeit an das alte Herrscherhaus der Hohenzollern; denn die Verbundenheit zwischen deren fränkischer und brandenburgischpreußischer Linie war in den Jahrzehnten vor der Annexion durch Bayern eindrucksvoll bestätigt worden, nachdem der letzte Ansbacher Markgraf abgedankt, Karl August von Hardenberg 1790 die Verwaltung der fränkischen Fürstentümer für Preußen übernommen und aus einer Agglomeration von Herrschaftsrechten und Gerichtsbarkeiten einen einheitlichen und geschlossenen modernen Staat gebildet hatte ${ }^{801}$. Als im Winter 1805/06 erstmals Gerüchte auftauchten, der Übergang an Bayern stehe bevor, richtete die beunruhigte Bevölkerung zahlreiche Bittschriften nach Berlin und flehte "mit blutendem Herzen zu ihrem König“, er möge das „heilige und ehrwürdige Band, welches die Vorsehung seit einem Jahrtausend zwischen den biederen Einwohnern von Anspach und Baireuth und den Brandenburgischen Beherrschern knüpfte", nicht gewaltsam lösen ${ }^{802}$. Zwar ging Montgelas schon im ersten Jahrzehnt der bayerischen Herrschaft daran, die neuen

\footnotetext{
${ }^{796}$ M. Robert, Les Limousins des années trente, 1989, S. 60.

797 E. Weber, La fin, 1983, S. 109, 118, 125.

798 L. Pérouas, Une religion des Limousins?, 1993, S. 114.

$799 \mathrm{Ph}$. Vigier, Régions et régionalisme en France, 1977, S. 172.

${ }^{800}$ Vgl. H. Gollwitzer, Die politische Landschaft, 1964, S. $533 \mathrm{ff}$.

801 R. Ecke, Franken 1866, 1972, S. 45 f.

${ }^{802}$ U. Thürauf, Die öffentliche Meinung im Fürstentum Ansbach-Bayreuth, 1918, S. $91 \mathrm{ff}$.
} 
fränkischen Provinzen mit „bayerischem Nationalgefühl“ zu beseelen und vor allem die Beamtenschaft zur Mitarbeit beim Aufbau des modernen Bayern zu gewinnen ${ }^{803}$; doch noch Jahrzehnte später wäre Ludwig I. bereit gewesen, sich von den „fortwährend nicht anhänglichen Ansbachischen Bewohnern" zu trennen, wenn er damit die alte Kurpfalz wiedererwerben und eine territoriale Verbindung zum linksrheinischen Bayern hätte erreichen können ${ }^{804}$.

Günstiger für Bayern entwickelte sich zunächst die Stimmung in den mediatisierten freien Reichsstädten zumindest beim Bildungs- und Besitzbürgertum, dem es im Zuge der territorialen Neuordnung gelungen war, die jahrhundertealte Vorherrschaft einer dünnen patrizischen Oberschicht zu durchbrechen und fortan am Stadtregiment beteiligt zu werden ${ }^{805}$. Allerdings blieb gerade in den von der Industrialisierung kaum erfaßten alten Reichsstädten Westmittelfrankens in der politischen Aktivbürgerschaft ein ausgeprägtes „Bewußtsein von der besonderen historischen Vergangenheit ihrer Stadt" erhalten ${ }^{806}$, das sich noch einige Zeit lang als Österreich-Nostalgie artikulierte ${ }^{807}$. Die dann in der zweiten Hälfte des 19. Jahrhunderts verstärkt in restaurativer Form betriebene „reichische“ Traditionspflege enthielt - angesichts der spürbar gewordenen wirtschaftlichen Abseitsstellung der ungünstig im Grenzgebiet zu Württemberg gelegenen Städte - immer auch einen antibayerischen Unterton. Spätestens ab 1866/1871, als auch die Reichsstädter nicht mehr Österreich, sondern Preußen den „deutschen Beruf“ am ehesten zutrauten $^{808}$, verschmolz ihr - Bayern-kritisches - Bewußtsein mit der alten brandenburgischen Erinnerung in der Ansbacher Markgrafschaft zur spezifischen Form einer protestantisch geprägten fränkisch-nationalen Identität ${ }^{809}$.

Zur Verbundenheit mit den Hohenzollern, die im Kloster Heilsbronn eine Grablege hatten, trug wesentlich ein konfessionalistischer Motivationsstrang bei: nachdem die lutherischen Franken in den 1830er Jahren zum Opfer der Münchner Kniebeugungspolitik geworden waren, erneuerte sich die fränkische Affinität zu Preußen als der Schutzmacht des deutschen Protestantismus. Jedenfalls blieben die Bindungen an Preußen trotz aller Ergebenheitsadressen an das wittelsbachische Königspaar, etwa bei dessen Huldigungsreise durch Franken $1849^{810}$, in den mentalen Tiefenschichten weiter wirksam. Als zum Sedanstag 1880 der preußische Kronprinz Friedrich nach Westmittelfranken kam, bereiteten ihm die Rothenburger - vom Schützenverein bis zum Evangelischen Arbeiterverein - in der mit den Fahnen des neuen Reiches geschmückten Stadt einen begeisterten Emp-

${ }^{803}$ R. Endres, Der „Fränkische Separatismus“, 1980, S. 163.

${ }^{804}$ H. Meinhart, Franken in Bayern - Ein Problem!, 1949, S. 22.

${ }^{805}$ R. Endres, Der "Fränkische Separatismus“, 1980, S. 163 f. Allerdings sahen sich z. B. in Rothenburg auch jene Bürger, „die die Liquidation des reichsstädtischen Regiments enthusiastisch begrüßt hatten, ... angesichts der wirtschaftlichen Benachteiligung seit Aufhebung der staatlichen Souveränitätsrechte alsbald um ihre anfänglichen Hoffnungen betrogen“. G. Moritz, Rothenburg, 1996, S. 319.

${ }^{806}$ G. Hirschmann, Fortleben reichsstädtischen Bewußtseins in Franken nach 1806, 1968, S. 31.

${ }^{807}$ Der Rothenburger Stadtpfarrer brachte 1817 von der Kanzel herab sein Bedauern zum Ausdruck, „daß wir nicht so glücklich gewesen, wieder unter den segensreichen Schutz Österreichs zu kommen ...“. G. Moritz, Rothenburg, 1996, S. 318.

${ }^{808}$ Vgl. etwa G. Moritz, Rothenburg, 1996, S. 342.

${ }^{809}$ Zum Begriff des „Evangelischen Frankenlandes“ vgl. H. Gollwitzer, Die politische Landschaft, 1964, S. 535.

${ }^{810}$ R. Endres, Der „Fränkische Separatismus“, 1980, S. 174 f. 
fang; und „besonders auch aus dem Bauernstande“, so die Beobachtung der Lokalpresse, „hat sich unser hoher Gast alle Herzen im Fluge gewonnen"811.

Neben den historischen, ökonomischen und konfessionellen Aspekten hatte der fränkische Regionalismus noch eine weitere kulturpolitische Dimension. So beanstandete Wilhelm Löhe im Jahre 1848, daß „die fränkischen Kinder nichts von ihrem Stamm und von der fränkischen Geschichte erfahren", daß sie geradezu erzogen würden, „als wären sie baierischen Stammes“. Das seit 1848 weiter verstärkte Bestreben der Münchner Kulturpolitik, die Anhänglichkeit der fränkischen Schulkinder an die bayerische Dynastie zu fördern ${ }^{812}$, veranlaßte den Rektor des Ansbacher Gymnasiums zu der Einwendung, nicht nur „die ganze bayerische Geschichte verdiene eine Behandlung", vielmehr sei auch die Geschichte der einzelnen bayerischen Provinzen "gleichmäßig zu pflegen“. Der von der Regierung verwarnte Pädagoge erhielt daraufhin die Aufforderung, binnen 24 Stunden anzuzeigen, "wieviel Stunden Unterricht in der verlangten bayerischen Geschichte erteilt werde "813. Ob die fortan „allzu gerne“ verbreitete Geschichtsklitterung, Franken habe einst ganz zum baierischen Nordgau gehört und sei 1806 nach Jahrhunderten „zur alten Stammesheimat zurückgekehrt“, das fränkische Stammesgefühl tatsächlich so schwer verletzte, wie dies Regionalisten später behaupteten ${ }^{814}$, braucht hier nicht abschließend geklärt zu werden. Ebenso am Rande der Erörterung kann die Diagnose einer „tiefen Wesensverschiedenheit Altbayerns von Franken und Schwaben" bleiben ${ }^{815}$, weil viel entscheidender und empirisch immer wieder zu belegen - jedenfalls das Bewußtsein war, im Verhältnis zum katholischen Altbayern von der Münchner Regierung benachteiligt zu werden.

Unter Prinzregent Luitpold, dessen Mutter evangelisch war, verstärkten sich indes die staatsbayerischen Überzeugungen im fränkischen Luthertum, nachdem schon die Politik des Ministeriums von der Pfordten in den 1860er Jahren versucht hatte, eine Synthese zwischen der Loyalität zum Königreich Bayern „und dem Wunsch nach Deutschlands Einigung " zu fördern ${ }^{816}$. Oberkonsistorialpräsident von Bezzel hielt dem Regenten anläßlich seines 90 . Geburtstages im März 1911 sogar zugute, in „das Erbe der fränkischen Fürsten eingetreten“" zu sein und das protestantische Kirchenwesen in den Landbezirken ebenso gestärkt und geschützt zu haben wie die theologische Fakultät zu Erlangen ${ }^{817}$. Doch trotz allem mochte sich die Pfarrerschaft des alten Reichskreises Franken „politisch im katholischen Bayern nie so ganz zu Hause fühlen "818; um die protestantische Geistlichkeit herum

811 Zur Reise des Kronprinzen, der auch dem Fürsten Hohenlohe in Schillingsfürst und dem Militär in Katterbach bei Ansbach einen Besuch abstattete, vgl. den Bericht in der Fränkischen Zeitung, 1. 9.1880 (Zitat) u. 5. 9. 1880.

812 Zur bayerischen Schulbuchpolitik vgl. W. K. Blessing, Staat und Kirche, 1982, S. 166.

${ }^{813}$ H. Meinhart, Franken in Bayern - Ein Problem!, 1949, S. 77.

${ }^{814}$ Ebd., S. 26, 77.

${ }^{815}$ In Wirklichkeit waren sich Franken und Altbayern ethnisch viel ähnlicher, als ,romantische Stammeslegenden" dies behaupteten. K. Bosl, Franken und Altbayern, 1970, S. 6.

${ }^{816}$ G. Moritz, Rothenburg, 1996, S. 340 f.

${ }^{817}$ LkAN Bay. Dekanat Windsbach, Nr. 172: Sonderabdruck aus Nr. 69 des Fränkischen Kuriers vom 9. März 1928.

${ }^{818}$ C. J. Roepke, Die Protestanten, 1972, S. 392 f. 
kristallisierte sich vielmehr eine von manchen als politisch dysfunktional empfundene, zumindest unterschwellig regionalistische Attitüde in der Bevölkerung ${ }^{819}$.

\section{Protestantischer Regionalismus in Westmittelfranken}

Wie virulent der Regionalismus im Westen Mittelfrankens während der Weimarer Jahre blieb, erwies sich in krisenhaften Situationen immer wieder. Schon der Münchner Räterevolution 1919 wurde in stürmischen Bauernversammlungen mit der Drohung „einer Lostrennung Frankens von Bayern“ begegnet, falls es der derzeitigen Regierung nicht gelingen sollte, „allen kommunistisch-bolschewistischen Umtrieben schärfstens entgegenzutreten "820. Als im Dezember 1919 dann die organisatorische Zukunft des Bundes der Landwirte im Reich auf dem Spiel stand, beharrte der mittelfränkische BdL-Führer Beckh darauf, daß „wir uns von den Ostelbiern nicht lossagen ... Ich halte von Bayern, seit sie nun sogar ihren König von den Juden haben davonjagen lassen, gar nichts ... "821. Auch im kirchlichen Bereich erschien manchen "die Trennung Frankens von Bayern immer wünschenswerter", denn mit der Abdankung des Königs war das Band, „das uns Franken an Bayern gebunden hat", beseitigt, und die Überzeugung wuchs, auch ohne Altbayern bestehen zu können, wenn "man in München keine Vernunft annehmen will“; schließlich sei Franken viele Jahrhunderte ein blühendes Land gewesen, ehe es "von Napoleon an Bayern verschenkt wurde" ${ }^{\text {"822 }}$.

Die Nationalkonservativen besaßen allerdings kein Monopol auf das regionalistische Sentiment. Bei Bedarf verstanden es vielmehr auch die Sozialdemokraten für sich zu nutzen, besonders nachdem die landespolitischen Machtverhältnisse sich grundlegend gewandelt hatten und der weit rechts stehende, monarchistischer Neigungen verdächtige von Kahr die Landesregierung übernommen hatte. Als es bei den Verfassungskonflikten zwischen der von Kahr vertretenen „Ordnungszelle Bayern" und der weiter links angesiedelten Berliner Reichsregierung zu Separationsdrohungen des Freistaats kam, löste dies bei „allen wahrhaft freiheitlich Gesinnten in Franken“ heftige Gegenreaktionen aus. Der heimische SPDAbgeordnete (und spätere Reichskanzler) Hermann Müller sprach nun, im Herbst 1921, offen von der Möglichkeit, eine umfassende Bewegung „zur Bildung eines selbständigen Franken" einzuleiten, falls die Kahr-Regierung im Streit mit Berlin nicht einlenkte ${ }^{823}$.

Die von den Nürnberger Mehrheitssozialdemokraten im Namen der fränkischen Arbeiterschaft ausgegebene Parole „Los von Bayern“ stieß dieses Mal allerdings im agrarprotestantischen Milieu, anders noch als 1919, auf wenig Gegenliebe. Der Bund der Landwirte wies die separatistischen Forderungen als „Frankenhetze“ zurück: „Die bodenständige Bevölkerung Frankens hält fest am Reiche, aber auch ebenso fest am bayerischen Staatsgedanken." Sich von Südbay-

${ }^{819}$ Vgl. W. K. Blessing, Staat und Kirche, 1982, S. $53 \mathrm{f}$.

${ }^{820}$ Fränkische Zeitung, 8. 4. 1919A.

821 M. Schumacher, Land und Politik, 1978, S. 482.

${ }^{822}$ Der Freimund, 1919, S. 56 u. 64; vgl. auch H. Speckner, Die Ordnungszelle Bayern, 1955, S. 40.

${ }^{823}$ R. Endres, Der "Fränkische Separatismus", 1980, S. 181, sowie undatierter Zeitungsartikel "Was wird werden?", in: StAN Pol. Nü-Fü, Nr. 537. 
ern und damit von Süddeutschland zu trennen, hätte für die fränkische Bauernschaft angesichts der politischen Konstellationen in München und Berlin nunmehr bedeutet, sich erneut „dem roten Terror ausliefern zu lassen " 824 .

Im Frühling des Krisenjahrs 1923 drohte die fränkische SPD auf dem Landesparteitag abermals mit der Lostrennung Frankens von Bayern ${ }^{825}$. Zwar sah sie sich von der Parteiführung in Berlin zurechtgewiesen, im Herbst wurden dennoch die Urheber einer weiteren Bewegung für die Errichtung einer Republik Franken „wohl in den Reihen der M.S.P." vermutet. In die Provinzpresse Westmittelfrankens fand dabei ein Artikel der Deutsch-Evangelischen Korrespondenz Eingang, der "den unter katholischem Einfluß stehenden Generalstaatskommissar" in München attackierte und mit dem Gedanken spielte, das protestantische Franken „von einem katholisch regierten, vom Reich sich trennenden Bayern“ abzulösen $^{826}$.

Auch in den folgenden Jahren hatte der mittelfränkische Regierungspräsident immer wieder Anlaß zur Klage, daß „republikanisch gesinnte Einwohner ... sich in außerbayerischen Teilen des Reiches und im Auslande geflissentlich als ,Franken' unter ausdrücklicher Ablehnung ihrer Eigenschaft als ,Bayern" " bezeichneten $^{827}$. Insgesamt verschob sich aber in der Mitte der 1920er Jahre das regionalistische Potential wieder nach dem nationalprotestantischen Spektrum hin; die Gefahr wuchs, „daß gerade durch die konfessionelle Spannung der bayerische Staatsgedanke empfindlich beschädigt werden kann "828. Denn das ausgeprägt stammesmäßige Sonderbewußtsein in einer der reichsten deutschen Kulturlandschaften, wie es z.B. aus einem Vortrag zum Wesen des „Fränkischen Protestantismus" auf der Erlanger Bezirkssynode 1926 sprach $^{829}$, erhielt aus den fortdauernden konfessionalistischen Affekten weiterhin wichtige Impulse, vor allem als in München im Rahmen einer sogenannten Staatsvereinfachung die Zusammenlegung der Ansbacher und Bayreuther Kreisregierungen nach Nürnberg diskutiert wurde. „Ursprünglich hatte man sogar daran gedacht, die Stadt Bamberg zum Regierungssitz für Mittel- und Oberfranken zu machen", empörten sich fränkische Lutheraner, dann wären „sämtliche bayerischen Regierungen in Bischofstädten gewesen "830. Pfarrer Steinlein brachte bei einer Ansbacher DNVP-Versammlung diesbezügliche „Besorgnisse des evangelischen Bevölkerungsteiles von Franken“ zum Ausdruck ${ }^{831}$; da es sich bei den Plänen „nicht um einen Einzelfall“ von Benachteiligung handelte, sondern „um eine Erscheinung, die wir Protestanten in Bayern nachgerade gewöhnt sind", rief sie - im übrigen auch im sozialdemokratischen Lager - viel Verbitterung hervor ${ }^{832}$. Als auch noch der Münchner Oberbür-

\footnotetext{
${ }^{824}$ Undatierter Zeitungsartikel „Eine deutliche Absage“, in: StAN Pol. Nü-Fü, Nr. 537.

${ }^{825}$ R. Endres, Der „Fränkische Separatismus“, 1980, S. 182.

${ }^{826}$ HStAM HMB, 19. 12. 1923.

${ }^{827}$ HStAM HMB, 19. 9. 1925.

${ }^{828}$ LkAN Bay. Dekanat Windsbach, Nr. 172: Sonderabdruck aus Nr. 69 des Fränkischen Kuriers vom 9. März 1928.

${ }^{829}$ K. Th. Bach, Das Verhältnis, 1982, S. 25.

830 Der Freimund, 1927, S. 403.

${ }^{831}$ HStAM HMB, 18. 11. 1927.

${ }^{832}$ Ebd.
} 
germeister proklamierte, „München ist Bayern“, wurde er daran erinnert, daß Bayern eine Demokratie sei, in der die Staatsgewalt vom Volke ausgehe ${ }^{833}$.

Zunehmend ging der ganze „Partikularismus der bayer. Regierung", die durch eigene Feiern „selbst am Volktrauertag ... die deutsche Volksgemeinschaft" störte, fränkischen Nationalprotestanten gegen den Strich ${ }^{834}$. So konnte die von Oberbayern ausgehende Heimatschutz-Bewegung zur Erhaltung der Eigenstaatlichkeit Bayerns und gegen eine zentralistische Reichsreform in Mittelfranken wenig Anklang finden: „Den meisten erscheint die Erhaltung der Reichseinheit wichtiger als die der Eigenstaatlichkeit der Länder. " ${ }^{835}$ Zwar lehnte man das Regieren vom „Kultur- und Börsenzentrum“ Berlin aus ab, hegte aber ebenso gegen München „einiges Mißtrauen“ und fürchtete separatistische und katholisch-klerikale Tendenzen in der Heimatschutz-Bewegung. Daß diese zur „Aufreißung einer Donaulinie führen“ müßten, fand nicht nur der deutschnationale Dinkelsbühler Bürgermeister "höchst bedenklich“836; auch das fränkische Landvolk, das im Sommer 1932 zahlreich den Schwedentag auf dem Hesselberg besuchte, wurde in seiner Ansicht bestärkt, für „uns Franken“ gebe es keine Mainlinie, sondern nur Brücken über den Main. Denn „über den Ländern steht das einige deutsche Reich"837.

Die sich verschlechternde Wirtschaftslage Ende der 1920er Jahre ließ vor allem die ökonomische Benachteiligung Frankens wieder verstärkt zum Thema werden ${ }^{838}$. In den evangelischen Kreisen des alten Reichsstädtchens Dinkelsbühl begegnete speziell die angebliche „Parteiherrschaft der bayerischen Volkspartei in Bayern" einem ständig wachsenden Mißtrauen ${ }^{839}$. So weit diese Einschätzung angesichts des erheblichen Einflusses der fränkisch-protestantisch geprägten DNVP in der Landesregierung - von der politischen Realität entfernt sein mochte ${ }^{840}$, so sehr hatte sich beim Dinkelsbühler Stadtrat die Meinung erhärtet, daß bei wirtschafts- und personalpolitischen Maßnahmen, insbesondere bei der Besetzung von Führungspositionen, nicht in erster Linie sachliche Gesichtspunkte maßgeblich waren, sondern Mitglieder der BVP oder anderer katholischer Organisationen bevorzugt würden.

Die Stimmung konnte auf der schon älteren Verärgerung unter der evangelischen Minderheit in Bayern aufbauen, deren Steuererträge die der Katholiken zwar fast erreichten, ohne daß dieses Steuerertragsverhältnis aber die Grundlage der „Parität“ bei der Verteilung der Staatszuschüsse an die beiden Kirchen bildete. Hinzu kam ein als ungerecht empfundenes Landtagswahlrecht, bei dem ein niederbayerischer Abgeordeter nur zwei Drittel der Stimmen benötigte, die man im dichter besiedelten Mittelfranken brauchte, um ein Mandat zu erringen. Demnach hatte Mittelfranken ein Drittel weniger Sitze als ihm zustanden und war „dauernd

${ }^{833}$ Der Freimund, 1929, S. 73.

${ }^{834}$ Ebd.

${ }^{835}$ HStAM HMB, 19. 12.1928.

${ }^{836} \mathrm{HStAM}$ HMB, 7. 1. 1930.

${ }^{837}$ Fränkische Zeitung, 5. 7. 1932.

${ }^{838}$ HStAM HMB, 19. 6. 1929, 4. 7. 1929.

${ }^{839}$ HStAM HMB, 7. 1. 1930.

${ }^{840}$ Vgl. M. Kittel, Z wischen völkischem Fundamentalismus und gouvernementaler Taktik, 1996, v. a. S. $878 \mathrm{ff}$. 
politisch stark benachteiligt “841. Die fränkische Sensibilität in Fragen der Gleichberechtigung war so groß, daß es schon übel vermerkt wurde, wenn den „Beteuerungen der heutigen Regierung (in München) der Ton der Herzlichkeit" gegenüber den nördlichen Landesteilen fehlte ${ }^{842}$.

Vor diesem Hintergrund suchte die NSDAP bei ihrem Aufstieg in der evangelischen Agrarprovinz beständig auch die regionalistischen Schichten der Milieumentalität in Westmittelfranken anzusprechen, die keineswegs „fast ganz auf die NS-Propaganda zurückzuführen" waren ${ }^{843}$. Allerdings hatten die Nationalsozialisten tatsächlich schon früh, 1925, ein „Erwachen des fränkischen Stammesbewußtseins" propagiert, und Streicher, obwohl von Geburt bayerischer Schwabe, betonte mehrfach, wie wenig Vertrauen Franken in die Münchner Regierung haben könne. Als die NSDAP Anfang der 1930er Jahre - trotz großer Stimmengewinne im Reich und im evangelischen Franken - im von der BVP dominierten Freistaat nicht vorankam, setzte sie in Franken noch stärker auf den antibayerischen Affekt und erzielte bei ihren Versammlungen mit Invektiven gegen die Regierung in München den „größte(n) Beifallssturm " ${ }^{844}$. Die weit über dem Landesdurchschnitt liegenden Wahlerfolge der NSDAP im evangelischen Bayern entwickelten nun zunehmend eine Eigendynamik, in deren Folge Franken und der Nationalsozialismus in der Außen- wie in der NS-Binnen-Perspektive fast zu einer Einheit verschmolzen.

\section{Katholischer versus republikanischer Regionalismus in der Corrèze}

Der fränkische Regionalismus, in spezifischer Weise mit dem protestantischen Konfessionalismus verbunden, hatte im altgläubigen bzw. antiklerikalen Limousin naturgemäß nicht seinesgleichen. Kleriker spielten in französischen Regionalbewegungen aber ebenfalls eine führende Rolle, im Limousin insgesamt weniger als andernorts - die Initiative zur Gründung des regionalen Félibrige 1890 war von dem jungen Briver Journalisten Louis de Nussac ausgegangen ${ }^{845}$-, doch auch hier waren die den Regionalismus tragenden Notabeln dem Katholizismus eng verbunden; und Joseph Roux, der aus einer Tuller Handwerkerfamilie stammende geistige Vater des limousinischen Félibrige und Verfasser einer "Grammaire limousine“, arbeitete selbst als Landpfarrer ${ }^{846}$. Roux repräsentierte den verbreiteten Typus des niederen Geistlichen, der mitten im Volk wirkte, gar nicht umhinkam, den regionalen Dialekt zu sprechen, und der sich vor diesem Hintergrund besonders um die Pflege des heimatlichen Idioms bekümmerte. Aber auch höhere

${ }^{841}$ Der Freimund, 1929, S. 175,1931 , S. 319

842 LkAN Bay. Dekanat Windsbach, Nr. 172: Sonderabdruck aus Nr. 69 des Fränkischen Kuriers vom 9. März 1928.

${ }^{843}$ Hier scheint R. Hambrecht (Der Aufstieg, 1976, S. 257) den Einfluß der NS-Agitation zu über-, die regionalistischen Potentiale in der Gesamtgesellschaft zu unterschätzen.

844 Ebd.

${ }^{845} \mathrm{~J}$. Nouaillac, Histoire du Limousin et de la Marche, 1931, S. 267.

${ }_{846}$ M. Zorzi, La conscience régionale, 1996, S. 35 ff.; M.-F. Andrieux, Le Félibre en Limousin, 1985 , S. 34, 224, und G. Cholvy, Régionalisme et clergé catholique, 1977, S. 196. 
Geistliche wie der Bischof von Limoges bedienten sich zur Evangelisation der Landbevölkerung der heimischen Mundart ${ }^{847}$.

Die Kirchenverwaltung mit ihren siebzehn Provinzen entsprach den großen historisch gewachsenen Regionen Frankreichs und setzte sich über die zentralistisch-"revolutionäre" Departementseinteilung hinweg ${ }^{848}$. Frédéric Mistral zählte denn auch (1875) die Bewahrung der Religion und vor allem des Katholizismus, der als Eckstein der französischen Traditionen begriffen wurde, zu den Grundbedingungen der nationalen Erneuerung. Nur die Verbindung von religiösem und sprachlichem Traditionalismus - „die alte Sprache des Landes ... von Stadt zu Stadt, von Provinz zu Provinz“ - schien dem Félibrige wirklich geeignet, „den Namen Frankreichs zu preisen" und seine wunderbare Vielfalt zu dokumentieren $^{849}$. In Französisch, der "Sprache Voltaires“, wurden dagegen die ganzen, in traditionalistischen Augen schlechten Bücher gedruckt, die Religion und Moral untergruben. Vor allem seit den 1870er Jahren, als die zentralistische Politik der Regierung Mac-Mahon regionalistische Gegenbewegungen provozierte ${ }^{850}$, lehnte eine wachsende Zahl von Klerikern die aus dem Geist von 1789 hervorgegangene Zentralisierung und mit ihr die Republik ab. Die exponierte Rolle der Pastoren in der regionalistischen Bewegung und die in ihren Reihen oft verfochtenen traditionalistischen, antiegalitären Gesellschaftsentwürfe mit einer besonderen Wertschätzung des christlichen Mittelalters ${ }^{851}$ trugen im Gegenzug nicht unerheblich dazu bei, das Mißtrauen der Republikaner gegen föderalistische Reformen und selbst gegen jene kulturelle Heimatpflege wachzuhalten, der sich die Dorfpfarrer in ihrer oft reich bemessenen Freizeit widmeten ${ }^{852}$. Auch in dieser Hinsicht bildete der Volksschullehrer als Multiplikator eines universellen Wissens, das er nicht aus den weniger ergiebigen Quellen des heimatlichen Dorfes zu schöpfen beanspruchte, sondern aus denen der gesamten Menschheit, ein ideologisch-progressives Gegengewicht zum pastoralen Traditionsüberhang ${ }^{853}$.

Angesichts der tief wurzelnden republikanischen Vorbehalte gegen den mit den Namen von Mistral, Barrès und Maurras verknüpften „Föderalismus" ${ }^{\text {(854 }}$ blieb der politische Einfluß der 1900 von Jean-Charles Brun gegründeten, ideologisch disparaten ${ }^{855}$, explizit "unpolitischen" ${ }^{856}$ Féderation Régionaliste Française „so gut wie null“857. Immerhin konnte der Félibre in diesen Jahren in Brive, Argentat,

${ }^{847}$ R. Limouzin-Lamotte, Le diocèse de Limoges, 1953, S. 195.

${ }^{848}$ K. Pleyer, Die Landschaft im neuen Frankreich, 1935, S. 217.

${ }^{849} \mathrm{G}$. Cholvy, Régionalisme et clergé catholique, 1977, S. 195.

${ }^{850} \mathrm{H}$. Möller, Regionalismus und Zentralismus, 1996, S. 15.

${ }^{851}$ M. Zorzi, La conscience régionale, 1996, S. 136ff., 148. So wurde etwa von einem Autor im „Lemouzi“ (1897) das Prinzip des sozialen Aufstiegs ausdrücklich zurückgewiesen.

$852 \mathrm{Ph}$. Vigier, Régions et régionalisme en France, 1977, S. 173.

$853 \mathrm{Vgl}$. G. Rossi-Landi, La région, 1992.

854 Th. Flory, Le mouvement régionaliste français, 1966, S. 95. A.-M. Thiesse (Le régionalisme, 1994, S. 291) hat darauf hingewiesen, daß der maßgeblich von Maurras geprägte Begriff des „fédéralisme" wegen dessen Verwicklung in die Affäre Dreyfus durch einen neuen, unbelasteten Begriff den des Regionalismus - abgelöst werden mußte.

$855 \mathrm{Ph}$. Vigier, Régions et régionalisme en France, 1977, S. 174.

${ }^{856}$ Der von Brun betonte unpolitische Charakter des Regionalismus war Grundlage seiner Kontroverse mit dem Royalisten Maurras. Th. Flory, Le mouvement régionaliste français, 1966, S. 88.

${ }^{857}$ G. Rossi-Landi, La région, 1992, S. 87; vgl auch K. Möckl, Föderalismus und Regionalismus, 1983, S. 538 f., sowie Ph. Vigier, Régions et régionalisme en France, 1977, S. $162 \mathrm{f}$. 
Tulle und Chamboulive „Schulen“ einrichten ${ }^{858}$, auch einige corrézische Bürgermeister engagierten sich in der regionalistischen Bewegung, und in Ussel oder Bort nahmen selbst Präfekten oder Minister an den festlichen Veranstaltungen des Félibrige teil ${ }^{859}$. Sogar Staatspräsident Raymond Poincaré, eine Symbolfigur des französischen Nationalismus, traf sich zu Beginn seines Septennats mit Frédéric Mistral zum Frühstück ${ }^{860}$. Denn seit den 1880 er Jahren hatte sich - auf der rechten wie auf der linken Seite des politischen Spektrums - die Vorstellung entwickelt, daß die Liebe zum „kleinen Vaterland“ das Denken für die Liebe zu Frankreich vorbereite ${ }^{861}$, jedenfalls dann, wenn der Lokalpatriotismus die Ebene nostalgischer Folklore nicht verließ. Wenn also der Staat den Félibre akzeptierte, so zwang er ihn gleichzeitig dazu, sich auf „die Rolle eines ,Poeten “ ${ }^{\text {' }}{ }^{662}$ zu beschränken und politische Forderungen zurückzustellen. Auf diesem Wege gelang es, „das regionalistische Bewußtsein ... in die republikanische Ideologie“ zu integrieren ${ }^{863}$.

Politisch aufschlußreich war vor allem die Haltung des Parti Radical, der Traditionskompanie der „einen und unteilbaren Republik“, die trotz agraristischer Vorbehalte gegen den Moloch Paris und antizentralistischer Affekte ihrer ländlichen Basis regionalistische Forderungen programmatisch ziemlich niedrig hing ${ }^{864}$. Dies galt erst recht für die Zeit nach dem Weltkrieg, als die Reibungsverluste bei der Wiederangliederung Elsaß-Lothringens die französische Regionalismusdiskussion stärker politisierten. Wer nun in der Stunde der Gefahr für die Staatseinheit die Prinzipien des Zentralismus antastete, vergriff sich in den Augen der PRSFührung am revolutionär-republikanischen Erbe. Eine Verwaltungsreform auf der Grundlage der Regionen, wie sie die Radicaux - nicht nur in der Corrèze - im Wahlkampf 1919 forderten, hatte vor diesem Hintergrund keine Realisierungschance ${ }^{865}$. Die Schaffung von Wirtschaftsregionen durch das Reformdekret Étienne Clémentels 1919 blieb Torso, weil ihre rechtliche und ökonomische Kompetenz - auf der Basis regional kooperierender Handelskammern - zu schmal war $^{866}$. Vergeblich auch berief sich die Provinz gegen den staatlichen Zentralismus auf die Gleichheitsprinzipien der Revolution ${ }^{867}$.

Zwischen ihrer republikanischen Leidenschaft und ihrer wirtschafts- und strukturpolitischen Vernunft als Provinzpartei hin- und hergerissen, blieb das Gefühl, von Paris benachteiligt zu werden, einer „exzessiven Zentralisierung ${ }^{\text {“868 }}$ ausgesetzt zu sein, bei den corrézischen Radicaux infolgedessen während der ganzen Zwischenkriegszeit latent vorhanden. Radikale Parlamentskandidaten wiesen

${ }^{858}$ L. Pérouas, Une religion des Limousins?, 1993, S. 113.

${ }^{859}$ M. Zorzi, La conscience régionale, 1996, S. 93; K. Pleyer, Die Landschaft im neuen Frankreich, 1935, S. 246.

${ }^{860}$ M. Agulhon, Conscience nationale et conscience régionale en France, 1980, S. 247.

${ }^{861}$ Hierzu mit Belegen aus der Zeitschrift Lemouzi M. Zorzi, La conscience régionale, 1996, S. 92 ff., sowie Ph. Martel, Regionale Identität und nationale Kultur in Frankreich, 1992, S. 112.

${ }^{862}$ M. Zorzi, La conscience régionale, 1996, S. 132.

${ }^{863}$ Ebd., S. 133. Im Lemouzi kamen neben kritischen Stimmen zur Französischen Revolution immer wieder auch glühende Anhänger zu Wort. M. Zorzi, La conscience régionale, 1996, S. $141 \mathrm{f}$.

${ }^{864} \mathrm{~S}$. Berstein, Le parti radical et le problème du centralisme, 1977, S. $231 \mathrm{f}$.

${ }^{865}$ Ebd., S. 234, 236.

866 J. Milhau, Le mouvement régionaliste, 1972, S. 135, sowie Th. Flory, Le mouvement, 1966, S. $94 \mathrm{ff}$.

${ }^{867}$ Vgl. La Défense Paysanne de la Corrèze, 15. 8. 1924.

${ }^{868}$ L'Action républicaine de la Corrèze, 5. 5. 1934. 
ganz bewußt darauf hin, daß sie im Stimmkreis geboren und aufgewachsen waren: „Ich bin ... ein Kind des Landes“, und verbanden die Betonung ihrer regionalen Herkunft mit der Forderung nach mehr departementalen und kommunalen Freiheiten ${ }^{869}$. Ein gewisser regionalistischer Habitus mußte den corrézischen PRSPolitikern schon im Blick auf ihre bäuerliche Klientel ratsam scheinen.

Denn dort war die Kritik an einer als schleppend empfundenen Verbesserung der ländlichen Infrastruktur, die in scharfem Kontrast zu Priviliegien für die $\mathrm{Me}-$ tropole Paris stand, gerade im Kontext der Landflucht-Debatte ${ }^{870}$ ziemlich heftig; deutlich wurde dies etwa 1924, als von der Erhöhung der Bahntarife der Pariser Raum ausgespart blieb, obwohl dort ohnehin schon reduzierte Preise galten ${ }^{871}$. Besonders wenig Verständnis hatte man zudem für kolonialpolitische Maßnahmen: daß der Staat beispielsweise hunderte Millionen Francs für den Straßenbau in der syrischen und marokkanischen Wüste ausgab, aber kein Geld aufbrachte, „um zu verhindern, daß Frankreich durch die Landflucht eine wirkliche Wüste

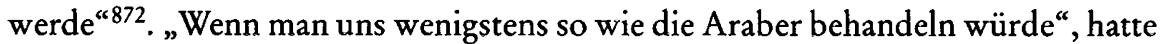
schon früher ein Tuller Rechtsanwalt geklagt, und damit eine Stimmung artikuliert, die auf einer nachhaltigen Erfahrung der Corréziens mit der zentralistischen Politik der Pariser Regierungen beruhte. Als die Binnenschiffahrt - auch auf der Dordogne - ihren Aufschwung nahm, hatten sie etwa vergeblich die Kanalisation der Vézère gefordert; auch gegen das schleppende Tempo, mit dem die Eisenbahnlinien in der Corrèze gebaut wurden, hatten sie protestieren müssen ${ }^{873}$.

Das corrézische Benachteiligungssyndrom war indes auf eine merkwürdige Weise mit republikanischem Selbstbewußtsein gegenüber dem politisch wetterwendischen Paris verbunden. So ließen die "faschistisch“ gedeuteten Februarunruhen 1934 in den Augen der radikalsozialistischen „Action républicaine de la Corrèze“ die Spaltung zwischen den blinden, anonoymen, zu allen Verrücktheiten verführbaren Massen der Hauptstadt einerseits und der viel dünner gesäten, aber überlegter handelnden und vor allem republikanischer gesonnenen Bevölkerung in der Provinz offensichtlich werden. Es genügte also nicht, so die Warnung an die „Extremisten von links und rechts“, durch einen Gewaltstreich den Elysee zu nehmen: „Paris wird Frankreich nicht beherrschen. Die Provinz wird genug guten republikanischen Geist entfalten, um es daran zu hindern. " 874 Dabei setzten die corrézischen Radicaux besonders auf "unsere Landwirte“, deren "gesunder Menschenverstand" (bon sens) über die Institution des Senats die unberechenbaren Städte kontrolliere ${ }^{875}$, ganz im Sinne des schon von Alain gepriesenen „paysan du Danube“: "Radikal oder besser noch radikalsozialistisch nennt man einen Abgeordneten, der aus seinem Dorf kommt, um den Parisern eine Lektion zu erteilen" ${ }^{876}$.

${ }^{869}$ Siehe die radikalsozialistischen Professions de foi in: ADC 3 M 195.

${ }^{870}$ Frédéric Mistral war nicht zufällig zum Ehrenpräsidenten der Französischen Liga gegen die Land-

flucht ernannt worden. J. Pitié, L'exode rurale, 1980, S. 83.

${ }^{871}$ La Défense Paysanne de la Corrèze, 15. 8. 1924.

872 Ebd., 30. 12. 1925.

${ }^{873}$ Vgl. R. Morichon, Histoire du Limousin et de la Marche, 1976, S. 203.

${ }^{874}$ L'Action Républicaine de la Corrèze, 24. 2. 1934.

875 Ebd., 5. 5. 1934.

${ }^{876} \mathrm{~J}$.-Th. Nordmann, Histoire des radicaux, 1976, S. $141 \mathrm{f}$. 
Die radikalsozialistisch-republikanische Variante regionalistischen Denkens darf indes nicht den Blick auf die auch für das Limousin wichtige Verbindung von Regionalismus und Action française verstellen ${ }^{877}$. Schließlich war der Félibrige die geistige Heimat von Charles Maurras, der nur einer Monarchie die notwendige Regionalisierung zutraute. Die Republik mit ihrem Prinzip der demokratischen Wahlen hielt er demgegenüber für strukturell unfähig zu regionalistischen Reformen, weil jede Partei zum Zwecke ihres Machterhalts zu zentralistischer Politik neigen müßte; das sei nachgerade die Bedingung für ihre Wiederwahl ${ }^{878}$. Viele Regionalisten fanden die Argumentation von Maurras überzeugend; die limousinischen Félibristen wie Georges Gaudy, Albert Pestour und René Farnier machten hier keine Ausnahme, wie Veranstaltungen über „Die Wiedergeburt der Provinzen und die Rückkehr des Königs“ deutlich machten ${ }^{879}$. Der Schriftsteller Pestour, Chefredakteur des royalistischen Wochenblattes in der Region, hielt noch 1927 daran fest, daß das Limousin ein zweisprachiges Land sei, und warf dem republikanischen System vor, mit seiner „Lobpreisung der Gleichheit" die ganze Félibrige-Literatur lächerlich zu machen ${ }^{880}$. Auch Farnier bekräftigte, daß das auf Wahlen basierende parlamentarische System ein unüberwindliches Hindernis für jede ernsthafte Dezentralisierung darstelle ${ }^{881}$.

Als sich ein Kommunalpolitiker in der Xaintrie für die Gründung einer Bauernpartei aussprach, um endlich die Bahnlinie von Argentat nach dem benachbarten Salers durchzusetzen, waren die royalistischen Regionalisten entsetzt: „Noch eine Partei“", die ihre Forderungen wieder nur an die leere Kasse des Staates richten könne. Die nicht gebaute Lokalbahn war für die Action française ein neuerlicher Beweis, daß der republikanische Staat schamlos Steuergelder verschwende und das Wohlergehen der Regionen vernachlässige. Müßte Frankreich „nicht den Parlamentarismus durchleiden“, wäre die Bahnlinie längst gebaut, denn würde „morgen der König wiedergeboren“, so ihr Credo, kümmerte er sich „schon bald um seine Xaintrie“. Schließlich verkörpere der König die Nation, während die Politiker nur ihre Parteien verkörperten ${ }^{882}$.

Natürlich wurde diese Form des Regionalismus besonders von dezidiert linken Republikanern als reaktionär empfunden ${ }^{883}$, und ihr Mißtrauen übertrugen sie auf den gesamten Félibrige, der in der Zwischenkriegszeit seine Aktivitäten im Limousin - nicht nur im engeren kulturellen Bereich mit Gesangvereinen und Tanzgruppen - verbreitern konnte ${ }^{884}$. Argwohn weckten besonders die Jahresfeiern mit Gottesdiensten in Langue d'oc, noch dazu mit besonders konservativen Pre-

877 Zum regelrechten Mistral-Kult der Action française vgl. Ph. Martel, La revendication occitane entre les deux guerres, 1989, S. $339 \mathrm{ff}$.

${ }^{878}$ G. Rossi-Landi, La région, 1992, S. 85 f.

${ }^{879}$ Le Salut National, 15. 4. 1928.

880 Ebd., 13. 2. 1927.

${ }^{881}$ Vgl. den Hinweis auf Farniers Aufsatz in der Gazette du Centre 1919 bei M.-F. Andrieux, Le Félibre en Limousin, 1985, S. 198.

${ }^{882}$ Le Salut National, 4. 3. 1928.

${ }^{883}$ Denn gerade um ihre Ideen in „ein ländliches und reaktionäres Frankreich“ eindringen lassen zu können, hatten die Republikaner eines zentralistischen Staatsapparats bedurft. Siehe M. Philipponneau, La gauche et le régionalisme, 1977, S. 530.

${ }^{884}$ M. Robert, Les limousins des années trente, 1989, S. 71; zu den Anfängen der kulturellen Arbeit, etwa der Einführung jährlicher Blütenfeste, vgl. J. Nouaillac, Histoire du Limousin, 1931, S. 267. 
digten, die eine Verbindung zwischen Dechristianisierung, allgemeinem Traditionsverfall und zurückgehender Praxis des Dialekts herstellten und, wie 1922 in der Tuller Kathedrale, sogar gegen moderne Tänze zu Felde zogen ${ }^{885}$.

So war es kein Wunder, daß die großen Feiern zum 100. Geburtstag von Joseph Roux $^{886}$ im September 1934 und die öffentliche Aufmerksamkeit, die der Félibrige damit gewann ${ }^{887}$, den corrézischen Sozialisten verdächtig vorkamen. Schon im Vorfeld hatte die Voix corrézienne gegen die Teilnahme der staatlichen Schulen an der Tuller Gedenkfeier polemisiert, da Roux doch bekanntermaßen der „allerschärfste Widersacher" des laizistischen Systems gewesen sei und die Demokratie als „betrunkene Kurtisane“ bezeichnet habe ${ }^{888}$. Der sozialistische Appell, sich dem „feindlichen Einfall“ der Regionalisten entgegenzustellen, wirkte so verunsichernd, daß die Tuller Gedenkveranstaltung schließlich „mit einem Minimum an offizieller Feierlichkeit“ ablief und nur wenig Prominenz erschien. Während im katholisch-konservativen Lager die Enttäuschung über "gewisse Politiker" unverkennbar war ${ }^{889}$, konnten sich die Sozialisten ob dieses "schönen Fiaskos“ die Hände reiben ${ }^{890}$. Sie begnügten sich damit, ihre regionalistische Sensibilität auf dem Wege nostalgisch-folkloristischer Dialektpflege zu bekunden, etwa mit okzitanischen Geschichten im SFIO-Parteiorgan oder mit einer mundartlichen Version der "Internationale ${ }^{\text {"891. }}$. Und die Kommunisten näherten sich ohnehin erst ab Mitte der 1930er Jahre im Rahmen ihrer Volksfrontstrategie auch der okzitanischen Bewegung ${ }^{892}$.

In der Corrèze war mithin ein wesentlicher Teil des regionalistischen Potentials durch seine Verbindung mit der politisch inakzeptablen Action française oder wenigstens den suspekten Katholisch-Konservativen, wo der Dialekt nach wie vor besonders geschätzt wurde ${ }^{893}$, nicht voll aktivierbar ${ }^{894}$. Dies gilt allerdings so eindeutig nur für den ethnisch-kulturell motivierten Regionalismus, während auf der ökonomischen und psychologischen Ebene in der Corrèze sogar mehr Niedergeschlagenheit und latente Unzufriedenheit mit der peripheren Lage vorherrschte als in Westmittelfranken. Die Bauern des Limousin waren seit Molières „Pourceaugnac" (Ferkel) ungefähr genauso der Lächerlichkeit preisgegeben wie die Bürger von Schilda in Deutschland. Und wie tief Molière die Menschen in der

${ }^{885}$ M.-F. Andrieux, Le Félibre en Limousin, 1985, S. 224.

${ }^{886}$ Zum Profil von J. Roux vgl. auch P. Barral, Les agrariens français, 1968, S. 132.

${ }^{887}$ Vgl. etwa L'Action Républicaine de la Corrèze, 22. 9. 1934; La Croix de la Corrèze, 23. 9. 1934.

${ }^{888}$ La Voix Corrézienne, 13. 5. 1934.

${ }^{889} \mathrm{La}$ Croix de la Corrèze, 16. 9. 1934.

${ }^{890} \mathrm{La}$ Voix Corrézienne, 30. 9. 1934.

${ }^{891}$ Vgl. ebd., 7.1. 1934.

$892 \mathrm{Ph}$. Martel, La revendication occitane, 1989, S. $342 \mathrm{ff}$.

${ }^{893}$ Beim Mittagessen an einem von der katholischen Jugend in Brive organisierten Tag der Landwirtschaft wurde von allen ausgebrachten Toasts der in corrézischem Dialekt am meisten bejubelt. La Semaine Religieuse du Diocèse de Tulle, 1924, S. 353 f.; auch die Gemäßigten bekundeten im Wahlkampf ihre Sympathie für den Regionalismus. Vgl. das Programm der Liste Lasteyrie in: ADC 3 M 195.

${ }^{894}$ Es war kein Zufall, daß sich auch der im Februar 1934 gegründete rechtskonservative Réveil du Bas Limousin der Félibrige-Thematik annahm. Vgl. etwa: Le Réveil du Bas Limousin, 6. 6. u. 20. 6. 1935. 
Provinz mit seinem Stück verletzt hatte, war schon an dem Ausmaß der Kritik in der Lokalpresse abzulesen ${ }^{895}$.

Im Verein mit der tatsächlichen wirtschaftlichen Benachteiligung war jedenfalls der Boden für eine oppositionelle Mentalität auch breiterer Schichten bereitet, wobei sturer Antietatismus eine wichtige Rolle spielte. Welche Form auch immer der Staat hatte, die Bauern verstanden ihn nicht, er sprach eine andere Sprache, und es gab für sie auch gar keinen Grund, „diese überhaupt verstehen zu wol-

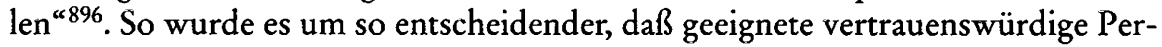
sönlichkeiten aus der engeren Heimat möglichst weit in der Hierarchie des Pariser Zentralismus aufrückten, um ihm dann das Mögliche abzutrotzen. Andernfalls hieß es wie in Uzerche, die Stadt habe „zu ihrem Unglück“ niemals eine Persönlichkeit von nationalem Format an der Spitze gehabt ${ }^{897}$. Ein Henri Queuille konnte demgegenüber sogar Zustimmung vom katholischen Gegner erfahren, als er 1934 einmal mehr in ein Kabinett berufen wurde. Unter der Überschrift „Die Corrèze regiert" äußerte die Croix de la Corrèze den Wunsch, Queuille möge alle ministeriellen Rekorde schlagen, seine Landsleute könnten sich nur über das Vertrauen freuen, das ihm in Paris offensichtlich entgegengebracht werde ${ }^{898}$.

Wohl wurde das Regionalbewußtsein nicht zuletzt von sich benachteiligt fühlenden kulturbewußten, wirtschaftlich aktiven und politisch engagierten Führungsschichten in den regionalen Zentren produziert ${ }^{899}$ und zur Steuerung der Wählermassen mit eingesetzt ${ }^{900}$; dies implizierte aber, daß es als lebensweltlich relevante kognitive Struktur bei der breiten Bevölkerung in der Corrèze ebenso vorhanden war wie in Franken ${ }^{901}$, wenn auch auf dem flachen bäuerlichen Land eher „diffus-expressiv“, weniger ideologisch, sondern mit einer stärker „emotional-identitiven Bindung" an den lokalen Raum sowie materiellen Hintergedan$k^{2}{ }^{902}$. Trotz uneinheitlicher und nicht durchgehender Determinationsmuster regionalen Bewußtseins konnte an seiner politischen Wirksamkeit in Franken wie im Limousin kaum gezweifelt werden. Allerdings war der Regionalismus in der Corrèze, in einen republikanischen und einen katholischen Flügel gespalten ${ }^{903}$, schwächer als in Westmittelfranken ${ }^{904}$. Vor dem Hintergrund der republikanisch-

${ }^{895}$ R. Morichon, Histoire du Limousin et de la Marche, 1976, S. 203; J. D. Neigebaur, Schilderung der Provinz Limousin, 1817, S. 1.

${ }^{896}$ So P. Bitoun, Agriculture et politique, 1981, S. 74, in Anlehnung an C. Levis Thesen über die Bauern in Süditalien.

897 L. Bournazel, Histoire d'Uzerche, 1987, S. 161.

${ }^{898} \mathrm{La}$ Croix de la Corrèze, 4. 2. 1934.

${ }^{899}$ Der Mitgliederanteil der Bauern im Félibrige lag 1930 bei $5,2 \%$, der des Klerus bei 4,5\%, Beamte, Angestellte und Freie Berufe dominierten. Vgl. Ph. Martel, Le Félibrige 1876-1947, 1984, S. 12.

900 Vgl. P. Weich hart, Raumbezogene Identität, 1990, S. 92.

901 Demgegenüber wurde für die Gegenwart des Regionalbewußtseins in Franken behauptet, es sei keine allgemein verbreitete Kategorie räumlicher Orientierung, sondern auf das Bildungsbürgertum und seine Institutionen beschränkt. Vgl. E. Wirth, Franken gegen Bayern, 1987, v. a. S. 280, 283. Vgl. ferner: Region und Regionalismus, 1982.

${ }^{902}$ H.-P. Meier-Dallach u.a., Regionalbewußtsein, soziale Schichtung und politische Kultur, 1987, S. $381 \mathrm{f}$.

${ }^{903}$ So befanden sich etwa unter den Gründern der École Limousine zwei große Rivalen der Briver Lokalpolitik: Pierre Verlhac, Direktor der konservativ-bonapartistischen Zeitung Le Conciliateur, und der liberale Freimaurer Marcel Roche. M. Zorzi, La conscience régionale, 1996, S. 135.

${ }^{904}$ Nach Maurice Agulhon zeigten im übrigen gerade die Wahlerfolge der Linken und der „massive Respekt" des roten Midi für die französische Demokratie, wie schwach dort das Regionalbewußt- 
laizistischen Milieumentalität vermochte sich Protest gegen zentralistische Strukturpolitik in der Corrèze auch in einem Votum für die linken Parteien zu artikulieren ${ }^{905}$, während der überwiegend nationalprotestantische Regionalismus in Westmittelfranken von einer konfessionalistisch agierenden rechten Volksbewegung aufgegriffen werden konnte.

sein ausgeprägt und wie weit die nationale Akkulturation fortgeschritten war. M. Agulhon, Conscience nationale, 1980, S. 252, 255.

905 Vgl. etwa die Geschichte des „roten Midi“ bei K. Mondner/O. Barlet, Südfrankreich/Okzitanien?, 1978, S. $24 \mathrm{ff}$. Daß die ebenfalls unter dem Pariser Zentralismus leidende Bretagne rechts votierte, ist demgegenüber kein Widerspruch, sondern verweist auf ihre andere politische Kultur, in deren Rahmen sich vagabundierende regionalistische Potentiale auch in anderer Richtung Bahn brechen konnten. Vgl. abweichend hiervon: W. Brustein, The Social Origins of Political Regionalism, 1988, S. $23 \mathrm{f}$. 